PATRICK BOHL

THE IMPACT OF AIRPORT RETAIL ENVIRONMENT ON PASSENGER EMOTIONS AND BEHAVIOUR 
Department of Marketing

Supervisor: András Bauer

(C) 2013 Patrick Bohl 
CORVINUS UNIVERSITY OF BUDAPEST

DOCTORAL PROGRAMME IN MANAGEMENT

AND BUSINESS ADMINISTRATION

\title{
THE IMPACT OF AIRPORT RETAIL ENVIRONMENT ON PASSENGER EMOTIONS AND BEHAVIOUR
}

\author{
DOCTORAL DISSERTATION
}

PATRICK BOHL

BUDAPEST, 2013 



\section{TABLE OF CONTENTS}

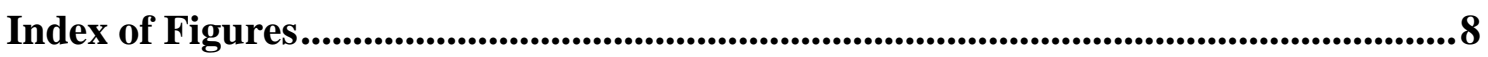

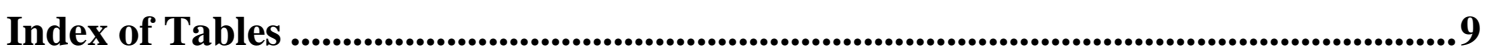

Index of Appendices ...................................................................................................11

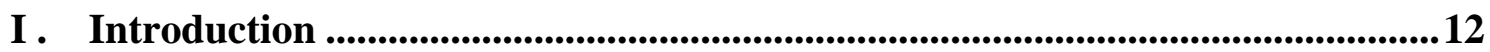

I.1. Overview of the topic ..................................................................................................12

I.2. Contribution to scientific and managerial knowledge.............................................13

I.3. Structure of the thesis proposal .........................................................................................15

I.4. Acknowledgments ..............................................................................................................15

II . Literature Review .......................................................................................... 17

II.1. Retail environments and servicescapes ...................................................................17

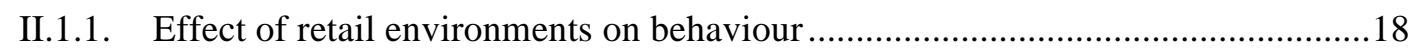

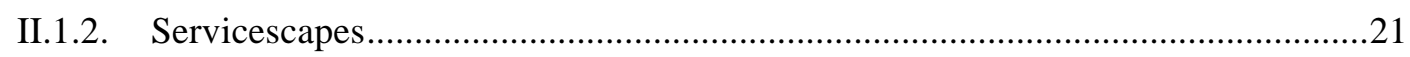

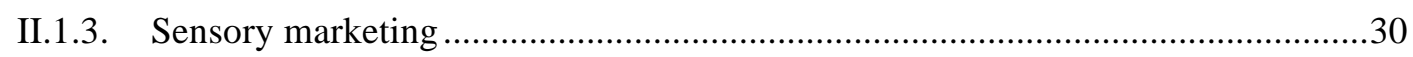

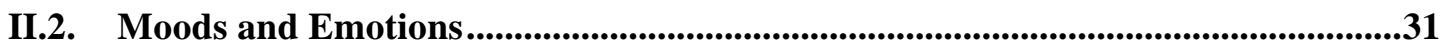

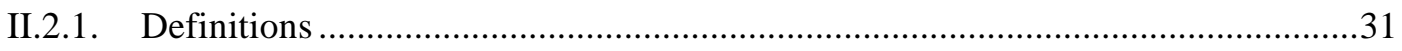

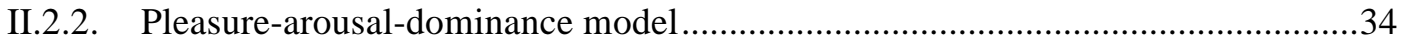

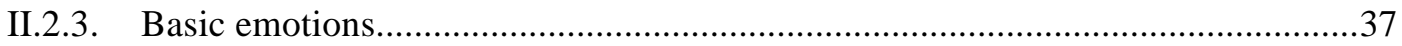

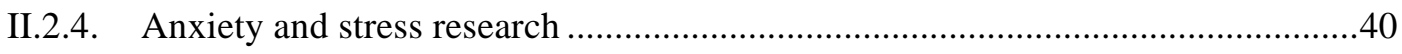

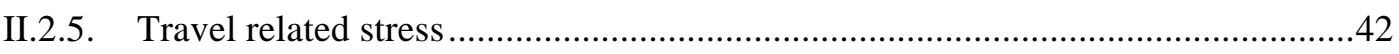

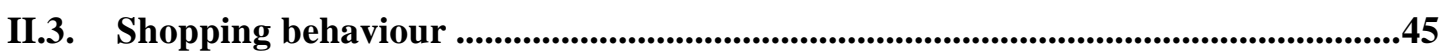

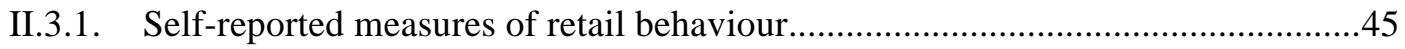

II.3.2. Observed measures of retail behaviour ..............................................................48

II.4. Summary ….......................................................................................................................49

III . Airport retailing - a managerial perspective............................................................52

III.1. Literature overview .....................................................................................................52

III.2. Concepts of airport retailing..................................................................................................56

III.3. Socio-demographic drivers of retail revenue ...........................................................59

III.4. Performance measures of airport retailing ................................................................61 
III.5. Discussion

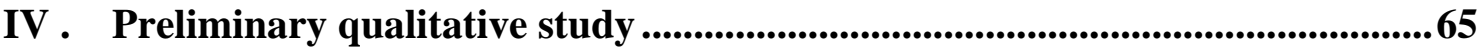

IV.1. Objectives and research questions.................................................................................65

IV.2. Research methodology …........................................................................................................66

IV.3. Research design ....................................................................................................................69

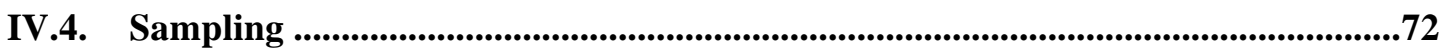

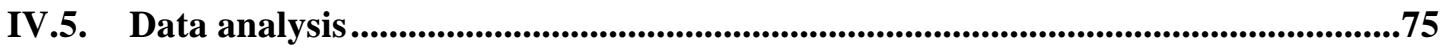

IV.6. Results and discussion ...................................................................................................76

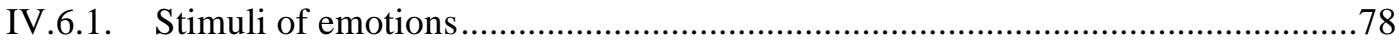

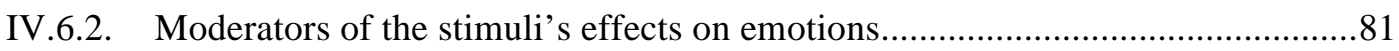

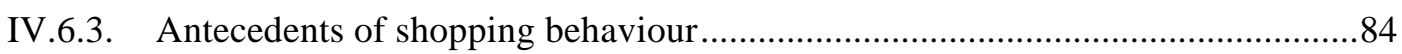

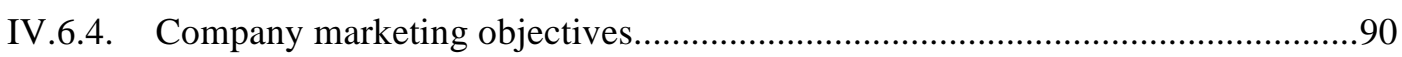

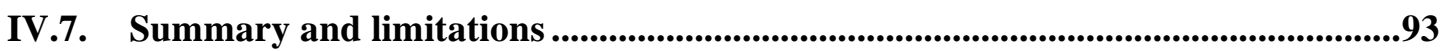

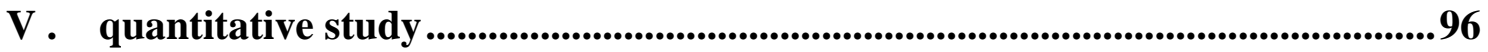

V.1. Objectives and research questions ...................................................................................96

V.2. Hypotheses of the quantitative study .............................................................................98

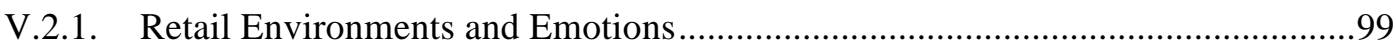

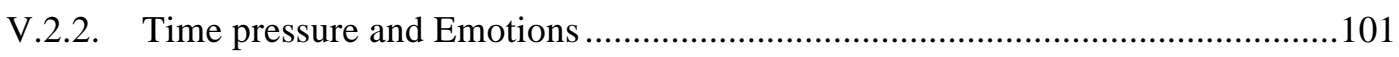

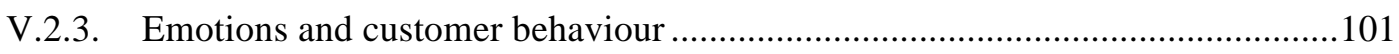

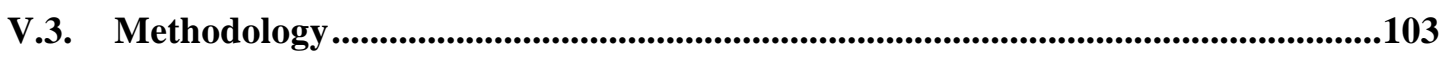

V.4. Definition and operationalization of variables...............................................................103

V.4.1. The variables used in the conceptual model were obtained from the literature or developed based on previous studies as well as the qualitative pre-study. Measures of the

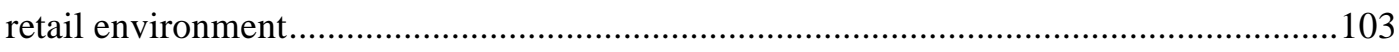

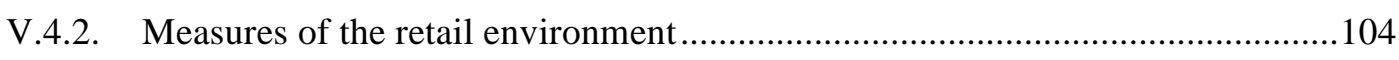

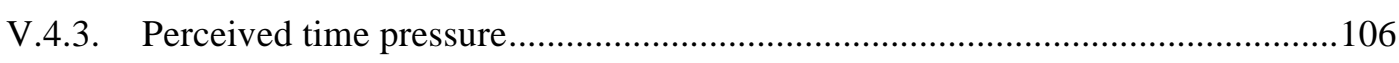

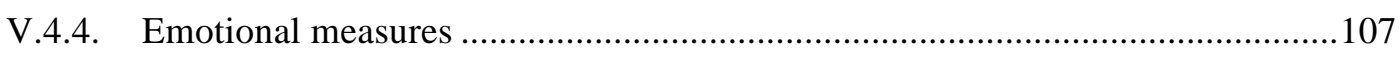

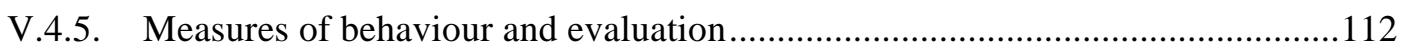

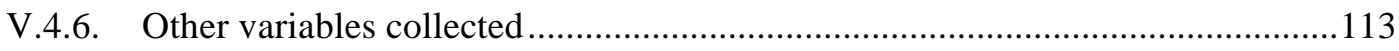

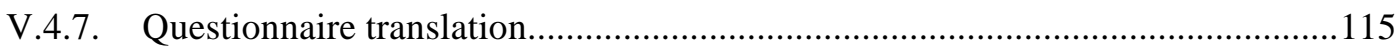

V.5. Data Analysis and Results..................................................................................................115

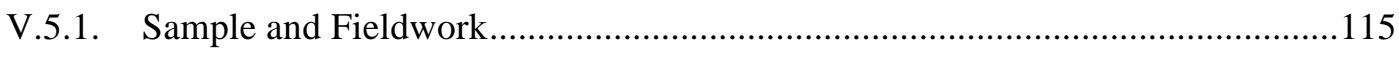


V.5.2. Analysis of the measurement models.

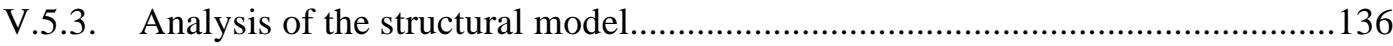

V.5.4. The effect of the retail environment on emotions ..............................................138

V.5.5. The effect of emotions on behaviour and store evaluation .................................140

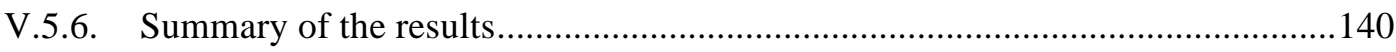

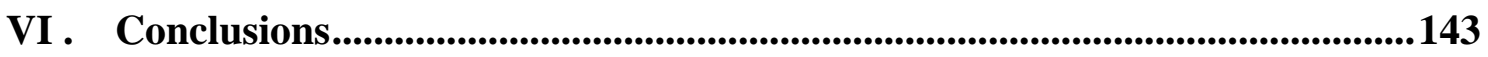

VI.1. Conclusions of the qualitative study ...........................................................144

VI.2. Conclusions of the quantitative study ...........................................................146

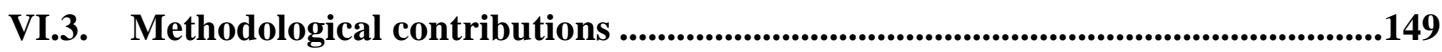

VI.4. Theoretical significance ..........................................................................................150

VI.5. Implications for practitioners ..............................................................................................150

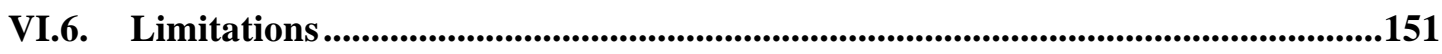

VI.7. Directions for future research........................................................................151

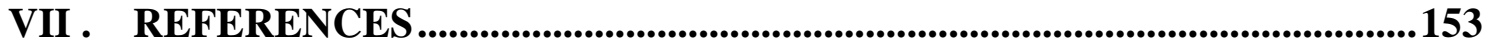

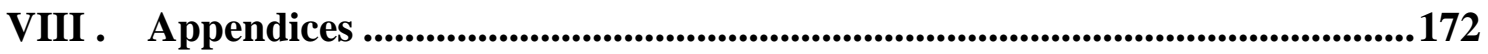




\section{INDEX OF FIGURES}

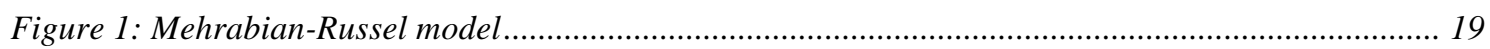

Figure 2: Two dimensions pleasure and arousal and corresponding emotional states............................. 36

Figure 3: Six basic emotions (and one neutral) as displayed by KDEF pictures .................................... 39

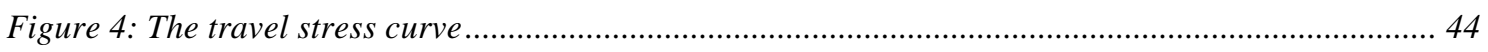

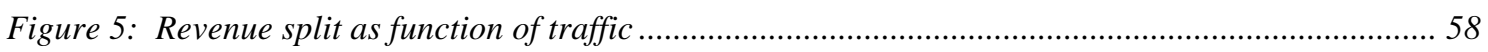

Figure 6: Process of data collection and analysis with respective stages of grounded theory.................. 68

Figure 7: Data saturation: Number of concepts discovered by number of respondents............................. 74

Figure 8: Overview of the main sub-categories (preliminary study) ................................................... 77

Figure 9: Proposed model of environmental effect on store patronage ................................................... 99

Figure 10: Hold-out picture scale as displayed on tablet device during interview ............................... 111

Figure 11: Locations of recruitment and interviews inside airport terminal........................................ 117

Figure 12: Structural model and standardised path coefficients ...................................................... 137 


\section{INDEX OF TABLES}

Table 1. Components of the servicescape.....

Table 2: Oatley-Johnson-Laird model of basic emotions, stimuli and effects..................................... 34

Table 3: Categorisation of sources of airport revenues ................................................................ 57

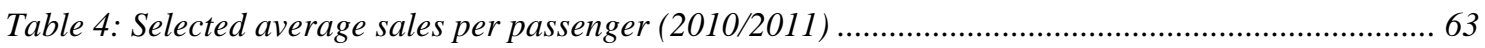

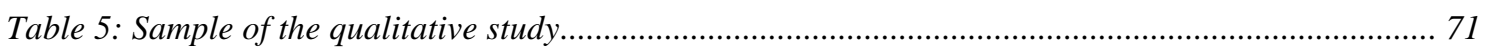

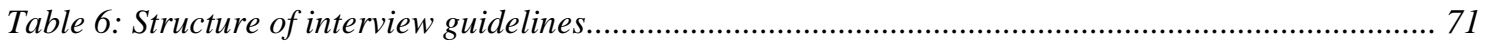

Table 7: Frequency of airports by passenger volume ........................................................................ 72

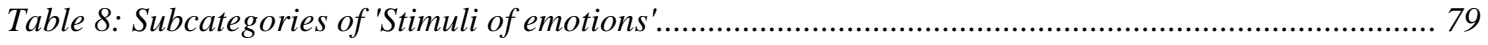

Table 9: Subcategories of 'moderators of stimuli's effects on emotions' ................................................. 82

Table 10: Subcategories of 'antecedents of shopping behaviour' ...................................................... 85

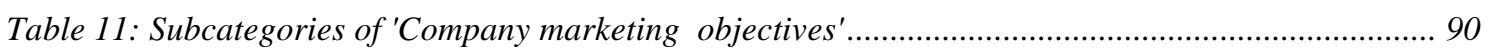

Table 12: Overview of variables used in quantitative study............................................................ 104

Table 13: Items measuring perception of an airport store environment .............................................. 105

Table 14: Operationalisation of Approach/avoidance and evaluation constructs (dependent variables) 113

Table 15: Composition of the quota and respondents ................................................................. 118

Table 16: Demographical composition of the sub-sample ............................................................ 120

Table 17: Behaviour of respondents (time/spending) ................................................................. 121

Table 18: Store environment - results of Explorative Factor Analysis (Principle Component Analysis)

Table 19: Confirmative Factor Analysis of the physical and social factor scales 126

Table 20: Goodness of fit of the measurement model (environmental variables)............................... 127

Table 21: Pearson correlation matrix for time pressure and related items ..................................... 128

Table 22: Principal Component Analysis for time pressure and environmental items .......................... 129

Table 23: Principle Component Analysis for emotional measures - factor loadings ........................... 130

Table 24: Confirmatory Factor Analysis and selected quality indicators of approach/avoidance and

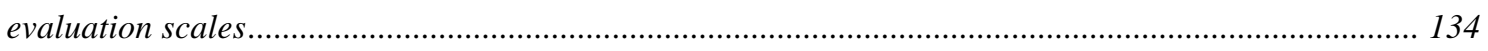

Table 25: Main fit indices of the structural equation model ........................................................ 138

Table 26: Summary of the structural equation model ................................................................. 141

Table 27: List of respondents in semi structured management interviews......................................... 173 
Table 28: Members of the panel of content experts..

Table 29: Parameter Summary (Group number 1)

Table 30: Pearson correlation matrix for assessment of physical factors, social factors, moderator variables. 183

Table 31: Pearson correlation matrix for assessment of emotions, time pressure, Affect Grid... 184

Table 32: Pearson correlation matrix for assessment of behavioural and evaluation variables....... 185

Table 33: Stand. regression weights and reliability coefficients. 186 


\section{INDEX OF APPENDICES}

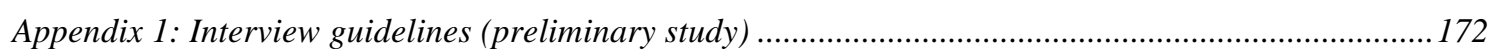

Appendix 2: Respondents in semi structured management interview.................................................... 173

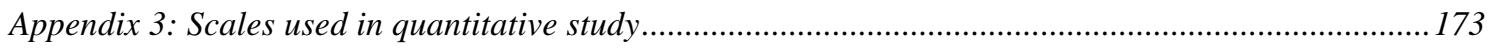

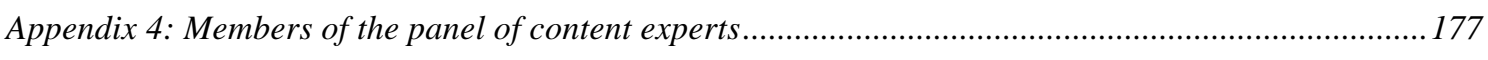

Appendix 5: Results of the testing of the conceptual model ................................................................ 177 


\title{
I . INTRODUCTION
}

\begin{abstract}
Abruptly there was the airportscape: wide, empty spaces and the nubby green line of the Rio Grande a few miles to the west. In the east, beyond the city, mountains stood up awkwardly in a haze that made them look like props. More Southwest planes stood collected on the runway - dull gold with understripes of red and orange like so many sedimented rocks. A sign rolling by the window said KIRTLAND AIR FORCE BASE. Out in the ninety-degree heat stood a shuttle bus to Santa-Fe, sixty miles north.
\end{abstract}

D.J.H. Jones: Murder in the New Age (2000).

\section{I.1. Overview of the topic}

Retail research suggests that the behaviour of shoppers is influenced by the atmospherics of the environment they are in, for example store ambience, design, behaviour and appearance of personnel. Environmental psychologists have proposed a Stimulus-Organism-Response taxonomy, where the environment (stimulus) has an impact on the emotional states of consumers (organism) (Donovan \& Rossiter, 1982). Changes to the emotional state, in turn, mediate the behavioural response, which could be to either "avoid" (stay for a shorter time, purchase less items, etc.) or "approach" the environment (stay for longer, purchase more than planned etc.) (Mehrabian \& Russell, 1974). Due to the pivotal role of emotions, a range of studies into the emotional states of consumers and effects on shopping behaviour have been conducted (Bohl, 2012; Ezeh \& Harris, 2007; L. W. Turley \& Milliman, 2000). It has been found that state pleasure is the positive appraisal of a stimulus and leads to approach type behaviour. When pleasure is neutral, moderate levels of state arousal (correlating with mental alertness or physical activity) lead to approach, extreme levels lead to avoidance (Donovan \& Rossiter, 1982).

One may argue that many passengers in major airports departure areas experience such high or extreme levels of arousal. Sales in such airportscapes ${ }^{1}$ are estimated to generate

\footnotetext{
${ }^{1}$ The physical environments customers experience in service industries have been referred to as 'servicescapes' (Bitner, 1992), and because much of this dissertation investigates the specifics of airport retail environments, we will also use the term 'airportscape' when referring to this industry, which was first used in a novel by D.J.H. Jones (2000).
} 
an output of 29 billion US-dollars per year worldwide (Bamberger, Bettati, Hoefflinger, Kuruvilla, \& Wille, 2009). Individual airport duty free operations can reach over 1 billion US-Dollars in annual sales, as in the case of London Heathrow. However, airports are environments full of uncertainty, and can be intimidating and frightening. Regular travellers may worry about long waiting times at check-in or passenger security checkpoints. Less seasoned passengers may not know how to use check-in machines, feel their private sphere violated because of body searches, or are simply afraid to fly. Airport managers have stated that passengers are unlikely to shop until after they have completed check-in and security screening check-points, because of the stress and anxiety involved. There are also very positive feelings involved, for example when people are about to leave on a long awaited holiday. Despite this, hardly any research was conducted investigating the effect of airportscapes on emotions and shopping behaviour based on the stimulus-organism-response paradigm.

\section{I.2. Contribution to scientific and managerial knowledge}

The present work contains of a review of the relevant literature from both retailing and service marketing but also related fields in psychology and airport management. A qualitative study was conducted in order to gain a managerial perspective of the topic under investigation involving interviews with senior managers at TOP 50 European airports. With interviews lasting $1-1.5$ hours on average, the data collected is very valuable and assumed to have good external validity. It suggests that several emotions may be present at the same time, for example happiness and excitement on the one hand and stress and anger on the other hand. Airport retail outlets are therefore designed to reduce stress while keeping arousal levels high in order to maximize the effects of the retail environment on marketing outcomes. As the literature overview will show (see section III.1) there are only a limited number of studies into this phenomenon, and none are based on expert interviews. Next, the main cause-effect relationships are being investigated in a quantitative survey among passengers at a major airport. Respondents were intercepted when entering the airport's check-in hall, and interviewed before and after the main duty free store, which every passenger passes after security screening ( $N=947)$. Because verbal descriptions of emotions may lead to bias across nationalities, a relatively new instrument was chosen, involving hold-out pictures of facial expressions, which represent different emotional states. It has been suggested that most 
emotional states can be traced back to few basic emotions, each of which is accompanied by facial expressions (Fridlund, Ekman, \& Oster, 1987). The measure used here is based on respondents rating of pictures showing models enacting these emotions. This methodology delivered good results across languages and cultures, allow faster data collection than verbal scales, and, because it adds variety to long surveys, may lead to a higher survey completion rate. The underlying conceptual model hypothising relationships between the environment, emotions and behaviour as suggested by the literature (Mehrabian \& Russell, 1974) could be confirmed while using these innovative measures with a high goodness of fit. At the same time, this study also contribute to the methodological discussion by highlighting some limitations of this measure.

Also, the findings deliver additional knowledge in the field of retail and service marketing, where several gaps of knowledge in this field have been highlighted in the past (Cronin Jr., 2003; Ezeh \& Harris, 2007; Hoffman \& Turley, 2002). Most studies on environmental atmospherics have investigated only one or two elements, such as background music and scent (Mattila \& Wirtz, 2001; Morrison, Gan, Dubelaar, \& Oppewal, 2011; Spangenberg, Grohmann, \& Sprott, 2005), or attempted to use one overall environmental measure, such as information load (Donovan \& Rossiter, 1982). Instead, we ${ }^{2}$ found that environmental stimuli inside a store (Baker, 1987) have two underlying dimensions, physical factors (e.g., ambience, store design) and social (staff behaviour, appearance), which both influence emotions. The used measure showed good reliability and validity.

Findings also have a high value to practitioners at aviation and other industries with similarly high arousal levels and extended service encounters (cruise ships, theme parks etc.) or retail settings which involve time pressure (shopping near closing time, during lunch breaks, or before Christmas).

Lastly, many empirical studies in this field rely on laboratory settings or real life but with small samples only, often consisting of students. In those cases research is mainly set inside one store, ignoring the effect that the previously entered environment has on shoppers. We avoided this by conducting interviews with passengers in live

\footnotetext{
${ }^{2}$ The use of the first person plural ('we') refers to the author, following academic tradition that reporting research results should not be a piece of personal opinion. Nevertheless, this is a unique work and was written solely by myself.
} 
airportscapes, measuring passenger emotions and behaviour in the main duty free store and focus on a holistic emotional state triggered by many features of the passenger's surroundings.

\section{I.3. Structure of the dissertation}

The structure consists of five parts. First, we provide an overview of the relevant scientific literature in the field of marketing, retailing and consumer behaviour as well as neighbouring fields such as psychology. This section will not only introduce the most important phenomena being studies, but also shows how the empirical research delivers new knowledge (Section II ). The following part provides an overview of the airport retail industry as well as a summary of the current state of knowledge based on scientific but also some trade literature. We demonstrate the value for practitioners in this field (Section III). During the second half of 2012, we have conducted a preliminary study, which together with the related scientific literature supports the measurement model and hypotheses analysed in the empirical part. We describe the objectives, research questions, and applied methodology, and summarize the main findings in Section IV . The following section (Section V ) contains the conceptional model of how airport retail environment influence emotions and shopping behaviour, the detailed hypotheses of the conceptional the model, as well as how these were tested in the quantitative study. Section VI summarises and discusses the outcome, highlights the novel aspects of this dissertation for research and practice as well as avenues for future research.

\section{I.4. Acknowledgments}

I want to thank my family for their patience and support during the writing of this dissertation. A number of persons have significantly contributed to the success of the qualitative study as well as the analysis and discussion of the survey data, and also deserve to be named. I am grateful for the support and comments received by many colleagues and friends, and would like to thank especially (in alphabetical order):

$\downarrow$ Alan Bork, Kam Jandu, Zsófia Tajti, Jost Lammers, Judit Papp at Budapest Airport Zrt.;

$\downarrow$ All participants of previous expert panels and forums related to this research, especially Dr. Irma Agárdi, Dr. András Bauer, Ádam Csepeti, Dr. Tamás 
Gyulavári, Dr. Ariel Mitev, Dr. Barbara Jenes, Dr. Krisztina Kolos, Dr. Péter Nagy, Dr. Judit Simon, Boglárka Zsótér of Corvinus University of Budapest;

$\rightarrow$ Dr. Lászlo Árva of ESSCA;

$\uparrow$ Bacher János, Melinda Mesterházy of GfK Hungaria Kft;

$\neg$ Dr. Evangelos Peter Poungias of AviAlliance GmbH;

$\rightarrow$ Dr. Per Carlbring of Umeå University, Sweden;

$\rightarrow$ Dr. Matthew Weinstein of University of Wisconson, USA;

$\downarrow$ As well as: Andy Agozzi, Gerry Crawford, Lutz Deubel, Silke Devacht, Mark Evenden, Elke Haffner, Benedicte Lefin, Stephanie Lehmann, Martyn Lloyd, Adil Raïhani, Marta Marina Ruiz Guirao, Johan Schölvinck, Vicki Wyatt for kind support during the qualitative research phase. 


\section{II . LITERATURE REVIEW}

The effect of retail environment on shopping behaviour and opinion about stores and experience has been sparked great interest in various fields, including services and retail marketing, consumer behaviour, psychology as well as architectural design. In order to position this study among the existing body of knowledge as well as justifying the hypotheses and measures proposed, a detailed overview of the relevant literature is provided. First, the servicescapes literature is presented, which discusses the stimuli of retail and service environments. Then, the role of emotions in general retailing as well as airport retailing is discussed. Finally measures of shopping behaviour are being discussed.

\section{II.1. Retail environments and servicescapes}

The buying process in a retail environment is triggered when consumers recognise that they have an unsatisfied need. Especially when shopping for fun, the decision to enter a particular store, how much time to spend inside, and to buy or not to buy is heavily influenced by the shopping environment and its effect on customers' emotions. Consequently, retailers design their shops so that customers are attracted, locate merchandise easily, motivate unplanned purchases, and offer a satisfying shopping experience (Levy \& Weitz, 2009). A study found that $87 \%$ of Hungarian retailers consider the styles, colours and size of their shop an important part of tactical marketing (Józsa, Bátor, \& Sassné Grósz, 1999). Understanding the effects of the shopping environment is therefore of great managerial importance.

The influence of environmental cues on consumer behaviour has been widely discussed in the scientific literature, since Donovan and Rossiter (1982) introduced the concept of environmental psychology to marketing research. Their basic model assumes a Stimulus-Organism-Response taxonomy, where the environment (stimulus) has an impact on the emotional states of consumers along three dimensions, pleasure, arousal or dominance (organism). These act as mediators on the response, which is a behaviour characterised as avoiding or approaching (Mehrabian \& Russell, 1974; Woodworth, 1928). The model has been widely applied by the English speaking research community (L. W. Turley \& Milliman, 2000) but has also been translated for use in Hungary (e.g., Törőcsik, 1995), Germany (e.g., Bost, 1987) and Austria (e.g., Meixner, 1999), for 
example. A significant effort has been made to understand which specific environmental cues need to be modified in a store (e.g., lightning, scent, music etc.) in order to increase sales, extend the time spend in the store or other approach behaviours. The servicescape literature has stressed that both customers and employees are an important part of the environment, and the model has been extended to include the effects of atmospherics on people, whose behaviour in turn has an effect on other people (Bitner, 1990).

\section{II.1.1. Effect of retail environments on behaviour}

The notion that store atmosphere influences consumer behaviour was introduced to marketing research by Kotler, who initially defined atmosphere to be a component of store image along with other variables, such as brightness and crowding (Kotler, 1973). However, most research on store atmosphere today builds on the Mehrabian-Russel model (M-R model), which is at the heart of a research stream called 'environmental psychology' and was first applied to retail settings by Donovan \& Rossiter (1982). Environmental psychology is concerned with "(1) the direct impact of physical stimuli on human emotions and (2) the effect of the physical stimuli on a variety of behaviours, such as work performance or social interaction” (Mehrabian \& Russell, 1974, p. 4).

Early environmental psychologists applied a Stimulus-Organism-Response (S-O-R) paradigm (Woodworth, 1928) which involves a stimulus taxonomy (e.g., environmental cues), a set of intervening or mediating variables (e.g., the level of arousal caused) and a taxonomy of responses (e.g., patronising a store) (Mehrabian \& Russell, 1974). In a consumer environment, the large number of individual atmospheric effects makes identifying and influencing these individually a complex undertaking. Initial M-R models have instead measured the information rate, or load of an environment. Load is defined as 1.) how well an individual knows and environment and can predict what will happen (amount of environmental novelty) and 2.) the number of elements, features and changes in an environment (complexity, Mehrabian, 1976). A high load environment is novel, surprising, crowded and is assumed to stimulate and alert a person (Donovan \& Rossiter, 1982).

Mehrabian also noted that personality traits of the individual need to be considered, a notion which has been ignored by the large majority of studies to date. He suggests that a consumer's response will be mediated by the individual's ability to select among 
incoming stimuli. The M-R model assumes that the environment influences a person's emotional state, which can be described along three orthogonal dimensions PleasureDispleasure, Arousal-Nonarousal and Dominance-Submissiveness. Pleasure indicates the degree to which a person is happy, pleased, satisfied, contented, hopeful, and/or relaxed. A person would score high on the Arousal construct if he/she is frenzied, jittery, aroused, stimulated or excited. Dominance refers to the extent to which a person feels in control of the situation and is able to act freely in the environment (Donovan, Rossiter, Marcoolyn, \& Nesdale, 1994).

Figure 1: Mehrabian-Russel model

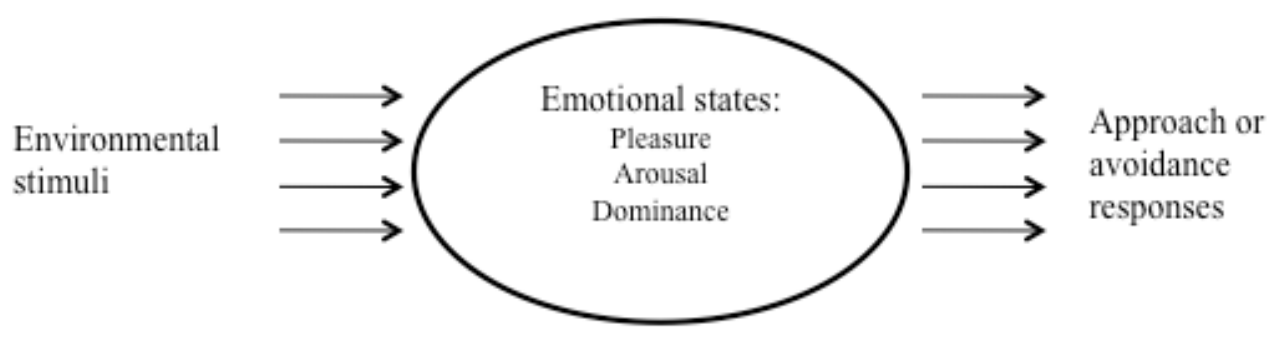

source: Donovan \& Rossiter, 1982

Two of the emotional states, namely pleasure and arousal, appear to interact with each other. With a pleasure of close to zero (neutral), a moderate arousal causes a positive response and very high or low levels of arousal cause a negative response in the S-O-R taxonomy. However in an unpleasant environment (negative pleasure), the higher the arousal, the more negative the response (Mehrabian \& Russell, 1974).

The three emotional states determine and mediate the environment's effect on the response, which can be either approach or avoidance type behaviours. For example, consumers responding positively will want to spend more time in the environment, want to look around and interact with other individuals present. It will lead to enhanced performance or satisfaction (Mehrabian \& Russell, 1974).Although increasing sales may be the prime objective of many servicescape designs, studies more often group possible reactions into two forms of behaviour - approach or avoidance. Avoidance (not to stay, explore, affiliate or work) (Mehrabian \& Russell, 1974) may actually be a valid objective, as one may want to avoid under aged from entering a Casino or make restaurant patrons leave their table as soon as possible to allow new customers taking their seats (d'Astous, 2000). The Mehrabian-Russel model has been supported by both 
empirical evidence and physiological reasoning and was applied widely since then (Donovan \& Rossiter, 1982; Donovan, et al., 1994; Meryl Paula Gardner, 1985; Koo \& Lee, 2011; Mehrabian \& Russell, 1974).

A wider perspective towards modelling store patronage was suggested by Monroe and Guiltinan (1975). Store patronage is largely determined by purchase needs and purchase habits, but then influenced subconsciously by the consumers perceived retail store types and characteristics. These are filtered through attitudes before a patronage decision is made (Monroe \& Guiltinan, 1975). This approach is similar to the environmental stimuli aspects of the Mehrabian-Russel model in the sense that the signals sent by a store's environment to consumers while in the store influence purchasing decisions. However, a valuable extension is the circular nature of the Monroe-Guiltinan model, which means that shopping experiences shape the customer's habits and attitudes, as well as the store's image, which in turn influence future patronage decisions and loyalty (see also Kenesei, 2002).

A further important extension to the M-R model was offered by Bitner (1990) who notes that in service industries, the built environment affects not only customers but also employees as both "interact with each other within the organisation's physical facility" (Bitner, 1990, p. 85). She states that the effect of perceived environmental cues on the organism is being moderated by personal as well as situational factors. In addition to personality traits (e.g. screening behaviour) as suggested in the M-R model, also expectations, mood states of individuals entering an environment and so on are influencing the impact of servicescapes on internal responses (Bitner, 1990, p. 85). While mood states are a personal feature, they have been shown to be affected by the environment itself; as a highly arousing environment will affect a person in an anxious and fatigued state differently than a relaxed and awake individual (Meryl Paula Gardner, 1985). People who are time sensitive will be more affected by crowding in a store then those who are more patient (Harrell \& Hutt, 1976).

Early environmental psychologists focused on consumer emotions as the dominant organism in the S-O-R paradigm, however the model has since been expanded with other, cognitive and physiological organism. Cognition contains thoughts, perception and beliefs obtained through direct interaction with the environment, product or service offerings, review of information obtained from other sources or comparison of these information with memory (Blackwell, Miniard, \& Engel, 2001; Holbrook, 1986; 
Werner Kroeber-Riel \& Weinberg, 2003; Olson, 1980). The impact of the environment on cognitive processes has been confirmed by several researchers, especially ambient stimuli may influence service quality and merchandise quality as rated by customers. For example studies showed that perceptions of store image and quality may be influenced by ambient scent (J.-C. Chebat \& Michon, 2003), or music in the retail area (Sweeney \& Wyber, 2002). Perceived price and quality have been shown to be influenced by perception of store design and in-store music (Baker, Parasuraman, Grewal, \& Voss, 2002). purchases. Service quality perceptions as well as store evaluation were linked to subjective evaluations of the facility (I. W. Turley \& Fugate, 1992).

However, one may argue that cognitive processes have significantly lower explanatory power of the effects of servicescape on behaviour than emotions. In a study measuring consumer consumption experiences in various restaurants, Kim and Moon (2009) found that the effect of the servicescape on emotions was three times stronger than the effect on perceived service quality, which likely to be a primarily cognitive assessment. In high entertainment type restaurants (those with live entertainment, for example), no effect on service quality could be found. This dissertation deals with airport retail environments, which are high excitement and high pleasure environments (Thomas, omar) and as such similar to the high entertainment type environments. In fact, the study found no direct relationship between quality and revisit intention, however quality influenced emotions, which in turn partly determines revisit intentions. This is in line with the concept of the cognitive theory of emotion (Richard S Lazarus, 1991), which states that emotions have a mediating effect between cognition and consequent human behaviours (eg., J.-C. Chebat \& Michon, 2003; Richard S Lazarus, 1991; R.S. Lazarus, 1994). Consequently, this dissertation focuses on the mediating role of emotions while the effect of airport environments on cognition will have to be a future study.

\section{II.1.2. Servicescapes}

The physical surroundings in which service encounters take place have been coined 'servicescapes' in the early 1990's (Bitner, 1992, p. 50). One early definition of servicescapes calls them "buying environments [designed] to produce specific emotional effects in the buyer that enhance his purchase probability" (Kotler, 1973). A newer and less restrictive definition suggests they are "consciously designed places, 
calculated to produce commercially significant actions" (Arnould, Price, \& Tierney, 1998, p. 90). Several important differences can be noted: Firstly, service marketing extends to not only places where buying takes place, but could include areas where service is delivered. Next, it is not always purchase probability that is the objective, instead affiliation with sales personnel or evaluation of a store are other, valid objectives of servicescape design. In contrast to Arnould's definition, one could argue that environments affect consumers regardless of the fact if they were consciously designed or not. Both previous definitions also ignore the fact that atmospherics affect employees as well as customers (Baker, Levy, \& Grewal, 1992). For these reasons, this thesis is based on the following definition of servicescapes:

"all of the objective physical factors that can be controlled by the firm to enhance (or constrain) employee and customer actions" (Bitner, 1992, p. 65).

Consequently, servicescapes located inside an airport can be termed airportscapes. Previous studies measured various stimuli's influence on shopping behaviour by experimentally modifying colour, music or scent. Although it has been suggested, that the importance of individual components of the servicescape is likely to vary between organisations (Bitner, 1992), several authors have suggested universal categories (Baker, 1987; Berman \& Evans, 1995; L. W. Turley \& Milliman, 2000).

These universal categories could also indicate how many dimensions servicescapes have. There have been several approaches to divide the objective factors into categories. Baker (1987) identified environmental cues to be either Ambient Factors, Design Factors, or Social Factors. Based on her view, ambient factors, such as music, scent or air quality do not motivate purchase decisions when they are simply meeting customer expectations. An extreme ambient factor, such as very high or very low temperature can lead to avoidance behaviour. There could be exceptions, however, when extreme levels may have a positive impact on consumer behaviour, for example the scent of fresh bread attracting customers to a bakery (Baker, 1987).

She defines design factors to be either aesthetic or functional: Aesthetic factors are physical cues which customers observe (colour, architecture, style, materials etc.) and influence the level of pleasure in the service experience (Aubert-Gamet, 1997). Functional factors facilitate the behaviour of customers in the servicescape and include 
layout, signage and comfort (Baker, 1987). Social Factors include the influence by human presence in the servicescape, which was not completely integrated in the early studies in environmental psychology (Baker, et al., 1992). The service personnel present in a customer environment, it's size, appearance, and behaviour, has also been shown to impact consumer behaviour (Baker, et al., 1992; Bitner, 1990; L. W. Turley \& Milliman, 2000). Furthermore, the appearance, behaviour and number of other customers are a crucial human facet of the environment (see for example studies on how crowding influences purchase intentions by (Eroglu \& Machleit, 1990; Machleit, Kellaris, \& Eroglu, 1994)).

An alternative classification was suggested by Berman and Evans(1995), who in addition to Baker's three categories suggested adding two more; one containing all variables related to the environment outside the store to a separate category ('external variables') and a second one containing 'point of purchase' variables, such as price displays, signs, cards, product displays and so on. The focus on external variables is an important extension of the traditional concept of store design, and is highly relevant to shopping mall research (see for example Michon, Chebat, \& Turley, 2005). The stimuli outside the store, including both variables which can be directly influenced by the store, such as shop windows and external signage, but also those which can only be influenced by shopping mall management (or in case of stand-alone stores through the local municipality), can be expected to influence the likelihood to enter a store. One could think of examples such as bad smells or dirty sidewalks near the entrance of a shop. A weak point of this classification is that the 'point of purchase' category has a high overlap with the 'general interior' category, and the following pairs of variables are assigned to different categories, but are probably impossible to separate in reality: product displays vs. merchandise, 'wall decorations' vs. 'paint and wall paper', 'color schemes' vs. 'pictures'. Also, it does not consider human factors such as staff appearance or other customers (L. W. Turley \& Milliman, 2000).

The Baker framework has been the starting point for research performed by Bitner (1992). Her framework differentiates between three types of servicescape cues: Ambient conditions, space/function and signs/symbols/artifacts. These cues have an effect on customers and employees, representing the 'human element'. Their reaction to the environment also influences each other's actions, and therefore considers elements of exchange which are important to service marketing. 
For the setting of this thesis, the following special aspects should be considered. External elements are relevant in principle, but difficult to control in complex environments. The qualitative study will include a detailed discussion of how the stimuli of environments experienced before entering the retail area can cause a change in emotions. The scope of the quantitative study, however, will be limited to a single store environment. Also, human factors play an important role in the scope of this thesis, because airport retail concepts require a high number of sales staff to help customers in an unfamiliar environment and actively sell in a time pressured environment. While Bitner (1992) considers staff behaviour as a consequence of the servicescape, one could also argue that staff numbers, appearance and behaviour can be directly influenced by management and therefore the same type of stimuli in customers can be triggered with human factors as with physical factors. In summary, we therefore find the structure suggested by Baker (1987) most relevant: It seperates out human factors as antecedents of consumer reactions, and does exclude external factors.

\section{$\underline{\text { Ambient factors }}$}

Positive perceptions of the environment of a shopping mall have been shown to have some positive effect on the level of excitement, which in turn leads to higher repatronage intentions. The decor, layout, music, etc. of a mall are especially important to keep customers in a mall once they enter (Wakefield \& Baker, 1998). The physical appearance of a firm's premises can have a positive effect on customer attribution and satisfaction. A study evaluating service companies showed that neat, well kept, organised customer service areas achieved higher satisfaction ratings by customers after a service failure occurred (Bitner, 1990).

Ambient temperature level was found to influence interpersonal attraction of people (Griffitt, 1970). However, other studies found no measurable effect of temperature levels on desire to stay in a shopping mall (Wakefield \& Baker, 1998). It seems likely that while acceptable levels of temperature go unnoticed by customers, too high or low levels increase the probability of avoidance behaviour (Baker, 1987).

Music in a shopping environment has attracted much attention (Baker, et al., 1992; Broekemier, Marquardt, \& Gentry, 2008; Garlin \& Owen, 2006; Hui, Dubé, \& Chebat, 1997; Mattila \& Wirtz, 2001; Milliman, 1982, 1986; Morin, Dubé, \& Chebat, 2007; Yalch \& Spangenberg, 1988, 1990, 2000). The studies show that music has an impact 
on sales, time spent in the environment (both perceived and actual), and the state of arousal.

Table 1. Components of the servicescape

\begin{tabular}{|c|c|c|}
\hline Ambient Factors & $\begin{array}{l}\text { Background conditions that exist } \\
\text { below the level of our immediate } \\
\text { awareness }\end{array}$ & $\begin{array}{l}\text { Air Quality } \\
\text { - Temperature } \\
\text { - Humidity } \\
\text { - Circulation/Ventilation } \\
\text { Noise (Level/Pitch) } \\
\text { Scent } \\
\text { Cleanliness }\end{array}$ \\
\hline Design Factors & $\begin{array}{l}\text { Stimuli that exist at the forefront } \\
\text { of our awareness }\end{array}$ & $\begin{array}{l}\text { Aesthetic } \\
\text { Architecture Colour Style } \\
\text { Materials Décor } \\
\text { Scale Shape } \\
\text { Texture, Pattern } \\
\text { Functional } \\
\text { Layout } \\
\text { Comfort } \\
\text { Signage } \\
\text { Accessories } \\
\end{array}$ \\
\hline Social Factors & People in the Environment & $\begin{array}{l}\text { Audience (Other Customers) } \\
\text { Number, Appearance, Behaviour } \\
\text { Service Personnel } \\
\text { Number, Appearance, Behaviour }\end{array}$ \\
\hline
\end{tabular}

The extend of the effect depends on the type of music, e.g., foreground vs. background music (Yalch \& Spangenberg, 1988, 2000), the tempo and volume of music (Milliman, 1982, 1986; Oakes \& North, 2008), and the age of the patron (Yalch \& Spangenberg, 1990). Several studies point out that the outcome of ambient music is mediated by its congruity with other environmental cues. For example, the genre of music needs to be congruent with a restaurant's atmosphere to increase length of stay and spending (Baker, et al., 1992; Grewal, Baker, Levy, \& Voss, 2003; Vida, 2008; Wilson, 2003). Finally, if customers like the music, they tend to evaluate a servicescape more positively (Dubé \& Morin, 2001), perceive waiting time to be shorter (Bailey \& Areni, 2006; Hui, et al., 1997), and spend more (Caldwell \& Hibbert, 2002). See also Oakes and North (2008) for an overview of congruity effects.

Also, scents and aroma as an interior variable have been examined, albeit with varying outcomes (Mattila \& Wirtz, 2001; Spangenberg, Crowley, \& Henderson, 1996). Several studies have confirmed that the mere presence or absence of a scent has a significant influence on consumer behaviour, irrespective of the odour. Bone and Ellen (1999) identified 34 studies showing statistically significant effects of scent presence on 
consumers' response. In general it can be assumed that pleasantly scented environments lead to approach behaviours while unpleasant environments cause avoidance. This reaction may occur without customers even being aware of the presence of the smell (Bradford \& Desrochers, 2009; P. Ward, Davies, \& Kooijman, 2007). The effect appears to depend on the specific type of the scent: Firstly, the scent needs to have a perceived association with the store-type to gain positive responses. Presence of a pleasant but non-associated scent may even lead to negative responses (Parsons, 2009). Secondly, the presence of mediation variables, such as gender, may be considered. For example, one study confirmed that in the presence of gender-congruent ambient scent ('rose maroc' for men, 'vanilla' for women) shoppers perceive to have spent more time in the store, bought more items and spent more money on their purchases (Spangenberg, Sprott, Grohmann, \& Tracy, 2006).

During pre-Christmas periods, stores often combine seasonal music with ambient scents to enhance the effect. In an experimental setting the impact of four possible combinations (Christmas scent/no scent, Christmas music/no music) on respondents' intentions to visit a store were tested. While scents had a positive effect with music present, the effect was neutral or even negative when no music was present (Spangenberg, et al., 2005).

Colour schemes applied in elements of the interior design of servicescapes have been shown to have an effect on shopping behaviour (Babin, Hardesty, \& Suter, 2003; J.-C. Chebat \& Morrin, 2007; Ellis \& Ficek, 2001). Shoppers can be more attracted to a retail display (Bellizzi, Crowley, \& Hasty, 1983), are more likely to purchase, be aroused, have a different image of store and merchandise or spend more time in the environment (Bellizzi \& Hite, 1992), depending on the colours applied. While some studies showed that lightning factors can influence both store image, examination and handling of merchandise (Baker, et al., 1992);(Summers \& Hebert, 2001), others found no significant effect (Areni \& Kim, 1994).

\section{$\underline{\text { Design factors }}$}

The number of research into effects of external variables is limited. We found only one study looking at the impact of environmental attributes of a larger area around the servicescape (for example a shopping district) on shopper behaviour. While customers were shown to form perceptions of large complex macro environments, this varied 
greatly depending on shopper typology (Grossbart, Mittelstaedt, Curtis, \& Rogers, 1975). An objective measure of the effect of window display design on sales has been developed (Edwards \& Shackley, 1992). Mixed support has been found for the hypothesis that the facilities in which physician meet their patients impact customer attitudes toward care received and customer satisfaction (Pinto \& Leonidas, 1994). More recent research into a consumer's decision to enter the store based on information received from window displays suggests that product category related information has a stronger effect on purchase decisions then store-related information. Also preknowledge of the customer about the product category have a mediating effect on shopping decisions: Consumers with medium knowledge of clothing are more influenced by window displays then those with low or high knowledge (Sen, Block, \& Chandran, 2002).

One study included external variables as items in a general measure of store atmosphere (access, parking, exterior of building, landscaping of garden, outdoor exhibition area), however failed to present evidence for a relationship between atmosphere and purchasing behaviour (Pan, Su, \& Chiang, 2008). The type of storefront display used was shown to have a 'spill over' effect onto the store image. Innovative displays (such as column stands, standing flags) have led to consumers perceiving a store to be more 'sophisticated', 'modern', and 'trendy' (Cornelius, Natter, \& Faure, 2010).

There is an apparent lack of studies analysing how variables such as traffic flow, location of departments, and allocation of merchandise within departments impact the emotional states of customers and their behaviour. Most research in this area has dealt with the subject of store layout as a means to provide customers space to shop easily (rather related to the concept of crowding) or to control traffic flow on the floor (Hasty \& Reardon, 1996; Levy \& Weitz, 2009). For example, a prominent floor display of a product increases sales significantly irrespective of the type or size of retail store (e.g., Gagnon \& Osterhaus, 1985). Another article reports that the layout of merchandise in power aisle has an effect on perceived price levels (Smith \& Burns, 1996).

A separate research stream has emerged identifying the effect on online store layout and product positioning, claiming that predictions based on classical retail literature do not always apply (Vrechopoulos, O’Keefe, Doukidis, \& Siomkos, 2004). 
In-store displays can be product displays, including point-of-purchase or shelf space, signs, cards or wall decorations. They play an important role in any retailers strategy, and therefore receive significant coverage in the literature (Berman \& Evans, 1995; Levy \& Weitz, 2009) however to our knowledge, no study investigates the environmental psychological aspects of interior displays.

Product displays in a store increase consumer's sensitivity to promotions and prices and decrease brand loyalty (Bawa, Landwehr, \& Krishna, 1989). Product displays increase the probability of unplanned purchase, but not of planned purchase. This effect is significantly stronger for product categories that are purchased relatively often (Inman, Winer, \& Ferraro, 2009).

Attaching signs stating a promotional price in large letters to certain brands increases the likelihood of choice. While individuals which are likely to process additional issuerelevant information (high-need-for-cognition individuals) would only react if the price displayed actually was lower than the standard price, others change behaviour purely because of the signage being present (Inman, McAlister, \& Hoyer, 1990). Furthermore, not only the content but also purely the amount of information contained on in-store displays positively influences consumer choice. When customers need to decide between two very similar products, they would prefer those which contain most information. However if a product is of superior quality to another, it is advisable to provide less information (Patton III, 1981).

\section{$\underline{\text { Social factors }}$}

Retail personnel's number, appearance and behaviour impacts consumer's perception of a firm and therefore influences behaviour (Bitner, 1992; L. W. Turley \& Milliman, 2000). For example, when service failures occur, employees dressed in unprofessional attire have been shown to negatively influence a customer's attribution and satisfaction (Bitner, 1990). The number and friendliness of employees has a positive impact on levels of pleasure and arousal, which in turn impacts willingness to buy (Baker, et al., 1992). Stores with more sales personnel on the shop floor greeting customers were perceived as providing a higher service quality then stores with less staff not offering a greeting (Baker, Grewal, \& Parasuraman, 1994; Hutton \& Richardson, 1995).

The effect of other customers' presence has been widely discussed (Machleit, Eroglu, \& Mantel, 2000; Machleit \& Mantel, 2001). An individual's assessment of the presence of 
others in a limited space will be referred to as the perception of crowding. It is important to differentiate this from density, i.e. the actual number of other shoppers present (Harrell \& Hutt, 1976). The perception of crowding can be either human crowding (a closed confined feeling experience from high human density) or spatial crowding (feelings of restricted physical body movements due to high spatial density) (Harrell, Hutt, \& Anderson, 1980; Machleit, et al., 1994). Note that the feelings associated by the proximity of others can be related to both presence of people (a human variable), but is also to questions of store layout.

Several studies confirm that crowding has a negative influence on atmospheric perceptions, lead to negative emotions (unhappy, irritated), has a negative effect on satisfaction (Eroglu \& Machleit, 1990; Hui \& Bateson, 1991; Machleit, et al., 2000) and in extreme cases even to emotional venting or confronting behaviour (Whiting, 2009). However, higher density does not lead to negative perceptions of crowding if customers are in control over the environment (Hui \& Bateson, 1991). Also, a study conducted at two retail stores in Taiwan suggested a positive relationship between human crowding and pleasure ( $\mathrm{Li}, \mathrm{Kim}, \&$ Lee, 2009), suggesting that culture could be an important mediator. The fact that Taiwan scores relatively low on the cultural dimension individualism (Hofstede, 2001, 2011) suggests that Taiwanese feel more comfortable if they are part of a larger group, compared to North Americans, for example.

Another positive effect of density on pleasure can be derived from manning theory, which states that every setting requires an optimal number of occupants to function effectively (Wicker, 1979). If the density is lower than ideal, increasing the level of crowding will cause the retail functions to work more effectively, leading to increased pleasure levels with the consumer. For example an Apple Store may create a sense of an excitement when customers have to wait in line to get in (Wakefield \& Blodgett, 1994). It has been suggested that the relationship between crowding and emotions could in fact be inverse v-shaped, with emotional reactions to the presence of others turning to negative when the social size exceeds an individual's level of comfort (Argo, Dahl, \& Manchanda, 2005). A study conducted in an extended service setting (a restaurant) showed that while crowding reduces levels of satisfaction when the objective is of a utilitarian nature (a quick bite to eat), it may increase satisfaction in extended hedonic service settings (an enjoyable meal, Noone \& Mattila, 2009). 


\section{II.1.3. Sensory marketing}

Our research also relates to a research stream which was coined sensory marketing in 2008 (Krishna, 2010) and represents a renewed interest in how influencing the five senses (vision, touch, audition, smell and taste) can be integrated into more classical marketing mix elements. Although much of the research in the field of environmental psychology and servicescapes seems to be reasonably well defined (see for example regular reviews (Bohl, 2012; Ezeh \& Harris, 2007; L. W. Turley \& Milliman, 2000), its scope appears limited to the effect of stimuli affecting individuals because of their mere presence in an environment. There is only limited research into senses such as food tastes (Kahn \& Isen, 1993), or the effect of spoken displays as opposed to static displays (Unnava, Agarwal, \& Haugtvedt, 1996). For example the categorisation of environmental cues by Baker (1987) and Bitner (1990) do not include categories for these. These open important avenues for future servicescape research. After all, in-store tasting has been shown to positively influence consumer evaluations (Sprott \& Shimp, 2004) and attract customers and increase sales as well as time spend in stores (Bruwer, Lesschaeve, \& Campbell, 2012). Equally, digital signage (such as in-store monitors) are used regularly, and have been shown to influence approach behaviour (Dennis, Newman, Michon, Brakus, \& Wrigh, 2010). While these concepts are out of scope for this thesis, much of the findings of this study contribute to the wider concepts of sensory marketing and we agree that a wider definition of the relevant senses in retail settings is needed.

Secondly, the conceptual framework of sensory marketing focuses on consumer's perception of the sensation, arguing that it is the awareness or understanding of sensory information by consumers which triggers emotional and cognition processes (Krishna, 2012). This is in conflict with assumptions by environmental psychologists, who argue there are also environmental cues which influence behaviour without consumers being aware of them, such as in-store scent (Bradford \& Desrochers, 2009; P. Ward, et al., 2007) or an anti-clockwise path designs in supermarkets (Andrea Groeppel-Klein \& Bartmann, 2008). In fact, it has been argued that only psychophysiological measures of emotional reactions achieve sufficient discriminant validity, because of the respondent being unaware of the reason for or existence of the affect (A. Groeppel-Klein, 2005). These arguments would suggest that the scope of sensory marketing is too narrow in this respect and should incorporate also subconscious effects of the environment. In 
summary, one can state that there are some differences in scope of the two research streams. However as this study will later show, measures of a store's perceived lighting, ease of finding things and architecture are highly correlated, suggesting that customers are unable to clearly differentiate between the effects. This would argue that the present study does not fit the assumptions of the sensory marketing school. At the same time, current topics of sensory marketing contain several avenues for potential new airport retailing research, such as the effect of food tasting on emotions and behaviour.

\section{II.2. Moods and Emotions}

Understanding emotions is important, because they are key drivers behind a consumer's approach or avoidance behaviour (Aubert-Gamet, 1997; Hutton \& Richardson, 1995). The Stimulus-Organism.Response concept assumes emotions to be a mediator between retail atmosphere (stimulus) and shopping behaviour (response). Several studies have shown that servicescapes affect customers' emotional states, by either enhancing or suppressing them (Baker, et al., 1992; Hui \& Bateson, 1991; Wakefield \& Baker, 1998). However, emotions are difficult to verbalise and transient and thus, difficult to recall (Donovan \& Rossiter, 1982). For the purposes of this thesis proposal, we will therefore start by a number of definitions and introduce various approaches to explaining and measuring emotions.

\section{II.2.1. Definitions}

Scientific research in emotions reaches as far back as Charles Darwin (1872) and William James (1890) but has only over the last 30 years received greater attention from consumer behaviour and psychology, with literature overviews provided from time to time by Fridlund (1987), Oatley and Jenkins (1992) and Oatley et al.(2011). Darwin's theory of evolution proposes that emotional expressions are indexes of an inner state, and lead to the development of measurements of facial expressions as indicators of emotional states (see, for example, the Facial Expression Analysis Tool, Kaiser \& Wehrle, 2001). He postulates that these inner states are inborn, and visible in humans and animals alike. Most researchers agree that emotions are not the inner feeling itself, but merely a mental state that has been caused by some change 'inside'. This is also

more practical, since conceptualizing or even measuring the 'core feeling' would be impossible, in the same way as the experience of seeing the colour yellow or blue. 
James called emotions "feelings" of inner states, the colour and warmth of an experience (James, 1890), in reaction to an external event. The stimuli could also be a mere thought, for example memories of a past event (N. H. Frijda, 2010).

Emotions are often expressed by gestures, postures, facial features etc., and are accompanied by physiological features, such as changes in heart rate or skin conductance (Plutchik \& Kellerman, 1989). Cognitive theorists assume that people are usually aware of emotions, and are able to express emotions using language (Keith Oatley \& Jenkins, 1992). Research involving three- and six-year olds has shown that children and adults understand emotions in terms of goals and outcomes, i.e. emotions influence plans to keep, give up, reinstate or change goals (Stein \& Levine, 1989).

The terms emotions, mood, affect are currently being used by researchers without a commonly agreed differentiation between them, and therefore we will define what we mean by these terms in the following paragraphs. Affect seems to be mostly used as an umbrella term for several mental processes, including moods and emotions. Gardner (1985) has reviewed a wide range of studies in both, consumer behaviour and psychology and found the most generally accepted definition for moods to be feeling states which are subjectively perceived by individuals. They are states - which are transient - and are linked to specific periods and situations, as opposed to the long term (Westbrook, 1980), for example they are not personality dispositions such as optimism/pessimism (Meryl Paula Gardner, 1985). One may or may not be aware of a mood, and they are not intentional and more global then specific. Although there are clearly different types of positive (cheeriness, peacefulness) and negative (guilt, depression) affects, only very few studies investigate the effect of more than one mood (Meryl Paula Gardner, 1985). People in positive moods have indicated more satisfaction with their lives than those in negative mood conditions (Diener, Shigehiro, \& Lucas, 2009). This relationship will be important in later parts of this thesis proposal, because we will identify life satisfaction as a good indicator of moods.

Emotions are more intense then moods, more attention-grabbing, and tied to a specific behaviour (Hermalin \& Isen, 2007). One is aware of them, because emotions may redirect attention from the source and interrupt ongoing behaviour (Simon, 1967). Emotions can be defined as a "mental state of readiness that arises from a cognitive appraisal of events or thoughts" (Bagozzi, Gopinath, \& Nyer, 1999, p. 184; see also Richard S Lazarus, 1991; Keith Oatley \& Jenkins, 1992). Emotions are more strongly 
linked to physiological changes than moods, and are lasting for no longer then a few hours, whereas moods last from several hours to days (Bagozzi, et al., 1999).

We would therefore argue that underlying moods of customers are important, as they may exist in parallel to emotional states at the same time. However, we investigate the short-term impact of the servicescape on consumer's behaviour, and based on the above definition, consumers' emotions are more relevant for a dynamic analysis, and should remain the focus of the investigation.

Emotions arise as a reaction to a specific stimulus. For example unexpectedly meeting an old friend may lead to a state of surprise and joy, where surprise may last for a short period, but new stimuli for 'joy' may arise during the interaction with the friend or even in the form of memories after the meeting. To be more precise, emotions arise in response to an appraisal of something of importance. In the above example, the relevance is not the unexpected nature of the meeting, nor the friendship, but the fact that the individual has noted the friend, remembered the good times, and decided to stop the person in order to experience positive feelings, and to give the other person positive feelings, something which at that time was important enough to stop and talk. Not the event or physical circumstance produces the emotion, but the unique psychological appraisal by the person. The appraisal process is therefore of large importance to understanding emotions and has formed a research stream around the appraisal theory (Nico H Frijda, 1986; Richard S Lazarus, 1991). We will discuss the main concepts of appraisal theory in section II.2.4 in relation to anxiety and stress.

Emotions arise when an event or change of circumstances (stimulus) are expected to have a significant effect on a personal goal. The outcome of the appraisal process therefore highly depends on the goals of the individual. Oatley-Johnson-Laird have postulated that the perceived effect of a stimulus on the current plans is in fact eliciting emotions, and differentiated five basic emotions (other emotions were not considered basic as they are combinations of the five) by their juncture of the current plan. For example sadness is elicited, when an important personal goal (plan) was not achieved, or an active goal was lost, taken away, or deemed unachievable. The physiological reaction could range from doing nothing, via attempting to passively cope with the emotion to actively searching for a new goal (goals) to return to equilibrium. Goals are defined as "symbolic representations of possible states of the environment that a system will try to achieve" (Keith Oatley \& Johnson-laird, 1987, p. 30). Plans are sequences of 
changes between these representations, which a system (e.g., a customer) can establish and then carry out in order to achieve goals. Some plans may also be unconsciously such as following other people when they move through unknown environments to avoid getting lost. Positive emotions occur when events or circumstances suggest that goals can be reached and individuals can continue with the plan, negative emotions require revision of plans or loss of a goal (Keith Oatley \& Johnson-laird, 1987).

Table 2: Oatley-Johnson-Laird model of basic emotions, stimuli and effects

\begin{tabular}{|c|c|c|}
\hline Emotion & Juncture of current plan & State to which transition occurs \\
\hline Happiness & Subgoals being achieved & $\begin{array}{l}\text { Continue with plan, modifying as } \\
\text { necessary }\end{array}$ \\
\hline Sadness & $\begin{array}{l}\text { Failure of major plan or loss } \\
\text { of active goal }\end{array}$ & Do nothing/search for new plan \\
\hline Anxiety & $\begin{array}{l}\text { Self-preservation goal } \\
\text { threatened }\end{array}$ & $\begin{array}{l}\text { Stop, attend vigilantly to } \\
\text { environment and/or escape }\end{array}$ \\
\hline Anger & Active plan frustrated & Try harder, and/or aggress \\
\hline Disgust & Gustatory goal violated & Reject substance and/or withdraw \\
\hline
\end{tabular}

source: Oatley \& Johnson-Laird (1987)

There are three measures of emotions which have received significant attention in marketing (Machleit \& Eroglu, 2000): (1) Mehrabian-Russel (1974) propose emotions are well represented by the three categories of response: Pleasure, Arousal, and Dominance. (2) Plutchik (1980) postulates 8 basic categories of emotions (fear, anger, joy, sadness, acceptance, disgust, expectancy and surprise). (3) Izard's (1977) Differential Emotions Theory proposes to measure 10 fundamental emotions. We will in turn introduce these concepts and then present the concept used in the quantitative study.

\section{II.2.2. Pleasure-arousal-dominance model}

The M-R model states that three measures pleasure, arousal and dominance are required to capture all emotional effects caused by consumer environments (Mehrabian \& Russell, 1974). They postulate that people will enjoy spending more time and possibly more money in those stores where they feel pleasure and a moderate or high 
degree of arousal as well as the right level of dominance. The measure for pleasuredispleasure was meant to represent the positive or negative appraisal of a stimulus, whereas the arousal-nonarousal measure should correlate with the level of physical activity or mental alertness. The dominance-submissiveness measure (i.e., feelings of control and influence over others and situations) controls for effects of stimulus potency. Initially, each measure consisted of six adjective pairs, which were placed at opposite ends of 9 spaces, and respondents were asked to mark one of the 9 to describe their feelings. Adjective pairs included the following: happy-unhappy, pleased-annoyed, and contented-melancholic to state pleasure; stimulated-relaxed, jittery-dull, and excited-calm for state arousal; and controlling-controlled, influential-influenced, and important-awed to state dominance. The Pleasure, Arousal, and Dominance factors accounted for $27 \%, 23 \%$, and 14\% of total variance, respectively (Mehrabian \& Russell, 1974).

The three dimensions are conceptually orthogonal, however the model suggests a codependency of pleasure and arousal: When pleasure is neutral, i.e. neither pleasing nor displeasing, moderate levels of arousal cause approach behaviour whereas very high or low levels of arousal cause avoidance (Donovan \& Rossiter, 1982).

The Pleasure-Arousal scales used by M-R have been updated several times. DonovanRossiter (1982) replaced three bipolar items to match contemporary language (for example important-awed with important-insignificant). Their factor analysis of the 18 bipolar items confirmed three factors, with satisfactory alphas for pleasure (.90) and arousal (.86) but low for dominance (.65). Several dominance items loaded also high on pleasure and arousal dimensions. In fact, the M-R scales are often used without dominance measures (Russell \& Pratt, 1980). Mehrabian also published various alterations of the scale. A newer version of his measurement models feature a 16-item scale for pleasure, a 9-item scale for arousal and a 9-item scale for dominance, with roughly an equal amount of positive and negative emotions for each of the three dimensions (Mehrabian, 1995).

Dominance represents the feeling of the customer controlling as opposed to being controlled and being influential as opposed to being influenced. This may be increased by clear signage, or increased personal space (Bitner, 1990). In situations of crowding, dominance has been shown to be relevant (Machleit \& Eroglu, 2000). Several studies suggest that dominance is an independent or even moderating variable. Perceived 
control may be an antecedent of pleasure, influenced by both consumer density and consumer choice. Depending on the service setting, perceived control can lead to high pleasure in a high density bar, but to low pleasure in a crowded bank (Hui \& Bateson, 1991). Other studies have suggested that dominance was unnecessary, with pleasure and arousal being sufficient to represent emotions (e.g., Ridgway, Dawson, \& Bloch, 1989; Sweeney \& Wyber, 2002). Furthermore, there may be emotions which load high on both dimensions, and create four additional vectors (see Figure 2). For example, gloomy would be the combination of unpleasant and sleepy, and so forth (Russell \& Pratt, 1980; Törőcsik, 1995).

Figure 2: Two dimensions pleasure and arousal and corresponding emotional states

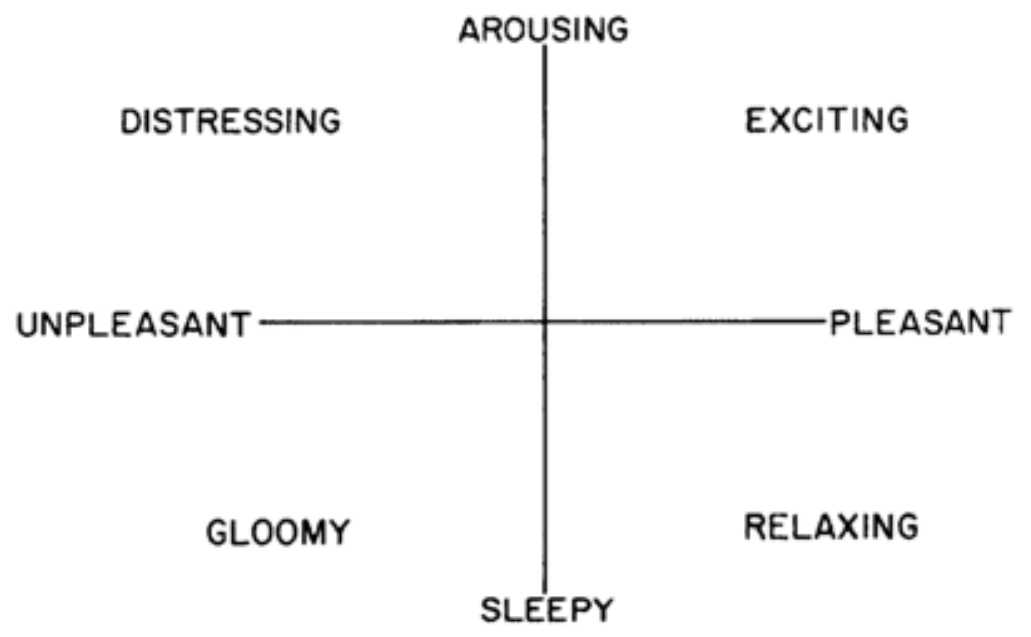

source: Russell \& Pratt (1980)

In order to address the issue of questionnaire length, the Affect Grid scale was developed, which is a shortened measurement instrument based on the eight emotional states. The measure involves respondents to indicate their emotional state in a $9 \times 9$ matrix (grid) along the dimensions pleasure and arousal, allowing to simultaneously indicate a response on both dimensions. The reliability and validity reported by the author of the scale as well as confirmation studies is sufficiently well to use this scale as a control variable (Dubé, Chebat, \& Morin, 1995; Russell, Weiss, \& Mendelsohn, 1989).

We acknowledge the widespread usage of the M-R scale, however, there are some limitations to be considered. The dominance dimension has not received the same 
empirical support as pleasure and arousal dimensions. However in unknown environments, such as the airport servicescapes, not feeling in control or feeling a strong dependency on others may be very important to include (Machleit \& Eroglu, 2000). The fact that acceptable levels of validity could be reached by a much lower number of items then proposed by $M-R$ suggests that the original $M-R$ scale may place an unnecessary burden on respondents. We have therefore reviewed other measures of emotions, which have not received similar criticism about a major dimension of the model, and have also a lower number of items, as brevity of the questionnaire is of key importance in our study.

\section{II.2.3. Basic emotions}

In search for appropriate measures of emotions for consumer behaviour, Havlena \& Holbrook (1986) state that M-R covers many facets of emotions and is therefore a preferable measure. However their study was not specific for retail concepts. They question if all of the emotions are pertinent in a shopping context, and if a shorter more appropriate measure can be found.

Plutchik (cf. Havlena \& Holbrook, 1986; Plutchik, 1980) proposes eight basic emotional categories, as primary reaction to events and circumstances. It assumes that all other emotions can be traced back to one or several of these eight (fear, anger, joy, sadness, acceptance, disgust, expectancy and surprise), and while there is no final agreement if all are relevant to consumption behaviour, they have been widely applied in consumer research. The emotional categories were represented by 24 items, which are measured on a seven-position scale measuring intensity from "not at all" to "very strongly". In a comparative study, the Plutchik scale was found to contain less information, whereas the M-R scale represented 7 of the 8 emotions of Plutchik reliably. In a factor analysis, it was confirmed that M-R contains three P-A-D dimensions, whereas Plutchik's scale contained three dimensions of which only the first one (positive/negative affect) was explainable (cf. Havlena \& Holbrook, 1986). Because of the length of the scale, it also does not deliver any additional benefits of brevity, which could outweigh these shortcomings.

An alternative measure are the fundamental emotions described as the Differential Emotions Theory by Izard (1977), which has become increasingly popular with consumer researchers (Machleit \& Eroglu, 2000). Izard (1977) postulates that emotions 
are accurately represented with 10 emotion types (joy, sadness, interest, anger, guilt, shy, disgust, contempt, surprise, fear), which can be measured by two or three items each. It contains some negative emotions (anger, or disgust due to poor interactions with salespersons) which are not included in the M-R measure but are indeed relevant for a retail setting (Machleit \& Eroglu, 2000). In the initial study, respondents were asked to indicate how they feel for each of these 27 items on a 5-point scale. Coefficient alpha reliability ranged from .71 to .90 for all dimensions (Izard, 1977). A comparative study compared Izard's scale to the one used in M-R as well as the Plutchik scale in a retail setting. Mehrabian-Russel's scale explained much less of the variance found in each of the other two scales, than vice versa. This suggests that the M-R scale may be missing emotions relevant in retail marketing. Little difference was found between the Izard and the Plutchik scale (Machleit \& Eroglu, 2000).

Including very long measurements into surveys can increase respondent fatigue, or result in a lower response rate. This is a problem with all of the above scales, and attempts have been made to reduce the number of items required to measure emotions. Izard argues that dimensional approaches to measuring emotions are unhelpful, and promotes that 10 distinct emotions are basic and interact without being clearly allocated to a positive/negative dimension(Izard, 1977, 2007). Other studies have reduced the number of items even further while still achieving acceptable levels of computed reliability. Scales with six items each were also used, with alpha values of .88 and .77, respectively (Donovan, et al., 1994). One study used two constructs with 4 and 3 items achieving alpha scores of .72 and .64, respectively (Ridgway, et al., 1989).

For this particular study, we argue that the scale used should be 1) as short as possible, 2) easy to understand across cultures and languages, and 3) efficient in that it should measure only basic emotions, but not those which may be combinations of the basic emotions. We agree with Izard's more recent (2007) findings (which have somewhat shifted from the original model presented 30 years ago) that basic emotions should be natural emotions, i.e. those which are common to cultures because they are part of a human's DNA, and not subject to effects of learning or socialization. In being natural, they also satisfy the requirements to elicit some form of physiological reaction, such as facial expressions (Ekman, 1992). In using facial expressions, we not only reduce the number of items per emotion to one (i.e. a single facial expression), but also circumvent the problematic area of translation. 
Izard's six natural basic emotions are interest, joy/happiness, sadness, anger, disgust and fear (Izard, 2007). Others have proposed similar schemes (K. Oatley, et al., 2011). It has been suggested to replace interest with surprise, as interest could be understood as a reaction to a novel even or circumstance, which is appraised to help achieving goals, thus causing happiness as well. Surprise is a more neutral measure and probably correlates to both positive and negative emotions, giving it more explanatory power (Westbrook, 1987). It also has been linked to distinct facial expressions, making it a more reliable measure across cultures (Ekman, Sorenson, \& Friesen, 1969). Several studies replace fear with anxiety which is possibly a weaker type of emotion, and thus more likely to pick up emotional states which maybe have not yet reached the level of outright fear.

It has been suggested that even small changes in the environment can influence the customers' emotions, for example a quick smile of a salesperson or having to wait too long for a doctor's appointment (Meryl Paula Gardner, 1985). We therefore measured the state emotions of respondents by asking them to rate each of the six basic emotions: anger, fear/anxiety, disgust, joy/happiness, sadness, surprise depending on how accurately they represent their current feeling on a sliding scale from 0 (not at all) to 100 (fully).

Figure 3: Six basic emotions (and one neutral) as displayed by KDEF pictures

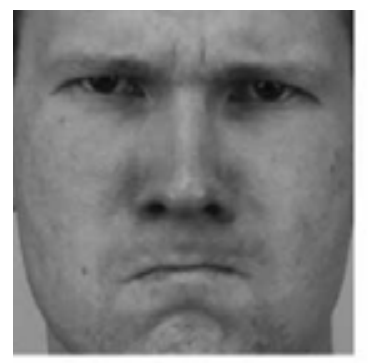

Angry

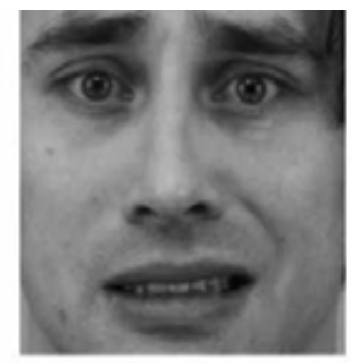

Fearful

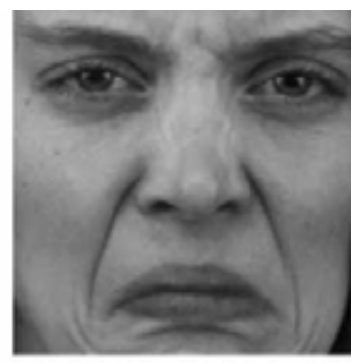

Disgusted

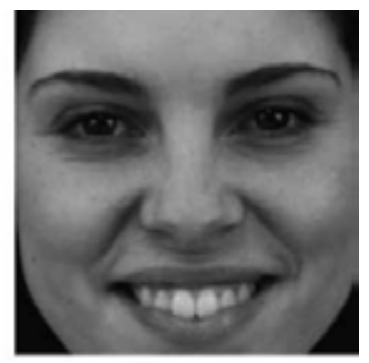

Happy

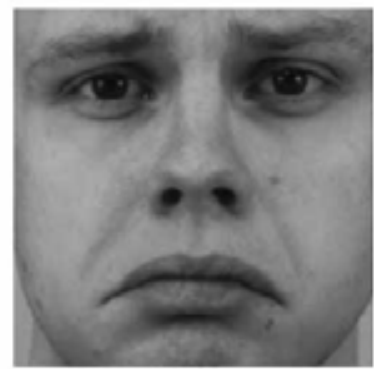

Sad

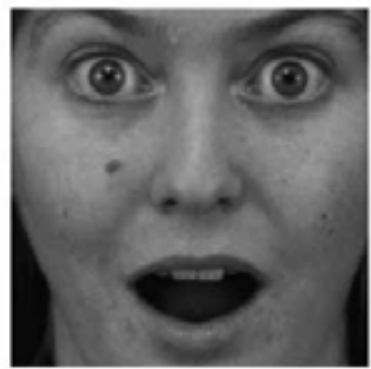

Surprised

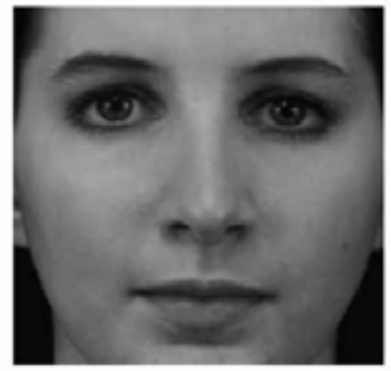

Neutral

source: Karolinska Directed Emotional Faces stimuli (Goeleven, De Raedt, Leyman, \& Verschuere, 2008, p. 1097) 
The set of detailed measures will be presented and discussed in section V.4.4. We present an overview and definition in Figure 3. However, as we will show later, pictural representations of emotions may be superior to words, because words tend to be controlled by the lexical executive system, pictures have privileged access to the semantic system (W. R. Glaser \& Glaser, 1989).

Because fear/anxiety is an emotion of key relevance to the airport retail environment, we will now discuss this in greater detail in the following section.

\section{II.2.4. Anxiety and stress research}

Anxiety is a psychological distress which is closely linked to stress, and in some cases even used interchangeably (Gillis, 1992; Spielberger, 1972). Anxiety can be defined as "a vague, uneasy feeling of discomfort or dread accompanied by an autonomic response, with the source often non-specific or unknown to the individual; a feeling of apprehension caused by anticipation of danger" (Schweitzer \& Ladwig, 2002, p. 144). While anxiety was identified by many as one of the basic emotions (Darwin, 1872; Ekman, 1973; Spielberger, 1972), we have found many important contributions to the topic in a literature stream termed stress research. We identify those aspects which are relevant for our understanding of anxiety.

Psychological literature traditionally places emphasis on the individual's perception and evaluation of the potential harm posed by objective environmental experiences. As with basic emotions, it can be argued that events are only stressful for those who appraise them as such. In other words, stress appraisal is not only determined by the stimulus but also by the person's interpretation of their relationship to the environment.

The mainstream of stress research began with Hans Seyle's work in the 1930s, who is therefore often referred to as "the father of stress". Based on the conclusions of a series of animal studies, he first defined stress as "the non-specific response of the body to any demand for change" (Selye, 1936, p. 32) and developed a stress theory called General Adaptation Syndrome (GAS) based on this idea. Later on, Levine and Ursin defined stress as a condition caused by a lack of information (uncertainty or unpredictability) about obtaining positive outcomes or avoiding negative ones (Levine \& Ursin, 1991). Numerous other authors defined three aspects of stress as well: unpredictability, uncontrollability and intensity (Averill, 1973; Cohen, 1978; Richard S Lazarus, 1966). 
Selye identified two different types of stress, eustress and distress. He described the former one as agreeable or healthy, and the latter as disagreeable or pathogenic. "The way a certain stimulus will be received depends upon its intensity and the particular receptiveness of the affected person" (Selye, 1976, p. 54). It is distress which we consider to be similar to anxiety, whereas eustress is more similar to the concept of flow, a positive emotion which has been shown to occur when high demand on personal resources is paired with feelings of achievement (Csikszentmihalyi, 1990). Another typology of stress makes a distinction between chronic and acute stress. Acute or situation specific stress is triggered by stressful events that involve a sudden onset, are relatively short lived in duration and manifest in distress almost immediately (B. J. Evans \& Coman, 1993; Newton, 1989). Chronic stress on the other hand means being exposed to an ongoing chronic stressor resulting in several stressful events (Wheaton, 1990) and is also referred to as general life stress. This thesis focuses on analysing acute stress. Travel is a too short experience to result into chronic stress.

A consensus in psychology literature seems to emerge to define stress as a process, which is produced in the case of a discrepancy between the demands of the environment and the organism's capacity to respond. Therefore the environment is appraised by the person as exceeding their resources and endangering their well-being (Richard $S$ Lazarus, 1966; Richard S Lazarus \& Folkman, 1987; McGrath, 1970). Research by Bruchon-Schweitzer (Schweitzer \& Ladwig, 2002) also supports the idea that the perception of stress by the individual depends on the event and on the resources available for coping. The cognitive-relational theory of stress emphasizes the continuous, reciprocal nature of the interaction between the person and the environment. These definitions point to two processes as central mediators within the personenvironment transaction: cognitive appraisal and coping (Richard S Lazarus \& Folkman, 1984).

The concept of appraisal was introduced into emotion research by Arnold (1960) and elaborated with respect to stress processes by Lazarus (Richard S Lazarus; Richard S Lazarus \& Launier, 1978). The cognitive appraisal concept is based on the idea that the stress process is dependent on a person's expectations about the significance and outcome of a specific event. These appraisals are determined by a number of personal and situational factors. Personal factors include motivational dispositions, goals and values, while some of the situational parameters are predictability and controllability of 
a potentially stressful event. Lazarus (1966) distinguishes two basic forms of appraisal, primary and secondary. Primary appraisal is the initial interpretation of a stressful event and concerns whether the event is relevant in terms of the individual's well-being. Secondary appraisal is the person's evaluation of the possible coping strategies and options related to the event. A study examining the appraisal and coping processes of 54 Swedish police officers facing acute stressful events found that primary appraisals were strongly influenced by the situational context, while secondary appraisals were consistent across situations (Larsson, Kempe, \& Starrin, 1988). Peacock, Wong \& Reker (1993) differentiated between threat and challenge; primary appraisals were associated with different types of coping strategies. Challenge appraisals are related to problem-focused coping such as planning, seeking assistance and taking direct action. Threat appraisals are associated with emotion-focused coping strategies, such as positive interpretation, distancing and escape/avoidance. It is important to mention the coping strategy of reappraisal as well. According to the cognitive-relational theory, appraisals can change over time due to coping effectiveness, altered requirements or improvements in personal abilities. In other words, reappraisal leads to a new appraisal of the stressfulness of a situation after gathering new information from the environment (Richard S Lazarus \& Folkman, 1984). An important factor that influences a person's appraisal of a situation is their perceived controllability of the situation (Mark, Robertson, \& Caputi, 1997). Coping is usually defined as "the cognitive and behavioural efforts made to master, tolerate, or reduce external and internal demands and conflicts among them" (Folkman \& Lazarus, 1980, p. 223).

\section{II.2.5. Travel related stress}

There is some literature dealing particularly with anxiety related to travel (by car, train or aeroplane), which in the related literature was differentiated between the acute stress, i.e. similar to the emotion anxiety/fear and chronic stress, i.e. a longer term trait stress which may be related to illness.

One stream of research deals with negative emotions experienced while commuting between home and work. When stress related to the commute to work is followed by a negative experience (task frustration), performance slowed down significantly in a group of 74 participants. The State Driver Stress measure was used (Hennessy \& Jakubowski, 2007). Stress during way to work has shown to cause workplace 
aggression among males (Hennessy, 2008). Research conducted with participants while they were on their way to work (using mobile telephones) showed stress increased during high congestion. Participants preferred active (problem focused) rather then passive (emotions focused) coping with stress. This study found perceived control over the environment ('I feel I have control over this driving situation') as well as time urgency ('I am in a hurry', 'I am concerned about getting to my destination on time' etc.) to be a major intervening variable in the appraisal process. The scale used was a State Driver Stress Inventory containing six positive (e.g., relaxed, contented) and six negative (e.g., tense, nervous) items (Hennessy \& Wiesenthal, 1997).

The stress caused by train commuting was shown to be lower for non-stop rides then if passengers need to connect, with the effect moderated by total length of trip as well as predictability of the trip (Wener, Evans, Phillips, \& Nadler, 2003). Train commuters during rush hour suggest that while the overall density of the train car had no negative effect, sitting immediately next to another passenger affected stress levels and post-test performance of respondents. Therefore, crowding measured as people per area probably does not fully capture the negative experience, as only crowding in proximity triggers negative affect. Key reasons were found to be "intrusion of personal space, combined with lack of control of the situation and if this happens with strangers" (Gary W. Evans \& Wener, 2007, p. 93).

Another study showed that crowding, delays and accessibility to railway stations had the highest influence on anxiety related to train travel (in that descending order). Gender and riding frequency (once per month or more often) also influenced the strength of the effect. Gender had an influence on items 'provision of accurate timetable information' (males showing increased anxiety) and 'taking the night train' (females showing increased anxiety) (Cheng, 2010).

We found only one scientific study investigating emotions related to air travel. Its author investigated anxious reactions to adverse air travel events (air travel anxiety, 8 items), angry reactions to other passengers (air travel anger, 6 items) and beliefs that airline/airport will ensure comfort and security (airline/airport trust, 8 items) using an internet based survey among travellers. Airline/airport trust is related to frequency of travel, and may be an antecedent of air travel anxiety, while anxiety and anger were suggested to be two dimensions with moderate correlation to each other. Air travel anxiety was strongly related to fear of flying (Bricker, 2005). There are numerous 
studies on this particular health related aspect, in the field of clinical psychology. Fear of flying appears to be a multifacet construct, including fear of heights, fear of injury, fear of confinement, claustrophobia, fear of loss of control (Van Gerwen, Spinhoven, Diekstra, \& Van Dyck, 1997), but unrelated to specific events at an airport.

Figure 4: The travel stress curve

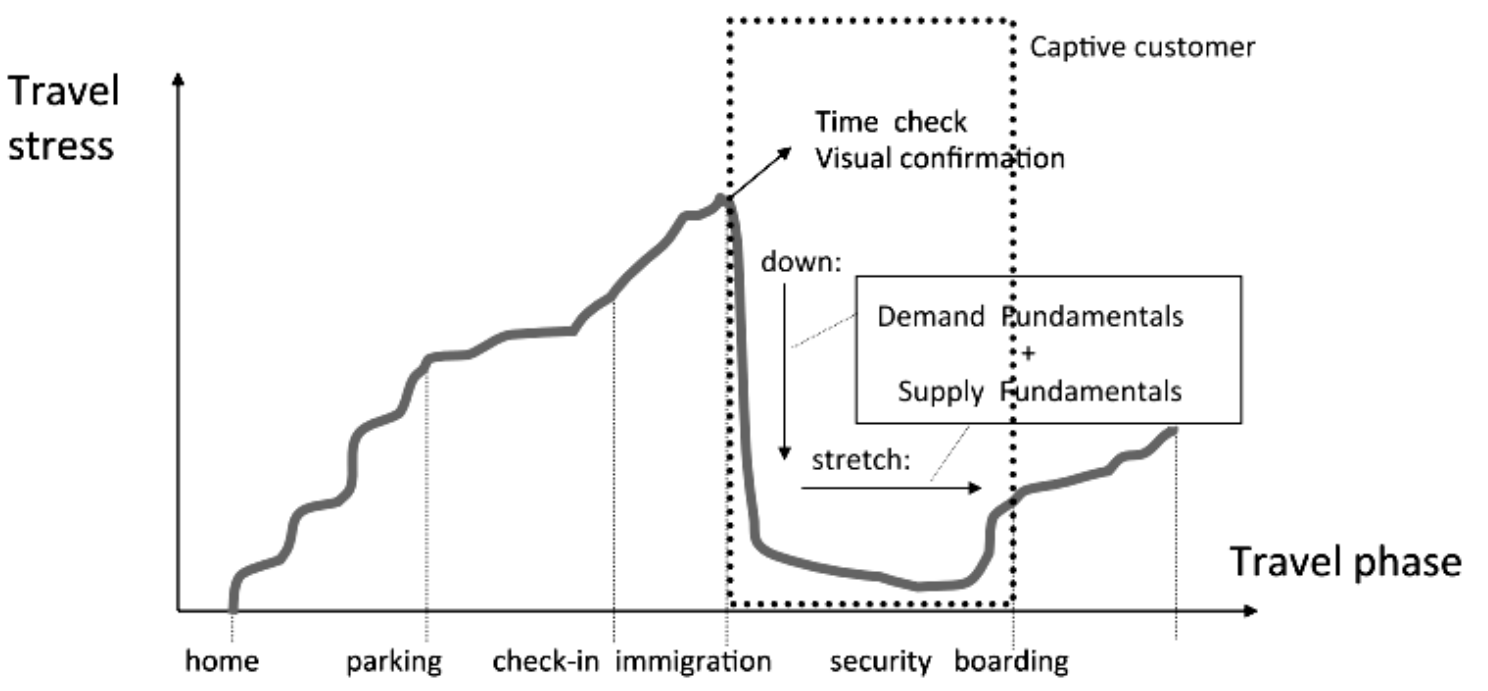

source: by Johan Schölvinck (2012)

Lastly we will present a concept of airport related stress, which is based on managerial insights and regularly cited by airport professionals, however has not yet been empirically verified. The "Travel Stress Curve" (see Figure 4) postulates that passenger's level of travel related anxiety (termed 'stress') changes significantly during the preparatory phase before travel. Compared to a base level (at home), stress increases constantly, as people move from phases 'parking' to 'check-in' and 'immigration'. Then, stress drops to near base level until shortly before customers reach 'security'. During the phase between immigration and security, customers are captive and most likely to take up 'impulse purchasing opportunities'. Because the average time in this phase is approximately 60 minutes at many airports, it is referred to as the 'happy hour'. Airports are advised to ensure process time is reduced before and after this phase to expand it. Also, time checks and visual confirmation of the gate location help to reduce stress faster after immigration (see also Crawford \& Melewar, 2003; Schölvinck, 2012). This thesis is partly motivated by the desire to empirically verify this concept, and integrate it into existing knowledge of servicescapes. 


\section{II.3. Shopping behaviour}

\section{II.3.1. Self-reported measures of retail behaviour}

Retail customers may exhibit different behaviours depending on their emotional states while exposed to the particular environment. The Approach-Avoidance framework suggests that all behaviours involve either approaching or avoiding the store or the retail offering, and thus, can be measured as a one dimensional factor (Donovan \& Rossiter, 1982, based on Mehrabian and Russel, 1974). This section discusses the effect of pleasure and arousal type emotions on behaviour, and reviews the approach-avoidance framework in terms of its applicability to the research questions of this thesis.

Isen et al. (1978) found that consumers in a positive mood evaluated consumer goods more favourably than those in a neutral mood. Furthermore, studies confirmed that retail products are evaluated more positively in a more pleasant environment (Bitner, 1984, 1992). An explanation for this is served by the network theory of emotions, which postulates that when in a positive mood, the brain activates the corresponding emotion node. This activation spreads out to other nodes associated with the positive emotion node, which are usually those related to other positive things or events. Because these are activated, people are more likely to evaluate the positive aspects of a situation or environment (mood-congruity effect, see Bower, 1981). Furthermore, a positive mood may subconsciously be used as additional information when evaluating a retail product (Schwarz, 1990). Consumers who feel good may attribute this feeling to the store or the product perception, which could result in a more favourable evaluation. The ApproachAvoidance framework therefore incorporate three items related to affect towards the store (Like the store, enjoy shopping in this store, intend returning to this store) (Donovan \& Rossiter, 1982).

Pleasure can also cause a longer time or more money spent in a store (Donovan \& Rossiter, 1982; Donovan, et al., 1994). This could be because of innate stimulusresponse mechanisms, in a way as erotic stimuli (pictures of attractive people), luxury (expensive watches) or nature (plants, fresh fruit) may cause attention and desire. Customers may stay longer than planned as they wish to extend the feelings of pleasure associated with the environment. Regarding spending, it could be argued that higher spending, induced by emotions, is more likely to be strongly related to impulse shopping behaviour. Consumer research found that customers in a positive mood spend 
more money than originally planned (Donovan, et al., 1994; Sherman \& Smith, 1987). Impulse buyers in general seem to have a more positive emotional state then others (Weinberg \& Gottwald, 1982). Generally speaking, risk taking behaviour is more likely in a positive compared to a neutral mood if the risks are low. This can be explained by a tendency to evaluate the likely benefits compared to the negative consequences more positively, if one is in a positive mood (Isen, Nygren, \& Ashby, 1988; Isen \& Patrick, 1983). This could also mean a higher readiness to spend on smaller items, even if there is a risk that they are not really required, or that the spending is more than initially planned. Again, the Approach-Avoidance framework includes items related to the above (browsing in the store, spending more time than planned, unplanned spending, Donovan 1994). However, several studies fail to identify a relationship between emotions and actual spending levels (Brüggen, Foubert, \& Gremler, 2011; Donovan \& Rossiter, 1982; Spies, Hesse, \& Loesch, 1997).

Arousal theory assumes that the physical readiness to take action influences behaviour along several dimensions. Initially, arousal was assumed to be one-dimensional by neurophysiological theorists (Lindsley, 1951). According to them, the level of arousal is determined by a subcortical system located in the brain stem called the reticular activation system (RAS). External stimuli (e.g., the sight of a product) or impulses from other areas of the central nervous systems (e.g., a thought process) can trigger excitement in the RAS, which then alerts other functional units of the brain to take a stand-by position, and the person is in an alert state of mind. Also, the RAS stimulates upper areas of the brain responsible for the processing of information (W. Kroeber-Riel, 1979). As arousal increases, the performance in information processing tasks improves up to an 'optimal level of arousal', after which it declines again (Hansen, 1972). A second dimension of arousal is the Affect Arousal system, which is centred on the amygdala, and - if activated - focuses attention, and causes immediate reaction to stimuli, such as fight or flight, startle or freeze. These processes can change behaviour in the form of defence reactions but also trigger negative emotions. Physiological changes caused are heart rate as well as electrodermal variations. Thirdly, the 'preparation activation' system controls motivational aspects of arousal. Expectations in combination with the external or internal stimuli are transformed in a ready state for reaction, and may be followed by physically approaching or avoiding environments (A. Groeppel-Klein, 2005). For a retail environment, this means that intense physical 
stimuli which caused the arousal may automatically cause an orientation. For example bright displays or daylight may cause people to move there from darker areas of a store, or loud and disliked music may make customers leave. Other stimuli in the store may be surprising, novel, and raise attention levels and activity because the mind prepares to acquire, compute and store new information (A. Groeppel-Klein, 2005).

One could argue that a high level of attention leads to more intense browsing and a longer than planned time in the store, thus supporting several items of the approachavoidance frameworks. It is also likely that a more active mind encourages people to interact and communicate with those around, suggesting a link between arousal and affiliation. However, it is unlikely that arousal leads to a more positive evaluation (affect) of the store, or intention to return. Mehrabian and Russel (1974) differentiate into four aspects of approach and avoidance in a retail setting:

1. Physically approach or avoid the environment at a basic level.

2. Look around, explore or remain inanimate in the environment.

3. Communicate with others or ignore communication attempts from others.

4. Enhanced or hindered performance and satisfaction with the task (i.e. repeatshopping frequency or reinforcement of time and money expenditures in the store).

Donovan and Rossiter (1982) developed seven items in order to measure these phenomena in a retail environment; 1. liking of the environment, 2. enjoyment of shopping, 3. intention to return, 4. feeling friendly to a stranger, 5. approach other people, 6. unplanned spending, 7. browsing time and exploring. This has been widely used (Ezeh \& Harris, 2007 ). They found that pleasure is the major predictor of all seven, accounting for $44 \%$ of the variation in intended approach-avoidance behaviours in retail stores. Donovan and Rossiter have used a single factor with items representing these four M-R aspects with Cronbach alpha values above .70 (Donovan \& Rossiter, 1982), and others have achieved similar internal consistency values (Mattila \& Wirtz, 2001; Sweeney \& Wyber, 2002). Although they used all seven as items of one factor, they confirm, that it contains distinctly different types of behaviour, a severe limitation of this framework. Affect related items (liking, enjoying) have shown to have a stronger relationship to pleasure, whereas time spent in store, and affiliation (communication with others) had moderate relations to pleasure. Surprisingly, arousal had only a weak relationship to affiliation, and none to the other factors. However arousal was found to 
interact with pleasure, i.e. in pleasant environments, it did predict approach/avoidance, as well as time and affiliation (Donovan \& Rossiter, 1982). This could be explained if there was an optimal level of arousal, and if arousal influenced the ability to acquire and process information, and - in a pleasant environment - therefore strengthens the effect of the emotions on behaviour. On the other hand, the qualitative study performed as part of this research suggests that high stress levels limit the ability of customers in airport servicescape settings to notice and consider retail offers, which are linked to levels of arousal (A. Groeppel-Klein, 2005; Werner Kroeber-Riel \& Weinberg, 2003), and therefore a reduction of arousal should positively influence approach behaviour such as browsing activity and spending more time in a store.

Several of the above measures are intentions of future behaviour. Although it is being claimed that behavioural intentions are regarded as a surrogate indicator of actual behaviour in marketing studies (Fishbein \& Ajzen, 1975), it would not be prudent to assume this for airports. Firstly, many of the visitors are tourists on the way back home, which are not likely to return to this airport any time soon. Secondly, airport shopping is closely linked to the travel experience, and respondents could easily misunderstand questions about 'intention to spend more time' or 'intention to return soon' as referring to the overall airport product rather than the visit to the individual shop. To cater for this, the variables will have to be rephrased to reflect the actual behaviour in the store they have just visited. Another alternative approach, which is being discussed for completeness, is to obtain observed data.

\section{II.3.2. Observed measures of retail behaviour}

In an alternative approach, (Spangenberg, et al., 1996) used a four item factor containing intention to visit store (high, medium, low, self-reported), intention to purchase selected items (high, medium, low, self-reported), time spent in a store (in seconds, observed), number of product tags examined for selected items (in seconds, observed). Their analysis confirmed a significant impact of ambient scent on all of these items. This measure includes both self-reported as well as observed variables, and although it misses some elements of the original approach/arousal concept proposed by the M-R model (such as affiliation), including observed measures could strengthens the external validity of the perception measures. Previous research showed that the perception of time spent in an environment may be influenced by external stimuli, such 
as music or scent (Baker, et al., 1992; Spangenberg, et al., 2006; L. W. Turley \& Milliman, 2000), therefore observed measures may be superior or at least should be used to control for these effects. Also self-reported spending could be prone to social desirability bias. Previous studies suggested that impulse shopping behaviour has been linked to individuals' inability to control their urge to spend, or to spending money 'senselessly', and respondents may therefore report untrue amounts (Hoch \& Loewenstein, 1991).

\section{II.4. Summary}

There has been extensive evidence linking retail environments to consumer behaviour and evaluation of stores and merchandise. Servicescapes, defined to be the "objective physical factors that can be controlled by the firm to enhance (or constrain) employee and customer actions" (Bitner, 1992, p. 65), include physical factors of the store interior, such as ambience and design, as well as social factors, including number, appearance and behaviour of staff and consumers (Baker, 1987).

We have discussed the types of servicescape stimuli in three groups, ambient factors (eg., temperature), design factors (eg., easy of finding merchandise), and social factors (eg., appearance of staff). Ambient temperature level was found to influence interpersonal attraction of people (Griffitt, 1970). Although it has been suggested that in-store layout is important to influence traffic flow (Hasty \& Reardon, 1996; Levy \& Weitz, 2009), there is little research into how easy navigation in a store may influence behaviour. Staff appearance has been shown to influence customer's emotions and satisfaction after service failures (Bitner, 1990). The number and friendliness of employees has a positive impact on customer emotions, which in turn impacts willingness to buy (Baker, et al., 1992).

The effect of the environment on behaviour is mediated by cognition (J.-C. Chebat \& Michon, 2003) and emotion (Donovan \& Rossiter, 1982). As airport retail areas are creating a high level of excitement (Omar, 2001; Thomas, 1997), emotions are likely to be significantly more influential on the relationship then cognition (W. G. Kim \& Moon, 2009). Emotion has been measured in three dimensions - pleasure, arousal, dominance - (Mehrabian \& Russell, 1974) but many studies found two dimensions (pleasure/arousal) sufficient, with pleasure having more explanatory power of behaviour then arousal (Russell \& Pratt, 1980). Other researchers found that 10 factors are 
required to determined emotions (Izard, 1977). The concept of natural basic emotions postulates that there are seven emotions which are the same across ages and cultures, and each is accompanied with a unique facial expression (Ekman \& Friesen, 1971; Izard, 2007; K. Oatley, et al., 2011).

Among emotions, anxiety in general and acute stress in particular are especially relevant for this stury. Acute stress is a condition caused by a lack of information (uncertainty or unpredictability) about obtaining positive outcomes or avoiding negative ones (Levine \& Ursin, 1991).It is characterised by unpredictability, uncontrollability and intensity (Averill, 1973; Cohen, 1978; Richard S Lazarus, 1966). Appraisal theory assumes that after being exposed to a stressor (stimuli), an individual first determines if an event is relevant in terms of the person's well being (primary appraisal). Then the person evaluates possible coping strategies and options related to the event (Richard S Lazarus, 1966). Appraisals can change over time, as individuals gather new information from the environment and reappraise the event (Richard S Lazarus \& Folkman, 1984).

These concepts are relevant when discussing travel related anxiety. The limited research dealing with air travel stress proposes it is three dimensional, consisting of trust towards an airport/airline, angry reactions to other passengers and a dimension similar to fear of flying (Bricker, 2005; Van Gerwen, et al., 1997). Airport related stress is often caused by anticipated problems with the mandatory process involving check-in, security screening, passport control and boarding (Crawford \& Melewar, 2003). Practitioners brought forward the concept of the 'travel stress curve' proposing that stress levels gradually increase between departing home and passing imigration, then decline sharply, only to increase again before boarding (Schölvinck, 2012).

Past studies have discussed shopping behaviour measures such as the amount of time or money spent in the store (Donovan \& Rossiter, 1982; Donovan, et al., 1994; Sherman \& Smith, 1987), or as the extend to which customers approach or avoid an environment and people (Donovan \& Rossiter, 1982). The liking of the store and evaluation of shopping has been measured as part of the same approach/avoidance dimension in the past (Mattila \& Wirtz, 2001; Sweeney \& Wyber, 2002). Studies failed to establish a direct link between spending and environmental cues (Brüggen, et al., 2011; Spies, et al., 1997). 
In summary, there is a rich literature to build upon. At the same time, we have identified a number of gaps which this reasearch is able to fill. Firstly, there seems to be a need to adjust the servicescapes analysed to the specific service environment to achieve sufficient validity of the measure. Due to the lack of previous research in airport retail settings, this study contributes by identifying appropriate measures from the literature. Also, there is no agreement to how to measure emotions. While many studies established pleasure as a dominant dimension, the second dimension (often arousal) has had less explanatory power and - in fact - has been hypothised to be a necessary condition for any other emotions to moderate effects on behaviour arousal (A. Groeppel-Klein, 2005). Also, in airport retail areas and other high pleasure, high time pressure environments, stress seems to be a important, and is therefore considered the second important dimension of relevant emotions. 


\section{III .AIRPORT RETAILING - A MANAGERIAL PERSPECTIVE}

Due to the speciality of airport retailing, a separate chapter is devoted to the review of past publications related to this particular field. Next an overview of the literature is provided, starting with organisational and legal aspects (such as relationships between retail operators and airport owners/operators), followed by aspects of shopping behaviour in airports as well as marketing output measures used by airport management. This chapter will show how the present study contributes to the field, but also has been used as a main source for developing the conceptual model tested in the empirical part of this thesis.

\section{III.1. Literature overview}

Scientific literature on consumer behaviour in airport retail environments is scarce. A review of the airport retail related literature shows that most scientific studies were published by industry specific journals, such as the Journal of Air Transport Management and Tourism Management. Some contributions were made in general retail marketing publications, such as the Journal of Services Marketing. Less often did we find publications in the general marketing literature, with the notable exception of the Journal of Consumer Behaviour. Other disciplines, such as psychology, have produced studies on travel stress, for example in the Journal of Counseling Psychology. The first publications on airport retail management have been by practitioners, such as Doganis (1992), former CEO of Olympic Airways or active airport retail managers (Freathy \& O'Connell, 1998). From time to time, presentations by industry consultants are made public and serve as a valuable resource for data or phenomena (Bamberger, et al., 2009; Boether, 2008; Heinzelmann, 1991).

We first review existing studies related to the organisations operating airport retail units. Insights on consumer behaviour in airport environments follow next. We then discuss managerial perspectives on relevant output measures and marketing variables, sources of retail revenue and the main coefficient determining retail revenues.

During the last 10 - 15 years, many airports have had changes of the model of operating, partly triggered by a trend to privatisation of state owned airports, and partly by an ongoing commercialisation of airports. Graham provides an overview of commercial revenue development in Europe at the start of the Millennium and concludes that there 
exist significant pressures on airports to further grow these in order to meet profitability expectations. Increases in fuel prices and economic slowdown in Europe may keep travellers away or spending levels low. At the same time, European regulators warn of upcoming capacity constraints at major airports, which may lead to congestion, causing crowding, inefficient procedures and other negative influences on the passenger experience. The emergence of low cost carriers have caused limitations to designing airport retail zones as they require low cost facilities and fast processes causing lower dwell time (Graham, 2009). Changes in the regulatory, legal and commercial environments have led to airport retail operations receiving a high strategic priority for airports the U.K. (Thompson, 2007) and New Zealand (Lyon \& Francis, 2006), for example. The importance of commercial activities for the overall efficiency of airports has been determined using six years' worth of Spanish airport performance data (Tovar \& Martín-Cejas, 2009).

Retail units at an airport are rarely operated by the same organisation as the airport. Changes in the commercial and regulatory environment have led to four emerging types of relationships between retailers and airports in Europe, with carrying levels of operational involvement by the airport (described in brackets): Concessionaire based retailing (very low), Management contracts (low), Joint Venture Retailing (high), and Authority managed retailing (very high) (Freathy \& O'Connell, 1999b). Concessionaire Based Retailing, being the most common form, involves airports contracting retail operators, which are responsible for the purchase and sale of goods and services. While some airports simply provide the physical facilities of the terminal, including water, energy, light, etc., others engage in marketing the retail offer to customers, working with concessionaires to maximize revenues. Contracts often include both fixed payments and a percentage of sales, sometimes with a minimum payment guarantee. Authority Managed Retailing covers airports which chose to operate stores themselves, including purchasing, storing and merchandising produce. Often, highly specialised retail, such as flower shops, is still being contracted out but the large majority of income is generated by selling directly to customers. Management Contracts are employed when an airport wishes to control retail operation, including buying and selling of stock, but is lacking the expertise or manpower of managing single elements of the operation. For example, contracts may be awarded to a third party for managing a set of stores, and result in a management fee payment linked to a pre-agreed sales performance. All 
operational costs and revenues go to the airport. Joint Venture Retailing has become more common after Western European airport operators have started to offer their expertise to airports in Eastern Europe, the Middle East and the Far East. This approach solves issues if a local authority does not want to award a concession agreement entirely to a foreign entity, or the Western partner may not be able to purchase certain goods at attractive conditions locally (Freathy \& O'Connell, 1999b).

In a study among 115 commercial airports worldwide, $4.3 \%$ of airports had own duty free operations and none for other retail operations. Most airports assign all duty free sales activities at an airport to a single concessionary (75\%), whereas for other retail, most prefer a variety of concessionaries (96\%). The revenue structure at most airports $(69 \%)$ is based on a combination of a sales related payment and a fixed rent whereas $30 \%$ of participating airports rely on only a percentage of sales (Rimmer, 2011). A study based on a small group surveys among Asian airports finds that having one master-concessionaire for all airport retail is the most appropriate method (H.-B. Kim \& Shin, 2001). Should several airports of the same owner be competing with each other, a study asserts that competition is effective, as long as only the commercial activities are franchised out to separate, competing operators and revenues shared between parties (Gillen \& Morrison, 2005).

One stream of research discusses what drives passenger's shopping behaviour at airports. A study at Brussels Airport revealed three main segments, 'mood shoppers', 'shopping lovers' and 'apathetic shoppers', depending on the individuals shopping motivation and attitude (Geuens, Vantomme, \& Brengman, 2004). Others argue that an a priori segmentation of travellers based on motivation may not be possible: Factors such as time available for shopping, traffic flow in the retail area, composition of the travelling group, previous knowledge of the airport, or reason for travelling may also have an impact on store patronage (Freathy \& O'Connell, 2012). A survey in Spain found available time and reason for travelling to be the most relevant variables to explain expenditure in the commercial area (Torres, Dominguez, Valdes, \& Aza, 2005). A survey among passengers of an airport in England revealed that only gender and 'association of airports with shopping (or not)' were statistically significant in explaining propensity to shop, while age, socio-economic group, purpose of visit and time allowed prior to departure was not. At the same time, the most frequently cited reason for browsing was 'to fill in time', followed by 'to find a particular product' 
(Baron \& Wass, 1996). A Taiwanese survey found travel related products as well as souvenirs to be the main items searched, with age, gender and the type of travel companion having an impact on shopping behaviour (Perng, Chow, \& Liao, 2010).

Impulse shopping occurs in a situation when there is no intend to buy a specific brand, or even from the category, before patronizing the store. While pure impulse shopping, which occurs when customers did not plan to buy neither the brand nor the category, is fairly rare in high street retail (Cobb \& Hoyer, 1986), this is more common at airports (Omar \& Kent, 2001). As much as 70 percent of airport shopping is done on impulse (Crawford \& Melewar, 2003). The impulse effect differs depending on the psychological effects of the experience, as well as the presence of normative traits (Volkova, 2009).Receiving an impulse not automatically results in an action, for example time pressure, consumer's economic position, social visibility and the shopping impulse itself may lead to a faster evaluation of a prospective purchase then usual (Hoch \& Loewenstein, 1991). Social visibility is relevant here, because impulse shopping may be considered socially undesirable. Airport provide social anonymity if passengers are travelling alone, in which case the likelihood of impulse shopping should be higher. Also the social relationship with other travellers in the group may plan an important role (Omar \& Kent, 2001). Unaccompanied passengers tend to buy higher cost products (Perng, et al., 2010). Still, the understanding of impulse shopping as well as using appropriate marketing tools to encourage this behaviour is still uncommon among airport managers (Crawford \& Melewar, 2003).

The total commercial revenue of airports are much related to passenger traffic growth, with passengers of charter airlines have a stronger effect on sales then low cost passengers, followed by traditional airlines. This may be because charter airlines use larger planes, have more passengers on board, and leisure passengers spend more than business travellers (Omar \& Kent, 2001). However, a long-term study in the U.K. showed that for small regional airports, the impact of low cost airlines traffic growth on commercial revenues was significantly stronger than the other types (Papatheodorou \& Lei, 2006). A study in the US showed that international passengers spent significantly more on specialty retail, while transfer passengers were more important for food and beverage $(F \& B)$ sales. Terminals with a high share of low cost passengers showed a lower $\mathrm{F} \& \mathrm{~B}$ revenue per square foot, also specialty revenue variances were highly dependent on the type of terminals (Volkova \& Müller, 2012). 


\section{III.2. Concepts of airport retailing}

This section introduces the concept of aeronautical and non-aeronautical airport revenues, and explains what has led airports to recently put a high emphasis on nonaeronautical, and especially retail activities.

As the main function of airports is to handle aircraft and passengers, their services are charged to airlines on a per-flight as well as a per-passenger basis (landing fees, passenger service fees, security screening fees etc.). These constitute the aeronautical revenues. Sources of non-aeronautical or commercial revenues primarily come from either rent or concessions fees. Rental fees are levied for space provided to airport users (e.g., airlines, freight forwarders), or indirect users (e.g., hotels, catering firms). Also, commercial airports offer a range of shopping and service facilities to customers, which usually produce a concession fee, but may also include an element of rent.

Airports may also provide some of these services themselves, in which case they are no longer a concession fee see Table 3: , /Doganis, 1992 \#713\}. The scope of this dissertation is limited to retail marketing and therefore we focus on incomes generated through sales activities at in-terminal facilities, which can be any of the follows:

1. Rent of lease income;

2. Concession income;

3. Direct sales.

Recently, airports have started to actively develop the share of commercial revenues. In 1994, non-aeronautical revenues accounted on average for $42 \%$ of the total (Freathy \& O'Connell, 1999a), while this number increased to $47 \%$ in 2010 (Rimmer, 2011). Customers are looking for lowest fares and therefore airlines are focusing more on lowering operational costs. With airport charges accounting for about $8 \%$ of an airline's operating costs on average (AEA, 2008), and therefore being a considerable cost factor, airlines apply a mounting pressure on airports to reduce or at least maintain aeronautical charges (Ryanair, 2012, p. 57). More recently, airports and local governments have been reported to even pay low cost airlines to operate flights hoping to generate sufficient other income for the airport and surrounding economy to justify this arrangement (2012b). 
Table 3: Categorisation of sources of airport revenues

\begin{tabular}{|l|l|}
\hline \multicolumn{2}{|c|}{ Total Revenues } \\
\hline \multicolumn{1}{|c|}{ Aeronautical revenues } & \multicolumn{1}{c|}{$\begin{array}{c}\text { Non-aeronautical or } \\
\text { commercial revenues }\end{array}$} \\
\hline $\begin{array}{l}\text { Landing fees } \\
\text { Aircraft parking, storage etc. } \\
\text { Passenger charges } \\
\text { Noise charges }\end{array}$ Security charges $*$ & $\begin{array}{l}\text { Rents or lease incomes (from tenants) } \\
\text { Recharges to tenants (for electricity, } \\
\text { cleaning etc.) }\end{array}$ \\
$\begin{array}{l}\text { Freight/Baggage charges } \\
\text { Apron services and aircraft handling* }\end{array}$ & $\begin{array}{l}\text { Concession income (from shops, catering, } \\
\text { banks, car parks, hotels etc.) } \\
\text { Direct sales* } \\
\text { Car-park revenue* } \\
\text { Miscellaneous (e.g. interests earned) } \\
\text { Non-airport related activities (e.g. real } \\
\text { estate development) }\end{array}$ \\
$\begin{array}{l}\text { Fuel throughput surcharges } \\
\text { Passenger freight and } \\
\text { baggage handling charges }\end{array}$ & $\begin{array}{l}\text { Passenger freight and } \\
\text { baggage handling charges }\end{array}$ \\
\hline
\end{tabular}

*if provided by the airport. Not all airports have access to all revenues listed.

Source: (Doganis, 1992), p.54

Furthermore, governments often put a limitation on absolute or relative increases of airport charges after privatization, especially in the case of airports in a dominating market position (Doganis, 1992). At the same time there is an increasing requirement to invest into new technology, for example EU airports are required to implement systems for screening hand baggage for liquid explosives by April 2013 (Commission, 2010). Faced with rising costs and restricted abilities to increase aeronautical revenues, airport operators are focusing on maximizing performance of retail, parking and real estate revenues.

The share of commercial revenues of total airport revenues grow with increasing passenger numbers, as shopping, catering and car-parking facilities are expanded. Industry data suggests that this share typically grows to about $40-50 \%$ of total income once airports have reached 8-10 million passengers annually. Shares tend to then remain at that level because the amount of space being available at attractive locations as well as acceptable market rents are limited, see Figure 5 (Doganis, 1992). Consequently, to ensure consistency, the scope of my analysis is limited to airports above 8 million passengers. 
Figure 5: Revenue split as function of traffic

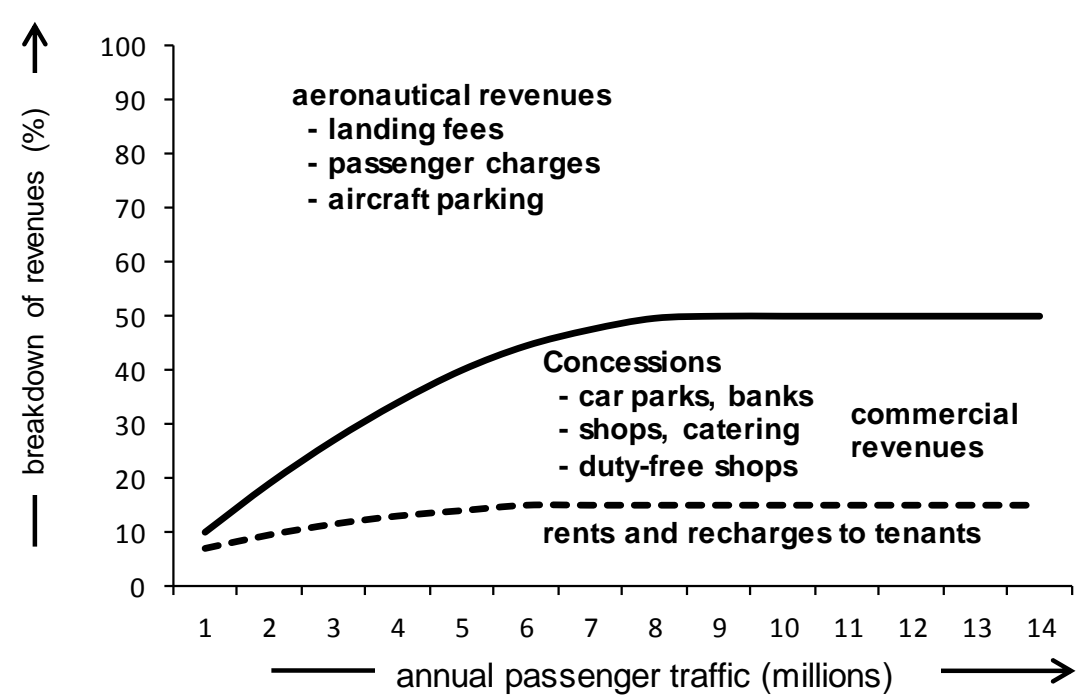

Source: (Doganis, 1992) p.56

The global airport retailing market is estimated to be worth 29 billion USD (Bamberger et al., 2009), compared to the overall global retail sales volume of 13.9 trillion USD (2011). It is has undergone a high growth phase averaging $87.6 \%$ during the first five years of the millennium (Thompson, 2007). The consulting firm Arthur D. Little is assuming airport duty free sales to grow by 6 points above forecasted air passenger growth rates for the period 2008-2012 (Bamberger, et al., 2009). Although being a specialized industry, much of the dynamics of airport retail are similar and applicable to shopping malls, as airports are essentially a variety of retail concepts under one roof. However they provide a much better terrain for researchers, since the most important customer segment - passengers - have to pass through several mandatory points and therefore sampling and monitoring passengers is much easier. It should be recognized, that airport retail space is reaching higher sales per square meter compared to even the most successful shopping centres. in 2010, average sales generated were 34492 USD/square meter of airport shop space (Rimmer, 2011), whereas a shopping centre in Germany, for example, generated between 10,000 - 30,000 USD/square meter (Liermann \& Rumetsch, 2011).

Major international airports are nothing short of international shopping malls. London's Heathrow Airport, for example, comprises of 66,000 sqm of retail space. The largest airport 'shopping centers' have sales volumes of over 1 billion USD (Dubai, London 
Heathrow), with half of the TOP 10 airports by retail revenue being located in Europe (Baier, 2010). From here onwards, the scope of the analysis will be limited to European airports. Despite this limitation, much of the findings should be generally applicable to the global industry.

\section{III.3. Socio-demographic drivers of retail revenue}

In this section, we will present the main antecedents of retail revenues, based on the few studies on airport retailing published to date.

Thomas (1997) identified two emotional anomalities present in people when at an airport. Firstly, stress levels are increased, because customers are out of their daily routine. Secondly, she notes an increase in levels of anticipation and excitement. The research shows that passenger's stress levels reduce when they receive their boarding pass, but excitement remains high. This period is referred to as 'happy hour', suggesting that airport retail is mainly concerned with manipulating this happy hour Thomas (1997).

Several studies have analysed demographics influence on spending behaviour. Gender was found to have an influence (Baron \& Wass, 1996; Perng, et al., 2010), socioeconomic group was not found to be relevant area (Baron \& Wass, 1996; Torres, et al., 2005), and age was considered to be significant by some studies (Perng, et al., 2010), by others not (Baron \& Wass, 1996). Ethnic origin was considered an important antecedent of retail spend by several studies. The share of commercial revenues increase in line with the share of international passengers (Tovar \& Martín-Cejas, 2009). Typically a non-resident will spend more at an airport than a resident, because air travellers may want to avoid carrying duty-free purchases with them while on holidays and rather buy on the way home. One can assume that souvenirs and presents are rather bought at the end then at the beginning of a holiday. Airport managers have suggested that Asian, Middle-eastern and Russian passengers achieve a higher spend per person than most other nationalities. North Americans tend to spend relatively little at airports (Doganis, 1992).

Passengers aware of airport retail concepts, exclusive offers and the price advantage of duty free stores are an important segment. A passenger survey in the U.K. found that 
association of airports with shopping (or not) was one of only two statistically significant in explaining propensity to shop (Baron \& Wass, 1996).

The most frequently cited reason for browsing airport shops was 'to fill in time', followed by 'to find a particular product', however the actual time before departure could not be identified as a driver (Baron \& Wass, 1996). Contrary to that, other surveys found available time to passenger ('dwell time') leads to higher spending in the commercial area. A longer dwell time would increase the time customers have time to inspect the offer and to find products which they planned to buy, but also lead to more impulse shopping (Freathy \& O'Connell, 2012).

The reason for travel (business or leisure) has been proposed as a determinant for retail revenues, because business passengers tend to spend less time at airports and travel more frequently (Doganis, 1992). They may not buy duty free on every trip, and spend the reduced time in airport lounges. (Omar \& Kent, 2001) and Torres (2005) showed that business travellers spend less on average then leisure travellers. There are also indications that this effect is reversed if boarding time is less than 45 minutes. This suggests that available time is an important moderator to determine spending levels (Torres et al., 2005). On the other hand (Baron \& Wass, 2006) 's study did not identify the reason for a trip to have a significant influence on shopping behaviour. It could be that business travellers shop less due to their high frequency of travel and consequently lower level of excitement related to flying. It has been proposed that higher knowledge of the airport reduces airport spending levels (Freathy \& Connell, 2012).

Also, the duration of a trip may influence the spending levels of passengers. Heinzelmann (1991) found that only $25 \%$ of passengers going on a one-day trip shop at Frankfurt airport, while the ratio is $50 \%$ for passengers spending two weeks or more on a trip. However, one could argue that could be linked to other reasons, for example oneday trips are more likely to be done by commuters or business passengers, which are in a different mood, possibly under time pressure, or at least less excited about the trip than people going on a two-week holiday.

The behaviour of customers using low cost carriers has been found to differ from that of traditional or charter passengers. At large airports (over 3 mill. passengers), the contribution of low cost carrier passengers to commercial revenues is smaller, but not at smaller airports (Papatheodorou \& Lei, 2006). At terminals serving only low cost 
carriers, food \& beverage and speciality retail revenue per passenger are lower than in terminals serving only traditional airlines in the US. Terminals dominated by LCCs generate $34 \%$ less per enplaning passenger, and consequently $7 \%$ less rent payments to airport operators (Volkova \& Müller, 2012).

The location of shops within a terminal in relation to the natural passenger flow is an important driver of revenues, too. If shops are located well visible in the flow of traffic, the likelihood of visiting is increased (Freathy \& O'Connell, 2012). A recent trend are 'walk-through' duty-free shops, which require passengers to pass through a shop on the way to departure gates (Peneder, 2008). Having to up or down a floor to enter a shop reduces the shopping potential by about $40 \%$ (Heinzelmann, 1991). Passengers seem to feel more comfortable when having located their departure gate, therefore shops in viewing distance of the gates may lead to a longer dwell time then shops from where the gates are not visible, or which are a long way away from the gates.

A dominant motivation of shopping at airports seems to be impulse shopping, which occurs when customers did not plan to buy neither the brand nor the category, is fairly low in high street retail (Cobb \& Hoyer, 1986), this is more common at airports (Omar $\&$ Kent, 2001). The impulse effect differs depending on the psychological effects of the experience, as well as the presence of normative traits. (Volkova, 2009).

Impulse shopping may be considered socially undesirable; however airports provide 'social anonymity' if passengers are travelling alone, suggesting that the number of travellers in a group is also a relevant antecedent. In fact, unaccompanied passengers tend to buy higher cost products (Perng, et al., 2010). Also the social relationship with other travellers in the group may plan an important role (Freathy \& O'Connell, 2012; Omar \& Kent, 2001).

\section{III.4. Performance measures of airport retailing}

In order to define a relevant dependent variable for the proposed research project, we now investigate the main marketing outcomes airport operators would consider important. There is no accepted industry practice for measuring airport performance as of today, but commercially oriented airports typically have several or all of the following objectives:

1. Ensure efficiency in allocation and use of airport resources; 
2. generate revenue sufficient to cover costs and, hopefully, to generate profits;

3. provide a sound guide for future investments (Doganis, 1992, p. 81).

Providing an example relating to airport retail objectives, the British Airport Authority in 1985 , forced by the economic crisis of the 1980's to focus more on commercial revenues, defined their targets as follows:

- to increase duty-free and tax-free income per international departing passenger by 4.75 per cent in real terms,

- to increase other concession income per passenger by $4.75 \%$ per cent in real terms,

- to increase gross rental income by 4.5 per cent in real terms (Doganis, 1992, p.60).

There appears to be a general consensus in the literature, that retail sales volumes are the dominating indicator of performance to evaluate and airport's retail activities (Graham, 2009; Tovar \& Martín-Cejas, 2009; Volkova, 2009).

Because airports do not allow the general public to air side areas behind security screening areas (which is where most of the retail outlets are), retail revenues are in part determined by the total passengers passing through. Although an airport's overall objective may be to maximize overall retail revenues, the volume of passengers are largely determined by factors outside of control for an airport retail operator (Albers, Koch, \& Ruff, 2005; H.-B. Kim \& Shin, 2001). Therefore, it would be reasonable to measure Revenue per passenger instead as a key performance indicator (Graham, 2009):

retail revenue per passenger $=$

penetration rate $x$ conversion rate $x$ average transaction value

This perspective outlines why airports and retail operators need to work together to maximize revenues. Firstly, customers need to be convinced to enter shops before they have a chance to buy. Achieving a high penetration rate (share of passengers patronising shops) is clearly a joint responsibility, which an airport can influence, for example by designing the traffic flow to maximize footfall near the stores, while individual stores may use promotional displays and attractive brands to attract visitors. Next, the conversion rate (share of visitors buying) can be rather influenced by store operators than the airport, as this largely depends on to what extend the specific store's offer meets the customer's needs, but also depends on the right target groups being guided to the right stores by airport operators, for example. Lastly, the average transaction value depends on many factors influenced by both the operator and the concessionaire, for 
example the category mix on offer, the income levels of customers, or the skills of the sales teams on the shop floor.

A study among 115 commercial airports (50 being in Europe) have revealed average spend per passenger to be as shown in Table 4.

Table 4: Selected average sales per passenger (2010/2011)

\begin{tabular}{ll}
\hline Duty-Free Sales per Departing International Passenger*: & 26.8 USD \\
Duty-Paid Sales per Departing Intra-EU Passenger: & 20.5 USD \\
Food and Beverage Sales per Departing Passenger: & 3.7 USD \\
Retail Sales per Departing Passenger: & 5.2 USD \\
Currency Exchange Sales per International Departing Passenger: & 28.7 USD \\
\hline *For airports located within the EU, sales apply to passengers traveling to non-EU \\
destinations. Source: (Rimmer, 2011).
\end{tabular}

\section{III.5. Discussion}

In summary, the majorities of studies use personal factors or situational factors to explain actual spend, but only few integrate emotions as being a mediator between antecedents and marketing outcomes. We will illustrate this issue with an example. Several studies (Doganis, 1992; Omar \& Kent, 2001) show that business travellers spend less than leisure passengers, except within 45 minutes of departure (Torres et al., 2005). We would argue that this could be explained by two other moderators. First, experienced travellers may arrive later (within 45 minutes of departure), therefore experience with airport processes may be a more relevant moderator. Also, time pressure before departure could be a moderator on spending levels, because there is less time to search for lower priced items (Omar \& Kent, 2001).

$70 \%$ of shopping is impulse driven, which is highly related to the emotional state of an individual. Ten years ago, there was still a low understanding of these concepts and appropriate marketing tools to encourage this behaviour (Crawford \& Melewar, 2003). Although the body of knowledge in this field has improved until today, there are still relatively few empirical studies published. The literature reviewed suggests that emotions are important antecedents, especially stress levels, excitement and anticipation. Gender, ethnic origin and (maybe) age could be relevant demographic factors, but also personality traits, such as proneness for impulse shopping, knowledge of the airport and association of airports with shopping affect shopping behaviour. Although there were studies suggesting that the above mentioned factors influence 
passenger spending or store patronage, they did not discuss interaction effects among them, and their relationship with the airport service environment. Situation based factors were dwell time, duration of trip, choice of airline, location of shop and number of travellers in a group. The latter was suggested to have an effect on shopping motivation. Duration of trip and choice of airline may influence the passenger's needs (longer trips, or those without free on board meals may call for buying snacks and drinks). But it could also be argued that customer service levels of low cost carriers (less airport personnel, no ticket desk, longer queues in less space), lack of pre-allocated seating and strict enforcement of hand luggage regulations are causing negative emotions and lower dwell time (Graham, 2009). Often airports cannot influence the type of carrier, therefore practitioners are in need of studies describing reasons and how to counteract them (for example by employing more airport personnel or provide information regarding hand luggage regulations).

Many studies discuss stress/anxiety having a negative effect on retail expenditure (Schölvinck, 2012), however the M-R model suggests that a moderate level of arousal is only leading to approach behaviour if it is coupled with high levels of pleasure. Therefore claims that there are underlying positive emotions associated with travel, which are temporarily 'overshadowed' by negative emotions (e.g., anxiety, fear) need to be investigated in more detail (Thomas, 1997).

We have identified no study that proposes an overarching model explaining the emotional factors determining shopping behaviour at commercial airports. We therefore hope that this thesis will give some important managerial insights and allow recommendations for practitioners in airport and similar retail environments. 


\section{IV . PRELIMINARY QUALITATIVE STUDY}

The literature review of airport retail related studies suggest that there is still little empirical research on the main antecedents of shopping behaviour in airport environments. There is no agreement in terms of the most relevant moderators of shopping behaviour, although a number of promising studies were made which shall guide the development of hypotheses for this thesis. The lack of literature is surprising given that airport retail units are at premium locations, with a captive audience which may be more excited and open to impulse offers then high street customers. The literature related to retail environments and their effect on emotions and shopping behaviour, however, is far more advanced. The M-R model has been applied frequently, and several studies confirmed the determining role of servicescapes for emotional states of the customer, which in turn influence shopping behaviour. With support from literature in psychology, we have attempted to summarize the main body of knowledge relevant to this study. To help in developing propositions toward a model of airport shopping, a preliminary study was undertaken. First, the objectives and research questions of this study are stated, and then the methodology and design are presented. Finally, we present the data as well as discuss the results. The chapter closes with a summary.

\section{IV.1. Objectives and research questions}

The study aimed at identifying the relevant aspects of airport environments, consumer emotions, consumer behaviour and corporate marketing objectives in the European airport retail business, from a managerial perspective. We attempted to identify the main variables influencing shopping behaviour of departing passengers. This involves independent variables, mediators and moderators which impact approaching of stores, shopping, and average retail spending as well as proposed relationships between them.

The exploratory research project involved expert interviews conducted by the author. While being a valuable research project on its own right, this research's main purpose is help in the development of hypotheses to be tested in the planned quantitative research project. Its outcome may also identify underresearched areas and justifies why the planned quantitative study, forming the main part of the thesis work, is a relevant and important contribution to the body of knowledge in retail marketing. 
Based on the above objectives, the following research questions were formulated:

- How is shopping behaviour influenced by the airport environment (including social factors such as service encounters) at major European airports?

- How are passenger's emotions influenced by the airport environment at major European airports?

- What are the most relevant moods and emotional states of passengers when at the airport?

- How do emotions change over time, as passengers move through the different stages of the departure process?

- How do airport operators influence environments and service encounters to maximize retail sales?

Because the objective is to gain an understanding of consumer behaviour, the subject of investigation here is the consumer rather than the respondents of the qualitative study, and the goal was to collect the expert's understanding of consumer behaviour. This was considered in the sample selection, design of interview guidelines as well as within the interviews themselves. Also, some data was collected about the respondent's, the individual managers and the respective company's overall retail marketing objectives.

\section{IV.2. Research methodology}

The chosen research method was intensive semi-structured interviews with senior managers of European airport operators, which will be analysed using content analysis. Qualitative and intensive corporate interviews have been used extensively in order to collect information about the inside perspective of international business firms. Qualitative research offers flexibility without requiring large samples and provides an overview of the phenomena from a holistic perspective (King, 1994; Schoenberger, 1991). Managerial interviews allow taking an insider's stance to the company, which can be strengthened by scheduling the interviews in the respondent's office. It requires a strong sense of contextualisation, and the individual statements being made to be coded as a function of the context they are being used in, rather than in isolation. Because the small sample size allows the author to conduct all interviews himself, he is able to obtain a close proximity to the phenomenon under study (Yeung, 1995).

The analysis of data followed the principles of grounded theory (B. G. Glaser \& Strauss, 1967), which seemed most appropriate given the complexity and multiple facets of the research problem. Grounded theory is a methodology for developing theory based on 
systematically gathered and analysed data, used also regularly in the field of management and marketing research (Mitev, 2012).

The objective is a set of relationships proposed between concepts and sets of concepts, and the methodology allows integrating comments by the researcher during its development. It is flexible in the sense that data collection and initial analysis takes place at the same time. Once the first set of data is obtained, the researcher may draw first conclusions, and even adjust the process of data collection. It is scientific, because it is a consistent, systematic examination of the phenomenon (B. G. Glaser, 1978). Some grounded theorists require that researchers have as little as possible knowledge of the subject as possible, to ensure that theory is developed purely based on the data. They stipulate that eventually the researcher will bend the findings towards a certain predisposition (B. G. Glaser, 1978). Strauss, on the other hand, postulates that researchers should have a general understanding of underlying paradigms before collecting data, while keeping an open mind for new emerging concepts. Knowledge is then deducted from data, and paradigms or models verified, during the data collection process. As the researcher progresses through the phases of coding, which will be described later, an inductive approach is used to develop a theory (Strauss, 1987).

In this case, the same person planning the study and developing the interview guidelines also did both, data collecting and coding. It can therefore not be avoided to also consider previously developed knowledge of the subject. The experience during the study showed, that this can also be an advantage, since the interviewer now has the opportunity to recognize concepts which contradict with or expand existing knowledge, and focus more effort in understanding these during data collection. Secondly, a research question should be formulated identifying the phenomenon to be studied, and therefore is meant to influence data collection and coding. Developing a research question without a first understanding of previously developed models may do more harm than good. Lastly, access to senior managers of the leading airports was only possible with personal presence of the author in this particular case. Overall we consider the present methodology to be acceptable. The author was motivated to minimize interviewer bias and attempted not to influence answers. To further ensure transparency, all interviews were transcribed in full.

The process of data collection and analysis follows a set sequence. Data is collected, and coded in three stages: The text is broken into units of analysis (a statement being 
made), and variables are defined and coded as categories in a sketchy form (open coding). Categories are described on a high level at first. Then, axial coding involves the researcher searching for causal relationships, and regrouping of categories. Researchers are encouraged to take additional notes as well at this stage to record their intuitive ideas and observations (B. G. Glaser \& Strauss, 1967). Coding processes as well as data collection processes can now be adjusted. Axial coding should deliver an explanation how categories and sub-categories are related to each other. These basic concepts are nodes in a network, which are further explained by a second hierarchy of categories describing certain aspects of the basic concepts, and in some cases a third hierarchy, which provide sub-aspects of the second level. At the end of this phase, the notes should be reviewed and scanned for insights, which have been proved to be grounded. The last phase termed selective coding leads to the selection of a core category, which is the central theme to which all other categories are related. The stage is complete when relationships are validated, integrated and refined. The outcome should lead to a theory, or a selection of hypothesis for further testing (Corbin \& Strauss, 1990).

Figure 6: Process of data collection and analysis with respective stages of grounded theory

\begin{tabular}{|l|l|}
\hline Stage in the study & Grounded Theory stage \\
\hline Preliminary stage & Open coding \\
- Collect data & - Commence coding of text-statements \\
- Write interview guidelines & - Produce variables and sub-categories \\
- Conduct interviews 1-3 (Jul - Aug & \\
2012) & \\
\hline Main stage & Axial coding \\
- Revise interview guidelines & - Identify causal relationships \\
- Conduct interviews 4-10 & - Produce categories (nodes) \\
(Sept - Dec 2012) & - Reduce and cluster sub-categories \\
\hline Final stage & Selective coding \\
- Expert evaluation & - Identify core category, develop \\
- Conduct further interviews until & categories in greater detail \\
saturation (Jan - Feb 2013) & - Generate hypotheses \\
& - Produce narrative \\
& - Confirm hypotheses with data \\
\hline
\end{tabular}




\section{IV.3. Research design}

Based on the objectives, it is clear that there are three units of analysis, the consumer, the environment, and the organisation. The design of the research allows analysing all three during the same interviews. Respondents were recruited to have several years of experience in consumer behaviour from a managerial perspective, and be in senior management positions responsible for retail turnover at major airports. This criteria was determined based on the assumption that organisations require a high level of knowledge regarding the topics under investigation from these individuals, and the consistency of statements and level of knowledge shown during interviews indeed confirmed that this was the case. Although the data certainly contains valid information about consumers and environments, a limitation of the research is that it certainly reflects the experience and views of the individual and/or his/her employer, and may therefore be biased based on the organisation's objective. This will be overcome by a second, quantitative study, which includes direct measures of consumer behaviour as well as the respective environments.

Due to the nature of the subject, the interviews will involve companies based in different countries and require discussing language aspects as well. There is an increasing use of qualitative research in international business and marketing in a crossnational and cross-cultural setting (Earley \& Singh, 1995; Peng, Peterson, \& Shyi, 1991).

All respondents had a sufficient level of English language skills and therefore the default language of interviews was English. Also, using one language has the benefits of standardization of both questions as well as coding of answers, thus reducing the possibility of misinterpretation. On the other hand, there are also some negative side effects for empirical research. Managers may feel more at ease to speak in their mother tongue to the interviewer, and also provide more information (Sinkovics \& Penz, 2011). Respondents were given a choice to speak English, German, or French during the interview. Offering this option allowed 6 out of 10 respondents to use their mother tongue.

Interviews were conducted mostly in person and in two cases over the phone. Compared to phone interviews, personal (face-to-face) interviews are believed to yield slightly better data quality (de Leeuw \& van der Zouwen, 1988; Jordan, Marcus, \& Reeder, 
1980). It has also been suggested that social desirability bias is weaker in case of sensitive topics in surveys (Tourangeau \& Yan, 2007). The experience during the study showed that personal interviews are less likely to be cancelled or rescheduled, and respondents are ready to allocate more time to the interview. However, phone interviews also have some significant advantages: They reduce the need to travel (and thus costs), and reduce interviewer effects (Shuy, 2003). It has been shown that the differences between the two are negligible and added costs involved in personal interviewing not justifiable (Siemiatycki, 1979). This study uses both, personal and phone interviews (see Table 5), and manages the potential issues accordingly, for example phone interviews were scheduled with additional time added. For the purposes of the present study, social desirability effects can be considered to be low, because the respondents are senior managers and providing inaccurate information may have a negative effect on the image of the respondent. The need to travel for personal interviews was managed by combining interviews with other business, which in turn caused a relatively long period field period of 6 months.

Postal surveys were not considered: Semi-structured interviews require the flexibility to rephrase questions, and add probing questions if required. Also, personal/phone interviews are superior to self-administered surveys with respect to sampling accuracy a written questionnaire carries the risk of being handed down to less senior employees to being answered, and makes it difficult to control the unit of analysis. Lastly, personal interviews allow building a personal rapport with the researcher, which may lead to more detailed and more accurate answers.

In order to access the experiences of the interviewed persons, one needs to define interview guidelines in advance. However, since the objective of this part of the research is to develop hypotheses, it would be wrong to construct a fixed questionnaire with standardized questions and lose the ability to explore new categories as they emerge in the conversation or probe deeper, if necessary. On the other hand, a 'friendly conversation' with open-ended, unstructured interview guidelines may not yield a sufficient amount of data, as respondents may 'wander off' into unrelated subjects (Seidman, 1991). To address this, we chose a semi-structured approach, and developed a list of open-ended questions, which are being asked to all respondents. 
Table 5: Sample of the qualitative study

\section{Company's annual passengers (million, 2011) Number}

Above 20

5

10 -less then 20

5 - less then 10

2

Less then 5

0

Method of interview

Number

Personal Interview

8

Phone Interview 2

Language of interview

Number

English (mother tongue of resp.)

2

English (not mother tongue of resp.) 4

German (mother tongue of resp.) 4

Company based in (Number)

Austria (1), Belgium (1), Germany (4), Hungary (1), Spain (1), United Kingdom (2)

Table 6: Structure of interview guidelines

\begin{tabular}{|l|l|}
\hline Related to sampling & $\begin{array}{l}\text { Company name, position of the respondent, } \\
\text { responsibilities, seniority, location, time, date. }\end{array}$ \\
\hline Introduction & $\begin{array}{l}\text { Motivation of shopping at airports } \\
\text { Definition of shopper emotions }\end{array}$ \\
\hline Drivers of retail behaviour & Factors influencing shopping behaviour \\
\hline Emotions & $\begin{array}{l}\text { Emotions as drivers of behaviour } \\
\text { What influences Emotions } \\
\text { Emotional changes along the airport process } \\
\text { (in stages) } \\
\text { Impact of flights delays or cancellations }\end{array}$ \\
\hline Strategic and tactical considerations & $\begin{array}{l}\text { Role of the above in company objectives } \\
\text { influencing emotions and behaviour as a } \\
\text { marketing tool }\end{array}$ \\
\hline Further sampling questions & size of airport, size of retail area, no. of outlets \\
\hline & source: own data. See Appendix for a full copy.
\end{tabular}

The interview guidelines started with a general introduction which was read out to respondents, followed by a general question to start the conversation: "Why do people 
shop at an airport?". Then, 19 questions were included, which the interviewer was required to cover during the interviews.

The order of questions was adapted to the flow of conversation. Extensive probing techniques were used. After the open coding phase was completed, some questions were revised, and others added, to ensure that enough data was collected for emerging concepts or relationships between variables in the interview.

\section{IV.4. Sampling}

The sample was recruited from managers at the TOP 50 airport operators in Europe, based on annual passenger traffic handled (see Table 5). Passenger volume is a strong driver of retail revenues and as previously set forth, according to Doganis (1992), an annual volume of 8-10 million passengers is required for airports to reach the maximum level of retail spend per passenger. Also, limiting the scope to the largest airports increases the likelihood that the organisation has a good level of knowledge about consumer behaviour, and has established a dedicated business unit for retail sales. The study was geographically limited to Europe to ensure internal consistency. The European airport retail industry has undergone major changes in the last 10 years since the abolition of Duty Free sales for passengers travelling inside the European Union. This led to a major reduction in sales of the important categories liquor and cigarettes but also put airports under pressure to develop new strategies to maintain their position (Freathy \& O'Connell, 2012). At the same time, many of the findings will probably apply to major airports in other countries, too.

Table 7: Frequency of airports by passenger volume

\begin{tabular}{|c|c|c|}
\hline $\begin{array}{c}\text { Annual passenger } \\
\text { traffic }\end{array}$ & $\begin{array}{c}\text { Largest European } \\
\text { airports }(\mathbf{n = 5 0})\end{array}$ & $\begin{array}{c}\text { Airports in sample } \\
(\mathbf{n = 1 0})\end{array}$ \\
\hline anove 50m & 3 & 1 \\
\hline $\mathbf{2 0}-\mathbf{5 0}$ mill. & 17 & 4 \\
\hline $\mathbf{1 0 - 2 0}$ mill. & 17 & 3 \\
\hline $\mathbf{5 - 1 0}$ mill. & 13 & 2 \\
\hline TOTAL & 50 & 10
\end{tabular}

Source: own data, annual passenger volumes are 2012 data based on http://anna.aero

An important aspect is the recognition that companies may consider their knowledge of consumer behaviour to be a competitive advantage and therefore confidential. When researching business organisations, obtaining reliable qualitative data requires a 
significant degree of opportunism by the researcher (Bresnen, 1988). In selecting the sample, it may be justifiable to prefer companies where a personal relationship exists, or where the absence of gate keepers or company restrictions allow data to be collected, over other companies, which may be either out of reach or delivering unreliable, incomplete data.

Top or second level managers of the targeted airports were identified following a snowball method: Once a manager was identified using the author's network, he/she was included in the sample, provided that sampling criteria are met. If an interview was held, this manager was then asked to recommend a further manager meeting the criteria and so forth. In order to be included in the sample the respondent had to:

- be employed by a TOP50 European airport operator (by number of annual passengers);

- have accountability for the organisation's revenues from retail concessions or operation (senior management level);

- have at least 5 years of managerial experience in this or similar role;

- occupy a role requiring a good understanding of passenger behaviour and psychology;

- be in regular contact with retail operators at the respective airport.

In all except two cases, the interview setting was in the respondent's office, at a prearranged formal meeting time, and respondents generally seemed willing to support the process. Following the recommendation of Yow (1994) to use the least offensive voice recorder available - a mobile phone - to create a sound file of each interview after obtaining permission, and respondents seemed not to be disturbed by the phone's presence. Recordings were archived in mp3 format and transcribed in Microsoft Word $\odot$, to satisfy the criteria of replicability. Non-English interviews were transcribed in English by a native speaker and checked by the researcher. In cases of doubt, industry experts were consulted and further explanations added to the respective statements in parenthesis to aid coding.

Supplementary data such as related company brochures and information on the airport's retail environment were obtained before the interviews from the company's website or provided by the respondent in the form of electronic or printed reports and brochures. 
In order to determine the appropriate sample size, we followed the concept of data saturation (B. G. Glaser \& Strauss, 1967; Lincoln, 1985; Rubin, 1995). Rather than predetermine the number of required interviews, data was continuously collected until it become clear that no new underlying themes, concepts, findings, or problems were mentioned by respondents, and therefore we would not yield any additional benefit by continuing. The level of saturation is influenced by a distribution of views of interest and the complexity of the topic. There have been suggestions that saturation can be reached with 12 interviews (Guest, Bunce, \& Johnson, 2006), while a more widespread view is that no general number can be determined (J. D. Douglas, 1976; Seidman, 1991). The approach taken here used the criterion suggested by Francis et al. (2010). The sample size is set at 10 interviews with a diverse sampling. The stopping criterion is positive if no further information was found after a set of a further three interviews.

Figure 7: Data saturation: Number of concepts discovered by number of respondents

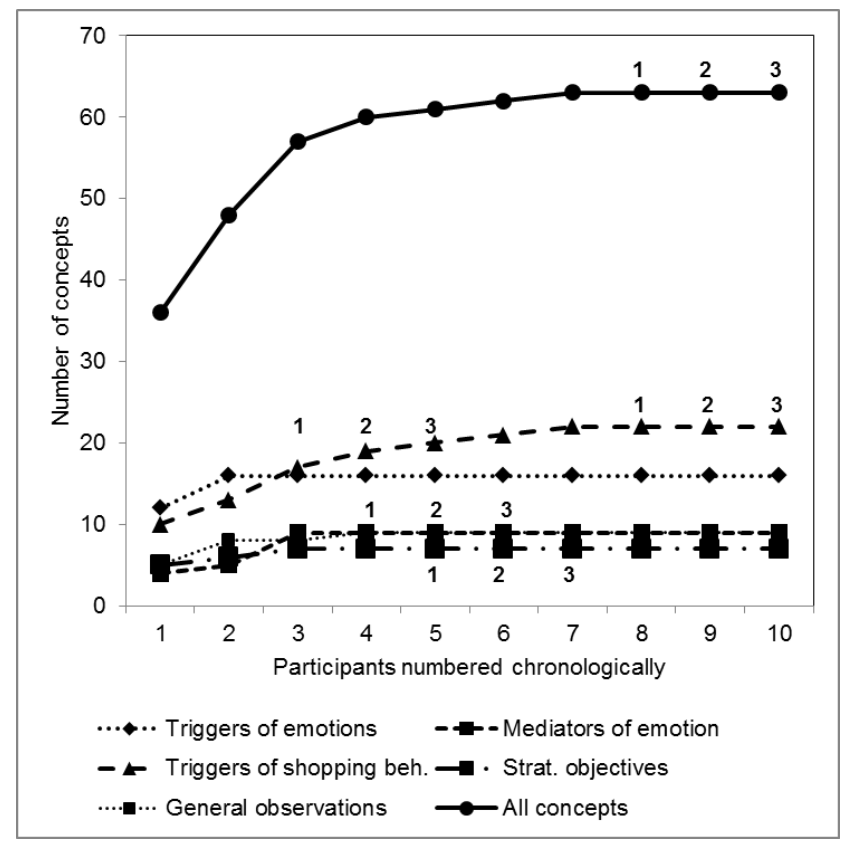

source: own data

After the tenth interview each additional interview is checked for newly emerging concepts, and if for three consecutive interviews no new concepts were found in either one of them, the data collection process was stopped. The coding process was started after the third interview, and it became obvious after a few iterations, that a relatively small number of interviews will be sufficient. After 7 interviews, the maximum number of concepts/coding categories was reached, and interviews 8 - 10 did not yield any 
additional concepts. The stopping criterion was therefore reached after interview 10 (see Figure 7).

\section{IV.5. Data analysis}

The coding process is a crucial part of this research, therefore we will describe it in greater detail in the following section. The coding process applied follows the three stages of grounded theory.

\section{Stage 1 - Open Coding}

The interview transcripts were reviewed in chronological order and each time a new phenomenon was identified, a new variable was created, which we will term concept. The coding process was completed with the assistance of the qualitative data analysis software TAMS Analyser (Hart, 2011; Weinstein, 2012). All interview transcripts were uploaded, and open and axial coding was performed using this software. The same statement could be allocated to several concepts. Any textual element matching a previously identified concept was coded. Questions and statements by the interviewer were recorded but not coded. At the end of all coding processes, a total of 214 concepts were assigned to 700 text statements. 61 concepts were assigned to text statements in $50 \%$ of interviews or more, 107 concepts appeared in $25 \%$ of interviews or more.

\section{Stage 2 - Axial Coding}

After the first three interviews were completed, all concepts were analysed and grouped based on their similarity. Redundant concepts were merged, and any concepts not detailed enough were reviewed consulting the respective statements. A decision had to be made regarding the size of the node system, which should cover the aspects in sufficient detail to formulate exact hypotheses without being too complex. First, concepts representing the same phenomena or relationship were grouped to form subcategories. For example: "Flight delays are good for business" became a sub-category, including concepts being "Delays of over 45 minutes causes passengers to start shopping again" or "Long delays cause people to shop to kill time". Sub-categories were then grouped again, and so on. During this process a theory started emerging from the data, while sub-categories were regrouped several times. For example, initially the concepts "security staff not well trained in customer service cause stress" and "queues at security screening cause stress" were allocated to the same sub-category. During the 
next stage of coding, it appeared that the first refers to a service encounter (customer experience while being checked by a security guard), whereas the second refers to human crowding while waiting). In the first case, anxiety, anger or surprise is caused by an event taking place when the passenger met a poorly trained security officer, but the second case refers to either an increasing likelihood to miss a flight, or to being uncomfortable in crowded places. This process was completed with the definition of the central nodes, which branch out to lower level categories and so on, forming a network. Three levels were sufficient to allocate all variables included in the analysis. At the end of this process, the data set was reduced to 63 concepts.

\section{Stage 3 - Selective Coding}

The final stage involves the search for a code category as well as the development of lower level categories in greater detail, identification of concepts and collection of statements from the original transcripts to allow the development of theory.

During the definition of final categories and sub-categories, all notes and researcher's impressions have been taken into consideration, and the emerging concepts were verified with related literature to ensure external validity. Then, the derived categorisation scheme was discussed in a workshop attended by four researchers with relevant academic qualification and a minimum of 10 years of experience in retail related marketing research or qualitative methodology. Based on feedback from the workshop, several sub-categories and variables were reassigned, or excluded from the analysis. It is expected that the additional two interviews will yield no further insights, because the stopping criteria was met already at $n=10$. The next section summarizes briefly the findings in as far they are relevant for the proposed quantitative research.

\section{IV.6. Results and discussion}

In total 214 concepts were found, and after removing redundancies and coding following the process described above, they were grouped in sub-categories structured around five main categories as shown in. We will now present the findings grouped by category and sub-category.

The largest category - stimuli of emotions - contains statements about events or circumstances which are causing emotions of airport customers, according to the statements made by respondents. The next category contains moderators of effects on 
emotions, most often related to the personal or situational factors of the customers. For example the following text statement would fall into this category "People who are travelling 2 or 3 times per year have more familiarity with the airport, the terminals, the layout, and so their anxiety (...) is much less.", which been coded as 'FrequentTravellersNotEasilyStressed', and would be allocated to the sub group 'Air travel experience'.

Figure 8: Overview of the main sub-categories (preliminary study)

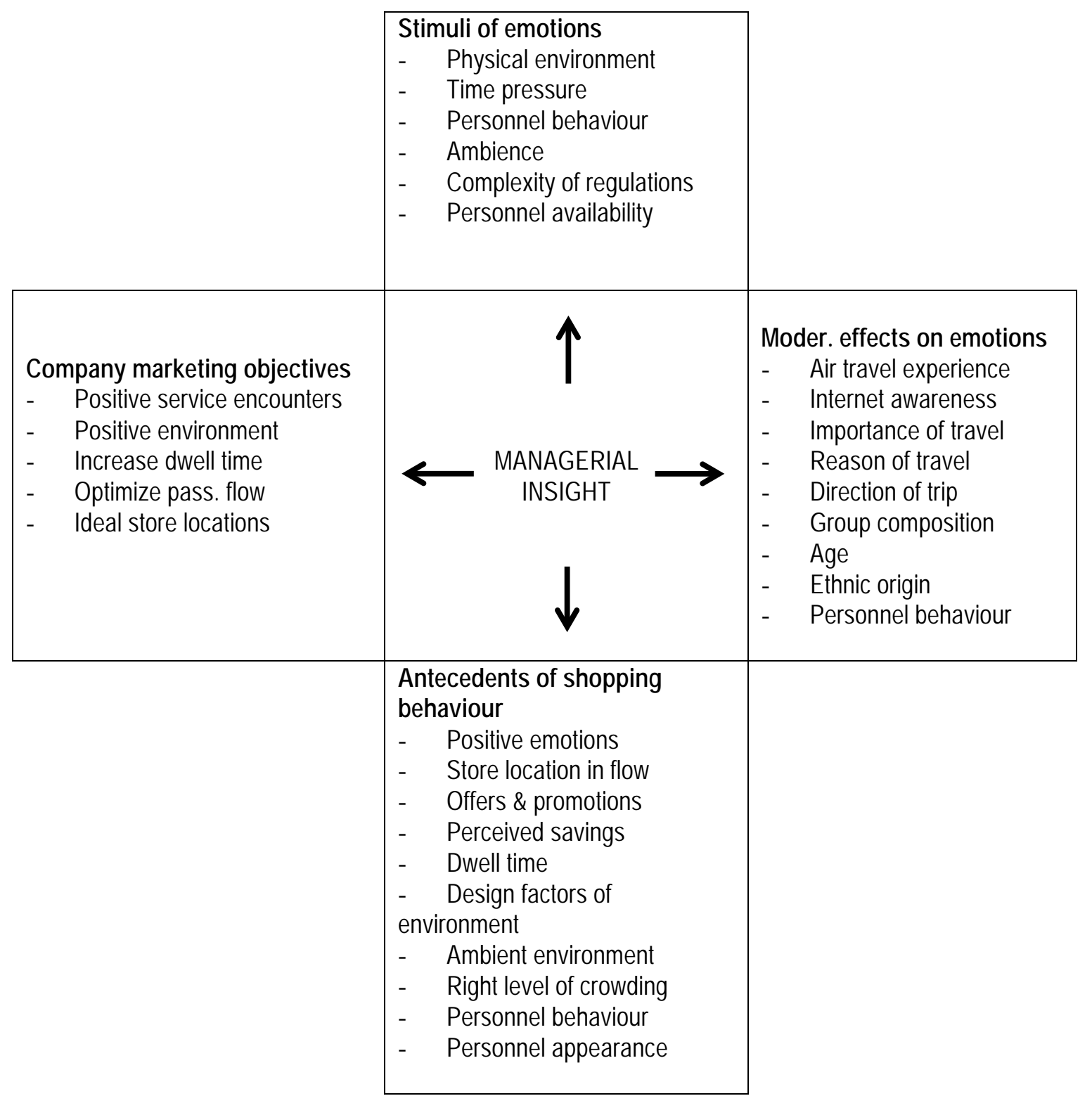

source: own data

The third category refers to statements about all events and circumstances which are antecedents to shopping behaviour or any marketing output variable. It may seem odd to group these two quite distinct concepts together, because a customer's behaviour is 
quite different from an output measure, in fact they probably have a cause-and-effect relationship. However, respondents have often used them interchangeably, for example the following terms were meant to mean the same thing: ' $A B C$ obviously increases your retail spend'; ' $A B C$ is good for sales'; 'That's what our retail concessionaires really like'. When building the model, we will certainly take this into account.

Fourth, all statements stating company marketing objectives or future plans form a separate category. And lastly, a number of general observations were made, which could not be connected to the previous nodes, but still contain important data.

\section{IV.6.1. Stimuli of emotions}

The participants discussed the emotions of passengers in great detail, and all stated that - consciously and subconsciously - the emotional state of passengers has a strong influence on their propensity to shop, amount spent and therefore overall the retail performance of the retail outlets.

"So there is a correlation between how people feel, and how the process has gone, their journey through the airport and their propensity of how they purchase. (10)

Negative emotions have been termed 'stress', 'anxiety', 'fear', 'restlessness', 'uncomfortable feeling', 'worry', 'nervousness', 'anger', 'disorientation' by respondents. The data contains a notion that stress/anxiety and related negative emotions are caused by either very recent events or environmental changes, or by concerns and fears about events or environments which may be coming in the immediate future. This suggests that the emotions relevant to airport environments are rather short term.

Statements referring to positive emotions contained the words 'relaxation', 'pleasure', 'happiness', 'calmness', 'positive mood', 'shopping mood', 'being activated', 'being comfortable', 'feeling of security', 'excitement', 'positive feeling', 'feeling good', 'sense of tranquillity', 'holiday feeling'. The words for positive emotions were often used interchangeably therefore the data may not be fit for detailed analysis into the type of emotion. These statements were usually not explained in further detail, but were also often understood as the absence of negative feelings. Respondents were confident that low levels of anxiety, and being in control and aware of the environment would automatically lead to positive feelings, as if most travellers would have underlying positive feelings which sometimes may be hidden or obstructed temporarily. 
There seems to be a general mood (as opposed to short termed emotions) related to the fact that the passenger is about to travel. The underlying positive mood linked to the airport experience, which - in most cases temporarily - paired with other emotions caused by the environment, service encounters or individual events at the airport.

There is a pleasant feeling of 'holiday', you have worked for this, are entitled to be pampered, a nice hotel, it is quiet, children have animation, the holiday feeling leads to a hedonistic desire to shop, already before departure. (2)

Negative moods may be caused by personal traits, such as fear of flying. Those who mentioned fear of flying as an issue agree that these are so strong that it would be impossible to overcome during the short time at the airport. The concepts have been grouped into sub-categories as shown in Table 8.

Table 8: Subcategories of 'Stimuli of emotions'

\section{Category: Stimuli of emotions}

Sub-categories: Cues emitted by the physical environment, time pressure, personnel behaviour, ambient elements, crowding, personnel availability

source: own data

The physical environment emerged as a main driver of emotions. All respondents confirmed that they were designing and adjusting the interior of the building with emotions in mind. This includes elements of the design including layout of buildings and retail outlets, way-finding (signage, information provided). Spacious areas, places to sit and relax and easy to follow processes trigger positive emotions, when they reduce the likelihood of delays and increase a feeling of being in control of the journey.

Also the infrastructure of the building, both the building itself and everything inside, such as wayfinding systems, passenger information systems, or even places where people can inform themselves, inside a shop or at the airport information, this is a key external factor. (4)

(...) feeling good depends on the availability of seating facilities. (10)

Especially families, they often look for a place to camp, and then they take turns walking around the shops, so seating is important, it should just be close to the shops.

[Shop front design?] This is standardised to have sence of tranquility (2)

Also ambient elements can cause positive emotions. This includes use of high lighting (especially natural daylight), materials, background music, water, as well as absence of smells, but also only a limited number of promotions not to overload passengers. 
Things like natural light are actually incredibly important for passengers to have a sense of that time of day and the rhythm of time, that really helps to calm them, to make them feel reassured.(7)

We try to use materials in order to create a sense of calmness. (2)

We have a maximum volume set, and music should not be heard in the normal passenger flow. But inside shops it creates atmosphere. (1)

A small water play relaxes people (1)

People related factors such as crowding are considered when laying out infrastructure, for example aisles and paths are designed to avoid crowding, and to encourage a slow but directional flow of people (which also provides orientation and way finding). Heavy crowding, which may lead to an uncomfortable lack of private space, causes negative emotions for most people.

People use airports in order to travel from ' $\mathrm{A}$ ' to ' $\mathrm{B}$ ' and therefore any event which may compromise reaching that goal is an obstacle, and may be a stimuli for negative emotions. The most realistic threat is to be delayed on the way to the departure gate and miss a flight, and therefore perceived time pressure is a main cause of anxiety. Many participants have stated that this anxiety starts when leaving home until boarding the aeroplane. Perceiving a check-in queue to be long would lead to an increasing worry or fear.

Then once the person arrives and he sees a queue, it becomes a factor of uncertainty (1)

(Facing long queues - added by researcher) Then they start to get nervous. Because they don't know what effect that will have on their trip (4)

Anxiety generally increased when passengers move on to security, because there are not only queues, but there is also a concern if passengers took anything illegal, such as sharp items, or the complexity of regulations. Security guards wear uniforms similar to police officers, which immediately cause an increase in fear caused by staff appearance.

And there the additional stress factor are the regulations, especially if someone is not experienced related to liquids or forbidden items (1)

After security screening, passenger's concerns about missing the flight usually are quickly forgotten, if they still have enough time. Therefore the level of anxiety depends on their understanding of how long it takes to reach the departure gate and if that is sufficient or not. Consequently, lack of information or knowledge of the airport layout (unawareness of walking distances), can be perceived as time pressure. During the last minutes before boarding, passengers may have an increased level of anxiety again, but 
not due to fear of missing a flight, but related to the flight itself (where will I sit, who will sit next to me, will my kids behave well etc...).

Several respondents have stated that negative service encounters, very long queues due to slow service, negative experiences with service staff etc. lead to negative emotions. They argued that these types of negative emotions take longer to 'wear off' and should be avoided in the first place. There is an expectation that airport personnel (regardless of which company they work for) should support passengers in the process, and any lack of support causes annoyance, possibly anger rather than anxiety, and this negative feeling may prevail for the remainder of the airport journey.

The handling agent would have known about that delay hours before [but not informed passengers - added by interviewer]. And that infuriates passengers in such a degree, that they are not going to buy anything they are not going to drink anything. (10)

The provision of additional services may help reduce negative emotions, and may help passengers in coping with stress. Examples, which can reduce the likelihood of threatening events occurring are provision of a fast lane at security.

people who are pregnant or who have kids, the supervisor picks them out and separates them, so you don't have that stress level - Which you really notice in the people. (3)

I think generally a queue is always negative (...) if it gets critical heart shaped chocolate is being handed out, and people are purposely influenced by additional staff. To avoid that people get restless.(2)

Some airports also employ additional personnel to answer questions about distances of gates, encourage people to relax and visit the stores. In order to avoid negative experiences during a service encounter, airports invest in training customer contact personnel. The above suggest that both, personnel availability and personnel behaviour could be relevant stimuli.

\section{IV.6.2. Moderators of the stimuli's effects on emotions}

A major part of each interview was focusing on what personal and situational factors need to be considered to understand why in some cases the same environments or events lead to different emotional states. Table 9 summarised the sub-categories identified, which we will discuss in turn.

Frequently, explanations about effects on emotional states were differentiated for business and leisure travellers, assuming that business travellers are more experienced in air travel, and therefore have a better understanding of the airport processes, and are 
more accurate in assessing potential threats to achieving their objective. Experience would be related to the frequency of previous visits.

But this is really more for the leisure passenger, then the business one, because they know the process. (5)

Business and frequent flyers are hardly stressed at all because of security or passport control (2)

Table 9: Subcategories of 'moderators of stimuli's effects on emotions'

\section{Category: Moderators of stimuli's effects on emotions}

Sub-categories: Air travel experience, internet awareness, importance of travel, reason of travel, direction of travel, group composition, age, ethnic origin, supportive personnel

source: own data

Also, regular travellers may have a higher experience with missing flights, delayed or cancelled flights, and know ways of coping with these situations. This in turn reduces the overall threat and concerns. Also they are able to avoid potentially threatening situations, therefore avoiding any negative events (stimuli) before they occur.

(...)business people immediately start organisation, go to service center to rearrange flights to be able to get there (1)

The internet as a source for information prior to the process as well as technology used at the airport has been mentioned as being important. An individual's access to and knowledge of internet technology becomes a moderator of the anxiety caused by uncertainty.

[lower stress - added by interviewer] if they understood at home how the home-check-in works (...). We are moving further with technology, but we are also moving further away from a lot of people who don't use computers. (3)

Respondents have advised that the overall anxiety felt at airports depends on how important the travel is to the individual, and therefore how negative he/she would be affected by not being able to travel, or arriving late at the destination. Generally, regular commuters and business travellers seem to be less concerned - essentially they are probably travelling on behalf of a third party, and are not directly affected by lack of success. Therefore reason for travel may after all have some influence, too. 
Then the question is raised: what does the delay cause with them? That depends how the people are individually, and what the delay means for them. If you tell me I have 20 minutes delay, I take this on board, am angry for a short period, and then just spend my time. Others may get stressed, may have to inform other people, make phone calls, get worried, what happens with the connecting flight. (8)

On the other hand, consider tourists on the way to their annual holiday. A flight delay may not be a real threat, but missing a plane may have very serious consequences, as tickets are usually not refundable, and the threat may be losing a pre-paid holiday in its entirety. On the way home, also a serious delay may be annoying or even threatening, for example if the individual may get late to work as a result. The direction of travel may also play a certain moderating role (inbound or outbound).

If you have a house abroad (...) it's a bus, isn't it. It's actually a means of getting from A to B. (10)

Therefore it could either be anxiety if it is an important meeting, where decisions need to be made, or if he knows what is expected, for example living in A but needs to work in B that's possible. This is the normal way to work. (3)

[except families:] For other passengers - in case of several hours delay, before starting a holiday, one is disappointed, but it is not a serious problem. (1)

For transfer passengers who want to return home, it's more stressful, because they already have travel behind them, and just want to go home. (1)

Some environments are more threatening because of the group composition. Often mentioned was the stress involved in travelling with children, because they add to the uncertainty of the journey.

It's really an awful process for those passengers, also with kids when you have to put the buggy on the trail [meaning: into x-ray machine - added by interviewer], and it's awful, and afterwards: "phew!"

Travelling in larger groups reduces the stress, because the other members of the group, or - if present - a group leader provide information, and add a feeling of security. Several respondents mentioned that especially Asian group travellers appear more relaxed, because the group's leader takes responsibility for a successful process. This could be explained with less stressful events are avoided and potentially threatening stimuli are not noticed. Also coping with negative emotions is supported by the group leader.

Chinese travellers, they come in groups. Everything is managed, the stress is managed. (3)

Elderly passengers have been noted to behave differently. While respondents have not suggested that older passengers are more or less responsive to stimuli, they are understood to allow significantly more time for the airport process. 
Older people, for example, come a lot earlier, they are a lot more worried about the time it takes. (9)

If their flight leaves at 7 am, they wake up at midnight. (3)

Ethnic origin has been mentioned frequently as a moderator of anxiety. This difference could be caused by one culture displaying a higher resilience to stress, or in general less concerned about time pressure. Also, public crowding seems to have a different impact on Asian nationals compared to Europeans. In fact, some respondents mentioned that the 'ideal' level of crowding is higher for Asian travellers then Europeans.

However Asian travellers handle this stress better than Germans, even if they have been paged 10 times. (3)

The other interesting factor, different nations have different levels of accepting of crowds (1)

The fact that someone is not a local national and language skills also moderate the impact of the environment.

I'm thinking if language could be a barrier, for example at security control one could be asked questions which one cannot answer. This may lead to fear. (1)

All respondents have therefore named the reduction of queues or the provision of information about length of queue or waiting time as a good way to help coping with anxiety. Information can reduce the individual's perceived waiting time, and also help to reassess the threat of queues. Also, anxiety can be reduced by moving an individual to the top of the queue (if the departure of a flight is very close), or by allowing certain people to use a 'fast track' lane based on age (elderly, or families with very young children) or medical considerations. Personnel can offset negative circumstances, such as perceived disorientation or concerns about being late. Conceptionally speaking, when passengers are attempting to cope with a problem, then the presence of personnel can influence the success of coping, and in turn remove the stimuli for stress or anxiety.

Today among the airlines there is a queue management, where staff walks down the queues and they provide information. Or if it gets critical heart shaped chocolate is being handed out, and people are purposely influenced by additional staff. To avoid that people get restless or very dissatisfied.(2)

\section{IV.6.3. Antecedents of shopping behaviour}

The following section summarized concepts which concern factors influencing shopping behaviour and store patronage. In many cases, practitioners did not mention which specific behaviour the concepts influence. For example they may just say 'good for the store', which could mean a positive impact on any output variable such as sales, 
visitors, or margin. Respondents used shopping behaviour as overarching concept of store patronage, time spent in store, likelihood to browse, and spending. In order to accurately represent the data, the following concepts presented were mentioned to be important drivers of retail output, but the effect could be influenced by mediators or moderators (such as emotions or cognition). The sub-categories identified (some of which are similar to section IV.6.1 above) are displayed in Table 10).

The emotional state people are in has been mentioned as the key driver for retail performance. Both, the presence of positive emotions and absence of negative emotions are important. Most respondents assumed that there was an underlying positive mood, an excitement about travelling, which can be enhanced or sometimes created by the airport experience. If passengers in this mood are exposed to retail offers, positive shopping behaviour increases. Negative emotions reduce the likelihood of shopping, mostly because passengers try to cope with their emotions first. That often involves focusing on most important tasks, which in an airport is usually reaching the gate on time. When these objectives are not threatened, negative emotions decline and the likelihood to shop increases again. Hedonic shopping motivations exist, and there are passengers which shop to cope with anxiety.

If they have negative feelings, people don't shop unless absolutely necessary. So you are touching on an extremely important point here. Feelings play a huge role. (9)

All the operational stress needs to be behind them. (5)

And once you've got through the process of check-in and security, that's when the excitement starts about your holiday, that's when your mind-set clicks over into "Right, we're here, and we're going on a holiday". That's when you are going to see a much more excited and open mind-set, (7)

It is positive for retail if stress caused by time pressure can be removed (1)

Table 10: Subcategories of 'antecedents of shopping behaviour'

\section{Category: antecedents of shopping behaviour}

Sub-categories: Positive (lack of negative) emotion, store location in flow, offers \& promotion, perceived savings, dwell time, design factors of environment, ambient environment, right level of crowding, personnel behaviour and appearance 
An important driver of retail performance in any industry is the location of the store. In airportscapes, the store location in relation to the passenger flow receives the main focus. The number of by-passers therefore not only depends on the location of the store but also on the physical design of the infrastructure, as well as other drivers of passenger behaviour. Stores located on another level then the main flow have a much lower penetration rate. Another extreme are walk-though concepts, which ensures $100 \%$ visit rate for that particular store, but could reduce interest in other stores. Passenger behaviour can also be influenced, for example the location of 'magnet' stores or rest rooms may have an effect on passenger flows, such as the provision of moving walkways. Stores at the exit of moving walkways are likely to have a much higher traffic then those located at the middle.

Mostly we see: Shops need to be in the flow. If the retail is not in the flow, you have an issue mainly. (5)

In the terminals, that means for example sometimes even just to take a staircase upstairs to a higher level, or to walk along a detour, not all airports are ideally structured (8)

Is there a moving escalator, is there an escalator, is it easy to see or do I need to walk around a corner, then I don't do it. If it's easy, then they are participating. (2)

However once he is a kilometre away, it is difficult, then he will not return. (1)

Planned shopping involves a search for particular product offers and promotions, therefore the presence of attractive product categories, product displays, store fronts, and well-known brands has been mentioned as driver of retail sales. Also impulse shopping is being triggered by brands, where international brands in general seem to work best given the multinational characteristics of the audience in an airport. People shopping for luxury items will expect to find luxury brands, and in general higher price levels at airports are not perceived as a negative thing, if paired with promotions signalling 'you can get luxury products for a better price than elsewhere'. Also, global airport retailers are offering 'travel exclusive' products, which are packaged or bundled in a way not available at high street stores.

Airport operators underline the proposition that airports offer value for money, which is related to mainly duty free products, but is also a perception of all airport products regardless of them being free of taxes or not. This has been shown to drive retail sales. Consequently, the presence of attractive promotions at all times has been mentioned as a factor influencing retail performance positively.

If they pass a shop front which is really attracting, interesting for them, then they might enter the shop, the retail units. (5) 
They see the products to the sides, and if he wants to look at them, then he approaches them. If he wants to walk through, he can do that without pressure. But it has been shown that this is rather incentivising people to stop. (2)

The value of brand influences them (1)

There is a trend - especially in Duty Free - that retailers (...) ask for special products to be produced which are only available at airports. That can also be a reason to buy (8)

Impulse shopping is being created by the offer, timely concepts, (1)

These are also important, they need to find their product, and maybe if they want to just buy a nice accessory or a souvenir from that location, they need to find the store, and find and attractive offer matching their wallet (8)

Also the communication at the promotion or the communication of products at entrance of the shop. If you see '- 50\%': 'Oh wow, then I will enter the shop'. (5)

Driven by the Duty Free concept, the airports are offering perceived savings, in the view of many passengers. Although this is not the case in all categories, partly caused by the abolition of duty free for intra-EU travel, this image applies across all categories, and is therefore an important antecedent. This is being supported by displays of promotions, as well as the branding as 'duty free' or 'travel value' or similar.

Shopping at the airport, that is for most people: Duty Free. (...) Even if people don't travel regularly, they have that impression that everything is cheaper, because you pay no duty. (9)

'Tax Free Pricing' message is key to why most people shop at the airport, because there are savings that they can get compared to a high street price. (7)

And one of the categories that has actually been increasing if you look at the European market, is simply luxury products. Anything from Montblanc fountain pens, to foie gras. The environment itself is actually creating this feeling (6)

That image of luxury for a lower price still prevails. (9)

An extended dwell time in the retail areas is an important driver of average propensity to shop and average spending per passenger. Dwell time is a similar concept to passenger flow. Furthermore, a slowing down of passenger flow will lead to a higher dwell time. Also, there are design elements, such as flight information screens and comfortable seating areas, which lead to passengers stopping, looking around, and possibly identifying an attractive store which leads them to spend more time in the area. As discussed earlier, dwell time can actively be influenced by airports by not informing them of gate locations, and thus 'forcing' them to stay in central nodes of the building. One respondent said that one of his main managerial tasks was to 'grab minutes here and there', because 'Increasing dwell time, that's money' (respondent 6).

Obviously it's a time pressured environment, we have a certain amount of dwell time within the departure lounge, I think people's behaviour is also driven to a degree by the amount of time they have available. (7) 
providing all necessary information as soon as possible to the passenger to make sure that they are not wasting any time searching for information (1)

If you have time enough, and then you see a product that is attractive for you. (5)

The design factors of the environment are important drivers of retail behaviour. As partly discussed earlier in this section, the direction of passenger flow in relation to retail offers is an antecedent of shopping behaviour. Also, dwell time can be influenced by architectural design. Signage as well as lighting (brightness, especially daylight attracts people) is being used to support passengers staying in proximity of stores or to view store offerings. The location of restaurants and cafe's as well as seating areas in relation to store fronts is and important driver. Groups have been reported to identify seating locations first, and then take turns in visiting stores while others save seats and look after luggage.

The areas need to be designed so that people are feeling well, regarding light guidance, the guidance through the terminal needs to be clear, (8)

it's very important the way we treat ceilings, the way we treat floors, the guidings through terminals through the shop (3)

Otherwise they go immediately to the gate to see where it is, and if they have enough time, they go back to central retail to shop. (5)

The overall ambient environment of the airport's retail area, which in most cases is treated in isolation from the other, more functional environments (such as check-in or boarding areas), sets the mood for shopping. Airport managers have used elements including store fit out, decor, material, lighting, scent and colours to positively influence shopping behaviour.

give atmosphere, and then retail works very well. (1)

But by refreshing the shop, sales raised by $20 \%$. They were still selling the same things. But because the shop was much more appealing in the decor and the lighting and all that, it actually improved the penetration, just because it was better to look at, and more friendly. (10)

The daylight in the comfort zone is very important. We want to build the new building with a lot of new windows with daylight (5)

In the shops it's actually not so helpful, because there you want to play with the light to focus people on certain brands. There is bright light for cosmetics, a lot of white and blue, clean, bright colours. For tobacco, especially cigars, and maybe whiskey and so on, you may want warmer colours, wooden, earthy colours, and dim the lights (9)

We used cinnamon mixed with chocolate [scent - added by the author] over Christmas in the arrivals Duty Free and you could notice that once people entered into the shop, this caused atmosphere, because cinnamon is of course Christmassy, (3)

If you move through the duty free shop you have of course the smell of perfume, and the staff there are using the testers, so you have this distinct smell in the shop. (9) 
Stores should be inviting, but without signalling an overly expensive image. There seems to be a fine balance needed to offer luxury brands that are attractive to many travellers, but maintaining an image of value for money. In general, airport operators aim to create an atmosphere of 'feeling good', which is inviting to linger on, and explore shops without having to worry about being delayed in the process.

"If this is so luxurious, it must be expensive. I don't even read the price tags but in my mind already move along". (4)

The right level of crowding needs to be achieved. Passengers seem to avoid stores that are completely empty. This may be seen as a signal that products are expensive or unattractive.

Crowding - Where there is life, it attracts life. If there is movement somewhere it attracts. (...) Especially in the beginning, it is worth to get 5-6 students who are standing in the shop, and suddenly people enter the shop, because they see others who are interested, there is a snowball effect. (1)

At the same time, stores that are full of people suggest that it may take a long time to buy something, because there are queues at checkouts. And because delays to the process may put the objective to travel at risk, this has a negative effect on propensity to buy. Processing people fast in shops, which involves sufficient checkout counters and staff, has been mentioned as a driver of sales. Well-trained sales staff in the shop can help in faster decision making and also reduce crowding and increase sales.

In-store, but also other personnel behaviour and appearance has been named as important for retail performance. Airports are typically employing more staff then highstreet retailers, and for more and more customers this is an important element of deciding to buy, but also in comparing airport offers with each other. Due to the multinational nature of customers, language skills and cultural awareness is very important. Customers are often under pressure, therefore a helpful, friendly attitude at all times will be appreciated and in turn lead to more sales.

Service offered is more and more important (1)

Getting people into the store is relatively easy due to the concept (layout etc.), but in order to make a close, to sell, the staff is very important. And that's why stores (...) emphasize staff with good knowledge. (...)They should wear a badge, with or without names, showing which languages they speak... (2)

If customers can be approached by sales staff or not is up to the concessionaire, the only rule is that employees should speak English and ideally one more foreign language (2) 
Overall, the drivers of retail performance mentioned may affect shopping behaviour directly or indirectly. The main themes presented above have been mentioned by the majority of participants.

\section{IV.6.4. Company marketing objectives}

All respondents were aiming at increasing revenues of all retail units, regardless of whether the outlets were self-operated or leased out to concessionaires. They were tasked to identify new opportunities to increase sales, within the possibilities of the airport operator, or in cooperation with retail operators.

Table 11: Subcategories of 'Company marketing objectives'

\section{Category: Company marketing objectives}

Sub-categories: Provide positive service encounters, provide positive environment, increase dwell time, optimise passenger flow, optimise retail locations.

The first group of objectives concern the efforts to manage service encounters to avoid negative emotions. Respondents were aware of the negative impact of stress and similar negative emotions on spending behaviour, therefore an objective frequently mentioned was to avoid stressful situations from occurring. This can be excessive queuing, which lead to time pressure if the individual did not allow enough time before departure. It also refers to negative events in the service delivery chain (rude security officers, for example).

I would always regard a queue as something negative. Because waiting is really also connected to stress.(2)

But time pressure is always bad for shopping. They are focused on the process and don't look at the offers, don't sit down in the restaurants, just head for the gate. So we try to take as much time pressure out as we can. (9)

The second group of objectives are to provide a positive environment for passengers. Environments can be used to elicit positive emotions (mainly calmness, relaxation) and reduce negative emotions (mainly anxiety and fear) or help coping with negative emotions. These seem to be an underlying strategic objective of all respondents. 
Sometimes you can actually create an environment where you de-stress people. Even though they... they might be - they are - under time pressure. (6)

The lack of being in control of one's own destiny seems to create an unwanted anxiety and stress, and therefore the provision of orientation and sufficient information for passengers to plan their journey is a key objective.

„People need to know where they need to get to, and then they feel in control, they have orientation. So you know which gate you will be using, and there are maps of the terminal in many locations, you can use that to plan your trip through the airport. (9)

That's what we're doing. 'Distance to Gate' and then always use time, don't use distance. Because if you say 200 meters, people simply cannot relate to 200 meters, so what is it? 4 minutes - everybody knows. (6)

„We are now reviewing (...) if we want to proactively communicate on the web page in real time how long the queues in security screening are. (4)

The physical aspects of the environment are important for all retailers, however there are some important differences to high street retail. Airport managing companies aim to provide a comfortable environment (seating, textures), which provides clarity, lack of distraction, and guidance. The layout needs to also give a sense of direction, and encourage people to move on, in order to avoid crowding during peak hours. At the same time, people should not move too fast, otherwise they would not look at the offers.

The main question is if it is unorganised and not clearly directed. In our case there are many million people passing through but it is not feeling crowded because it moves into a defined direction. (1)

we have the objective the create an atmosphere of feeling good (2)"

During fitting out of stores, guidelines by the airport are often provided to ensure a clear and standardised line of design and material used.

"And this is why the whole shop front, lighting and colours is important. (5)

Also the design of the front is standard, size and position of the store names, they should not dominate the overall feel of the retail area (9)

The shops of the new airport cannot just stand in isolation in the middle of the room, the architects have made clear instructions how the shop facades need to be designed that it needs to be a standard design (2)"

Influencing background music or ambient scent in the main terminal areas is not among the objectives of the respondents (with one exception), although many are aware of the potential.

„No, what do you mean scent, like the smell of fresh bread? Well if it's there it's there. We do not actively influence that.(9)

But it is quite a fine line, and I think it's probably fine in retail environments, because people are choosing to be within those spaces, and it connects best with the personality of the brand. (7) 
Maximizing the passenger's time spent in the main retail area (or: increasing dwell time) has been mentioned as one of the main objectives when designing the airport environment. Respondents were aware that this may also involve minimizing the time available for boarding the aircraft, which is the actual reason to be in the airport in the first place. 7 out of 10 respondents in the sample hold back information about the gate location to achieve a longer dwell time. This is in contrast with the objective to reduce stress levels, and a trade-off is being made between the beneficial effects of long dwell time and the negative effect of lack of information.

What we don't want to is obviously to have people dwelling at the gates when the plane is two hours away. So it's hands on management of the call to gate time. (7)

We are running a project right now, and for four weeks now we test this: delaying the information about the gate number, simply not telling people until 40 minutes for Schengen and 50 minutes for Non-Schengen flights, where the gate is. (6)

Gate announcement times as late as possible. They should be like 15 minutes before boarding, maximum 30 minutes before boarding. (3)

This seems to be moderated by culture, because all three respondents opposing this policy were representing airports in Germany. It could incentivise people to continuously watch flight information displays and not enter the shops. Some airports decided against delaying gate announcements. Also this may depend on airline choice, as it has been mentioned that getting to the gate early may be more important for low cost airlines, which do not pre-assign seats, and therefore people who reach the gate first will get to choose the best seats.

First of all when we got the low costs in, and the airlines are herding them: "Hurry up, hurry up, don't be too late to the gate" which makes people unsecure about the time. (6)

Some airports publish gate information only very shortly before departure, but we believe that this increases stress levels even further. (1)

I believe that this stresses people. I was in London myself and was stressed, I found this terrible, I want to decide myself. Therefore we decided against that.(2)

Another objective is to speed up passenger processing before the retail area, this depends on the peakiness of daily traffic, staffing levels, infrastructure design and operational efficiency. Fast processing increases satisfaction and avoids stress and anxiety. Both, during set up and operation of these processes, costs and dwell time is being balanced against each other.

You are basically grabbing minutes, to create a nice half an hour of nice shopping time. Those airports who have it are very successful airports. (3)

We obviously want to keep queues at an acceptable level. (4) 
Of course it would be nice to reduce the queues, but that mostly depends on other companies, we are working with the airlines to reduce queues at check-in, but actually it's up to them, they determine the staff levels. (9)

The longer this all takes - before security - the worse for us. And for our concessionaires. This is a big topic! (4)

All have mentioned that the location of shops in the passenger flow is important.

The core topic is 'where is it?'. Location, location... Does the terminal create a passenger flow which guides the passenger at the right time, during his maximum level of shopping likelihood level, to the shop? (8)

What is important I think is, actually changing a passenger flow can have a really beneficial effect on people's propensity to purchase, or absolutely the opposite. Just changing the passenger flow will mean that they buy more from a shop or actually they will walk straight past it. (10)

What we plan to do is to first review the whole retail zone, and to put all Retail and Food and Bev in the flow. (5)

Airport operators are tasked with manage the passenger flow to get the maximum possible number of potential patrons close enough to notice the offerings. This involves locating the stores in the flow of passengers, and to avoid the number of 'dead spots' in the terminal, which are locations too far away from the main passenger flow to be noticed.

The majority of respondents have (or are planning to have) a walk-through duty free store. Those who said to avoid this have stated that the concept would not be appreciated by customers.

The passenger arrives from the security control, and automatically enters the $2000 \mathrm{sqm}$ walk-through duty free. I will send a link to the brochure. (2)

We recently enhanced our duty free shop, and put it in a different location, and it's a much nicer fit out, much larger, it's a walk through duty free, and that increases the spend, there's no doubt about that. (10)

Lastly, companies may want to cooperate closely with the retail partners, as either in the short or long term, benefits to the retail partners will also be a long term, and airports generally get involved quite detailed in lay out of new and existing retail outlets.

Also the design of the front is standard, size and position of the store names, they should not dominate the overall feel of the retail area (9)

We are quite hands-on in terms of agreeing, but they would drive it, because arguably they are the experts in the field. But they are not always experts in everything, and especially local issues (10)

\section{IV.7. Summary and limitations}


This study was conducted to gain managerial insight into the topic under investigation and to allow the development of hypotheses based on both primary data from the relevant industry as well as the literature for additional validity. This qualitative study is unique because it contains data obtained from senior executives among the leading companies in this industry in Europe, and while the subject of investigation is the passenger rather than the retail or airport company, it is an appropriate instrument given that the respondents are probably more aware of causal relationships than passengers themselves. With several hundred concepts identified it has been necessary to reduce and structure the findings, however the format presented in this section allows to gain an overview of the all relevant independent variables influencing marketing performance of airport retail units. It contains main antecedents of emotional states as well as shopping behaviour, but also a range of moderators relevant in this industry, which may not have been included in previous studies into retail environments (such as composition of group or choice of airline).

We argue that the results presented above have a good construct validity. Firstly, multiple sources of evidence were used. After the interview, company data was collected relevant to the subject, i.e. press releases, commercial brochures, reports in trade magazines. Then, concepts and categories were identified and any discrepancies reviewed individually. Multiple sources of data converged, and suggested a high level of construct validity (Lee, 1999). Also, key informants were involved and asked to provide feedback. The categories and sub-categories identified by each airport were discussed on a case by case basis with key informants who were familiar with the industry. Informants found not significant discrepancies. Finally, the fact that data saturation was already reached after only 7 interviews suggests a high internal validity of the methodology.

There are several limitations to be aware of. The sample was taken from the largest 50 airports in Europe. While this limitation is beneficial for homogeneity of the sample, findings may not apply to smaller airports, or other regions other than Europa. Furthermore, the interview guidelines were designed to focus on the environments' effect on emotions and shopping behaviour, therefore, other, non-emotional drivers of shopping behaviour may be underrepresented. These include motivational aspects as well as the role of product, pricing and communications strategy. We have noted that classic M-R models use the same approach, however it would be useful to extend the 
model further to cater for other marketing mix elements than the environment as well as interactions. 


\section{V . QUANTITATIVE STUDY}

A quantitiative study was conducted using the intercept survey methodology in August and September 2013. Results confirm that emotions play a pivotal role in determining shopping behaviour in an airport retail environment and customer evaluation of a store. First, the specific objectives of this study and research questions are described. Based on past literature and the qualitative pre-study, a number of hypotheses are proposed for empirical testing, and a methodology for this is being presented. Then, each measure used is being operationalised, and the process of questionnaire development is described. We describe the field work and sampling in some detail, and then use confirmatory factor analysis as well as other techniques to assess the reliability and validity of the measures applied. Next, a conceptual model is tested using structural equation modelling with good results. We include a brief summary. An extended discussion of the results is not included in this chapter, but forms a separate section as it not only discusses the outcome of the quantitative part but also incorporate findings from the qualitative study.

\section{V.1. Objectives and research questions}

One of the objectives of this dissertation is to extend the findings of the literature review and the qualitative pre-study by a quantitative study among customers. In the previous sections, we have presented research suggesting that the interior of a store influences shopper's emotions, and that they are relevant antecedent to shopping behaviour and evaluation of a store. Airports can be time-pressured but also high pleasure/ high arousal environments, therefore emotions are likely to play a dominant role in determining shopping behaviour, compared to cognitive or physiological processes. In fact, in certain settings emotion may be the most important "linking pin" that holds together the entire consumption experience (Holbrook, 1986, p.23 cf. M. A. Jones, Reynolds, \& Arnold, 2006). This would explain why studies have identified a relatively high share of impulse shopping taking place at airports (Crawford \& Melewar, 2003; Thomas, 1997). Despite the growing importance of the airport retail sector and comparable industries (e.g., amusement parks, recreational centres, airplanes), there is a surprising lack of quantitative research into this specific relationship, with the notable exception of Sulzmaier (2001). 
Also, there is still a lack of consensus on the emotional measures to be used to this end. There seems to be some agreement that relevant consumer emotions can be sufficiently explained by two-dimensional measures, and that one of the dimensions should be 'pleasure' or 'positive feeling'. Studies have defined the second dimension to be 'arousal'(Donovan \& Rossiter, 1982), however some criticism has been expressed regarding its content (Bagozzi, et al., 1999; J.-C. Chebat \& Michon, 2003; Izard, 2007). Based on managerial insight provided in the previous section, airport shoppers may experience two forms of arousal (excitement and acute stress) at the same time, with excitement, a feeling of happiness caused by the general atmosphere of airports and the travel ahead, but stress being short-termed and caused by stimuli perceived as obstacles to their journey at the airport. Academicians have confirmed that positive and negative feelings may indeed occur at the same time (Izard, 2007). One can imagine this easily when considering extreme sports (i.e., free climbing), where the excitement could not be imagined without a certain degree of fear.

Next, there seems to be no agreement in the retailing literature on global measures of store environments. Early research in environmental psychology used the single construct "information load" (Donovan \& Rossiter, 1982; Mehrabian \& Russell, 1974), however findings of such studies are difficult to apply in managerial decision making (Bitner, 1990; J. Ward, Bitner, \& Barnes, 1992). More recent studies have developed different scales to match the specific retail setting, including restaurants (Jang \& Namkung, 2009; W. G. Kim \& Moon, 2009; Milliman, 1986) and shopping malls (Michon, et al., 2005; Wakefield \& Baker, 1998). We wish to contribute to this discussion by developing a two-dimensional scale for airport retail environments based on scales previously developed for other retail concepts.

Emotional measures are difficult to apply across countries. To date, cross cultural research of emotions in retail environments focused on comparing customers from different cultures but living in the same country, such as French-Canadian vs. AngloCanadian shoppers (J.-C. Chebat \& Morrin, 2007), and Hispanic customers living in the U.S.A. (Seock, 2009). However in these cases emotions were measured using verbal scales. With increasing number of different cultures in a single study, it gets increasingly hard to develop and test multilingual emotional scales. As we were faced with this challenge we applied a relatively new approach of measuring basic emotions 
without the need for a verbal scale, using pictures of various facial expressions. The experience gained contains valuable methodological insights.

In summary, the quantitative section of this thesis aims to answer the following questions:

- Does the airport retail environment influence consumer emotions, and - in turn have an effect on their shopping behaviour?

- Do these emotions also influence shopper's post-hoc evaluation of the store and the shopping experience?

- How strong is the influence of in-store personnel compared to the physical factors of the store on consumer emotions in airport retailing?

- Can consumer emotions be operationalized with a two-dimensional construct representing pleasure/happiness and acute (short term) stress?

We will next transform these questions into hypotheses, so that they can be empirically tested using quantitative methods.

\section{V.2. Hypotheses of the quantitative study}

We have developed a conceptual model which delivers novel concepts and was tested in a quantitative study (see Figure 9). It should explain the effect of the physical and social aspects of a store's environment onto customer's approach behaviour as well as affect towards the store, mediated by the emotions of shoppers when in the store. It was not intended to be an overarching model covering all factors explaining buyer behaviour at an airport. Most notably, we do not dwell on the cognitive and physiological reaction of customer to the store environment and retail offers, because literature related to airport retail has repeatedly stated that emotions play a dominant role in in-store decision making (Crawford \& Melewar, 2003; Omar, 2001; Schölvinck, 2012; Volkova, 2009). Including these into the model would have made it too complex to measure with satisfactory goodness of fit, without adding significantly more explanatory value. However, an extension of our model offers potential for a future study.

In the following sections of the thesis, we will explain each proposed hypotheses in turn, by making reference to the relevant literature. Each of the causal effects hypothised in the model can also be justified by the view of a significant number of participants in the pre-study. This ensures that the suggested model is both, grounded in the literature and our own qualitative data. 
Figure 9: Proposed model of environmental effect on store patronage

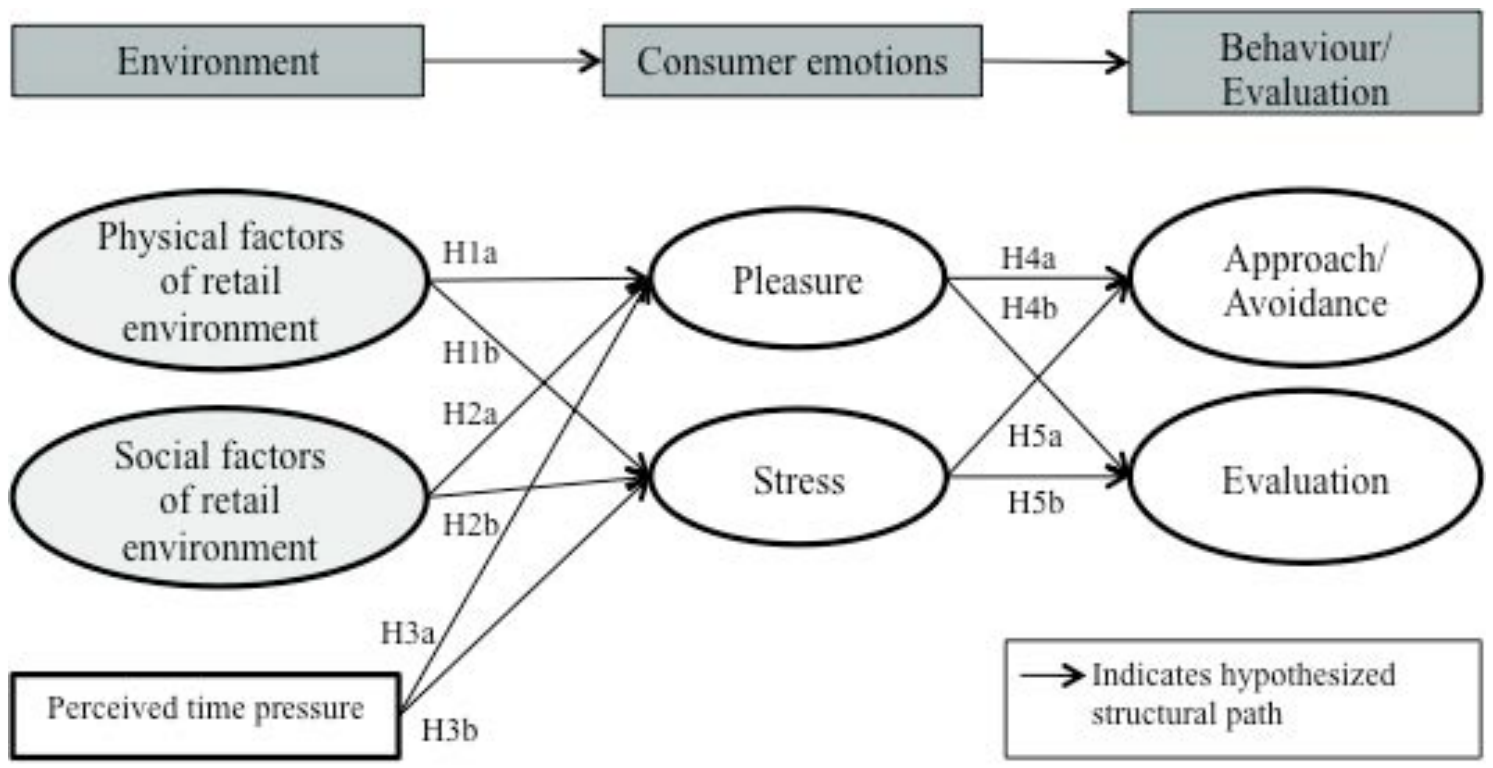

Source: own data

The pre-study suggested that shopping behaviour in airport environments follows the Stimulus-Organism-Response (S-O-R) paradigm, with stimuli variables (the environment) influencing a set of mediating variables (e.g. consumer emotions) which cause certain behaviours and attitudes towards the store (Mehrabian \& Russell, 1974; Woodworth, 1928). All airport retail managers interviewed have stated that environmental cues such as staff behaviour or airport ambience influence the emotional state of customers.

\section{V.2.1. Retail environments and emotions}

According to Bitner and others (Aubert-Gamet, 1997; Bitner, 1992), spacial layout and functionality are influencing the emotions of people in the servicescape. The way seating areas, aisles, walkways and entrances are designed have been shown to have a positive effect on excitement, and in turn intention to repatronise in leisure service settings (Wakefield \& Blodgett, 1994). Attractive design and layout of a shopping mall has been shown to cause excitement and desire to stay (Wakefield \& Baker, 1998). The provision of signage could be especially relevant at airports, as lack of signage may lead to feeling lost and not being in control. The perception of lower personal control has 
been shown to reduce pleasure (Hui \& Bateson, 1991). The pre-study suggests that attractive design includes the provision of lines of sight from retail outlets into the central area, and managing a natural, uni-directional flow of passengers through the building even during peak hours. Attractive facilities and organized merchandise have shown to have a positive effect on perceptions on service quality, and merchandise quality in retail studies (Baker, et al., 2002).

Attractive ambience has been proposed to have a positive effect on store patronage (see Ezeh \& Harris, 2007, for an overview), especially background music, lighting and scent (Baker, et al., 1992; Spangenberg, et al., 2006; L. W. Turley \& Milliman, 2000). As not all ambient cues are relevant to this setting, we selected those which were considered relevant by participants in the pre-study: lighting (e.g., Summers \& Hebert, 2001), air temperature and quality (Baker, 1987), cleanliness of the environment (Meryl P Gardner \& Siomkos, 1986; Wakefield \& Blodgett, 1999) and scent (J.-C. Chebat \& Michon, 2003). Baker (1987) has pointed out that ambient factors of the environment may not cause any effect on emotions when they are at an acceptable level (Morrin \& Ratneshwar, 2003), but effect negative emotions when they are causing discomfort. The attractiveness of a scent can increase dwell time (Spangenberg, et al., 1996). Based on the above, we postulate that:

H1a/b: A favourable perception of the physical factors of a retail environment increases customer pleasure (a) and reduces customer stress (b).

A number of studies have identified 'human factors' to be an important dimension of the environmental cues customers are exposed to in any retail setting (Baker, 1987; Bitner, 1992; Grewal, et al., 2003). People are key to the exchange process in the service industry as personnel delivering the service interact with customers to determine the outcome of the service encounter. Following the approach of Baker (1987) we consider these human factors or 'social factors' part of the servicescape, the environment where the service encounter takes place. In an airport setting, the preliminary study indicated that the behaviour and appearance of staff are most relevant factors. In air travel environments clean, colourful uniforms and proper personal grooming, for example, are assumed to create confidence in customers and alleviate fears (Kotler, 1973). The 
behaviour of staff has been shown to be a major driver of consumer emotions in retail and can lead to either approach or avoidance behaviour (Aubert-Gamet, 1997; J. Ward, et al., 1992). Therefore:

H2a/b: A favourable perception of the social factors of a retail environment increases customer pleasure (a) and reduces customer stress (b).

\section{V.2.2. Time pressure and Emotions}

There are numerous studies showing that time pressure also has a direct effect on purchase behaviours in retail stores (Dhar \& Nowlis, 1999; Nowlis, 1995). It has been argued that customers expecting to wait long for service are less likely to enter a store (Grewal, et al., 2003). The customer's mood may have an influence on the strength of this effect (Hui, et al., 1997). We assume that perceived wait duration as a construct is closely related to perceived time pressure if the customer has a limited time budget: If there is less time available to perform planned tasks, because of unexpected time pressure, customers are likely to get anger or other emotions. Because a large proportion of decisions to buy at airports are made on impulse (Crawford \& Melewar, 2003; Omar, 2001) we argue that intentions to buy will decline with perceived time pressure increasing (Iyer, 1989), mediated by the emotional state of the customer. An airport study found no effect of time pressure on emotions along the pleasure dimension, but a significant effect on items 'frenzied', 'jittery' and 'awake' (Bowes, 1998). We therefore propose to test effects on both positive and negative emotions and argue that:

H3a/b: Higher perceived time pressure reduces customer pleasure (a) and increases customer stress (b).

\section{V.2.3. Emotions and customer behaviour}

The M-R model suggests that pleasant environments cause approach behaviour, while unpleasant environments cause avoidance behaviour (Mehrabian \& Russell, 1974). In a retail setting, pleasure caused by in-store stimuli has been shown to influence consumer 
behaviour, and lead to a desire to browse in the store, spend more time in the store and affiliate with others in the store (Donovan \& Rossiter, 1982). Also, most managers involved in the pre-study have confirmed that consumer emotions are mediators of the effect of the environment on shopping behaviour. Furthermore, individuals in a positive mood tend to evaluate environmental stimuli more positively, and therefore show a higher affect towards a store, evaluate their shopping experience better, than if they were in a negative mood (Bagozzi, et al., 1999). We therefore propose:

H4a/b: A higher level of pleasure has a positive effect on approach behaviour (a) and evaluation of the store (b).

The same studies (Mehrabian \& Russell, 1974, Donovan, 1982 \#584) suggest that also arousal has an influence on behaviour. People feeling alert, excited, stimulated or active are more likely to show approach behaviour. Mall ambience (design, music, layout and décor) have been shown to influence excitement and desire to stay at the mall (Wakefield \& Baker, 1998). Some studies in fact show that arousal is more important than pleasure to predict time spent in a store (Sherman \& Smith, 1987). However, these are in conflict with findings of the pre-study. Respondents stated both 'excited', and 'relaxed' passengers were more likely to approach stores and spend more than not excited, or nervous passengers. It could therefore be, that excited and relaxed, for example, are not items located at opposite ends of the 'arousal' dimension as assumed by environmental psychologists. In addition to the pleasure dimension, we suggest to define a new type of arousal dimension which is relevant to this environment. The highest negative arousals which could occur at airports has to be those feelings triggered when an event or circumstance causes the passenger to be delayed or threatens reaching the departure gate on time. Using the basic natural emotions of Ekman and Friesen (1971) anger and frustration is being caused, combined with a feeling of surprise. We call this construct 'stress'. Our hypothesis is therefore:

H5a/b: A higher level of stress has a negative effect on approach behaviour (a) and evaluation of the store (b). 


\section{V.3. Methodology}

To test the hypotheses, data was collected in a customer survey involving personal interviews with by-passers in a live retail environment. Questionnaires were developed in English, then translated into Hungarian using double-back translation followed by expert verification in case of discrepancies. Answers were recorded to Samsung Galaxy Tab(C) tablet devices during interviews in order to minimize data entry error, and allow real-time supervision of interviewers. Also, the use of modern technology in previous studies conducted by the author has been shown to increase participation rates.

Further variables were obtained from scanner data collected at tills and boarding gates. This provided actual sales data as well as actual time spent at the airport, inside the shop, and the time until departure of the flight. All data was collected and stored with full informed consent of the respondents, following European and Hungarian regulations regarding data privacy. No personal data was stored as a result of the study and all data was analysed in anonymised format.

\section{V.4. Definition and operationalization of variables}

\section{V.4.1. The variables used in the conceptual model were obtained from the literature or developed based on previous studies as well as the qualitative pre-study. Measures of the retail environment}

It has been claimed that there is no agreement on a standard measure of retail environmental cues or servicescapes to date (Ezeh \& Harris, 2007). Instead, studies often develop measures to fit the individual setting of the research. A study investigating the servicescape of a sporting event obtained 28 items from Bitner (1992) and Baker (1987) and found that 14 of them highly correlate and form a single factor with high explanatory value. They include items such as 'available space', 'superior physical environment', 'attractive color scheme', 'excellent lighting' and 'pleasant smell' but none relating to other people present (Hightower, Brady, \& Baker, 2002).

Table 12 provides an overview of the variables with their source as well as the number of initial items used in the questionnaire and their scales. We will now discuss their operationalization in turn. The questionnaire also included demographic variables (e.g., nationality, age), additional control variables (e.g., time spent in store, amount purchased), as well as some other questions for purposes not relating to this dissertation. 


\section{V.4.2. Measures of the retail environment}

It has been claimed that there is no agreement on a standard measure of retail environmental cues or servicescapes to date (Ezeh \& Harris, 2007). Instead, studies often develop measures to fit the individual setting of the research. A study investigating the servicescape of a sporting event obtained 28 items from Bitner (1992) and Baker (1987) and found that 14 of them highly correlate and form a single factor with high explanatory value. They include items such as 'available space', 'superior physical environment', 'attractive color scheme', 'excellent lighting' and 'pleasant smell' but none relating to other people present (Hightower, Brady, \& Baker, 2002).

Table 12: Overview of variables used in quantitative study

\begin{tabular}{|c|c|c|}
\hline Variable & Source & No. of items, scale \\
\hline $\begin{array}{l}\text { Physical Factors of } \\
\text { the Retail } \\
\text { Environment }\end{array}$ & $\begin{array}{l}\text { Baker (1987) } \\
\text { d'Astous (2000) } \\
\text { Kim \& Moon (2009) } \\
\text { Wakefield \& Baker (1998) }\end{array}$ & $\begin{array}{l}\text { eleven items, 5-point scale (1 - } \\
\text { strongly disagree, } 5 \text { - strongly agree) }\end{array}$ \\
\hline $\begin{array}{l}\text { Social Factors of the } \\
\text { Retail Environment }\end{array}$ & $\begin{array}{l}\text { Bitner et al. (2002) } \\
\text { Hightower et al. (2002) } \\
\text { Machleit et al. (1994) }\end{array}$ & $\begin{array}{l}\text { five items, 5-point scale (1 - strongly } \\
\text { disagree, } 5 \text { - strongly agree) }\end{array}$ \\
\hline Time Pressure & Dhar \& Nowlis (1999) & $\begin{array}{l}\text { single item, 5-point scale (1-I don't } \\
\text { feel time pressure, 5- I feel great time } \\
\text { pressure) }\end{array}$ \\
\hline Pleasure (Emotions) & $\begin{array}{l}\text { (Samuelsson, Jarnvik, } \\
\text { Henningsson, Andersson, \& } \\
\text { Carlbring, 2012) } \\
\text { based on Ekman \& Friesen } \\
(1971)\end{array}$ & $\begin{array}{l}\text { Two items (pictures) } 100 \text {-point scale } \\
(0 \text { - feeling is not at all, } 100 \text { - very } \\
\text { characteristic of me) }\end{array}$ \\
\hline Stress (Emotions) & $\begin{array}{l}\text { (Samuelsson, et al., 2012) } \\
\text { based on Ekman \& Friesen } \\
(1971)\end{array}$ & $\begin{array}{l}\text { Two items (pictures) 100-point scale } \\
(0 \text { - feeling is not at all, } 100 \text { - very } \\
\text { characteristic of me) }\end{array}$ \\
\hline Approach/Avoidance & Donovan et al. (1994) & $\begin{array}{l}\text { Three items, 7-point scale (1-not at } \\
\text { all, 7-extremely) }\end{array}$ \\
\hline $\begin{array}{l}\text { Evaluation of the } \\
\text { store }\end{array}$ & Donovan et al. (1994) & $\begin{array}{l}\text { Three items, 7-point scale (1-not at all, } \\
\text { 7-extremely) }\end{array}$ \\
\hline $\begin{array}{l}\text { Arousal/Pleasure } \\
\text { (Affect Grid) }\end{array}$ & (Russell, et al., 1989) & $\begin{array}{l}\text { Two items, 9-point scale, by placing a } \\
\text { cross in a 9x9 matrix }\end{array}$ \\
\hline $\begin{array}{l}\text { Time spent in the } \\
\text { store (recalled) }\end{array}$ & Turley \& Milliman, 2000 & Single, minutes \\
\hline $\begin{array}{l}\text { Time spent in the } \\
\text { store (observed) }\end{array}$ & N/A & $\begin{array}{l}\text { Minutes, start of interview at store exit } \\
\text { - end of interception at store entry }\end{array}$ \\
\hline Spending (recalled) & N/A & Single, Euro or converted to Euro \\
\hline Spending (observed) & $\mathrm{N} / \mathrm{A}$ & Till data \\
\hline \multicolumn{3}{|c|}{$\begin{array}{l}\text { Further control variables collected: gender, age, educational background, economic status } \\
\text { nationality, country of residence. reason for travel, size and composition of travel group, } \\
\text { destination, inbound/outbound travel, airline }\end{array}$} \\
\hline
\end{tabular}


Another single measure has been developed for a study assessing a restaurant's physical environment, containing the five items 'layout/ easy to move around', 'appealing interior design', 'pleasant colours', 'comfortable lighting', 'pleasing background music' (Jang \& Namkung, 2009). These constructs are limited to the physical aspects of environments, and therefore insufficient to be used in a service industry setting: The importance of personnel and customers in the service industry has been firmly established (Bitner, 1990), and items such as the appearance and behaviour of staff (Bitner, 1992) as well as crowding due to other customers (Eroglu \& Harrell, 1986) should be considered to form a second factor. Two-dimensional measures have been used before successfully in international studies (Keillor, Hult, \& Kandemir, 2004).

Following the approach of previous studies (e.g.,Hightower, et al., 2002) the scale of this study was developed by refining items from the existing literature, with the objective to identify at least two factors describing the physical interior of the stores as well as the social factors (people inside the store). We collected items from the literature (Baker, 1987; Bitner, 1992) and searched for them among the coded transcripts of the qualitative pre-study. Only stimuli identified in at least half of the transcripts were retained, and statements were worded based on past studies (see Table 13 for sources).

Table 13: Items measuring perception of an airport store environment

\begin{tabular}{|c|c|c|}
\hline Variable & Item & Source \\
\hline \multicolumn{3}{|l|}{ Physical Factors: } \\
\hline Scent & Ifelt a disturbingly strong scent in the shop. * & d'Astous (2000) \\
\hline Lighting & The lighting is appropriate. & Wakefield \& Baker (1998) \\
\hline Temperature & The temperature in the shop was comfortable. & Wakefield \& Baker (1998) \\
\hline Colour & $\begin{array}{l}\text { The use of colours adds excitement to the store } \\
\text { environment }\end{array}$ & Kim \& Moon (2009) \\
\hline Architecture & $\begin{array}{l}\text { The shop's architecture gives it an attractive } \\
\text { character }\end{array}$ & Wakefield \& Baker (1998) \\
\hline Spacial crowding & $\begin{array}{l}\text { Standing in line at the check-out was un- } \\
\text { comfortable, there was too little space around me.* }\end{array}$ & $\begin{array}{l}\text { based on Machleit, } \\
\text { Kellaris \& Eroglu (1994) }\end{array}$ \\
\hline Comfort & $\begin{array}{l}\text { It is easy to walk around the store and find what } \\
\text { you are looking for. }\end{array}$ & Kim \& Moon (2009) \\
\hline Shape & $\begin{array}{l}\text { The aisles between the shelves are wide enough to } \\
\text { pass through easily, even with luggage. }\end{array}$ & $\begin{array}{l}\text { based on Kim \& Moon } \\
\text { (2009) }\end{array}$ \\
\hline Signage & $\begin{array}{l}\text { The signs and labels used in the shop helped me to } \\
\text { find my way, and do my shopping. }\end{array}$ & based on Baker (1987) \\
\hline \multicolumn{3}{|l|}{ Social factors: } \\
\hline Human Crowding & $\begin{array}{l}\text { I felt uncomfortable because of the many people } \\
\text { around me.* }\end{array}$ & $\begin{array}{l}\text { based on Machleit Kellaris } \\
\text { \& Eroglu (1994) }\end{array}$ \\
\hline
\end{tabular}




\begin{tabular}{|l|l|l|}
\hline Staff appearance & $\begin{array}{l}\text { Well-groomed and well-dressed assistants work in } \\
\text { the shop. }\end{array}$ & Bitner et al. (2002) \\
\hline $\begin{array}{l}\text { Staff behaviour } \\
\text { (item 1) }\end{array}$ & Shop assistants were friendly and helpful. & Hightower et al. (2002) \\
\hline $\begin{array}{l}\text { Staff behaviour } \\
\text { (item 2) }\end{array}$ & $\begin{array}{l}\text { The helpfulness of assistants is almost extreme, } \\
\text { disturbing. * }\end{array}$ & $\begin{array}{l}\text { based on Bitner et al. } \\
\text { (2002) }\end{array}$ \\
\hline $\begin{array}{l}\text { Staff behaviour } \\
\text { (item 3) }\end{array}$ & $\begin{array}{l}\text { Ifelt shop assistants gladly help customers when } \\
\text { needed. }\end{array}$ & $\begin{array}{l}\text { based on Bitner et al. } \\
\text { (2002) }\end{array}$ \\
\hline
\end{tabular}

*reverse coded. Source: own data

The batch of items was discussed with two independent expert panels, one consisting of three practitioners (airport managers) and one of two academicians (marketing professors), and reworded to fit the setting of the study if necessary. Wordings were adjusted until 100\% agreement was reached between the panels and then pre-tested; no issues related to understanding of the statements were reported. The final list of items is displayed in Table 13.

\section{V.4.3. Perceived time pressure}

Perceived time pressure has been defined as a "perceived constriction of the time available for an individual to perform a given task" (Iyer, 1989, p.43). This definition consists of three elements, (actual) time available, an individual's assessment of the time available compared to the expected time needed, and the demands of the task. A number of factors have been identified during interviews which influence perceived time pressure, including providing estimated waiting times, involving customers in provision of the service, giving people tasks to do during the wait, providing entertainment, the choice of colours, asking about customer's well being and playing soothing background music (see Bailey \& Areni, 2006, for an overview). Self-reported measures have been used previously in the literature. Time pressure has been measured with 5 -item scales (Putrevu \& Ratchford, 1997) and 3-item scales (Suri \& Monroe, 2003) successfully, and single item scales, as proposed by Nowlis (1995, Eroglu \& Machleit, 1990). We select a single item scale, as this reduces interview length which can reduce the number of incomplete questionnaires and also has the advantage of parsimony (Fuchs \& Diamantopoulos, 2009). If a single-item measure is "carefully crafted" it can be "at least as valid as multi-item measures of the same construct" (Bergkvist \& Rossiter, 2007, p.618). Participants in the qualitative study stated that time pressure was mainly caused by uncertainty felt by the passengers that they will be able to complete all steps of the mandatory airport process on time for their flight departure. To ensure that the question 
was understood by all respondents in the same way, we therefore expressed this concept and the steps of the mandatory process as well: "How much time pressure are you feeling right now (that is, you think you have to be in a hurry to do all the necessary activities and the ones you planned, e.g. check-in, security screening, passport control, shopping)?" on a 5-point likert scale from "I don't feel time pressure" to "I feel great time pressure". Also the correct understanding of this item was confirmed during pretests.

\section{V.4.4. Emotional measures}

In choosing the measures for emotions in this environment, there appears to be some agreement that consumer emotions can be appropriately captured with two dimensions (Bagozzi, et al., 1999). However there is less agreement on what these dimensions should include. As indicated in the literature review, most frameworks include 'pleasure' (sometimes called 'positive emotion' or 'happiness') as the most relevant emotional dimension in consumer settings (Bagozzi, et al., 1999; Mehrabian \& Russell, 1974; Ridgway, et al., 1989; Russell \& Pratt, 1980). Also, the qualitative pre-study confirmed that positive consumer emotions are related to higher sales. Emotions such as satisfaction, happiness, being pleased, joy, delighted, entertained load positively on with the pleasure scale, with fear, unhappiness, dissatisfaction, sadness, disappointment and boredom load negatively.

As a second dimension, the concept of 'Arousal' has been shown to be relevant in many retail concepts (Baker, 1987; Donovan \& Rossiter, 1982; A. Groeppel-Klein, 2005; Koo \& Lee, 2011). However, arousal scales have shown significantly lower reliability (Cronbach's alpha) than pleasure scales in several studies (e.g.,Dawson, Bloch, \& Ridgway, 1990; Oliver, 1993). This could be because items included in the arousal scale, such as excitement and distress, are measuring fundamentally different things. Our pre-study showed that customers who are excited about their upcoming trip are more likely to shop, those who are stressed and nervous are less likely to shop, or likely to shorten their time in the shops buying only essentials. Furthermore, it has been stated that excitement can be longer lasting, then temporary be overshadowed by short termed stress, and then again 're-appear' after customers enter the departure hall and realise there is no more obstacle to their plans to travel. Contrary to this, the M-R model postulate that excitement and distress are both loading high on the second, the 'arousal' 
dimension (Donovan \& Rossiter, 1982; Russell \& Pratt, 1980), suggesting that it may not meet the needs of this study. To overcome this we turn to stress research. Acute stress can occur if a person appraises an external stimulus as being a threat to achieve an important goal, in this case to complete all tasks on time (see section II.2.4 for a detailed discussion). This can be short lived, by successfully coping with the situation or the stressor disappearing. The pre-study confirms that airport operators provide more information about flights to support coping mechanisms. The provision of flight departure screens in many areas of the building allows customers to check if their flight is delayed and the location of their gate. This in turn increases the number of customers who can cope with their fear of missing a plane by obtaining information. Companies may also chose not to withhold some information, which slows down passenger flow (as they are waiting near screens for more information), but in turn increases uncertainty and stress.

Based on that research the above concept of temporary stress can best be described as a combination of surprise with anger. The subjective experience of surprise can be defined as fleeting sense of interruption of ongoing thought, as a brief uncertainty (Izard, 1977). This description could well describe the feeling of a person who wants to walk from airport entry to his/her departure gate, but then is suddenly and unexpectedly held up by an obstacle. Once the obstacle is removed, or the individual gains more information or experience, the fleeting emotion disappears. Furthermore, stressful events have shown to result in anger and anxiety (Eisler, Skidmore, \& Ward, 1988). For example anger was confirmed to be closely related to work related stress (Diong \& Bishop, 1999; Diong, et al., 2005). Anger is an emotion that is targeted at external stimuli, such as other people, and imply dissatisfaction as well as a desire to remove the cause. Again, this is similar to the concept of coping (Richard S Lazarus \& Folkman, 1984) which can also be aimed at removing the stressor (if the so-called 'active coping' strategy is chosen). In the same way as the combination of high 'arousal' with low 'pleasure' in the M-R framework (Mehrabian \& Russell, 1974) is expected to cause 'avoidance' behaviour, it would be reasonable to expect angry customers to avoid airport retail stores.

Based on the above discussion, we next looked for items which can be used for a valid measure of the pleasure dimension (such as happiness, joy, fear, sadness) as well as acute, short termed stress (such as surprise and anger). The literature review indicated 
that there is no agreement on the 'right' measure for emotions in marketing or psychology. Much of the research using verbal scales to measure consumer emotions (Izard, 2007; Mehrabian \& Russell, 1974; Wakefield \& Baker, 1998) required customers to recall their feelings when they were in a certain situation in the past. However, surprise, for example, is very short lived, and may be difficult to recall. Also responding to a verbal scale involves cognitive processes when answering, such as reading and processing the meaning of the words. Therefore answers may be mediated by cognitive abilities and yield lower validity. Multilanguage surveys are prone to unequality caused by translation, which in case of emotions is especially difficult since they are often multifaceted. Another approach is to measure the psychophysiological reactions assumed to be caused by the same stimuli at the same time, or to be an expression of the emotion. Heart rate and cortisol levels in the saliva have been shown to increase during stressful periods and are regularly used to measure acute stress levels (Dickerson \& Kemeny, 2004; Kirschbaum \& Hellhammer, 1989). However, it would be reasonable to assume that fewer respondents would agree to these invasive measures, and therefore introduce a self-selection bias through sampling. Also the relationship between salivory cortisol and perceived stress has been challenged, for example no correlation could be found in a study among commuting train passengers (G. W. Evans $\&$ Wener, 2006). Another measure of short-term arousal may be the level of electrodermal reactivity (skin conductance), which can be measured with devices attached to a finger. Higher arousal is hypothised to increase electrodermal reactivity. This has been applied in shopping malls, and required the subject to carry an instrument which records measurements (A. Groeppel-Klein, 2005). Despite promising results of this innovative study, the carrying of these devices is not permitted in the airport retail area for security reasons, and could therefore not be considered for this study.

An alternative approach is based on the relationship between emotions and facial expressions which has been suggested in one of the first works on humans emotions by Darwin (1872), and firmly established by research in the 1980's (e.g., Ekman, 1992). Darwin stated that facial expressions occur in combination with other bodily responses as a reaction to external events. For example, we express anger by furrowing the brow and tightening the lip with teeth displayed, because these actions are part of an attack responds. He claimed that all people - regardless of race or culture - had the ability to express emotions in the same way using their faces (Darwin, 1872). Modern psychology 
has identified six emotional expressions to be correctly recognized both within and across cultures: anger, disgust, fear, happiness, sadness, surprise.

Research was done within industrialized countries, and later even confirmed with isolated tribed in New-Guinea (Ekman \& Friesen, 1971) to prove that these were not influenced by mass media but universal emotions. Tests of facial scales comparing the interpretation by Hungarian, Polish, American, Japanese, Vietnamese and Sumatran respondents indicates that there is no significant difference amongst allocating emotions to pictures across cultures (Biehl, et al., 1997).

The distinction between anger, disgust, fear, happiness, sadness and surprise has a universal facial expression (Ekman, 1992) and therefore measurement instruments have been developed based on this concept. One approach is to record consumers, and then code their facial expressions manually (Ekman \& Friesen, 1978) or automatically (Cohn, Zlochower, Lien, \& Kanade, 1999). While these techniques requires respondents to be in a stable position as well as extensive calibration of recording devices and therefore could not be used in the airport retail environment. Insted, we follow a process suggested by Desmet (2005), who assessed feelings towards a car by showing respondents 14 animated cartoon characters each displaying a different emotion, and then asking them to rate them on a 3-point scale (ranging from 'I do feel...' to 'I do not feel the emotion expressed by this animation'). These were shown to have a high correlation with verbal scales and also convergent validity across culture in a study with Dutch and Japanese subjects (Desmet, 2005). 
Figure 10: Hold-out picture scale as displayed on tablet device during interview

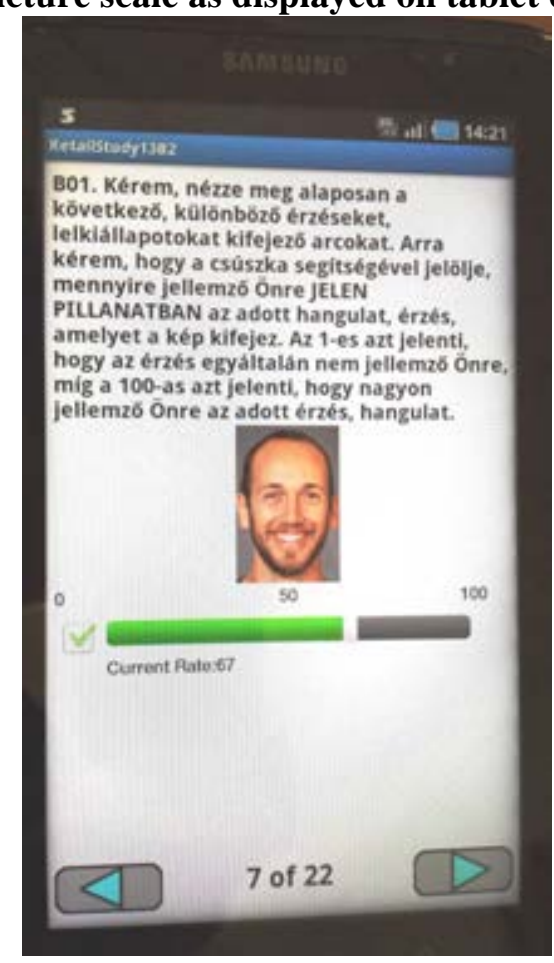

Source: Budapest Airport

Our measure is similar in the sense that respondents were asked to rate pictures of emotions in terms of how well they express their feelings. However, we limit the emotions to those proposed to be human basic emotions in research by Ekman (1992). Respondents were asked "how characteristic of you the mood, feeling the picture shows is", and positioned a slider using their finger to a location between 0 - "not at all characteristic" and 100 - "very characteristic". The use of picture scales can also be applied in self-reported measures, and therefore the benefits of not needing translation, or respondent language skills, can be used without the disadvantages of a facial measurement. See Figure 10 for an illustration of the tablet's design.

When determining a database of pictures to use for the scale, we reviewed the NimStim Face Stimulus Set (Tottenham, et al., 2009), the Karolinska Directed Emotional Faces (Goeleven, et al., 2008) and the Umeå University Database of Facial Expressions UUD (Samuelsson, et al., 2012). The quality of the database can be evaluated by comparing the mean proportion of correct interpretation of pictures in each scale, which was reported in all three cases by the authors. Raters were asked to identify how much each of the pictures represents each of the six basic emotions on Likert-type scales. The UUD (Samuelsson, et al., 2012) achieved the highest overal mean proportion of correct interpretations of $88 \%$, compared to $79 \%$ for NimStim (Tottenham et al., 2009) and 
$72 \%$ for the Karolinska Directed Emotional Faces (Goeleven et al., 2008). We therefore used the UUD with the owner's permission. UUD contains 424 facial images recorded of 60 amateur models of Swedish, Central European, Asian and Arabic origin. Models were instructed to display seven different facial expressions (angry, surprised, happy, sad, neutral, afraid and disgusted) following the concept of Ekman and Friesen (1971). One concern is the distorting effect that any difference of gender (Williams, et al., 2009) and age (Mill, Allik, Realo, \& Valk, 2009) of rater and model may have on accuracy of interpreting the emotion displayed. To minimize these effects, we first split the database into four groups according to gender and age (39 or less/40 or more) of the model. We then selected pictures with the highest rate of correct interpretation, one for each emotion, resulting in a set of $2 \times 2 \times 6=24$ pictures. Next, the set was pre-tested with employees of airport and a market research company, and any pictures which were found to distract the viewer from the task of rating the emotion, for example because models had a funny mustache, were replaced by the next highest ranking picture for that group and so forth. We then retrieved again the rate of correct interpretation of each individual picture from the above mentioned verification study (Samuelsson, et al., 2012). The mean rate of correct interpretation of the final set was $96.4 \%$ (Std.Dev. 4.2) which suggests that respondents will have a high likelihood to correctly interpreting the meaning of the picture. We used all six pictures of the scale, however pictures „disgust” and „fear” were not relevant for this study and discarded aftewards (see Appendix for an anonymised version of the scale used).

\section{V.4.5. Measures of behaviour and evaluation}

Consumer's behavioural intentions in relation to retail environments have been most frequently measured using the approach/avoidance framework (Mehrabian \& Russell, 1974), followed by time spent and sales (Turley \& Milliman, 2000). The M-R measure covers three factors, firstly, the intention to physically stay and explore the environment, secondly, the evaluation of and affect towards the place and also the intended time spent browsing. We adopted this measure to our study with some adjustments to fit to the settings of the study. Donovan and Rossiter (1982) used seven items to measure their APR/AVD measure, covering all above factors. We incorporated this measure except two: Time was excluded because time spent in an airport duty free store is likely to be strongly determined by several factors not related to the shopping experience, such as departure time of the flight, or desire to find the departure gate for 
peace of mind, and controlling for these effects would add complexity to the conceptual model reducing model fit. Instead, this study considers the concept of time as an independent variable influencing shopper's emotions, which is more relevant based on the pre-study. Next, we excluded 'Feel friendly to a stranger' as this could be understood to be a statement about the individual's personality rather an indicator of behaviour. Also, transportation research postulates that travellers on trains avoid sitting close to strangers as this is an intrusion to personal space (Gary W. Evans \& Wener, 2007), therefore this variable may have a reduced reliability in a travel environment.

Lastly we considered the issue of dimensionality. Items related to the affect towards the store have been shown to have a higher internal consistency than the overall score (Donovan \& Rossiter, 1982). Also, conceptually items 'enjoyment of shopping', 'liking a store' appear to be evaluations of a shopping experience, as the outcome of cognitive and emotional processes, rather than physical behaviour. We will therefore treat these three items as a separate construct (termed 'evaluation').

The seven items were rephrased to relate to actual rather than intended behaviour, because we intended to measure to link the perceived environment of a particular store with behaviour in that store. This was done with the objective to achieve a higher generalizability of results. For example "Would you want to avoid looking around?" was rephrased to "Did you avoid looking around?". The final batch of questions is shown in Table 14.

Table 14: Operationalisation of Approach/avoidance and evaluation constructs (dependent variables)

$\begin{array}{lll}\text { Concept Item scale } & \text { st }\end{array}$

\section{Approach/ Avoidance}

1. Store patronage Would you avoid ever having to return to this store? If you had enough time, how long would you want

7-point scale (1-not to stay in such a shop? at all, 7-extremely)

2. Exploration Did you avoid looking around or exploring this environment?

3. Affiliation Is this a place where you might try to avoid other people and avoid having to talk to them?

Evaluation

1. Enjoyment Did you enjoy shopping in this shop?

2. Liking

Did you like this store environment?

7-point scale (1-not at all, 7-extremely) 
In order to assess the validity of the picture scales described in section V.4.4, we have included a second emotional measure, based on the pleasure/arousal concept which is part of the traditional M-R model. We applied the Affect Grid, which is an instrument developed for short questionnaires, while at the same time providing good validity compared to longer verbal scales (Killgore, 1998; Menon \& Kahn, 2002; Russell, et al., 1989). The measure is based on the assumption that a large share of consumer's emotions can be measured along two dimensions, namely, pleasure and arousal (Russell \& Pratt, 1980). The 'affect grid' involves the respondents marking their current emotional state on a square shaped grid consisting of 9 x 9 small squares (See Appendix for details). Respondents are explained that they should mark squares right of the centre if they are feeling very pleasant and left of the centre if they are feeling unpleasant. Marks above the horizontal axis represent feelings of arousal, while marks below feelings of sleepiness. A mark in the centre of the grid means an everyday, neutral feeling, and the stronger feelings are, the further away from the centre marks are. Although the explanations take a fair amount of time, this grid allows respondents to use only one mark to advise their feelings, and also permits reporting 'in-between' emotions, for example respondents feeling 'excited' would mark somewhere in the upper right corner, and 'stressed' respondents use the upper left corner. Results are reported as two scores between 1 (low) to 9 (high) for each of the two dimensions pleasure and arousal. The scale has been reported to correlate strongly with the original scales developed by Mehrabian \& Russell (1974) on both the pleasure (corr. $=.77, \mathrm{p}<$ $.001)$ and arousal (corr. $=.80, \mathrm{p}<$.001) (Russell, et al., 1989).

In order to assess external validity of approach/avoidance measures, further variables were collected. Perceived time spent in the store is used as a control measure rather then behavioural output in reaction to the environment (as in Turley \& Milliman, 2000). We asked respondents to recall the total time spend in the store, as well as the time spend browsing. Any difference between the two could be explained by the time waiting at the check-out in case of payment. Also, respondents had their boarding passes scanned at the entrance of the store, and at the beginning of the interview when leaving the store. The difference between the two resulted in the actual time spent in the store. Furthermore, respondents were asked to recall the amount spent in the store when exiting. Responses were coded in Euro, with answers using other currencies converted 
at the daily average rate of exchange. Also, the actual spend by respondents was obtained from the check-out till data after all interviews were completed.

Standard demographic data was collected, including gender, age, educational background, economic status (income relative to peer group), nationality, country of residence. We also collected data regarding the upcoming trip, in order to assess the quality of the sample, including reason for travel (business, leisure, visiting friends and relatives), size and composition of travel group (family, friends, colleagues), destination, flight beginning of trip or end of trip (inbound/outbound travel) and airline.

\section{V.4.7. Questionnaire translation}

Respondents had a choice between English and Hungarian language questionnaires. These two languages were chosen because previous surveys done at the airport offered 7 languages, but these two were chosen by over 95\% of customers (Anonymous, 2012a). Each scale was developed in English first, because the literature used was in English. Then, Hungarian versions of items and scales were obtained from the literature, but only if they were published in peer-reviewed journals and applied in actual survey with satisfactory results. Demographical items which have been asked before in similar airport surveys were copied from those surveys (Anonymous, 2012a). Level of education, income levels, and questions relating to respondent's age are not literal translations but were rephrased to 'mean the same thing' in the other language. Next the remainder of the English version including annotations and instructions was translated into Hungarian by an independent researcher not involved in the project. Then, the Hungarian questionnaire was translated back into English, and any discrepancies between variables discussed in workshops, which agreed on the best translation with if necessary - reference back to the original English source article. Finally, both versions have been successfully tested in the field for correct understanding.

\section{V.5. Data Analysis and Results}

\section{V.5.1. Sample and Fieldwork}

This study is set in a real airport retail environment involving real shoppers to ensure a high external validity of the results. The store selected for the field work is the main Duty Free store located at Budapest Airport in Hungary. The store was opened in March 
2011 as part of a reconstruction of the central terminal section, features 1400 sqm of shop floor, and is open 24 hours serving departing passengers and airport staff. It is operated by German travel retailer Gebr. Heinemann under a long-term concession agreement. The store offers perfume, cosmetics, liquor, tobacco, fine foods, confectionary, clothes, toys and other gift items (Moodie, 2011). The store is located immediately behind the central passenger screening area, requiring all departing passenger to pass through (walk-through concept, see the area between intercept 1 and intercept 2 in Figure 11). The choice of this store has several benefits. All passengers have to pass through, therefore each participant has the same possibility to stop and look at the store offers, and purchase something. Also, all participants pass by the researcher's desk when exiting, which should reduce respondent mortality. Both, operators of the store and the airport supported the project. Similar stores can be found in many major international airports, ensuring that results will have higher generalizability.

The choice of this airport has several advantages. Based on a large scale 2012 passenger survey (Anonymous, 2012a), it can be assumed that there is a large variation of passenger characteristics present at this airport in the most important categories, which according to Freathy \& Connell (2012) are airline type and reason for travel. There was significant traffic both on low-cost (52\%) and traditional airlines (48\%), and there was an approximately equal share of passengers travelling for business (31\%), leisure (32\%) and visiting friends and relatives (37\%); the share of local passengers is not overly dominating (see Table 15). Only $1 \%$ of passengers transfer through the airport, therefore almost all customers are entering the airport through the main entrance, where recruitment took place. Also, the airport's share of retail revenues of the total revenues grows with a growing number of passengers, until annual passenger traffic reaches 8 million, thereafter revenue share growth remains stable (Doganis, 1992). Because this airport carries over 8.5 million passengers annually, we can assume that size will not bias the study. Finally, the company is privately owned ${ }^{3}$ and managed by AviAlliance, a worldwide airport operator group. This suggests a high level of professionalism and industry expertise in design and operation.

\footnotetext{
${ }^{3}$ The shareholders of the airport are AviAlliance GmbH (49.666\%), Malton Investment Pte Ltd. (18.167\%), Caisse de dépot ét placement de Québec (18.167\%), KfW IMPEX-Bank GmbH (4\%), Aero Investment S.á,r,l, (10\%).
} 
The data for this study was collected as part of a wider market research project run by the airport operator from August $23^{\text {rd }} 2013$ to September $8^{\text {th }} 2013$, under the leadership of the author. Fieldwork was distributed over all days of the week and hours of the day (Monday through Sunday, from 4 am - 10 pm) and interviewers were professionals, who were recruited, trained and supervised by a leading local market research firm. The data was provided for this publication at no charge.

The field force was controlled using several techniques: Firstly, time, location and duration of each interview was wirelessly recorded and cross checked for any anomalies, any questionable datasets were removed. Interviewers were observed by a supervisor and the author at random times. At least $10 \%$ of the data collection took place while under supervision. Finally, correlations between interview duration, missing values and interviewer were checked. These steps were taken to assure that cheating was minimized (Malhotra, 2009).

Figure 11: Locations of recruitment and interviews inside airport terminal

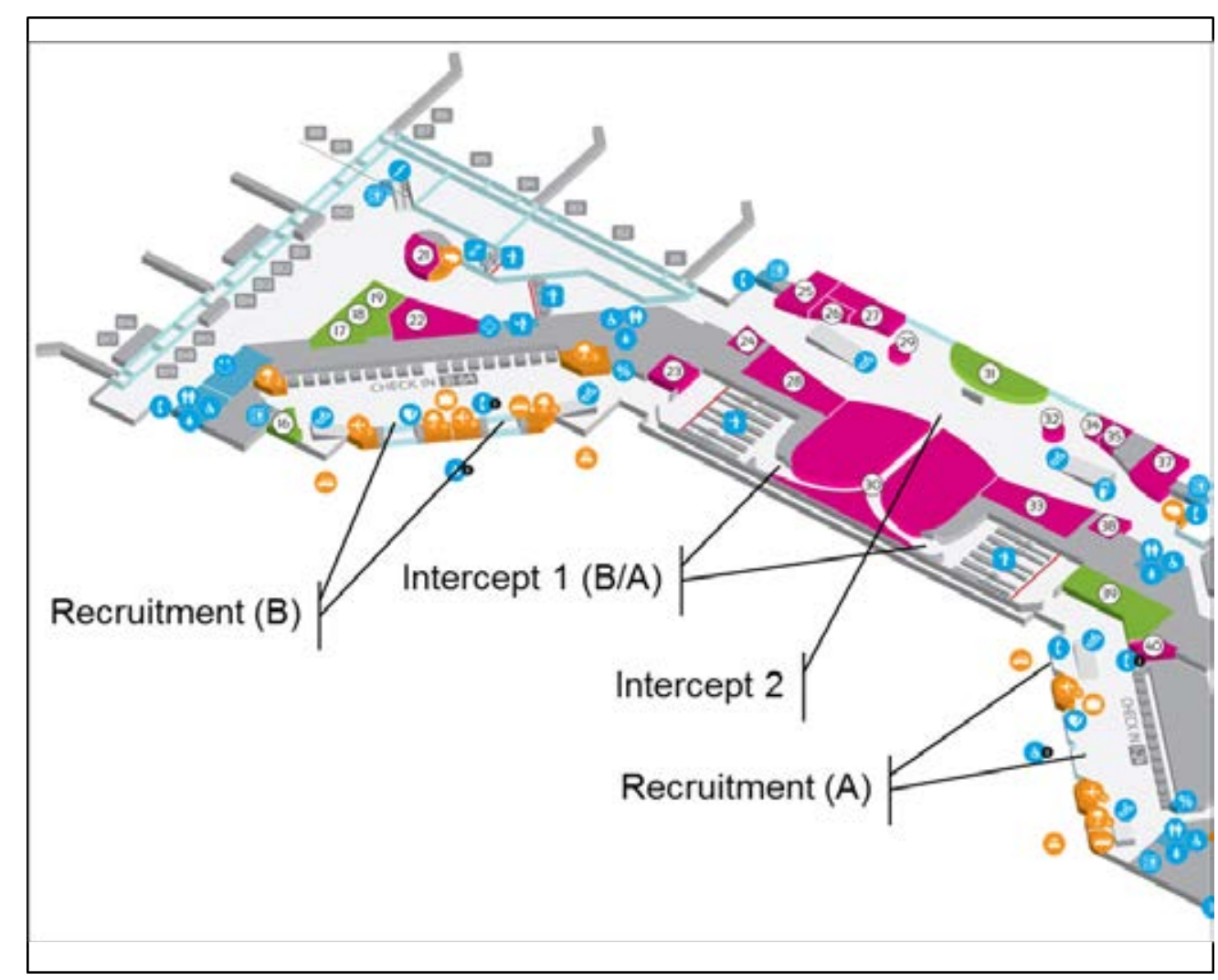

Source: own illustration using airport map retrieved online from http://www.bud.hu/english/ passengers/before_flight/interactive_map/t2_departure 


\section{Recruitment procedure}

The survey population - people who had a likelihood of being selected - were passengers departing from the airport between August $23^{\text {rd }} 2013$ and September $8^{\text {th }}$ 2013, entering through the main entrance of the terminal building (i.e. not transferring between flights). To participate, people were required to have sufficient time to complete the interviews (at least 70 minutes left until departure) and be aged 18-65. The quota sampling method was followed, i.e., to participate, passengers had to fit eligibility criteria, and recruitment was continued until the final composition of the sample matched the quota provided. Interviewers recruited participants by approaching the next person they saw entering the terminal building (marked 'Recruitment' in Figure 11). After completing a short screening questionnaire, they turned around, selected and approached the next person they saw. This procedure aims to minimize selection bias, as interviewers did not control or manipulate the passenger flow. After being asked for informed consent, respondents received a bar coded identification card and were told that a small gift would be given at the end to increase response rates. Respondents were then asked to process as normal, and report to the interviewers positioned at the exit of security screening (marked Intercept $1 \mathrm{~A} / 1 \mathrm{~B}$ in Figure 11). There, time of store entry was recorded, and passengers progressed until a full interview was performed at the single exit of the store (Intercept 2 in Figure 11). The respondent was required to participate in an additional interview before boarding his/her flight, but data collected was not reported in this study. All questions and instructions were read out and answers were recorded using a handheld tablet device.

A quota was chosen to reduce selection bias, but also to control for the effect of the survey being partly during school holidays. The quota matched the composition of the airports annual passenger survey sample regarding gender, age, airline type, reason for travel and interview language (Anonymous, 2012a) and was sufficiently achieved in the sampling (Table 15). Although intercept surveys cannot be considered representative, the above steps were taken so that the findings can provide some insight about the total population as well, within limitations.

Table 15: Composition of the quota and respondents

\begin{tabular}{|l|l|l|l|l|}
\hline & & $\begin{array}{l}\text { Quota* } \\
(\text { Share, \% })\end{array}$ & $\begin{array}{l}\text { Sample (N=947, } \\
\text { Share, \%) }\end{array}$ & Achievement (\%) \\
\hline Airline Type & LCC & 52 & 52 & 101 \\
\cline { 2 - 5 } & & & 52 &
\end{tabular}




\begin{tabular}{|c|c|c|c|c|}
\hline & FSC & 43 & 42 & 97 \\
\hline & Charter & 5 & 6 & 120 \\
\hline \multirow[t]{2}{*}{ Gender } & Male & 46 & 45 & 98 \\
\hline & Female & 54 & 55 & 102 \\
\hline \multirow[t]{2}{*}{ Citizen } & Hungarian & 54 & 54 & 99 \\
\hline & Foreigner & 46 & 46 & 101 \\
\hline \multirow{2}{*}{$\begin{array}{l}\text { Reason for } \\
\text { Travel }\end{array}$} & Business & 19 & 20 & 103 \\
\hline & Leisure & 81 & 80 & 99 \\
\hline \multirow[t]{2}{*}{ Destination } & Schengen & 70 & 69 & 98 \\
\hline & Non-schengen & 30 & 31 & 105 \\
\hline \multirow[t]{2}{*}{ Type of Passenger } & Departing & 99 & 100 & 99 \\
\hline & Transferring & 1 & 0 & 0 \\
\hline
\end{tabular}

As the topic of this dissertation investigates effects of the store environment on behaviour, it requires respondents be exposed to the store for a sufficient amount of time. Consequently, only respondents who answered that they ,stopped to check out the selection, or any of the products, prices" were included, leaving us with a sample size of $\mathrm{N}=294$. All following analysis is based on this sub sample, unless indicated otherwise.

\section{Composition of the sample of this study}

The composition of the sub sample is displayed in table Table 16. It shows a good degree of variation. The share of female respondents and those aged between 20-29 years is higher than the recruited sample, which could be caused by a higher tendency of females and younger people to spend time in stores. Participants in the survey were mostly on the way home after visiting Hungary (only 36\% were residing in Hungary, $7 \%$ in Romania), $82 \%$ travelled for leisure, $18 \%$ on business, and the most frequent final destinations were Germany (11.6\%), U.K. (8.2\%), Greece (7.1\%) or Spain $(5.4 \%)$. $54.5 \%$ used low cost carriers ('LCC'), mostly Wizz Air (27.6\%) followed by Ryanair (11.6\%), $40.8 \%$ full service carriers ('FSC'), and $4.8 \%$ charter airlines. $87.1 \%$ used the check-in desks to drop off bags or get boarding passes (after recruitment, but before the interviews), and $28.2 \%$ had to pass border control (after the interviews). For $23.5 \%$ this is the only flight during the last 12 months (mean: 8.1, std.dev.:12.0). For 50\% this was the only flight to/from this airport during the last 12 months, for $20.1 \%$ the second, most respondents are relatively unfamiliar with the store (Mean: 2.9, Std.Dev: 3.6). 
Table 16: Demographical composition of the sub-sample

\begin{tabular}{|c|c|c|}
\hline Scale Item $(\mathrm{N}=294)$ & & Frequency $(\%)$ \\
\hline \multirow[t]{2}{*}{ Gender } & Male & 42.5 \\
\hline & Female & 57.5 \\
\hline \multirow[t]{6}{*}{ Age } & 18-19 years old & 2.7 \\
\hline & $20-29$ years old & 38.1 \\
\hline & 30-39 years old & 35.0 \\
\hline & $40-49$ years old & 11.9 \\
\hline & $50-59$ years old & 8.5 \\
\hline & 60-65 years old & 3.7 \\
\hline \multirow[t]{2}{*}{ Citizenship } & Hungarian & 47.3 \\
\hline & Foreign & 52.7 \\
\hline \multirow[t]{5}{*}{ Country of Residence } & Hungary & 36.4 \\
\hline & United Kingdom & 7.8 \\
\hline & Germany & 7.1 \\
\hline & Romania & 6.8 \\
\hline & Other & 41.8 \\
\hline \multirow[t]{3}{*}{ Employment } & Employed & 77.9 \\
\hline & Student & 15.0 \\
\hline & Other & 7.1 \\
\hline \multirow[t]{3}{*}{ Maritial status } & Married & 49.0 \\
\hline & divorced/ widowed/ seperated & 7.1 \\
\hline & Single & 43.9 \\
\hline \multirow[t]{6}{*}{ Education } & eight years of elementary or less & 1.4 \\
\hline & vocational school & 2.7 \\
\hline & technical school & 8.2 \\
\hline & secondary grammar school & 23.5 \\
\hline & college/university & 61.6 \\
\hline & post graduate/PhD & 2.7 \\
\hline \multirow[t]{6}{*}{ Standard of living } & a lot lower than average & 0.7 \\
\hline & a little lower than average & 2.4 \\
\hline & Average & 62.9 \\
\hline & a little higher than average & 31.0 \\
\hline & a lot higher than average & 2.4 \\
\hline & don't know/no answer & 0.7 \\
\hline
\end{tabular}

source: own data

On average, participants were recruited two hours before their flight departed (upon arrival at the airport), then $87 \%$ used the check-in or baggage drop off desks queueing for an average of 14 minutes All participants passed security screening which involved 7 minutes of queuing on average before entering the store. Respondents reported spending an average of 12 minutes in the store. Self-reported time and money spent could be lower than actual as impulse shopping may not be socially desirable. 
Following the process recommended by Bush et al. (1985) we compared reported with actual data. We obtained time spent between intercept 1 and intercept 2 (see Figure 11) as well as actual sales data for each respondent from tills. We could match actual sales data to $79.3 \%$ of respondents. Based on this, time in the shop was assessed accurately, but average spending was understated (see Table 17). When ranking the respondents in order of the difference between actual and reported spending, the median value is 0 , and an equal number of participants over and understated the actual spending. This suggests that differences between actual and reported spending are more likely to be because payment at the till was made by another person and therefore not recorded.

There are various thresholds for minimum sample size in case of structural equation modeling in use today (Homburg \& Klarmann, 2006), therefore we use two methods to confirm that the sample is sufficiently large. Sample size $(\mathrm{N})$ is five times the number of parameters estimated (p) (Bentler \& Chou, 1987), because N=294 and p=48. Secondly, sample size should be $\mathrm{N}>\mathrm{p}+50$ according to another recommendation (Backhaus, Erichson, \& Weiber, 2011), which is also fullfilled.

Table 17: Behaviour of respondents (time/spending)

\begin{tabular}{|l|l|c|r|r|}
\hline Source & Item & N & Mean & Std.Dev. \\
\hline \multirow{5}{*}{ Self reported data } & Time spent browsing (min) & 294 & 10.4 & 6.5 \\
\cline { 2 - 5 } & Time in the shop (min) & 294 & 12.1 & 7.0 \\
\cline { 2 - 5 } & Spending (EUR) & 116 & 39.0 & 50.9 \\
\cline { 2 - 5 } & Time in check-in queue (min) & 256 & 13.8 & 11.7 \\
\cline { 2 - 5 } & Time in security screening queue (min) & 294 & 6.7 & 5.0 \\
\cline { 2 - 5 } & Total time spent with CheckIn/Sec (min) & 294 & 40.2 & 33.0 \\
\hline \multirow{5}{*}{ Scanner data } & Time in the shop (min) & 294 & 11.6 & 10.4 \\
\cline { 2 - 5 } & Spending (EUR) & 92 & 58.4 & 153.7 \\
\cline { 2 - 5 } & Recruited before flight departure (min) & 294 & 129.8 & 43.9 \\
\hline
\end{tabular}

\section{Evaluation of fieldwork quality}

Previous studies suggest that airport intercept surveys deliver similar results to household surveys, and have less influence of memory effects on responses. However, "last minute passengers" are more likely to be missed in intercept surveys, which are primarily business travellers (Denstadli, 2000). Mall intercept surveys have been found to be superior to telephone surveys, as less items are being refused, and questions about socially undesirable behaviour are answered more accurately (Bush \& Hair Jr, 1985). 
The drop-out rate is an indicator for the quality of the sampling, calculated to be the number of unfinished surveys divided by the number of recruited participants. Out of 1838 participants recruited to complete the survey, 985 participants completed interviews at all contact points. Therefore, the drop-out rate was $46.4 \%$ which is relatively high. However this was caused by the requirement that participants had to successfully report to three locations and complete lengthy interviews. Therefore, reasons for dropping out could be related to lack of time, or because they did not want to participate, but found it easier to say yes and then not appear at the next interview location.

In order to verify if there is any significant difference in the responses between respondents to the English language and the Hungarian language questionnaire, which would indicate translation errors, we performed an analysis of variance (ANOVA). First, we test if the dependent variables used (approach/avoidance and evaluation) have different means for respondents being either a native English or being native Hungarian speakers. Non-native speakers were excluded to control for language skills effects. The Null hypothesis (equal category) that there are no differences in the mean values between the two groups could not be rejected ${ }^{4}$, indicating that there is no bias caused by the language of the questionnaire.

History refers to specific events that are external but occur at the same time as the study (Malhotra, 2009). History may affect the dependent variable. Therefore, an industry news database (http://centreforaviation.com) was searched for major events affecting air travel, and three strikes were identified during the period (September $10^{\text {th }} 2013$ in Paris, September $2^{\text {nd }} 2013$ in Copenhagen, August 21 2013 in Hamburg). The airport confirmed to the author that all flights to these destinations operated as planned and therefore we assume they had no significant effect on respondents. A sales promotion was run in the duty free store during the first half of the field time. Buyers could win further prices when presenting their receipt to a hostess at the exit. We can assume that bias is present if more participants during the promotional period buy something in the store than they would after the promotional period. We split the cases into two groups (during/after sales promotion) and test the HO Hypothesis that there is no difference

\footnotetext{
${ }^{4}$ Results of the ANOVA statistically fail to reject the Null hypothesis for variables enjoyment of shopping $(\mathrm{F}=.767, \mathrm{df}=1, \mathrm{p}=.383)$, liking of store $(\mathrm{F}=.090, \mathrm{df}=1, \mathrm{p}=.764)$, positive experience $(\mathrm{F}=$ 2.546, $\mathrm{df}=1, \mathrm{p}=.112)$, returning to store $(\mathrm{F}=3.293, \mathrm{df}=1, \mathrm{p}=.071)$, affiliating with others $(\mathrm{F}=.470$, $\mathrm{df}=1, \mathrm{p}=.494)$, and explore $(\mathrm{F}=.045, \mathrm{df}=1, \mathrm{p}=.832)$.
} 
between the two groups regarding buying/not buying. Chi Square was 3.467 ( $\mathrm{df}=1, \mathrm{p}=$ .063) and we therefore fail to reject $\mathrm{H} 0$ at a $\mathrm{p}=.05$ confidence level. In fact, more participants bought something after the promotional period then during, which indicates that the study may have distracted them from considering participating in the promotion as well.

Non-response bias can occur if the characteristics of the sample differ from those of the entire population because people's refusal not to participate is not random. Anecdotally, interviewers reported that it was 'quite difficult' to recruit participants at the entrance doors as passengers were eager to complete airport formalities first. Most refusals were because passengers were in a hurry or wanted to clear formalities first. Other reasons could be language problems. Unfortunately, the number of refusals was not recorded, therefore we cannot report the response rate.

Selection bias can occur if an interviewer selects respondents based on some criteria other than at random. Although we attempted to reduce both errors by using the quota sampling method and putting emphasis on good selection, training and supervision of interviewers, it is possible that the aforementioned survey errors have occurred and we will now statistically assess these. Because the number and characteristics of refusals was not recorded, we cannot differentiate between non-response and selection bias. Bias can be assessed in two ways, either by comparing the sample with the entire population, or by comparing the sample with another, a benchmark sample. First, we tested for bias caused by estimates of a frame variable calculated on the respondent pool differing from the value calculated on the entire population. As we do not have data for all passengers, we use a completely random sample of passenger data obtained during the field period (control group). Flight number and check-in sequence number of every 526th passenger passing through passenger security during the time of the field work was obtained anonymously ( $\mathrm{N}_{\text {control_group }}=500$ ), and enriched with till data (the amount spent in the duty free store). The type of airline (low cost or full service airline) could be related to reason for travel, age or income levels and therefore considered a frame variable. Furthermore, spending is a relevant as it could be highly related to approach and evaluation of the store. Chi Square test was performed to test if $\left(\mathrm{H}_{0}=\right)$ there is a relationship between the type of airline chosen and the participation in the study. Statistically this hypothesis was rejected (chi square $=.329$, $\mathrm{df}=1, \mathrm{p}=.566$ ), therefore indicating that there is no bias present. Next, the amounts spent by shoppers included in 
the study $(\mathrm{N}=92)$ were compared with those in the control group which did buy something $\left(\mathrm{N}_{\text {control_group_2 }}=90\right)$. First, outliers which exceed three times the standard deviation were replaced with the value three times standard deviation. The mean spending of the study is 47.40 Euro (Std.Dev. $=70.49$ ) while the mean of the control group_2 is 49.76 Euro $($ Std. Dev.= 56.21). Then a t-test for independent samples is performed, assuming equal variances of the two samples. Due to the results $(t=-.249$, $\mathrm{df}=180, \mathrm{p}=.803)$ the hypothesis that there is any difference between the means of the two samples was rejected. Thus, there does not appear to be any nonresponse or selection bias on the sample means calculated for these estimates.

\section{V.5.2. Analysis of the measurement models}

The measurement models contain the latent constructs and specified the indicators of each construct. Firstly, the reliability and validity of the constructs and fit of measurement models is being examined. We will in turn discuss the environmental measures, the emotional measures and the behavioural measures.

\section{Measures of environmental cues}

In order to determine the scales to be used for environmental cues, we obtained a batch of 14 items from previous literature and reworded them to meet the airport retail setting grounded in findings from the qualitative study. It includes seven items which related to the effect of other people (customers and staff) in the store, and nine items related to the physical design and ambience of the store. Exploratory factor analysis (principal component analysis) was performed using SPSS20 to identify dimensionality of the items. Surprisingly, a three component solution with eigenvalues of over 1 provided a better fit of the data than a two component solution (see Table 18). Component 1 appears to represents the physical features of the store, with lighting, layout and cleanliness having high scores. In order to improve the internal consistency of this factor, we removed items with a factor score of less than 0.6 , as well as those also loading on other components (scores of $>.2$ on other components).

Table 18: Store environment - results of Explorative Factor Analysis (Principle Component Analysis)

\begin{tabular}{|c|c|c|c|c|}
\hline \multirow[b]{2}{*}{ Item (question) } & \multicolumn{3}{|c|}{ Component } & \multirow{2}{*}{$\begin{array}{c}\text { Item } \\
\text { retained }\end{array}$} \\
\hline & 1 & 2 & 3 & \\
\hline $\begin{array}{l}\text { The lighting is appropriate. } \\
\text { It is easy to walk around the store and find what you are looking for. }\end{array}$ & $\begin{array}{l}.759 \\
.746\end{array}$ & $\begin{array}{l}-.184 \\
-.075\end{array}$ & $\begin{array}{l}.133 \\
.142\end{array}$ & $\begin{array}{l}\text { yes } \\
\text { yes }\end{array}$ \\
\hline
\end{tabular}


The shop's architecture gives it an attractive character.

\begin{tabular}{|c|c|c|c|}
\hline .715 & -.145 & -.009 & yes \\
\hline .663 & .021 & .103 & yes \\
\hline & & & no \\
\hline .643 & -.291 & -.033 & \\
\hline .571 & .108 & .071 & no \\
\hline & & & no \\
\hline .505 & -.007 & .222 & \\
\hline-.020 & .708 & -.059 & no \\
\hline-.014 & .681 & -.008 & no \\
\hline-.126 & .671 & -.005 & no \\
\hline & & & no \\
\hline-.104 & .617 & -.175 & \\
\hline-.078 & .079 & .687 & yes \\
\hline .346 & -.299 & .553 & yes \\
\hline .373 & -.215 & .470 & yes \\
\hline
\end{tabular}

The temperature in the shop was comfortable.

The signs and labels used in the shop helped me to find my way, and do my shopping.

The use of colours adds excitement to the store environment.

The aisles between the shelves are wide enough to pass through easily,

even with luggage.

I felt uncomfortable because of the many people around me.

I felt a disturbingly strong scent in the shop.

The helpfulness of assistants is almost extreme, disturbing.

Standing in line at the check-out was uncomfortable, there was too little space around me.

I felt shop assistants gladly help customers when needed.

Well-groomed and well-dressed assistants work in the shop.

Shop assistants were friendly and helpful.

Rotated Component Matrix. Extraction Method: Principal Component Analysis.

Rotation Method: Varimax with Kaiser Normalization.

source: own data

Component 2 represents four reverse coded items, lack of comfort because of crowding, and lack of space near the check-out may be related as they are referring to human and special crowding. The third item strong scent does not seem to relate to the lack of space, and even less so the fourth item, disturbing helpfulness of assistants. The fact that these are loading on the same factor could be due to some response bias, as they were reverse coded, and in any case these items were not supposed to measure the same construct. Therefore the criterion of face validity is not fulfilled and the items were removed.

Component 3 consists of three items related to the sales staff present in the store. Two items about appearance and behaviour of staff also have a small loading on component 1, which suggests a correlation between two. However because they all related to the perception on employees while Component 1 relates to physical aspects of the store, they logically belong to the third component. Removing them would result in a single item construct 'helpfulness' which would lead to lower content validity. The methodology of structural equation modelling allows for some correlation of latent variables, we decide to retain these two items, but to revert back to the issue of correlation in the data analysis (Hair, Anderson, Tatham, \& Black, 1998).

After removing the items as discussed above we performed a confirmative factor analysis using AMOS20 to make the factorial structure more robust. 
Table 19: Confirmative Factor Analysis of the physical and social factor scales

\begin{tabular}{|c|c|c|c|c|c|c|c|}
\hline Construct & Item & \begin{tabular}{|l} 
Std. regr. \\
weight
\end{tabular} & Alpha & $\mathbf{N}=$ & CR & AVE & Var. \\
\hline \multirow[t]{4}{*}{ Physical factors } & Comfortable temperature & $0.603 * * *$ & \multirow[t]{4}{*}{0.731} & \multirow[t]{4}{*}{289} & \multirow[t]{4}{*}{0.827} & \multirow[t]{4}{*}{.546} & \multirow[t]{4}{*}{0.269} \\
\hline & Attractive architecture & $0.584 * * *$ & & & & & \\
\hline & Appropriate lighting & $0.728 * * *$ & & & & & \\
\hline & Easy to find things & $0.644 * * *$ & & & & & \\
\hline \multirow[t]{3}{*}{ Social factors } & Staff appearance & $0.648 * * *$ & \multirow[t]{3}{*}{0.465} & \multirow[t]{3}{*}{289} & \multirow[t]{3}{*}{0.667} & \multirow[t]{3}{*}{.427} & \multirow[t]{3}{*}{0.118} \\
\hline & Staff behaviour & $0.596 * * *$ & & & & & \\
\hline & Staff helpfulness & $0.266 * * *$ & & & & & \\
\hline
\end{tabular}

source: own data; $* * * p<.001$

Reliability of the final scales was good, as physical factors had a high internal consistency with Cronbach's alpha $=.731$ (Nunnally, 1967) and a high composite reliability $(\mathrm{CR})=.827$ (Fornell \& Larcker, 1981). The individual paths of the measurement model were sufficiently high with a probability of $\mathrm{p}<.001$. The construct social factors had a lower alpha value, however it has been suggested that $\mathrm{CR}$ is superior to alpha when assessing reliability with larger size samples (Fornell \& Larcker, 1981). $C R=0.667$ meeting minimum expectations, we therefore conclude the measure is reliable (staff helpfulness did not meet the criterion of indicator reliability). We tested face validity, construct validity (convergent, discriminant, nomological), and content validity for each measure.

Face validity of this scale implies that the items loading on the factor can be explained based on the researchers understanding of the items in reality. It is likely that customers in a store will assess the overall atmosphere and experience globally, and although temperature, lighting, design are physically separately controlled features of the store, they are subconsciously related (Baker, et al., 1992; Bitner, 1992). If one or several ambient stimuli are perceived to be negative, the overall assessment of the physical environment may be negative. The items are related in the sense that they are all elements of a comfortable, easy shopping experience. The social factors scale contains the main aspects of the stimuli emitted by in-store personnel, i.e. physical appearance and behaviour (friendliness, helpfulness) as suggested by the literature (Baker, et al., 1994; Baker, et al., 1992; Bitner, 1990; L. W. Turley \& Milliman, 2000). Face validity of both scales is therefore given. 
Convergent validity describes the extent to which items of a construct share variance and was assessed with the help of the average variance extracted (AVE). In one case the value is slightly below the threshold of 0.5 , which could be an indicator for weak convergent validity. The low explanatory power of the 'staff helpfulness' item weakens this measure considerably. However removal of the item would take out an important aspect of airport servicescapes, namely staff competence and knowledge, which are likely to be important elements of service as customers may be looking for orientation and confirmation. This item should be modified in future research.

Discriminant validity is high when a construct is really different from other constructs regarding its statistical content. One indicator if a good model fit of a confirmatory factor analysis, in the case of the measurement model environmental variables, all five model fit parameters were satisfactory (see Table 20).

Table 20: Goodness of fit of the measurement model (environmental variables)

\begin{tabular}{|l|l|l|l|}
\hline Measure & Minimum requirement (source) & Value & Result \\
\hline & $\leq 0,06(\mathrm{Hu}$ and Bentler, 1999) & & \\
RMSEA & $\leq 0,07$ if $\mathrm{CFI} \geq 0,92$ (Hair et al., 2010) & 0.015 & acceptable \\
\hline $\boldsymbol{\chi 2}$ /d.f. & $\leq 3$ (Bentler, 1990) & 1.069 & acceptable \\
\hline GFI & $\geq 0,90$ (Hair et al., 1992) & 0.986 & acceptable \\
\hline TLI & $\geq 0,90$ (Homburg and Baumgartner, 1996) & 0.996 & acceptable \\
\hline CFI & $\geq 0,90$ (Homburg and Baumgartner, 1996) & 0.997 & acceptable \\
\hline
\end{tabular}

Also a high composite reliability can be an indicator for good discriminant validity, which is given in this case. Furthermore, the covariance between the two constructs is .115 which is below the threshold of .5 .

Nomological validity requires that the patterns of correlation and noncorrelation match the theoretically predicted patterns of the conceptual model. We reviewed the correlation matrix (see Appendix) and based on that can confirm a satisfactory level of nomological validity. Content validity was checked by presenting the final scales to a panel of six content experts, who each have professional expertise in either marketing to consumers in airport retail settings or in performing consumer research in (airport) retail settings comprising practitioners and faculty (see Appendix). Items were accepted to have sufficient content validity if at least $50 \%$ of the panel voted that the item is essential to the performance of the construct (Lawshe, 1975). All items of the social and 
physical factors were considered essential by the majority of the panel, suggesting that content validity is present.

Perceived time pressure was measured with a single item (Eroglu \& Machleit, 1990; Nowlis, 1995) on a 5-point scale (1 - I don't feel time pressure, 5 - I feel great time pressure). The average time pressure was low (mean: 1.31) which could be because only respondents with sufficient time to complete all interviews as well as shop if desired were eligible to participate in the survey (criteria: at least 70 minutes before departure). We will now assess the validity of this measure.

The time pressure measure includes all three aspects of the definition used in previous time pressure research, namely 'perception', 'time constraint' and 'ability to perform a given task' with each task being spelled out to respondents (Iyer, 1989, p.43). We therefore assume the presence of face validity despite this being a single item construct. To assess nomological validity, we compared the correlation of this construct with other concepts conceptually related to time pressure. Passengers arriving later to the airport relative to departure time are more likely to be more under time pressure (arrival time before flight). Also, a single-item verbal measure of stress was recorded (are you currently experiencing stress?), which is likely to be high when perceived time pressure is high and vice versa. All two correlations are significant, suggesting the presence of nomological validity.

Table 21: Pearson correlation matrix for time pressure and related items

\begin{tabular}{|l|l|l|l|}
\hline & Time pressure & $\begin{array}{l}\text { Arrival time } \\
\text { before flight }\end{array}$ & $\begin{array}{l}\text { Acute stress } \\
\text { (verbal item) }\end{array}$ \\
\hline Time pressure & 1 & & \\
\hline Arrival time before flight & $-.159^{* *}$ & 1 & 1 \\
\hline Acute stress (verbal item) & $.231^{* *}$ & -.100 & Source: own data, $* * p<.01$ \\
\hline
\end{tabular}

AVE as a measure of convergent validity cannot be used for single-item measures, however convergent validity can also be assumed if the scale correlates well with similar measure, and should therefore be present because of above assessment of correlation. To assess discriminant validity we ran a separate factor analysis including all 14 environmental items and time pressure. Principle component analysis with a Varimax rotation proposes four components with eigenvalue $>1$, with time pressure being the only item loading on one component four. Lastly, the constructs content 
validity was confirmed by the content expert panel using the method described in the beginning of this section.

Table 22: Principal Component Analysis for time pressure and environmental items

\begin{tabular}{|l|c|c|c|c|}
\hline & \multicolumn{3}{|c|}{ Component } \\
\cline { 2 - 5 } & $\mathbf{1}$ & $\mathbf{2}$ & $\mathbf{3}$ & \multicolumn{1}{|c|}{$\mathbf{4}$} \\
\hline The lighting is appropriate. & .729 & .183 & .141 & .194 \\
\hline $\begin{array}{l}\text { It is easy to walk around the store and find what you are looking } \\
\text { for. }\end{array}$ & .722 & .073 & .145 & .180 \\
\hline The shop's architecture gives it an attractive character. & & & & \\
\hline The temperature in the shop was comfortable & .721 & .161 & -.021 & .048 \\
\hline The use of colours adds excitement to the store environment & .661 & -.012 & .095 & .072 \\
\hline $\begin{array}{l}\text { The signs and labels used in the shop helped me to find my way, } \\
\text { and do my shopping. }\end{array}$ & .559 &. .083 & .036 & -.103 \\
\hline $\begin{array}{l}\text { The aisles between the shelves are wide enough to pass through } \\
\text { easily, even with luggage }\end{array}$ & .514 & .014 & .212 & .393 \\
\hline I felt uncomfortable because of the many people around me. & .044 & .716 & .052 & -.061 \\
\hline I felt a disturbingly strong scent in the shop. & .004 & .680 & .021 & .040 \\
\hline $\begin{array}{l}\text { Standing in line at the check-out was uncomfortable, there was } \\
\text { too little space around me. }\end{array}$ & .154 & .641 & .157 &.- .192 \\
\hline The helpfulness of assistants is almost extreme, disturbing. & -.053 & -.646 & -.048 & -.297 \\
\hline I felt shop assistants gladly help customers when needed. & -.130 & -.116 & .723 & .173 \\
\hline Well-groomed and well-dressed assistants work in the shop & .318 & .280 & .569 & .155 \\
\hline Shop assistants were friendly and helpful. & .306 & .180 & .504 & .311 \\
\hline time pressure & -.207 & .070 & -.034 & -.694 \\
\hline
\end{tabular}

Extraction Method: Principal Component Analysis.

Rotation Method: Varimax with Kaiser Normalization.

source: own data

\section{Measures of Emotion}

Respondents were asked to rate pictures of emotional states in terms of how much they express their current state, on a scale from 0 (not at all) - 100 (completely). We hypothised a two-dimensional solution, with one dimension relating to the presence/absence of emotions of pleasure when leaving stores and a second measuring high/low levels of stress which may be caused by difficulties with the process or the environment of the airport, for example.

A principal component analysis confirmed two components with a good overall fit $(\mathrm{KMO}=.701$, Chi-square $=156.017$ with 15 d.f. and $\mathrm{p}<.001$, see Table 23). After rotation, $62.2 \%$ of the variance could be explained with two components, the first representing both positive (happiness) and negative (sad, afraid) emotions, and the second consisting of variables surprised and angry. Next we removed disgusted, 
because it was highly correlated with fear, although they should be distinct emotions: Fear relates to own wellbeing, whereas disgust is a reaction to something extremely untasteful, thus it was removed. Also sad was removed as it had factor loadings of over .2 on component 2 .

When discussing face validity, firstly it should be considered that the mean ratings of all items were close to the extreme values, except in the case of 'happy'. This could be because the pictures used (see Appendix) showed extreme facial expressions, and in case of negative emotions were not representative of the feelings of respondents at the time.

Table 23: Principle Component Analysis for emotional measures - factor loadings

\begin{tabular}{|l|r|r|r|r|}
\hline & Component 1 & Component 2 & Mean & Std.Dev. \\
\hline $\begin{array}{l}\text { Explained Variance } \\
\text { (Percent) }\end{array}$ & $\mathbf{3 8 . 0 4 3}$ & $\mathbf{2 4 . 1 7 3}$ & & \\
\hline Disgusted & $\mathbf{. 7 9 5}$ & .050 & 2.96 & 10.89 \\
\hline Afraid & $\mathbf{. 7 8 7}$ & .169 & 4.01 & 12.839 \\
\hline Sad & $\mathbf{. 7 8 6}$ & .396 & 4.52 & 13.917 \\
\hline Happy & $\mathbf{. . 6 1 9}$ & .068 & 79.50 & 24.616 \\
\hline Surprised & $\mathbf{. 0 0 7}$ & $\mathbf{. 8 1 2}$ & 7.13 & 18.440 \\
\hline Angry & .171 & $\mathbf{. 7 7 3}$ & 3.67 & 12.273 \\
\hline
\end{tabular}

Extraction Method: Principal Component Analysis.

Rotation Method: Varimax with Kaiser Normalization. N=294

The environment is light, colourful and offers a wide range of luxury products, therefore this was expected. We used the data 'as is', as it included sufficient variance. The construct pleasure being measured via items 'happy' and 'afraid' is in line with results of previous studies. 'Frightening' environments were found to be the almost direct opposite of 'Enjoyable' environments when 21 adjectives were subjected to a two dimensional principal component analysis (Russell \& Pratt, 1980). Watson and Tellegen's two-dimensional map of emotions proposes that feelings such as 'lonely, sad, unhappy' are the exact opposite of 'content, pleased, happy', suggesting that 'sad' would a more appropriate item for our pleasure construct (Watson \& Tellegen, 1985). In fact, the pearson correlation between sad and happy are higher than between happy and afraid. On the other hand, however, when swapping the two items, the variance explained reduces, probably because afraid also loads on the second dimension. The underlying concept behind the happy ratings of this study could therefore be the absence of fear (feeling safe) which can be most relevant at and before air travel, suggesting this 
construct has good face validity. Stress has been hypothised to be a combination an unexpected obstacle, a threat to achieve an important goal. Therefore, two items surprise and anger loading highly on the same component is in line with expectations. As discussed earlier, the most likely stressor at airports is an unexpected delay. In order of time, surprise is likely to occur first, when the stimuli occurs, followed by appraisal of the event/circumstance. When delays are externally caused, the outcome of appraisal could be blame, anger towards the cause. Recent studies showed that when a worsethan-expected outcome follows the prediction that something good will happen, that situation is labelled as causing anger, whereas if this was expected, it is labelled as causing sadness (Kirkland \& Cunningham, 2012). The face validity is therefore given.

A sign for discriminant validity can be the indicator reliability. It has been noted that coefficient alpha underestimates reliability and conceptually has little meaning for twoitem scales, and instead the Spearman-Brown coefficient (SB) should be used (Hulin, 2001). Because SB is used to assess the split-half reliability of a measure, and assuming that two items are measuring the same thing, this coefficient should be accurate to assess the reliability of two-item scale, too. The values are not sufficiently high to fully confirm reliability, with $\mathrm{SB}$ (pleasure) $=.546$ and $\mathrm{SB}$ (stress) $=.354$. By way of explanation, the overlap between surprise and anger is not complete, as obviously these are two emotions measuring different emotions (for example, surprise is a neutral, while anger is a negative emotion) and therefore a strong correlation was not to be expected. However there are only few unique facial expressions, which is a disadvantage to verbal scales, which allow using more detailed expressions of emotions. This needs to be balanced with the advantage of eliminating translation bias, for example.

Next, a confirmatory factor analysis was performed in AMOS20. Model fit was acceptable, four out of five fit indicators met the required levels (RMSEA $=0.049$, $\chi 2 /$ d.f. $=1.707, \mathrm{GFI}=.997, \mathrm{TLI}=.947, \mathrm{CFI}=.991)$. All regression coefficients were significant at the $\mathrm{p}=.001$ level. This indicates sufficient discriminant validity. Nomological Validity was assessed by correlation with other, similar measures. Next, we analysed pearson correlation between the four items by ranking them by their absolute size. The two highest ranking coefficients are those of the two constructs used, as expected. The third ranking coefficient (between surprise and fear) is very low but still significant at a .05 level although these items conceptionally belong to two different constructs. The correlation of any other, lower ranking coefficients were not significant, 
again in line with expectations. Next, we compared to the measure pleasure and arousal using the Affect Grid. The Pearson correlation coefficients between happy, afraid and pleasure is high and significant, whereas neither of them correlate with arousal. The stress construct should highly correlate with the verbal, single-item measure of acute stress. Respondents answered "Do you feel stressed right now?" on a scale from 0 - not stressed at all to 100 - going through massive stress (Lunardo \& Mbengue, 2009). The correlation is significant. Although the Pearson correlation with surprise is not significant, the one with anger is significant $(.253, \mathrm{p}<.01)$. Overall, we therefore propose that construct validity is good.

Finally, content validity was assessed by the expert panel. As expected, the discussion and questions concerned the low number of items used. Also it has been noted that if emotions are arranged around two dimensions in a circumplex fashion (as suggested by Russell (1980) and Watson and Tellegen (1985), two pictures per dimension can sufficiently cover a complex phenomenon. Judges said that the measure may not capture all emotions, and therefore some paths in a structural equation model may not be significant where in reality they are. At the same time, the items were confirmed to belong to the constructs as suggested, and the majority of votes asserted that the instrument had content validity.

\section{Dependent variables}

The validity and reliability of variables measuring the effect of emotional changes are analysed next (approach/avoidance behaviour, evaluation of the store). Approach/avoidance was measured by the sum of the items returning to this store, affiliating with others, exploration in this store as suggested by Donovan et al. (1982). Face validity requires the construct accurately describes the shoppers' behaviour as a reaction to the in-store experience. Data was collected immediately after customers left stores, thus reducing any possible memory bias, and also suggesting a superior external validity than, for example, in vitro studies. This concept of approach (Donovan \& Rossiter, 1982) was applied frequently (Baker, et al., 2002; Ezeh \& Harris, 2007) to cover the willingness or desire to move towards, stay in, explore, interact, perform well in, and return to the environment. This construct covers the 'explore', 'interact', and 'return' concepts; 'move towards' was omitted, because this store cannot be 'avoided' by passengers, 'perform well in' (=spending) was excluded, as this cannot be fully explained by emotions, but also has numerous other antecedents such as disposable 
income, shopping motivation, and cognitive processes related to needs and product offer would have to be controlled for, being out of scope for this study. However, more interaction with sales personnel and exploration increases the likelihood of sales. Further, environmental psychologists propose Evaluation of the store to be another dimension of consumer reaction to environmental stimuli. The two items 'enjoyment' and 'liking' have been used frequently to measure this concept (Donovan \& Rossiter, 1982), and they are relevant, as they express feelings towards the store after leaving, and therefore may lead to loyalty and positive word of mouth, for example. While all measures are highly related, one evaluates the act while the other is on the place and the third (experience) is an overall judgement. Therefore we consider the construct sufficiently face valid within the frame of environmental psychology.

The reliability of the measures acceptable, alpha values for approach/avoidance were .632 , while the evaluation scale had acceptable internal consistency and reliability with alpha $=.655$ (Kline, 1999). Discriminant validity was assessed again with confirmatory factor analysis of the measurement model including both constructs. The model fit was acceptable, as key indicators met the minimum requirements ${ }^{5},(\chi 2 /$ d.f. $=2.12$, RMSEA $=.062, \mathrm{TLI}=.893, \mathrm{CFI}=.959)$. This suggests that discriminant validity is given. However, the construct has low convergent validity, because AVE values are significantly below the suggested cutoff value of .5 .

To test nomological validity we review the correlation of both scales with other variables (see Appendix). Although we commented earlier that time spent in the store is dependent on several other factors, a correlation between approach, evaluation and time in the store should be significant and positive. This is the case for evaluation $(.233, \mathrm{p}<$ $.001)$ but not for approach $(-.126, \mathrm{p}<.01)$. Similarly to reliability indicators, the evaluation scale performs much better than approach. Content validity was judged to be better for the evaluation scale than for the approach scale. It has to be recognized that the fact that this scale has been used in the format for the first time leads to some limitations.

\footnotetext{
${ }^{5}$ GFI was not reported, intercepts were estimated.
} 
Table 24: Confirmatory Factor Analysis and selected quality indicators of approach/avoidance and evaluation scales

\begin{tabular}{|c|c|c|c|c|c|c|}
\hline Construct & Item & $\begin{array}{l}\text { Std. regr. } \\
\text { weight }\end{array}$ & Alpha & $\mathbf{N}=$ & CR & AVE \\
\hline \multirow{3}{*}{$\begin{array}{l}\text { Approach/ } \\
\text { Avoidance }\end{array}$} & Returning to the store* & $0.592 * * *$ & \multirow[t]{3}{*}{.632} & \multirow[t]{3}{*}{289} & \multirow[t]{3}{*}{0.389} & \multirow[t]{3}{*}{0.370} \\
\hline & Exploring the environment* & $0.682 * * *$ & & & & \\
\hline & Affiliating with other people* & $0.582 * * *$ & & & & \\
\hline \multirow[t]{3}{*}{ Evaluation } & Enjoyed shopping & $0.739 * * *$ & \multirow[t]{3}{*}{.655} & \multirow[t]{3}{*}{289} & \multirow[t]{3}{*}{0.663} & \multirow[t]{3}{*}{0.435} \\
\hline & Liked store environment & $0.469 * * *$ & & & & \\
\hline & Positive experience of the store & $0.667 * * *$ & & & & \\
\hline
\end{tabular}

Both scales have good discriminant and face validities, and approach has a low convergent validity, and therefore, it should be improved in future studies and results for this particular scale may only be generalizable with caution.

\section{Equivalence across countries}

Because this research involves participants from several countries, great care was be taken to maximize invariance of constructs, measures and samples across cultures (Steenkamp \& Baumgartner, 1998). We will establish the most likely sources of variance in the study and verify construct equivalence as well as measure equivalence of these following procedures recommended by Craig \& Douglas (2000).

In order to establish construct equivalence, we first have to ensure that concepts being studied actually exist across the countries studies, and are equivalent in all cultural settings. We also need to assess if the behaviour under study serve the same function, e.g., do people visit airport shops for the same reasons across cultures? And lastly, we have to ensure that each culture categorizes the behavior under investigation in the same way (Craig \& Douglas, 2000). In this study, the most relevant question is if respondents from different cultures assess stimuli at an airport differently, because uncertainty, lack of orientation, time pressure may be seen as more threatening then in other cultures. Hofstede differentiates countries based on their Uncertainty Avoidance Index score (UAIHofstede, 2001)), which reflects the extent to which members of a society attempt to minimize uncertainty. For example Swedes and Danes accept and feel comfortable in unstructured situations, and are more tolerant of change (low UAI) whereas citizens of Belgium and Poland require more stability (high UAI). UAI data was obtained from a website for most countries (Hofstede, 2011), less than $10 \%$ of the cases could not be 
assigned a UAI score due to missing data. Only respondents to the English questionnaire were included to control for translation invariance, and were then split into three groups of equal size according to their countries $\mathrm{UAI}$ score $\left(\mathrm{UAI}_{\text {group } 1}\right.$ : from 1 to $46, \mathrm{UAI}_{\text {group2}}$ : from 47 to $65, \mathrm{UAI}_{\text {group } 3}$ : from 66 to 112 ). We examine any differences in means of physical and social factors as well as pleasure and stress between the three groups using ANOVA. There is no significant variance in the means of pleasure $(\mathrm{F}=$ 2.254, $\mathrm{p}=.111)$ and stress $(\mathrm{F}=1.253, \mathrm{p}=.289)$. Both Welch and Brown-Forsythe tests of robustness were not significant. Therefore cultural aspects did not influence responses to these four constructs, and we can consider construct equivalence to be present.

Measure equivalence concerns the calibration system used in the measurement, the translation of the research instrument, and the metric equivalence of the instrument (Mullen, 1995). A potential pitfall is rating scales, for example Hungarian education grades students from 1 (poor) to 5 (very good) while the German system is opposite with 6 (poor) to 1 (very good). As these are the two largest nationalities among the sample, this could influence response patterns. To avoid any similarity with school scales we apply scales with 7 items or more. When measuring emotions, verbal scales were avoided altogether, instead a sliding scale on a continuum from 0 to 100 was used. Translation followed the procedure recommended by (S. P. Douglas \& Craig, 2006). To assess translation invariance, we split respondents into two groups by language of questionnaire, and performed an ANOVA analysis on all verbal items used in the final measurement models. No variance between the means of any variable was detected at a confidence level of .01 , with $\mathrm{F}$ values ranging from $.028(\mathrm{df}=1, \mathrm{p}=.866)$ to 3.845 (df $=1, \mathrm{p}=.051$ ).

Another necessary condition for measure equivalence is equal reliability across countries. As splitting the sample by country would have resulted in very small sample sizes other than Hungary, we compare reliability between non-Hungarian and Hungarian citizens for each of the four verbal scales of the model: First, the "physical factor' items resulted in Cronbach's alpha (other countries) $=.784$, while alpha (Hungary) $=.670$, and values cannot be improved by excluding items. For 'social factors', alpha (other countries) $=.374$ alpha (Hungary) $=.619$. After removing the item 'helpfulness of staff', the alpha value for 'others' improved to .697 while the reliability for Hungarian respondents deteriorated. It is likely that the Hungarian culture considers 
staff helping customers in a sales situation as being more similar to their friendliness and external appearance, whereas other cultures don't. For example, approaching a customer could be seen as impolite, intrusive by some cultures. To assess this, respondents were also asked to rate if the "helpfulness of assistant is almost extreme, disturbing", however an ANOVA could not identify a significant difference in the means between Hungarian and non-Hungarian respondents, and cultural differences such as these could to be the topic of a future study. Alpha values for approach/avoidance measure were .683 and .623 (other/Hungarian) and no improvement can be achieved made by excluding items. Alphas for Evaluation measures were .606 and .684 , with no improvements by exclusion. In summary, three out of four measures have shown good reliability across cultures (Hungarian/other countries), and the measure with lower reliability has one single item performing poorly. Because the objectives of the study is to assess the relationship of constructs across cultures, and not to compare means or nomological network between countries, partial measure invariance is sufficient (Steenkamp \& Baumgartner, 1998).

\section{V.5.3. Analysis of the structural model}

We tested the proposed model as well as tested the doctoral thesis' hypotheses with structural equation modelling (SEM). This method is preferred to test causal relationships between latent variables, which are grounded in theory (Backhaus, et al., 2011). In order to decide whether to use variance analytic approach (such as Partial Least Squares - PLS) or covariance structural analytic approach (e.g., Analysis of Moment Structures - AMOS), we had to consider that some of the constructs used are not yet well tested, such as the picture emotions scale. Also, a main objective is to verify if the proposed model is stable and has a good fit, therefore we prefer AMOS due to the wide range of overall goodness of fit indicators. A downside of AMOS is that a larger sample size is recommended for AMOS then for PLS (Homburg \& Klarmann, 2006). AMOS simultaneously estimates of all parameters of the model, using factor analysis. The relationship between the constructs is calculated based on the covariance between the indicators.

Missing values were replaced using the regression imputation method (Dagenais, 1973). Less than $5 \%$ of values were missing. Applying OLS regression, we used the existing 
items of each construct to estimate the missing value of that construct, and then replaced that estimate as if it were an actual obtained value.

Next we assess the goodness of fit of the obtained model. Absolute fit indices $(\chi 2 / \mathrm{df}$, RMSEA) test how well an a-priori model fits the sample data. As sample size is above 200 , it is more appropriate to report $\chi 2 / \mathrm{df}$ rather then $\chi 2$, at 1.912 is acceptable, as it is below the threshold values 5.0 (Wheaton, Muthen, Alwin, \& Summers, 1977) and 3.0 (Klarmann, 2011). The Root Mean Square Error of Approximation (RMSEA) is one of the most informative fit indices (Diamantopoulos \& Siguaw, 2000) and tells how well the model fits the population's covariance matrix, preferring models with fewer parameters. The reported value is .056 , which is below the cut off criteria of $0.06(\mathrm{Hu} \&$ Bentler, 1999) and therefore acceptable. Incremental fit indices compare the chi square values to a baseline model, in which all variables are uncorrelated.

Figure 12: Structural model and standardised path coefficients

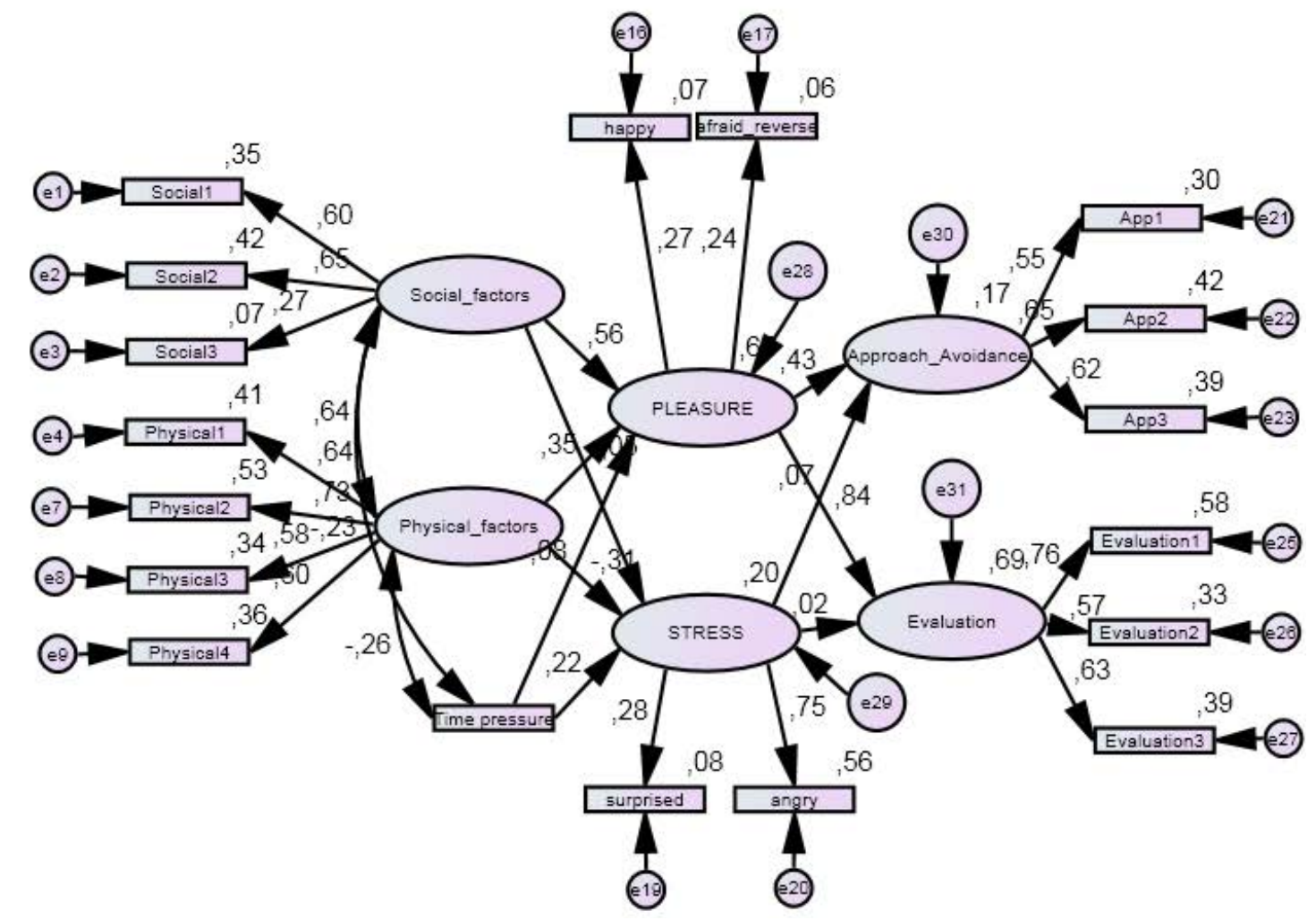

source: own data

The Tucker-Lewis Index (TLI) was .838, which is acceptable according to some authors (Hooper, Coughlan, \& Mullen, 2008) but considered low according to others $(\mathrm{Hu} \&$ Bentler, 1999). The Comparative Fit Index (CFI) with .870 was relatively poor. While 
cut-off values for NFI and CFI are generally .90, these indices penalize this model for its complexity. It has been reported that in complex models, parsimony fit indices can be as low as 0.5 even when other indicators are over .90 (Mulaik, et al., 1989). The sample size of 294 is sufficiently large: Based on the Bentler-Chou (1987) rule, the ideal sample size should be 5 times more than parameters, in this case 5 x $48=240$.

To evaluate the causal paths of the model, we first look at their statistical significance, and secondly at the strength of the relationship, i.e. at the standardized path coefficient, ranging from -1 to +1 . According to Chin (1998), standardized paths should be at least $|.20|$ to be meaningful for discussion. Based on this, six out of 10 hypothised causal relationships could be identified with the model. All of them were significant at the $\mathrm{p}=$ .05 level (see Table 26). We will now test the hypotheses of this dissertation in turn based on the structural equation model (SEM).

Table 25: Main fit indices of the structural equation model

\begin{tabular}{|l|l|l|l|}
\hline Measure & Minimum requirement (source) & Value & Result \\
\hline \multirow{4}{*}{ RMSEA } & $\leq 0,06$ (Hu and Bentler, 1999) & & \\
& $\leq 0,07$ if CFI $\geq 0,92$ (Hair et al., 2010) & 0.056 acceptable \\
\hline 22/d.f. & $\leq 3$ (Bentler, 1990) & 1.912 acceptable \\
\hline GFI & $\geq 0,90$ (Hair et al., 1992) & 0.914 acceptable \\
\hline TLI & $\geq 0,90$ (Homburg and Baumgartner, 1996) & 0.838 slightly below threshold \\
\hline CFI & $\geq 0,90$ (Homburg and Baumgartner, 1996) & 0.870 slightly below threshold \\
\hline
\end{tabular}

Source: own data

\section{V.5.4. The effect of the retail environment on emotions}

Hypothesis 1 predicted that a favourable perception of the physical factors of a retail environment increases customer pleasure $(H l a)$ and reduces customer stress $(H 2 b)$. The results show that physical factors of a store have a significant positive effect on pleasure (standardized path coefficient $=.345, \mathrm{p}<.05)$ as well as a negative effect on stress $(-$ $.308, \mathrm{p}<.05)$. Notably, the effect is equally strong on pleasure as on stress. It appears that the selected design and ambience of the store has achieved the desired impact on both positive feelings as well as reducing stress. The relationship between store environment and pleasure has been confirmed in numerous studies before (See section II. for a review of the literature). However, there appears to be a lack of studies discussing the effect of store interior on stress. This is an important finding for time 
pressured retail settings, where reducing surprises and angry feelings (the two items measuring stress) could be a key marketing objective.

Hypothesis 2 proposed that a favourable perception of the social factors of a retail environment increases customer pleasure $(H 2 a)$ and reduces customer stress $(H 2 b)$. The results confirm $\mathrm{H} 2 \mathrm{a}$ : in-store personnel have a strong effect on pleasure $(.560, \mathrm{p}<.05)$, again in line with the literature. The standardised path coefficient is larger than that of physical factors, suggesting that in the airport retail environment, sales staff has a higher influence over customer's feelings than the brick and mortar of the store. At the same time, customers may actively look for help from the staff due to the limited time available or because they are in an unknown environment. Against expectations, however, $H 2 b$ could not be statistically confirmed by the SEM. This is in conflict with findings from the qualitative pre-study, which suggested that appearance and behaviour of retail staff reduce customer stress by providing advice and orientation. One explanation for this discrepancy could be the low variance of the latent variable stress, which should be termed one of the limitations of this study. As research into shopping under time constraints is still an under researched area, we suggest to further improve the measure in future studies. Also, Social factor scores are highly correlated with those of physical factors, which somewhat reduces the explanatory power of each construct. The correlation suggests that respondents' feelings are influenced by an overall impression of the store, and it is also likely that the effects of store personnel and physical factors are complementary to each other. To illustrate this, let's consider the items staff friendliness and signage, which are items of two different constructs in this study. When passengers are asking for information, friendly staff may show them information tables, or signs which are helpful. Both physical and social factors together were necessary to provide the information, and possible reduce stress for the passenger. Hypothesis 3 anticipated that higher perceived time pressure reduces customer pleasure $(\mathrm{H} 3 \mathrm{a})$ and increases customer stress $(\mathrm{H} 3 \mathrm{~b})$. Statistically, the relationship between time pressure and pleasure could not be identified at a confidence level of $p=.05$, but time pressure has a significant effect on stress $(.216, \mathrm{p}<.01)$. Based on the data, we therefore reject $H 3 a$ and accept $H 3 b$. Firstly, these results confirms that time pressure has an impact on customer emotions as hypothised. Also, passengers shopping under time pressure do not seem to be influenced in their feelings of happiness, possibly the excitement and anticipation of the trip is strong enough to overcome the negative 
effects. Also, it is possible that the lack of time is not unexpected and therefore has no effect on shopping pleasure.

\section{V.5.5. The effect of emotions on behaviour and store evaluation}

Hypothesis 4 proposed that a higher level of pleasure has a positive effect on approach behaviour $(H 4 a)$ and affect towards the store $(H 4 b)$. The SEM confirmed a significant positive relationship between pleasure and approach/avoidance behaviour $(.428, \mathrm{p}<$ $.01)$ and a very strong relationship between pleasure and evaluation of the store $(.838, p$ $<.001)$. Both hypotheses $\mathrm{H} 4 \mathrm{a}$ and $\mathrm{H} 4 \mathrm{~b}$ can therefore be accepted. These findings support that customer pleasure is an important emotion that partly determines customers desire to approach a store. Such behaviour can involve a higher likelihood to return to the store, explore the environment and affiliate with other people. While these measures are not equal to higher sales, they may be necessary conditions for a sale to take place. One may argue that more interaction with sales personnel increases the possibility of buying, everything else being equal. Furthermore, pleasure also positively influences the evaluation of the store by customers, which could lead to higher loyalty (Babin \& Darden, 1996; Kenesei, 2002) and positive word of mouth (Wakefield \& Blodgett, 1994).

Hypothesis 5 predicted that a higher level of stress has a negative effect on approach behaviour $(\mathrm{H} 5 \mathrm{a})$ and affect towards the store $(\mathrm{H} 5 \mathrm{~b})$. The SEM did neither result in a statistically significant relationship between stress and behaviour nor between stress and store evaluation. $\mathrm{H} 5 \mathrm{a}$ and $\mathrm{H} 5 \mathrm{~b}$ are therefore rejected. In search for explanations for this unexpected outcome, one may firstly consider the low variance of the variable stress. Also, respondents could have recalled emotions of stress present before or when entering the store, but have weakened to such a degree that they did not influence behaviour. Even more, some respondents may have browsed to cope with stress, and evaluated the store positively relatively to the security screening environment before. While these findings ask more questions than provide answers, they contain much potential for further studies.

\section{V.5.6. Summary of the results}

The data analysed in the structural equation model confirms the importance of the store's physical environment as well as staff appearance and behaviour to influence 
behaviour and evaluation of the store, with pleasure being a mediator of this relationship. The right store ambience can cause feelings of happiness and reduce fear or anxiety, with store personnel's behaviour and appearance having a $60 \%$ higher impact then the store's physical features. As expected, customers are more likely to return, want to explore the store, and more likely to affiliate with other people if they have positive feelings. Positive feelings also lead to a more favourable evaluation of the store and the shopping inside the store. The model could not fully confirm the hypothised role of customer stress, which was measured by the construct 'stress' (the combination of surprise and anger measures). Only physical factors of the store environment can reduce stress levels, but not social elements of the servicescape. Also, stress was not shown to impact behaviour or even evaluation of the store.

Table 26: Summary of the structural equation model

\begin{tabular}{|c|c|l|c|l|c|}
\hline Hypothesis & confirmed & \multicolumn{3}{|c|}{ Causal Path } & $\begin{array}{c}\text { Std. Path } \\
\text { Coeff. }\end{array}$ \\
\hline H1a & yes & Pleasure & $<---$ & Physical factors & $.345^{*}$ \\
\hline $\mathrm{H} 1 \mathrm{~b}$ & yes & Stress & $<---$ & Physical factors & $-.308^{*}$ \\
\hline $\mathrm{H} 2 \mathrm{a}$ & yes & Pleasure & $<---$ & Social factors & $.560^{*}$ \\
\hline $\mathrm{H} 2 \mathrm{~b}$ & no & Stress & $<---$ & Social factors & n.s. \\
\hline $\mathrm{H} 3 \mathrm{a}$ & no & Pleasure & $<---$ & Time pressure & n.s. \\
\hline $\mathrm{H} 3 \mathrm{~b}$ & yes & Stress & $<---$ & Time pressure & $.216^{* *}$ \\
\hline $\mathrm{H} 4 \mathrm{a}$ & yes & Approach/Avoidance & $<---$ & Pleasure & $.428^{* *}$ \\
\hline $\mathrm{H} 4 \mathrm{~b}$ & yes & Evaluation & $<---$ & Pleasure & $.838^{* * *}$ \\
\hline $\mathrm{H} 5 \mathrm{a}$ & no & Approach/Avoidance & $<---$ & Stress & n.s. \\
\hline $\mathrm{H} 5 \mathrm{~b}$ & no & Evaluation & $<---$ & Stress & n.s. \\
\hline
\end{tabular}

However, six out of ten hypothised paths could be confirmed in both the qualitative preliminary study and the quantitative study. Although the stress measure requires further improvements, the pleasure measure seems to deliver acceptable results, in a multi language, multi cultural setting. Also, several scales were adopted from the literature to fit the settings, and considering that they have not been applied in this specific format in the airport retail environment have performed reasonably well. Especially the scale for physical factors of the store environment reached high reliability and validity while only consisting of 4 items. This scale is shorter then measures used in several previous studies (Baker, 1987; Bitner, 1992; Hightower, et al., 2002; Jang \& Namkung, 2009), therefore allowing shorter questionnaires. 
Finally we applied existing processes to improve and assess cross-country equivalence and discussed language aspects. Although airports are multi cultural environments, previous studies into airport shopping behaviour were either limited to one nationality (Geuens, et al., 2004) or did not assess validity and reliability of measures across nationality (Baron \& Wass, 1996; Mintel International Group Ltd, 2000 as reported by Crawford \& Melewar, 2003; Omar \& Kent, 2001; Perng, et al., 2010; Torres, et al., 2005).

Finally, the extensive fieldwork provides a large amount of data for further analysis. As discussed in the introduction, further data has been collected which has not been reported here, making the dataset itself a valuable contribution. Shopping intentions were measured upon recruitment, as well as before entering the store allowing a discussion of impulse shopping behaviour. We also collected qualitative data about events which happened at the airport, and which had an effect on the mood of the respondent, allowing an investigation of the effect of stressors (such as unfriendly staff, or long waiting in a queue) on emotions. Also, another questionnaire was completed before boarding a flight, which includes questions related to other stores as well as food and beverage outlets at the airport. This would allow expanding the scope of the analysis to a multi-store environment. I hope that analysis of this data will lead to further findings, and publications. 


\section{VI . CONCLUSIONS}

My dissertation aims to investigate the effect of airport retail environment on customer behaviour and evaluation. The choice of this topic was motivated by both academic as well as professional reasons: Academically, there has been much research discussing the impacts of the store environment on emotions and behaviour. However while positive emotions, or pleasure has been frequently found to be an important mediator of shoppers, there is a lack of agreement on the role of 'arousal' or 'activation'. Firstly, emotions felt by shoppers in a time pressured, high arousal environment (such as a passenger terminal) may be different in terms of their structure and dimensionality then felt in any normal, 'timeless' store. Excitement and stress may be opposites, rather then being both loading on the same dimension (arousal) as assumed by most environmental psychologists (Donovan \& Rossiter, 1982; Russell \& Pratt, 1980). The assumption by the underlying model that arousal that is too high weakens or even cancels the effect of the environment on behaviour (Mehrabian \& Russell, 1974) has been criticised as too simple, ignoring the complexities of arousal and activation theory (A. Groeppel-Klein, 2005; Werner Kroeber-Riel \& Weinberg, 2003). I wanted to extend the M-R model with time pressure (as an antecedent of emotion) and stress (as a dimension of emotional state) and test the fit of this modified model in an airport environment. A logical next research topic then could be the change of emotions over time, because appraisal theory states that stress levels can increase and fall depending on the appraisal of the likely impact of the stressor and the successful coping at the time (Richard S Lazarus, 1990; Richard S Lazarus \& Folkman, 1984). Further data was collected for each respondent at four different stages of the journey through the airport, yet waiting to be analysed. Secondly, all studies I have found discussing consumer behaviour in airport retail ignore the challenges of international research, such as bias caused by construct variance or measure variance across nationalities. Especially measuring emotions using an English language verbal scale seemed unsatisfactory, I therefore was looking for a non-verbal scale, which could be applied easily in airport questionnaires.

The topic also has a high professional relevance, because there is an increasing demand from airport stakeholders to improve returns of the non-aviation business, such as income from retail and food and beverage concessions. At the same time, more complex security regulations and low cost airline policy seem to put more and more burdens on 
passengers, reducing customer comfort and service. These trends make it increasingly difficult to put customers in the 'mood to shop'. A better understanding of the drivers of these spending moods could lead to higher revenues and overall better results.

A high value can be attributed to the insight gained during the qualitative preliminary study. Interviews were held with ten senior managers of Europe's largest and most successful airports, fully transcribed and coded. The questions were answered openly and in great detail (average interview length was over 1 hour), resulting in valuable data with high external validity. Only a small part could be discussed and tested in a quantitative study as part of this thesis, leaving room for future publications from this data.

This section summarises the main findings, starting with the conclusions of the qualitative pre-study, followed by a discussion of the quantitative study. Then, the methodological contribution and the theoretical significance of the thesis are presented. Next implications for practitioners and limitations of the study are discussed. Directions for further research are provided.

\section{VI.1. Conclusions of the qualitative study}

The data collected during the qualitative study can be considered to have high external validity, because it was collected during interviews with senior management of TOP 50 European airports, which have shared their views in an open and honest fashion. Each respondent was approached via a recommendation from another senior airport manager, ensuring a high level of trust and good access. Furthermore, after only seven interviews, no new concepts emerged among the interviews ('saturation') suggesting that the instrument was valid to get an overview of the relevant phenomena in the industry.

Practitioners mentioned that the retail offers at airports is more attractive than average city centre shopping areas, as they consist of well known international brands with often good prices. Therefore cognitive processes do play a role, and there is some planned shopping, especially on standard duty free items, such as tobacco and liquor. However airport design and operation is more targeted at influencing emotional processes, with the objective to generate impulse buying. Passengers are mostly in an active, aroused state, and can be easily converted to shoppers, as soon as their concerns, anxiety, and 
worries related to the trip a low enough to pay attention to environmental cues by the retail offer.

There was agreement that airport environments are unique, as they are filled with excitement of air travel, an image of exclusivity, but also have a reputation for offering duty free prices and good value. In addition, passengers waiting for flights are a captive audience, and are more likely to shop on impulse the longer they stay in the area of the stores. Airports therefore actively try to influence the dwelling time in certain areas. More attractive stores are bundled in central shopping areas in several airports, and those respondents who did not have such a design admired this concept, and several were planning to redesign the airport with that objective. Offering comfortable seating with a view to retail offers, or positioning restaurant and bar seating so that it faces retail outlets was mentioned by nearly all participants.

The only major point of disagreement was how to balance between provision of information and maximizing dwell time near stores. Some airport managers said that not publishing gate information until shortly before departure leads to passengers staying in a central area. Dwell time increases, and so does spending. Others claimed that this would increase stress levels, which in turn could reduce sales, and also reduces willingness to browse in shops, because people sit down near screens and waits for more information.

The qualitative survey suggested that despite the fact that arousal is high, the airport retail environment has a significant effect on shopping behaviour as well as evaluation of the store. Respondents also suggested that time pressure is an important antecedent of emotions, as delayed passengers are either less likely to notice environmental cues, or may react differently to stimuli. Time pressure for some people may cause no effect on shopping, and for others completing shopping faster, more efficiently, or be so stressed that they cannot concentrate on the stores.

The most relevant emotions which were mentioned were happiness, satisfaction (unhappiness, frustration) which appear more similar to each other and were hypothised to form one dimension, and relaxation, flow (stress, anger, nervousness) which could represent another dimension. Thus the qualitative study allowed to reconfirm some existing concepts, but allowed an important base to build the quantitative study on. 


\section{VI.2. Conclusions of the quantitative study}

The quantitative study was aiming to answer specific research questions how the airport retail environment influences consumer emotions, and - in turn - has an effect on their shopping behaviour and evaluation of the store. We also were interested in the influence of in-store personnel compared to the physical factors of the store on consumer emotions in airport retailing.

Customers at airports may perceive time pressure and anger when processes are delayed or take longer than expected (Taylor, 1994), which can influence emotions and behaviour in a store visited afterwards. Airports are also high pleasure environments, which have been linked to an above average likelihood of impulse shopping (Thomas, 1997). This is in conflict with some studies, which postulate that high arousal can reduce the impact of retail environment on behaviour (Donovan \& Rossiter, 1982; Foxall \& Greenley, 1999). Based on the qualitative pre-study it was proposed, that emotions relevant in airport duty free stores can be captured along two dimensions, termed pleasure and stress. In using a picture-based instrument, the data established a clear link between the environment of a store, emotions experienced by patrons and their behaviour and evaluation of the store. Customers who rated the airport duty free store environment positively also experienced higher levels of pleasure and lower levels of stress when leaving the store. The effect of social factors (sales staff) on emotions is $60 \%$ stronger then that of physical factors (store ambience and design), which stresses the importance of the sales staff in airport retail concepts. There are studies which ignore social cues (eg., Berman \& Evans, 1995), or only consider social stimuli by other customers (e.g., crowding research, Eroglu \& Machleit, 1990; Li, et al., 2009). Bitner (1990) showed that professional attire of service staff can increase customer's attribution and satisfaction. Baker et al. (1992) showed that social cues being present in a store increase arousal. Baker et al. (1994) proved that appropriately and friendly store personnel greeting customers improved perceived service quality. However, Turley \& Milliman (2000) suggest that more research is needed to understand this dimension of the retail environment. Even the classic servicescape model (Bitner, 1992) handles employee behaviours as a consequence of the physical environment. In her definition of the Servicescape, all "objective physical factors that can be controlled by the firm" (Bitner, 1992, p65) are included, however in her view this does not extend to behaviour and appearance of staff. Note that the role of flight crew uniforms in influencing 
passengers' anxiety on an airplane was noted over 40 years ago, but not empirically tested (Kotler, 1973). This study assumes that staff appearance and behaviour is set by the company as an element of the service marketing mix and therefore models social factors as antecedents of customer emotions.

Both the quantitative as well as the qualitative study confirm significant effects of the store environment on emotions, with the physical environment being related to both pleasure and stress, while the social environment only could be linked to pleasure. Previous studies confirm that happiness and pleasure can be positively influenced by the physical environments of malls (Wakefield \& Baker, 1998), individual store décor and design (Baker, et al., 2002; Spies, et al., 1997) and lighting (Areni \& Kim, 1994), for example. Our study found that design and ambient factors belong to the same dimension, whereas Wakefield \& Baker (1998) assert that they have differential effects on consumer responses. Their study was set in a multiple store environment (a mall), and therefore may have resulted in a higher variance than our study, which is limited to one store. Several authors have stated that design and ambient factors have different effects on consumer responses (Baker, 2002). However, our data suggests high intercorrelation and treats physical factors as a single dimension. This is in line with findings by Wakefield \& Baker (1998) who measured mall atmosphere using 12 items, and equally collapsed all items into a single construct, confirmed by a factor analysis with good model fit.

This study confirms that emotions influence consumer behaviour and opinion. The link between pleasure and behaviour as well as evaluation was significant, in line with past research; Chebat et al. (1995) found that pleasure had the strongest influence on approach. The measurement model chosen to measure stress did not confirm the hypothised effect on evaluation and behaviour. To date, little research has been done in this area in retail marketing. Most current stress research focuses on permanent or repeated acute stress after being exposed to ongoing disturbing stimuli (Folkman \& Lazarus, 1980; Larsson, et al., 1988; Mark, et al., 1997; Moksnes, Moljord, Espnes, \& Byrne, 2010), work-related stress (Newton, 1989; Wheaton, 1990) or commuter stress (G. W. Evans \& Wener, 2006; Hennessy, 2008; Wener, et al., 2003). The type of stress discussed here can be described as short-lived, acute stress. For example, stress during college examinations correlates highly with state anxiety and time urgency (Friend, 1982), which is also the case with both our measures of stress (picture scale and single- 
item verbal scale, see Pearson Correlation in Appendix). However we could not confirm any change in behaviour or evaluation as a consequence. One reason could be that shopping under time pressure leads to more planned pre-shopping, as was shown in a study among Christmas shoppers with self-imposed deadlines. This study also suggests that as Christmas gets closer, price sensitivity does not change, although feelings of regret after purchase do occur with some consumers (Miyazaki \& Carolina, 1993). Also it has been shown that time pressure leads to customers changing preferences, switching brands, or failing to buy intended products (Dhar \& Nowlis, 1999; Nowlis, 1995; Park, Iyer, \& Smith, 1989; Wright \& Weitz, 1977), however no studies could be located, which suggested a change of evaluation of the store itself. It is possible that at airports, the stress experienced is accepted (and maybe anticipated), and although being in a higher state of arousal, passengers still enter stores and affiliate with people in the same way.

Another explanation is that acute stress felt during the check-in and security screening process may be very short-lived and no longer influence behaviour in the duty free store. The qualitative study showed that several airports (including the location of the fieldwork of this study) place an 'orientation zone' just before the entrance of the duty free store, which offers place to sit down, groups to meet, and much information including airport maps and flight information screens. This is supposed to reduce stress levels before entering the retail area, and therefore respondents may still remember and report stress levels as were in the near past, however in-store behaviour was not affected. Next, there have been suggestions that store choice is affected by time pressure (Dhar \& Nowlis, 1999). Because this is the largest store, and located immediately in the path of the passenger, time pressure could in fact lead to a higher likelihood of shopping in this store rather than those, which require searching or diverting from the shortest path to the gate. This could be investigated in a future study involving more stores in the same environment.

Also, the design of the store (as well as staff uniforms) is distinctly different from that of security screening, therefore one could argue that customers are not allocating any 'blame' for negative experiences to the store. This would explain why the evaluation of the store and shopping experience was not moderated by stress and only by emotions along the 'pleasure' dimension. Another reason could be effects of the item 'anger' which is part of the stress measure. Anger can also increase approach. This would be in 
line with complement theory (Carver \& Scheier, 1990), which suggests that approach and avoidance do not only relate to positive and negative emotions. In fact, brain research found that people with higher dispositional anger have increased approach motivation and decreased withdrawal motivation. Anger can cause high levels of activity, which is focused and directed (Harmon-Jones \& Allen, 1998). One could argue that the duty free store plays an important role in coping with stress, as the staff in the store can give orientation and answer questions, but also shopping could be motivated by attempts to distract from or counterbalance feelings of anger (M. J. Arnold \& Reynolds, 2012).

The measures and constructs used for this study were shown to be equivalent across countries, which is important. Airport related research often involves a large number of countries without the possibility to develop separate measures or constructs for each, therefore the measures used in this study are likely to also work in other countries.

\section{VI.3. Methodological contributions}

This study is contributing to research methodology in several ways. Firstly, it applies a scale based on facial expressions to measure emotions in order to eliminate the possibility for measure variance across cultures. The 'stress' construct was less stable then the pleasure construct, which had good reliability, suggesting that it is possible to use picture-based scales to assess emotions. The scale was highly correlated with other scales assumed to measure the same concept (Russell, et al., 1989) and in general showed good validity. While the emotions showed were recognized by a high proportion of respondents correctly (Samuelsson, et al., 2012) they may have appeared extreme (especially the negative emotions), and resulted in less variance then desirable. However, based on our knowledge, this is one of the few attempts so far to measure the effect of retail environments on customer emotions using picture scales, and a contribution with relevance to those researchers considering to use graphic scales for measuring emotions. Visual imagery offers the benefit that pictures are more memorable than words (Lutz \& Lutz, 1978). Also retrieval of information in parallel is predominantly not verbal, whereas sequential information processing is a process that is more verbal (Paivio, 1975). We have shown, however, that there are numerous issues when applying a picture scale in practice, and caution needs to be exercised when generalising results. 
Also, we have contributed to the discussion of stress measures. While arousal and activation has been measured frequently in the past, acute stress is more often measured by identifying stressors rather than the emotional reactions. We proposed a construct consisting of the two basic emotions surprise and anger, which conceptionally and empirically is similar to the short-termed acute stress typically associated with air travel. We have also assumed that emotions are best measured with two dimensional constructs, however our review of the literature suggests that in airport environments, dimensions should not be positive/negative (Izard, 1977) or pleasure/arousal (Donovan \& Rossiter, 1982), as the important emotion of stress is not sufficiently represented.

\section{VI.4. Theoretical significance}

The present study has provided clear support for the presence of effects of airport retail environment on customer behaviour and store evaluation. Shoppers in airport environments are likely to be exposed to time pressure of varying levels, and to be less familiar with the environment. At the same time, there could be high levels of excitement and pleasure as well as anxiety caused by the anticipation of upcoming air travel. Despite these conditions, pleasure emerges as the dominant moderator of the effect of environmental cues on behaviour. The Mehrabian-Russel model also shows stable results in such extreme shopping environments. Staff appearance and behaviour are more important the store environment. Our results suggest that servicescapes can be analysed with a two-dimensional measure (physical and social factors). As expected, store evaluation as well as behaviour is influenced by the level of pleasure but not the level of stress. This could be because the stress measure used here picked up emotions which were felt before entering the store, however browsing activity led to stress reducing to a level where it did not affect shopping. This would confirm appraisal theory, if browsing and shopping distracted people and thus were a successful strategy of coping with anxiety.

\section{VI.5. Implications for practitioners}


This study has a number of implications for airport operators as well as retail concessionaires. The effect of staff appearance and behaviour on customer emotions is stronger then the effect of the physical store environment, underlining its importance in the service industry. It has also shown that any stress experienced by customers (possibly due to previous stressors/stimuli, such as long queues) will still be reported at the exit of the first duty free store, but has no effect on behaviour or evaluation. This may be caused by the design of the interior as well as passenger flow, as there is an orientation zone before the store entry, which allows groups to gather, and individuals to obtain information about next steps and time constraints. The study therefore confirmed the success of this concept. Also the study underlines the importance of assessing and controlling store environments as they influence customer emotions. Feelings of pleasure can be directly linked to a higher likelihood of customers browsing and affiliating with sales staff. Perceived time pressure significantly influences pleasure, and therefore needs to be monitored and managed accordingly.

\section{VI.6. Limitations}

The quantitative study has a number of limitations. Data was collected in only one store, with unchanged environmental characteristics during the field time. This meant that variations in the perceived physical environment are likely to be mainly caused by perception of the customers. It would be beneficial to repeat the study in several other stores to achieve higher variance within measures. Also, passengers with little time before departure were not recruited or dropped out of the study, therefore behaviour under extreme time pressure could not be addressed by this study. Findings are therefore only partly generalizable, and limited to customers arriving at least 70 minutes before departure to the airport. Measuring emotions using picture scales has been challenging, and results only partly satisfactory. While the construct pleasure has performed as expected in the conceptional model, stress did not, and therefore results may not be fully generalizable as a result of the lack of an established methodology of measuring emotions using picture scales.

\section{VI.7. Directions for future research}

The number of phenomena which were identified in the qualitative pre-study suggests that more research is required to fully understand all cause-effect relationships 
explaining airport shopping. A number of specific extensions of the present approach are being suggested: Firstly, much of the data collected in the quantitative study was not yet analysed. Because respondents completed interviews at four different stages of the airport process, including the measures related to environmental cues, emotions, planned or actual behaviour, a longitudinal study into the effects of servicescapes over time should be next. Due to the complexity, there is few research into how environments located before a store influence behaviour in that store, for example, although this is highly relevant in multi-store environments, such as shopping malls.

Next, cognitive effects, such as perceived service quality and value, could be included as mediator variables in a future model. There are two conflicting views, one suggesting that cognition is a mediator of the effect of the environment on emotions, and another one that it mediates the effect of emotions on behaviour. Both alternative models could be tested and compared. Also, other moderator effects could be modelled, such as access to information/experience, or general satisfaction with life.

Also, the use of pictures to represent emotions has been only partly successful. It would be valuable to compare various concepts (video animations, combination of verbal/visual scales, verbal scales) with each other to determine the viability of picture scales for the future. One should consider designing less extreme pictures more relevant to the airport environment.

Lastly, we have found only little effect of multinational variance of the data, which is somewhat surprising given that uncertainty avoidance, for example, is suggested to be a main factor when differentiating between cultures (Hofstede, 2001, 2011). As this also appears to be an under researched area in retail and service marketing, we encourage further research into the effect of culture on the impact of physical and social store environments on behaviour. 


\section{VII . REFERENCES}

AEA. (2008). Operating Economy of AEA Airlines, Closing Report 2007. Brussels.

Albers, S., Koch, B., \& Ruff, C. (2005). Strategic alliances between airlines and airports-theoretical assessment and practical evidence. Journal of Air Transport Management, 11(2), 49-58.

Anonymous. (2011). Retail Industry Global Report - 2010: Clearwater Corporate Finance.

Anonymous. (2012a). PaxFax Survey 2012 - Annual Passenger Survey. Company document. Budapest, Hungary: Budapest Airport Zrt.

Anonymous. (2012b). Verona Airport and Ryanair: the president of the province releases a declaration to AVIONEWS. AVIONEWS.

Areni, C. S., \& Kim, D. (1994). The influence of in-store lighting on consumers' examination of merchandise in a wine store. International Journal of Research in Marketing, 11, 117-125.

Argo, J. J., Dahl, D. W., \& Manchanda, R. V. (2005). The influence of a mere social presence in a retail context. Journal of Consumer Research, 32, 207-212.

Arnold, M. B. (1960). Emotion and personality. 1, New York: Cassell \& Co.

Arnold, M. J., \& Reynolds, K. E. (2012). Approach and Avoidance Motivation: Investigating Hedonic Consumption in a Retail Setting. Journal of Retailing, 88(3), 399-411.

Arnould, E. J., Price, L. L., \& Tierney, P. (1998). Communicative staging of the Wilderness servicescape. The Service Industries Journal, 18, 90-115.

Aubert-Gamet, V. (1997). Twisting servicescapes: Diversion of the physical environment in a re-appropriation process. Journal of Service Management, 8, 2641.

Averill, J. R. (1973). Personal control over aversive stimuli and its relationship to stress. Psychological Bulletin, 80, 286-303.

Babin, B. J., \& Darden, W. R. (1996). Good and bad shopping vibes: spending and patronage satisfaction. Journal of Business Research, 35, 201-206.

Babin, B. J., Hardesty, D. M., \& Suter, T. A. (2003). Color and shopping intentions the intervening effect of price fairness and perceived affect. Journal of Business Research, 56, 541-551.

Backhaus, K., Erichson, B., \& Weiber, R. (2011). Fortgeschrittene Multivariate Analysemethoden: Eine anwendungsorientierte Einführung (1. ed.). Heidelberg: Springer.

Bagozzi, R. P., Gopinath, M., \& Nyer, P. U. (1999). The role of emotions in marketing. Journal of the Academy of Marketing Science, 27, 184-206.

Baier, W. (2010). Das Einzelhandelsgeschaeft am Flughafen (Airport Retail Business). In Management Circle Intensiv-Seminar. Hamburg: Hochtief AirPort. 
Bailey, N., \& Areni, C. S. (2006). When a few minutes sound like a lifetime: Does atmospheric music expand or contract perceived time? Journal of Retailing, 82(3), 189-202.

Baker, J. (1987). The role of the environment in marketing services: the consumer perspective. In J. Czepiel, C. A. Congram \& J. Shanahan (Eds.), The Services Challenge: Integrating for Competitive Advantage (pp. 79-84). Chicago: American Marketing Association.

Baker, J., Grewal, D., \& Parasuraman, A. (1994). The influence of store environment on quality inferences and store image. Journal of the Academy of Marketing Science, $22,328-339$.

Baker, J., Levy, M., \& Grewal, D. (1992). An experimental approach to making retail store environmental decisions. Journal of Retailing, 68, 445-460.

Baker, J., Parasuraman, A., Grewal, D., \& Voss, G. B. (2002). The influence of multiple store environment cues on perceived merchandise value and patronage intentions. Journal of Marketing, 66, 120-141.

Bamberger, V., Bettati, A., Hoefflinger, S., Kuruvilla, T., \& Wille, V. (2009). Mastering airport retail - roadmap to new industry standards. Paris: Arthur.

Baron, S., \& Wass, K. (1996). Towards an understanding of airport shopping behaviour. The International Review of Retail, Distribution and Consumer Research, 6(3), 301-322.

Bawa, K., Landwehr, J. T., \& Krishna, A. A. (1989). Consumer response to retailers' marketing environments: an analysis of coffee purchase data. Journal of Retailing, 65, 471-495.

Bellizzi, J. A., Crowley, A. E., \& Hasty, R. W. (1983). The effects of color in store design. Journal of Retailing, 59, 21-47.

Bellizzi, J. A., \& Hite, R. E. (1992). Environmental color, consumer feelings, and purchase likelihood. Psychology and Marketing, 9, 347-363.

Bentler, P. M., \& Chou, C. P. (1987). Practical Issues in Structural Modeling. Sociological Methods \& Research, 16(1), 78-117.

Bergkvist, L., \& Rossiter, J. R. (2007). The predictive validity of multiple-item versus single-item measures of the same constructs. Journal of Marketing Research, 44(2), 175-184.

Berman, B., \& Evans, J. R. (1995). Retail management: a strategic approach. Pearson Education.

Biehl, M., Matsumoto, D., Ekman, P., Meant, V., Heider, K., Kudoh, T., \& Ton, V. (1997). Matsumoto and Ekman's Japanese and Caucasian Facial Expressions of Emotion (JACFEE): Reliability data and cross-national differences. Journal of Nonverbal Behaviour, 21, 3-21.

Bitner, M. J. (1990). Evaluating service encounters: the effects of physical surroundings and employee responses. Journal of Marketing, 54, 69-82.

Bitner, M. J. (1992). Servicescapes: the impact of physical surroundings on customers and employees. Journal of Marketing, 56, 57-71. 
Blackwell, R. D., Miniard, P. W., \& Engel, J. F. (2001). Consumer Behavior. Troy, MO: Harcourt College Publishers.

Boether, A. (2008). Thema des Jahres: Airport-Shopping (topic of the year: airport shopping). In Retail Opportunities Germany (pp. 5-9). Berlin.

Bohl, P. (2012). The effects of store atmosphere on behaviour - A literature review. Corvinus Marketing Tanulmánok(1), 1-23.

Bone, P. F., \& Ellen, P. S. (1999). Scents in the marketplace: explaining a fraction of olfaction. Journal of Retailing, 75, 243-262.

Bost, E. (1987). Ladenatmosphäre und Konsumentenverhalten (Retail atmospherics and consumer behaviour). Heidelberg: Physica-Verlag.

Bower, G. H. (1981). Mood and Memory. American Psychologist, 36(2), 129-148.

Bowes, B. (1998). The effects of emotion and time to shop on shopping - behaviour in an international airport terminal. 207-214.

Bradford, K. D., \& Desrochers, D. M. (2009). The use of scents to influence consumers: the sense of using scents to make cents. Journal of Business Ethics, 90, 141-153.

Bresnen, M. (1988). Insights on Site: Research into Construction Project Organizations. In A. Bryman (Ed.), Doing Research in Organisations (pp. 35-52). London: Routledge.

Bricker, J. B. (2005). Development and evaluation of the Air Travel Stress Scale. Journal of Counseling Psychology, 52(4), 615-628.

Broekemier, G., Marquardt, R., \& Gentry, J. W. (2008). An exploration of happy/sad and liked/disliked music effects on shopping intentions in a women's clothing store service setting. Journal of Services Marketing, 22(1), 59-67.

Brüggen, E. C., Foubert, B., \& Gremler, D. D. (2011). Extreme Makeover: Short- and Long-Term Effects of a Remodeled Servicescape. Journal of Marketing, 75(5), 7187.

Bruwer, J., Lesschaeve, I., \& Campbell, B. L. (2012). Consumption dynamics and demographics of Canadian wine consumers: Retailing insights from the tasting room channel Journal of Retailing and Consumer Services, 19(1), 45-58.

Bush, A. J., \& Hair Jr, J. F. (1985). An Assessment of the Mall Intercept as a Data Collection Method. Journal of Marketing Research (JMR), 22(2), 158-167.

Caldwell, C., \& Hibbert, S. A. (2002). The influence of music tempo and musical preference on restaurant patrons' behavior. Psychology and Marketing, 19, 895-917.

Carver, C. S., \& Scheier, M. F. (1990). Origins and functions of positive and negative effect - a control-process view. Psychological Review, 97(1), 19-35.

Chebat, J.-C., \& Michon, R. (2003). Impact of ambient odors on mall shoppers' emotions, cognition, and spending: a test of competitive causal theories. Journal of Business Research, 56, 529.

Chebat, J.-C., \& Morrin, M. (2007). Colors and cultures: Exploring the effects of mall décor on consumer perceptions. Journal of Business Research, 60(3), 189-196. 
Chebat, J. C., GelinasChebat, C., Vaninski, A., \& Filiatrault, P. (1995). The impact of mood on time perception, memorization, and acceptance of waiting. Genetic Social and General Psychology Monographs, 121(4), 413-424.

Cheng, Y.-H. (2010). Exploring passenger anxiety associated with train travel. Transportation, 37(6), 875-896.

Chin, W. W. (1998). Issues and opinion on structural equation modeling. MIS Quarterly, 22(1), 7-16.

Cobb, C. J., \& Hoyer, W. D. (1986). Planned versus impulse purchase behavior. Journal of Retailing, 62, 384-409.

Cohen, S. (1978). Environmental load and the allocation of attention. In A. Baum, J. E. Singer \& S. Valins (Eds.), Advances in environmental psychology (Vol. 1, pp. 129). Hillsdale, NJ: Erlbaum.

Cohn, J. F., Zlochower, A. J., Lien, J., \& Kanade, T. (1999). Automated face analysis by feature point tracking has high concurrent validity with manual FACS coding. Psychophysiology, 36(1), 35-43.

Commission, the European (2010). Commission Regulation (EU) No 297/2010.

Corbin, J., \& Strauss, A. L. (1990). Grounded Theory Research: Procedures, Canons, and Evaluative Criteria. Qualitative Sociology, 13, 3-21.

Cornelius, B., Natter, M., \& Faure, C. (2010). How storefront displays influence retail store image. Journal of Retailing and Consumer Services, 17(2), 143-151.

Craig, C. S., \& Douglas, J. D. (2000). International Marketing Research (2nd edition ed.). New York: John Wiley and Sons.

Crawford, G., \& Melewar, T. C. (2003). The importance of impulse purchasing behaviour in the international airport environment. Journal of Consumer Behaviour, 3, 85-98.

Cronin Jr., J. J. (2003). Looking back to see forward in services marketing: some ideas to consider. Managing Service Quality, 13, 332-337.

Csikszentmihalyi, M. (1990). Flow: The Psychology of Optimal Experience. NewYork: Harper Collins.

d'Astous, A. (2000). Irritating aspects of the shopping environment. Journal of Business Research, 49, 149-156.

Dagenais, M. G. (1973). The Use of Incomplete Observations in Multiple Regression Analysis: A Generalized Least Squares Approach. Journal of Econometrics, 1, 317328.

Darwin, C. (1872). The Expression of the Emotions in Man and the Animals. London: John Murray.

Dawson, S. A., Bloch, P. H., \& Ridgway, N. M. (1990). Shopping motives, emotional states, and retail outcomes. Journal of Retailing, 66, 408-427.

de Leeuw, E. D., \& van der Zouwen, J. (1988). Data quality in telephone and face-toface surveys - A comparative metaanalysis. In R. M. Groves, L. E. Biemer, J. T. Lyberg, W. L. Massey, I. Nicholls \& J. Waksberg (Eds.), Telephone survey methodology (pp. 283-300). New York: Wiley. 
Dennis, C., Newman, A., Michon, R., Brakus, J. J., \& Wrigh, L. T. (2010). The mediating effects of perception and emotion: Digital signage in mall atmospherics. Journal of Retailing and Consumer Services, 17, 205-215.

Denstadli, J. M. (2000). Analyzing Air Travel: A Comparison of Different Survey Methods and Data Collection Procedures. Journal of Travel Research, 39(4), 1-10.

Desmet, P. M. A. (2005). Measuring emotion. In M. A. Blythe, A. F. Monk, K. Overbeeke \& P. C. Wright (Eds.), Funology: from usability to enjoyment (pp. 111124). Dordrecht: Kluwer Academic Publishers.

Dhar, R., \& Nowlis, S. M. (1999). The effect of time pressure on consumer choice deferral. Journal of Consumer Research, 25, 369-384.

Diamantopoulos, A., \& Siguaw, J. A. (2000). Introducing LISREL. London: Sage Publications.

Dickerson, S. S., \& Kemeny, M. E. (2004). Acute Stressors and Cortisol Responses: A Theoretical Integration and Synthesis of Laboratory Research. Psychological Bulletin, 130(3), 355-391.

Diener, E., Shigehiro, O., \& Lucas, R. (2009). Subjective Well-Being: The science of happiness and life satisfaction (2nd ed. ed.). Oxford, U.K.: Oxford University Press.

Diong, S.-M., \& Bishop, G. D. (1999). Anger Expression, Coping Styles, and Wellbeing. Journal of Health Psychology, 4(1), 81-96.

Diong, S.-M., Bishop, G. D., Enkelmann, H. C., Tong, E. M. W., Why, Y. P., Ang, J. C. H., \& Khader, M. (2005). Anger, stress, coping, social support and health: Modelling the relationships. Psychol Health, 20(4), 467-495.

Doganis, R. (1992). The Airport Business. London and New York: Routledge.

Donovan, R. J., \& Rossiter, J. R. (1982). Store atmosphere: an environmental psychology approach. Journal of Retailing, 58, 34-57.

Donovan, R. J., Rossiter, J. R., Marcoolyn, G., \& Nesdale, A. (1994). Store atmosphere and purchasing behavior. Journal of Retailing, 70, 198-199.

Douglas, J. D. (1976). Investigative Social Research: Individual and Team Field Research. Beverly Hills: Sage.

Douglas, S. P., \& Craig, C. S. (2006). On Improving the Conceptual Foundations of International Marketing Research. Journal of International Marketing, 14(1), 1-22.

Dubé, L., Chebat, J.-C., \& Morin, S. (1995). The effects of background music on consumers' desire to affiliate in buyer-seller interactions. Psychology and Marketing, 12, 305-319.

Dubé, L., \& Morin, S. (2001). Background music pleasure and store evaluation: intensity effects and psychological mechanisms. Journal of Business Research, 54, 107-113.

Earley, C. P., \& Singh, H. (1995). International and intercultural management research: what's next. Academy of Management Journal, 38, 327-340.

Edwards, S., \& Shackley, M. (1992). Measuring the effectiveness of retail window display as an element of the marketing mix. International Journal of Advertising, $11,193-202$. 
Eisler, R. M., Skidmore, J. R., \& Ward, C. H. (1988). Masculine Gender-Role Stress Predictor of Anger, Anxiety, and Health-Risk Behaviors. Journal of Personality Assessment, 52(1), 133-141.

Ekman, P. (1973). Cross-cultural studies of facial expression. In P. Ekman (Ed.), Darwin and facial expression - A century of research in review. New York: Academic Press.

Ekman, P. (1992). Facial Expressions of Emotions - New Findings, New Questions. Psychological Science, 3, 34-38.

Ekman, P., \& Friesen, W. V. (1971). Constants across culture in the face and emotion. Journal of Personality and Social Psychology, 17, 124-129.

Ekman, P., \& Friesen, W. V. (1978). Facial Action Coding System (FACS): A technique for the measurement of facial actions. Palo Alto: Consulting Psychologists Press.

Ekman, P., Sorenson, E. R., \& Friesen, W. V. (1969). Pan-Cultural Elements in Facial Displays of Emotion. Science, 164, 86-88.

Ellis, L., \& Ficek, C. (2001). Color preferences according to gender and sexual orientation. Personality and Individual Differences, 31, 1375-1379.

Eroglu, S. A., \& Harrell, G. D. (1986). Retail crowding - theoretical and strategic implications. Journal of Retailing, 62, 346-363.

Eroglu, S. A., \& Machleit, K. A. (1990). An empirical study of retail crowding: antecedents and consequences. Journal of Retailing, 66, 201-221.

Evans, B. J., \& Coman, G. J. (1993). General versus specific measures of occupational stress: An Australia police survey. Stress Medicine, 9, 11-20.

Evans, G. W., \& Wener, R. E. (2006). Rail commuting duration and passenger stress. Health Psychol, 25(3), 408-412.

Evans, G. W., \& Wener, R. E. (2007). Crowding and personal space invasion on the train: Please don't make me sit in the middle. Journal of Environmental Psychology, 27(1), 90-94.

Ezeh, C., \& Harris, L. C. (2007). Servicescape research: a review and a research agenda. Marketing Review, 7, 59-78.

Fishbein, M., \& Ajzen, I. (1975). Belief, Attitude, Intention, and Behavior: An Introduction to Theory and Research. Reading, MA: Addison-Wesley.

Folkman, S., \& Lazarus, R. S. (1980). An analysis of coping in a middle-aged community sample. Journal of Health and Social Behavior, 21, 219-239.

Fornell, C., \& Larcker, D. F. (1981). Evaluating Structural Equation Models with Unobservable Variables and Measurement Error. Journal of Marketing Research, 18(1), 39-50.

Foxall, G. R., \& Greenley, G. E. (1999). Consumers' emotional responses to service environments. Journal of Business Research, 46, 149-158.

Francis, J. J., Johnston, M., Robertson, C., Glidewell, L., Entwistle, V., Eccles, M. P., \& Grimshaw, J. M. (2010). What is an adequate sample size? Operationalising data saturation for theory-based interview studies. Psychology, Health and Medicine, 25(10), 1229-1245. 
Freathy, P., \& O'Connell, F. (1998). European Airport Retailing - Growth Strategies for the New Millenium. London: Macmillan Publishers Limited.

Freathy, P., \& O'Connell, F. (1999a). Planning for Profit: the Commercialization of European Airports. Long Range Planning, 32, 587-597.

Freathy, P., \& O'Connell, F. (1999b). A Typology of European Airport Retailing. The Service Industries Journal, 19(3), 119-134.

Freathy, P., \& O'Connell, F. (2012). Spending time, spending money: passenger segmentation in an international airport. The International Review of Retail, Distribution and Consumer Research, 22(4), 397-416.

Fridlund, A. J., Ekman, P., \& Oster, H. (1987). Facial expressions of emotion: a review of the literature. In A. W. Siegman \& S. Feldstein (Eds.), Nonverbal Behaviour and Communication (2nd ed. ed., pp. 143-224). Hillsdale, NJ: Erlbaum.

Friend, K. E. (1982). Stress and Performance: Effects of Subjective Work Load and Time Urgency. Personnel Psychology, 35, 623-633.

Frijda, N. H. (1986). The Emotions. Cambridge: Cambridge University Press.

Frijda, N. H. (2010). Impulsive action and motivation. Biological Psychology, 84(3), 570-579.

Fuchs, C., \& Diamantopoulos, A. (2009). Using single-item measures for construct measurement in management research - conceptual issues and application guidelines. Die Betriebswirtschaft, 69(2), 195-210.

Gagnon, J. P., \& Osterhaus, J. T. (1985). Effectiveness of floor displays on the sales of retail products. Journal of Retailing, 61, 104-116.

Gardner, M. P. (1985). Mood states and consumer behaviour: a critical review. Journal of Consumer Research, 12, 281-300.

Gardner, M. P., \& Siomkos, G. J. (1986). Toward a methodology for assessing effects of in-atore atmospherics. Advances in Consumer Research, 13, 27-31.

Garlin, F. V., \& Owen, K. (2006). Setting the tone with the tune: A meta-analytic review of the effects of background music in retail settings. Journal of Business Research, 59(6), 755-764.

Geuens, M., Vantomme, D., \& Brengman, M. (2004). Developing a typology of airport shoppers. Tourism Management, 25(5), 615-622.

Gillen, D., \& Morrison, W. G. (2005). The economics of franchise contracts and airport policy. Journal of Air Transport Management, 11(1), 43-48.

Gillis, J. S. (1992). Stress, anxiety, and cognitive buffering. Behavioral medicine, 18, 79-83.

Glaser, B. G. (1978). Theoretical sensitivity - advances in the methodology of grounded theory. Mill Valley, CA: Sociology Press.

Glaser, B. G., \& Strauss, A. L. (1967). The discovery of grounded theory - strategies for qualitative research. Chicago: Aldine Publishing Company.

Glaser, W. R., \& Glaser, M. O. (1989). Context effects in stroop-like word and picture processing. Journal of Experimental Psychology, 118, 13-42. 
Goeleven, E., De Raedt, R., Leyman, L., \& Verschuere, B. (2008). The Karolinska Directed Emotional Faces: A validation study. Cognition \& Emotion, 22(6), 10941118.

Graham, A. (2009). How important are commercial revenues to today's airports? Journal of Air Transport Management, 15(3), 106-111.

Grewal, D., Baker, J., Levy, M., \& Voss, G. B. (2003). The effects of wait expectations and store atmosphere evaluations on patronage intentions in service-intensive retail stores. Journal of Retailing, 79(4), 259-268.

Griffitt, W. (1970). Environmental effects on interpersonal affective behavior: ambient effective temperature and attraction. Journal of Personality and Social Psychology, $15,240-244$.

Groeppel-Klein, A. (2005). Arousal and consumer in-store behavior. Brain Research Bulletin, 67(5), 428-437.

Groeppel-Klein, A., \& Bartmann, B. (2008). Anti-Clockwise or Clockwise? The Impact of Store Layout on the Process of Orientation in a Discount Store. European Advances in Consumer Research, 8, 415-416.

Grossbart, S. L., Mittelstaedt, R. A., Curtis, W. W., \& Rogers, R. D. (1975). Environmental sensitivity and shopping behavior. Journal of Business Research, 3, 281-294.

Guest, G., Bunce, A., \& Johnson, L. (2006). How many interviews are enough? An experiment with data saturation and variability. Field Methods, 18, 59-82.

Hair, J. F., Anderson, R. E., Tatham, R. L., \& Black, W. C. (1998). Multivariate data analysis (fifth ed. ed.). Upper Saddle River, NJ.: Prentice Hall.

Hansen, F. (1972). Consumer choice behavior: a cognitive theory: Free Press.

Harmon-Jones, E., \& Allen, J. J. B. (1998). Anger and frontal brain activity: EEG asymmetry consistent with approach motivation despite negative affective valence. Journal of Personality and Social Psychology, 74(5), 1310-1316.

Harrell, G. D., \& Hutt, M. D. (1976). Buyer behavior under conditions of crowding: an initial framework. Advances in Consumer Research, 3, 36-39.

Harrell, G. D., Hutt, M. D., \& Anderson, J. C. (1980). Path analysis of buyer behavior under conditions of crowding. Journal of Marketing Research, 17, 45-51.

Hart, T. (2011). Introduction to TAMS Analyser for Mac OSX. Center for Social Science Computation and Research University of Washington, Seattle.

Hasty, R. W., \& Reardon, J. (1996). Retail Management. New York: McGraw Hill.

Havlena, W. J., \& Holbrook, M. B. (1986). The varieties of consumption experience: Comparing two typologies of emotion in consumer behavior. Journal of Consumer Research, 13, 394-404.

Heinzelmann, U. (1991). Towards optimal concession revenues and rent. In Airport Economics and Finance Symposium. London: Polytechnic of Central London.

Hennessy, D. A. (2008). The impact of commuter stress on workplace aggression. Journal of Applied Social Psychology, 38, 2315-2335. 
Hennessy, D. A., \& Jakubowski, R. (2007). The impact of stressful commuting on subsequent performance during low versus high frustration tasks. In A. M. Columbus (Ed.), Advances in Psychology Research (pp. 263-272): Nova Science Publishers.

Hennessy, D. A., \& Wiesenthal, D. L. (1997). The relationship between traffic congestion, driver stress and direct versus indirect coping behavious. Ergonomics, 40, 348-361.

Hermalin, B. E., \& Isen, A. M. (2007). A model of the effect of affect on economic decision making. Quantitative Marketing and Economics, 6(1), 17-40.

Hightower, R., Brady, M. K., \& Baker, T. L. (2002). Investigating the role of the physical environment in hedonic service consumption: an exploratory study of sporting events. Journal of Business Research, 55, 697-707.

Hoch, S. J., \& Loewenstein, G. F. (1991). Time-inconsistent Preferences and Consumer Self-Control. Journal of Consumer Research, 17, 492-508.

Hoffman, D., \& Turley, L. W. (2002). Atmospherics, service encounters and consumer decision making: an integrative perspective. Journal of Marketing Theory and Practice, 10, 33-47.

Hofstede, G. (2001). Culture's consequences: comparing values, behaviors, institutions, and organizations across nations. Cultures Consequences Comparing Values Behaviors Institutions and Organizations across Nations.

Hofstede, G. (2011). Cultural Dimensions. geert-hofstede.com. Webpage. last accessed on 31 Sept., 2013.

Holbrook, M. B. (1986). Emotions in the consumption experience: toward a new model of consumer behavior. In R. A. Peterson, W. D. Hoyer \& W. R. Wilson (Eds.), The Role of Affect in Consumer Behavior: Emerging Theories and Applications (pp. 1752). Lexington, MA: Heath.

Homburg, C., \& Klarmann, M. (2006). Die Kausalanalyse in der empirischen betriebswirtschaftlichen Forschung -- Problemfelder und Anwendungsempfehlungen. (German). Die Betriebswirtschaft, 66(6), 727-748.

Hooper, D., Coughlan, J., \& Mullen, M. (2008). Structural Equation Modelling: Guidelines for Determining Model Fit. Electronic Journal of Business Research Methods, 6(1), 53-60.

Hu, L. T., \& Bentler, P. M. (1999). Cutoff Criteria for Fit Indexes in Covariance Structure Analysis: Conventional Criteria Versus New Alternatives. Structural Equation Modeling, 6(1), 1-55.

Hui, M. K., \& Bateson, J. E. G. (1991). Perceived control and the effects of crowding and consumer choice on the service experience. Journal of Consumer Research, 18, 174-184.

Hui, M. K., Dubé, L., \& Chebat, J.-C. (1997). The impact of music on consumers' reactions to waiting for services. Journal of Retailing, 73, 87-104.

Hulin, C. (2001). Can a reliability coefficient be too high? Journal of Consumer Psychology, 10(1-2), 55-56. 
Hutton, J. D., \& Richardson, L. D. (1995). Healthscapes: the role of the facility and physical environment on consumer attitudes, satisfaction, quality assessments, and behaviors. Health Care Management Review, 20, 48-61.

Inman, J. J., McAlister, L., \& Hoyer, W. D. (1990). Promotion signal: proxy for a price cut? Journal of Consumer Research, 17, 74-81.

Inman, J. J., Winer, R. S., \& Ferraro, R. (2009). The interplay among category characteristics, customer characteristics, and customer activities on in-store decision making. Journal of Marketing, 73, 19-29.

Isen, A. M., Nygren, T. E., \& Ashby, F. G. (1988). Influence of Positive Affect on the Subjective Utility of Gains and Losses - It Is Just Not Worth the Risk. Journal of Personality and Social Psychology, 55(5), 710-717.

Isen, A. M., \& Patrick, R. (1983). The Effect of Positive Feelings on Risk-Taking When the Chips Are Down. Organizational Behavior and Human Performance, 31(2), 194-202.

Isen, A. M., Shalker, T. E., Clark, M., \& Karp, L. (1978). Affect, accessibility of material in memory, and behavior - a cognitive loop? Journal of Personality and Social Psychology, 36(1), 1-12.

Iyer, E. S. (1989). Unplanned purchasing: knowledge of shopping environment and time pressure. Journal of Retailing, 65, 40-57.

Izard, C. E. (1977). Human Emotions. New York: Plenum Press.

Izard, C. E. (2007). Basic emotions, natural kinds, emotion schemas, and a new paradigm. Perspectives on Psychological Science, 2, 260-280.

James, W. (1890). The Principles of Psychology. New York: Henry.

Jang, S., \& Namkung, Y. (2009). Perceived quality, emotions, and behavioral intentions: Application of an extended Mehrabian-Russell model to restaurants. Journal of Business Research, 62(4), 451-460.

Jones, D. J. H. (2000). Murder in the new age. Albuquerque: University of New Mexico Press.

Jones, M. A., Reynolds, K. E., \& Arnold, M. J. (2006). Hedonic and utilitarian shopping value: Investigating differential effects on retail outcomes. Journal of Business Research, 59(9), 974-981.

Jordan, L. A., Marcus, A. C., \& Reeder, L. C. (1980). Response styles in telephone and household interviewing: A field experiment. Public Opinion Quarterly, 44, 10-22.

Józsa, L., Bátor, A., \& Sassné Grósz, A. (1999). Marketingtaktikai elemek a kiskereskedelemben (Elements of marketing tactics in retail). Marketing \& menedzsment, 33, 19-22.

Kahn, B. E., \& Isen, A. M. (1993). The influence of positive affect onvariety seeking among safe, enjoyable products. Journal of Consumer Research, 20(2), 257-270.

Kaiser, S., \& Wehrle, T. (2001). Facial expressions as indicators of appraisal processes. In K. R. Scherer, A. Schorr \& T. Johnstone (Eds.), Appraisal processes in emotions: Theory, methods, research (pp. 285-300). New York, NY: Oxford University Press.

Keillor, B. D., Hult, G. T. M., \& Kandemir, D. (2004). A study of the service encounter in eight countries. Journal of International Marketing, 12(1), 9-35. 
Kenesei, Z. (2002). A kiskereskedelem lehetőségei a vásárlók bolthűségének megtartásában (Possibilities in retail for retaining customer loyalty). Vezetéstudomány, 33, 20-29.

Killgore, W. D. S. (1998). The Affect Grid: A moderately valid, nonspecific measure of pleasure and arousal. Psychological Reports, 83(2), 639-642.

Kim, H.-B., \& Shin, J.-H. (2001). A contextual investigation of the operation and management of airport concessions. Tourism Management, 22, 149-155.

Kim, W. G., \& Moon, Y. J. (2009). Customers' cognitive, emotional, and actionable response to the servicescape: A test of the moderating effect of the restaurant type. International Journal of Hospitality Management, 28(1), 144-156.

King, N. (1994). The qualitative research interview. In S. Cassell \& G. Symon (Eds.), Qualitative Methods in Organizational Research: A Practical Guide (pp. 14-36). London: Sage.

Kirkland, T., \& Cunningham, W. A. (2012). Mapping emotions through time: how affective trajectories inform the language of emotion. Emotion, 12(2), 268-282.

Kirschbaum, C., \& Hellhammer, D. H. (1989). Salivary cortisol in psychobiological research: an overview. Neuropsychobiology, 22(3), 150-169.

Klarmann, M. (2011). Construct Measurement and Structural Equation Modeling. Doctoral Seminar, Corvinus University of Budapest. Budapest.

Kline, P. (1999). The handbook of psychological testing (2nd ed.). London: Routledge.

Koo, D.-M., \& Lee, J.-H. (2011). Inter-relationships among dominance, energetic and tense arousal, and pleasure, and differences in their impacts under online vs. offline environment. Computers in Human Behavior, 27(5), 1740-1750.

Kotler, P. (1973). Atmospherics as a marketing tool. Journal of Retailing, 49, 48-64.

Krishna, A. (2010). Sensory Marketing: Research on the Sensuality of Products. New York: Routledge.

Krishna, A. (2012). An integrative review of sensory marketing: Engaging the senses to affect perception, judgment and behavior. Journal of Consumer Psychology, 22(3), 332-351.

Kroeber-Riel, W. (1979). Activation Research - Psychobiological Approaches in Consumer Research. Journal of Consumer Research, 5(4), 240-250.

Kroeber-Riel, W., \& Weinberg, P. (2003). Konsumentenverhalten (Consumer behaviour). München: Vahlen.

Larsson, G., Kempe, C., \& Starrin, B. (1988). Appraisal and coping processes in acute time-limited stressful situations: A study of police officers. European Journal of Personality, 2, 259-276.

Lawshe, C. H. (1975). Quantitative Approach to Content Validity. Personnel Psychology, 28(4), 563-575.

Lazarus, R. S. (1966). Psychological stress and the coping process. McGrawHill series in psychology, New York, McGraw-Hill.

Lazarus, R. S. (1990). Theory-based stress measurement. Psychological Inquiry, 1, 313. 
Lazarus, R. S. (1991). Cognition and motivation in emotion. American Psychologist, 46, 352-367.

Lazarus, R. S. (1994). Emotion and Adaptation Oxford: Oxford University Press.

Lazarus, R. S., \& Folkman, S. (1984). Stress, appraisal, and coping. New York: Springer Publishing Company Inc,

Lazarus, R. S., \& Folkman, S. (1987). Transactional theory and research on emotions and coping. European Journal of Personality, 1, 141-169.

Lazarus, R. S., \& Launier, R. (1978). Stress-related transactions between person and environment. In L. Pervin \& M. Lewis (Eds.), Perspectives in interactional psychology (Vol. 287, pp. 287-327). New York: Plenum.

Lee, T. W. (1999). Using qualitative methods in organizational research. London: Sage.

Levine, S., \& Ursin, H. (1991). What is stress? In M. R. Brown, G. F. Koob \& C. Rivier (Eds.), Neurobiology and Neuroendocrinology of Stress (pp. 3-21). New York: Marcel Dekker, Inc.

Levy, M., \& Weitz, B. A. (2009). Retailing Management (7th ed.). Boston, USA: Irwin.

Li, J.-G. T., Kim, J.-O., \& Lee, S. Y. (2009). An empirical examination of perceived retail crowding, emotions, and retail outcomes. The Service Industries Journal, 29(5), 635-652.

Liermann, G., \& Rumetsch, S. (2011). German Retail Market Property Analysis. In (pp. 29). Frankfurt.

Lincoln, Y. S. \& Guba, E. G. (1985). Naturalistic inquiry. Newbury Park, CA: Sage Publications.

Lindsley, D. B. (1951). Emotion. In S. S. Stevens (Ed.), Handbook of Experimental Psychology. New York: Wiley \& Sons.

Lunardo, R., \& Mbengue, A. (2009). Perceived control and shopping behavior: The moderating role of the level of utilitarian motivational orientation. Journal of Retailing and Consumer Services, 16, 434-441.

Lutz, K. A., \& Lutz, R. J. (1978). Imagery eliciting strategies: Review and implication of research. In H. K. Hunt (Ed.), Advances in Consumer Research (Vol. V., pp. 611-620).

Lyon, D., \& Francis, G. (2006). Managing New Zealand's airports in the face of commercial challenges. Journal of Air Transport Management, 12(5), 220-226.

Machleit, K. A., \& Eroglu, S. A. (2000). Describing and measuring emotional response to shopping experience. Journal of Business Research, 49, 101-111.

Machleit, K. A., Eroglu, S. A., \& Mantel, S. P. (2000). Perceived retail crowding and shopping satisfaction: What modifies this relationship? Journal of Consumer Psychology, 9, 29-42.

Machleit, K. A., Kellaris, J. J., \& Eroglu, S. A. (1994). Human versus spatial dimensions of crowding perceptions in retail environments: a note on their measurement and effect on shopper satisfaction. Marketing Letters, 5, 183-194. 
Machleit, K. A., \& Mantel, S. P. (2001). Emotional response and shopping satisfaction: Moderating effects of shopper attributions. Journal of Business Research, 54, $97-$ 106.

Malhotra, N. K. (2009). Marketing Research (5th ed.). New York: Pearson/Prentice Hall.

Mark, H. A., Robertson, M., \& Caputi, P. (1997). Sources of acute stress and their appraisals and reappraisals among Australian police as a function of previous experience. Journal of Occupational and Organizational Psychology, 70, 337-356.

Mattila, A. S., \& Wirtz, J. (2001). Congruency of scent and music as a driver of in-store evaluations and behavior. Journal of Retailing, 77, 273-289.

McGrath, J. E. (1970). A conceptual formulation for research on stress. In J. E. McGrath (Ed.), Social and psychological factors in stress (pp. 10-21). New York: Holt, Rinehart, \& Winston.

Mehrabian, A. (1976). Public places and private spaces: the psychology of work, play and living environments. New York, NY: Basic Books, Inc.

Mehrabian, A. (1995). Framework for a comprehensive description and measurement of emotional states. Genetic, Social \& General Psychology Monographs, 121.

Mehrabian, A., \& Russell, J. A. (1974). An approach to environmental psychology. Cambridge, MA.: MIT Press.

Meixner, O. (1999). Konsumentenverhalten auf Bauernmärkten in Wien (Consumer behaviour at farmer markets in Vienna). Die Bodenkultur, 50, 263-277.

Menon, S., \& Kahn, B. E. (2002). Cross-category effects of induced arousal and pleasure on the Internet shopping experience. Journal of Retailing, 78, 31- 40.

Michon, R., Chebat, J.-C., \& Turley, L. W. (2005). Mall atmospherics: the interaction effects of the mall environment on shopping behavior. Journal of Business Research, 58, 576-583.

Mill, A., Allik, J., Realo, A., \& Valk, R. (2009). Age-related differences in emotion recognition ability: a cross-sectional study. Emotion, 9(5), 619-630.

Milliman, R. E. (1982). Using background music to affect the behavior of supermarket shoppers. Journal of Marketing, 46, 86-91.

Milliman, R. E. (1986). The influence of background music on the behavior of restaurant patrons. Journal of Consumer Research, 13, 286-289.

Mitev, A. Z. (2012). Grounded Theory, a kvalítatív kutatás klasszikus mérfoldköve. Vezetéstudómány, 18, 17-30.

Miyazaki, A. D., \& Carolina, S. (1993). How many shopping days until Christmas? A preliminary investigation of time pressures, deadlines, and planning levels on holiday gift purchases. Advances in Consumer Research, 20, 331-335.

Moksnes, U. K., Moljord, I. E. O., Espnes, G. A., \& Byrne, D. G. (2010). The association between stress and emotional states in adolescents: The role of gender and self-esteem. Personality and Individual Differences, 49(5), 430-435.

Monroe, K. B., \& Guiltinan, J. P. (1975). A path-analytic exploration of retail patronage influences. Journal of Consumer Research, 2, 19-28. 
Moodie, M. (2011). Reaching for the sky in Budapest. In The Moodie Report PLUS (Vol. 50, pp. 1-6).

Morin, S., Dubé, L., \& Chebat, J.-C. (2007). The role of pleasant music in servicescapes: A test of the dual model of environmental perception. Journal of Retailing, 83(1), 115-130.

Morrin, M., \& Ratneshwar, S. (2003). Does it make sense to use scents to enhance brand memory? Journal of Marketing Research, 40, 10-25.

Morrison, M., Gan, S., Dubelaar, C., \& Oppewal, H. (2011). In-store music and aroma influences on shopper behavior and satisfaction. Journal of Business Research, 64(6), 558-564.

Mulaik, S. A., James, L. R., Van Alstine, J., Bennet, N., Lind, S., \& Stilwell, C. D. (1989). Evaluation of Goodness-of-Fit Indices for Structural Equation Models. Psychological Bulletin, 105(3), 430-445.

Mullen, M. R. (1995). Diagnosing Measurement Equivalence in Cross-National Research. Journal of International Business Studies, 26(3), 573-596.

Newton, T. J. (1989). Occupational stress and coping with stress: a critique. Human Relations, 42, 441-461.

Noone, B. M., \& Mattila, A. S. (2009). Consumer reaction to crowding for extended service encounters. Managing Service Quality, 19(1), 31-41.

Nowlis, S. M. (1995). The effect of time pressure on the choice between brands that differ in quality, price, and product features. Marketing Letters, 6, 287-295.

Nunnally, J. C. (1967). Psychometric Theory. New York, NY: McGraw-Hill.

Oakes, S., \& North, A. C. (2008). Using music to influence cognitive and affective responses in queues of low and high crowd density. Journal of Marketing Management, 24(5-6), 589-602.

Oatley, K., \& Jenkins, J. M. (1992). Human emotions: function and dysfunction. Annual Review of Psychology, 55-85.

Oatley, K., \& Johnson-laird, P. N. (1987). Towards a Cognitive Theory of Emotions. Cognition \& Emotion, 1(1), 29-50.

Oatley, K., Parrott, W. G., Smith, C., \& Watts, F. (2011). Cognition and Emotion over twenty-five years. Cogn Emot, 25(8), 1341-1348.

Oliver, R. L. (1993). Cognitive, affective, and attribute bases of the satisfaction response. Journal of Consumer Research, 20, 418-430.

Olson, J. C. (1980). Encoding processes - Levels of processing and existing knowledge structures. Advances in Consumer Research, 7(1), 154-160.

Omar, O. (2001). Airport retailing: examining airline passengers' impulsive shopping behaviour. Journal of Euromarketing, 11, 87-105.

Omar, O., \& Kent, A. (2001). International airport influences on impulsive shopping: trait and normative approach. International Journal of Retail \& Distribution Management, 29, 226-235.

Paivio, A. (1975). Perceptual Comparisons through the Mind's Eye. Memory \& Cognition, 3(6), 635-647. 
Pan, F.-C., Su, S.-J., \& Chiang, C.-C. (2008). Dual attractiveness of winery: atmospheric cues on purchasing. International Journal of Wine Business Research, 20(2), 95-110.

Papatheodorou, A., \& Lei, Z. (2006). Leisure travel in Europe and airline business models: A study of regional airports in Great Britain. Journal of Air Transport Management, 12(1), 47-52.

Park, C. W., Iyer, E. S., \& Smith, D. C. (1989). The effects of situational factors on instore grocery shopping behavior: the role of store environment and time available for shopping. Journal of Consumer Research, 15, 422-433.

Parsons, A. G. (2009). Use of scent in a naturally odourless store. International Journal of Retail \& Distribution Management, 37(5), 440-452.

Patton III, W. E. (1981). Quantity of information and information display type as predictors of consumer choice of product brands. The Journal of Consumer Affairs, $15,92-105$.

Peacock, E. J., Wong, P. T. P., \& Reker, G. T. (1993). Relations between appraisals and coping schemas: Support for the congruence model. Canadian Journal of Behavioural Science, 25, 64-80.

Peneder, R. (2008). Anti-stress programmes in airport retailing. In Shop Aktuell (pp. 613). Amstetten.

Peng, T. K., Peterson, M. F., \& Shyi, Y.-P. (1991). Quantitative methods in crossnational management research: trends and equivalence issues. Journal of Organizational Behaviour, 12, 87-107.

Perng, S.-W., Chow, C.-C., \& Liao, W.-C. (2010). Analysis of shopping preference and satisfaction with airport retailing products. Journal of Air Transport Management, 16(5), 279-283.

Pinto, M. B., \& Leonidas, L. (1994). The impact of office characteristics on satisfaction with medical care: a "Before and After" analysis. Health Marketing Quarterly, 12, 43-54.

Plutchik, R. (1980). A psychoevolutionary synthesis. New York: Harper and Row.

Plutchik, R., \& Kellerman, H. (1989). Emotion: Theory, Research and Experience.

Putrevu, S., \& Ratchford, B. T. (1997). A model of search behavior with an application to grocery shopping. Journal of Retailing, 73, 463-486.

Ridgway, N. M., Dawson, S. A., \& Bloch, P. H. (1989). Pleasure and arousal in the marketplace: interpersonal differences in approach-avoidance responses. Marketing Letters, 1, 139-147.

Rimmer, J. (2011). The Airport Commercial Revenues Study (ACRS) 2010/11. The Moodie Report in cooperation with the S-A-P Group.

Rubin, H. J. (1995). Qualitative Interviewing: The Art of Hearing Data. Thousand Oaks, C A: Sage.

Russell, J. A., \& Pratt, G. (1980). A description of the affective quality attributed to environments. Journal of Personality and Social Psychology, 38, 311-322.

Russell, J. A., Weiss, A., \& Mendelsohn, G. a. (1989). Affect Grid: A single-item scale of pleasure and arousal. Journal of Personality and Social Psychology, 57, 493-502. 
Ryanair. (2012). Ryanair Annual Report 2012. Dublin, Ireland.

Samuelsson, H., Jarnvik, K., Henningsson, H., Andersson, J., \& Carlbring, P. (2012). The Umea University Database of Facial Expressions: a validation study. Journal of Medical Internet Research, 14(5), e136.

Schoenberger, E. (1991). The corporate interview as a research method in economic geography. Professional Geographer, 43, 180-189.

Schölvinck, J. (2012). Airport Retail Fundamentals: The Airport Retail Cockpit. In Presentation to Budapest Airport (available from the author upon request).

Schwarz, N. (1990). Feelings as information: Informational and motivational functions of affective states In E. T. Higgins \& R. M. Sorrentino (Eds.), Handbook of motivation and cognition: Foundation of social behaviour, Vol. 2 (Vol. xviii, pp. 621). New York, NY: Guilford Press.

Schweitzer, P. B., \& Ladwig, G. B. (2002). Anxiety. In B. J. Ackley \& L. G. B (Eds.), A Handbook to Planning Care (vol. I ed., pp. 44-150). St. Louis: Mosby.

Seidman, I. (1991). Interviewing as qualitative research: A guide for researchers in education and the social science.

Selye, H. (1936). A syndrome produced by diverse nocuous agents. Nature, 138, 32.

Selye, H. (1976). Forty years of stress research: principal remaining problems and misconceptions. Canadian Medical Association Journal, 115, 53-56.

Sen, S., Block, L. G., \& Chandran, S. (2002). Window displays and consumer shopping decisions. Journal of Retailing and Consumer Services, 9, 277-290.

Seock, Y.-K. (2009). Influence of retail store environmental cues on consumer patronage behavior across different retail store formats: An empirical analysis of US Hispanic consumers. Journal of Retailing and Consumer Services, 16, 329-339.

Sherman, E., \& Smith, R. B. (1987). Mood States of Shoppers and Store Image Promising Interactions and Possible Behavioral-Effects. Advances in Consumer Research, 14, 251-254.

Shuy, R. W. (2003). In-person versus telephone interviewing. In J. A. Holstein \& J. F. Gubrium (Eds.), Inside interviewing: New lenses, new concerns (pp. 175-193). Thousand Oaks, CA: Sage.

Siemiatycki, J. (1979). A comparison of mail, telephone, and home interview stategies for household health surveys. American Journal of Public Health, 69, 238-245.

Simon, H. A. (1967). Motivational and emotional controls of cognition. Psychological Review, 74, 29-39.

Sinkovics, R. R., \& Penz, E. (2011). Multilingual elite-interviews and software-based analysis: problems and solutions based on CAQDAS. International Journal of Market Research, 53(5), 705.

Smith, P., \& Burns, D. J. (1996). Atmospherics and retail environments: the case of the "power aisle". International Journal of Retail \& Distribution Management, 24(1), 7-14.

Spangenberg, E. R., Crowley, A. E., \& Henderson, P. W. (1996). Improving the store environment: do olfactory cues affect evaluations and behaviors? Journal of Marketing, 60, 67-80. 
Spangenberg, E. R., Grohmann, B., \& Sprott, D. E. (2005). It's beginning to smell (and sound) a lot like Christmas: the interactive effects of ambient scent and music in a retail setting. Journal of Business Research, 58(11), 1583-1589.

Spangenberg, E. R., Sprott, D. E., Grohmann, B., \& Tracy, D. L. (2006). Gendercongruent ambient scent influences on approach and avoidance behaviors in a retail store. Journal of Business Research, 59(12), 1281-1287.

Spielberger, C. D. (1972). Anxiety as an emotional state. In C. D. Spielberger (Ed.), Anxiety: Cu.rrent trends in theory and research (pp. 23-49). New York, NY: Academic Press.

Spies, K., Hesse, F., \& Loesch, K. (1997). Store atmosphere, mood and purchasing behavior. International Journal of Research in Marketing, 14(1), 1-17.

Sprott, D. E., \& Shimp, T. A. (2004). Using product sampling to augment the perceived quality of store brands. Journal of Retailing, 80, 305-315.

Steenkamp, J. B. E. M., \& Baumgartner, H. (1998). Assessing measurement invariance in cross-national consumer research. Journal of Consumer Research, 25(1), 78-90.

Stein, N. L., \& Levine, L. J. (1989). The causal organisation of emotional knowledge: A developmental Study. Cognition \& Emotion, 3, 343-378.

Strauss, A. L. (1987). Qualitative Analysis for Social Scientists. Cambridge, UK: Cambridge University Press.

Sulzmaier, S. (2001). Consumer-oriented business design - the case of airport management. Heidelberg: Physica-Verlag.

Summers, T. A., \& Hebert, P. R. (2001). Shedding some light on store atmospherics influence of illumination on consumer behavior. Journal of Business Research, 54, 145-150.

Suri, R., \& Monroe, K. B. (2003). The effects of time constraints on consumers' judgments of prices and products. Journal of Consumer Research, 30, 92-104.

Sweeney, J. C., \& Wyber, F. (2002). The role of cognitions and emotions in the musicapproach-avoidance behavior relationship. Journal of Services Marketing, 16, 5169.

Taylor, S. (1994). Waiting for service: the relationship between delays and evaluations of service. Journal of Marketing, 58, 56-69.

Thomas, D. (1997). Retail and leisure developments at London Gatwick Airport. Commercial Airport (British Airport Authority), 24, 38-41.

Thompson, B. (2007). Airport retailing in the UK. Journal of Retail and Leisure Property, 6(3), 203-211.

Törőcsik, M. (1995). Élményorientált vásárlás (Experienceoriented shopping). Marketing \& menedzsment, 29, 5-8.

Torres, E., Dominguez, J. S., Valdes, L., \& Aza, R. (2005). Passenger waiting time in an airport and expenditure carried out in the commercial area. Journal of Air Transport Management, 11, 363-367.

Tottenham, N., Tanaka, J. W., Leon, A. C., McCarry, T., Nurse, M., Hare, T. A., Marcus, D. J., Westerlund, A., Casey, B. J., \& Nelson, C. (2009). The NimStim set 
of facial expressions: judgments from untrained research participants. Psychiatry Res, 168(3), 242-249.

Tourangeau, R., \& Yan, T. (2007). Sensitive questions in surveys. Psychological Bulletin, 133, 859-883.

Tovar, B., \& Martín-Cejas, R. R. (2009). Are outsourcing and non-aeronautical revenues important drivers in the efficiency of Spanish airports? Journal of Air Transport Management, 15(5), 217-220.

Turley, I. W., \& Fugate, D. L. (1992). The Multidimensional Nature of Service Facilities: Viewpoints and Recommendations. Journal of Services Marketing, 6(3), $37-45$.

Turley, L. W., \& Milliman, R. E. (2000). Atmospheric effects on shopping behavior: a review of the experimental evidence. Journal of Business Research, 49, 193-211.

Unnava, H. R., Agarwal, S., \& Haugtvedt, C. P. (1996). Interactive effects of presentation modality and message-generated imagery on recall of advertising information. Journal of Consumer Research, 23(1), 81-88.

Van Gerwen, L. J., Spinhoven, P., Diekstra, R. F. W., \& Van Dyck, R. (1997). People who seek help for fear of flying: Typology of flying phobics. Behavior Therapy, 28, 237-251.

Vida, I. (2008). The impact of atmospherics on consumer behaviour: the case of the music fit in retail stores. Economic and Business Review, 10, 21-35.

Volkova, N. (2009). Determinants of retail revenue for today's airports. Berlin: The GAP research project.

Volkova, N., \& Müller, J. (2012). Assessing the non-aviation performance of selected US airports. Berlin: The GAP research project.

Vrechopoulos, A. P., O’Keefe, R. M., Doukidis, G. I., \& Siomkos, G. J. (2004). Virtual store layout: an experimental comparison in the context of grocery retail. Journal of Retailing, 80, 13-22.

Wakefield, K. L., \& Baker, J. (1998). Excitement at the mall: determinants and effects on shopping response. Journal of Retailing, 74, 515-539.

Wakefield, K. L., \& Blodgett, J. G. (1994). The importance of servicescapes in leisure service settings. Journal of Services Marketing, 8, 66-76.

Wakefield, K. L., \& Blodgett, J. G. (1999). Customer response to intangible and tangible service factors. Psychology and Marketing, 16, 51-68.

Ward, J., Bitner, M. J., \& Barnes, J. (1992). Measuring the prototypicality and meaning of retail environments. Journal of Retailing, 68. 194-220.

Ward, P., Davies, B. J., \& Kooijman, D. (2007). Olfaction and the retail environment: examining the influence of ambient scent. Service Business, 1(4), 295-316.

Watson, D., \& Tellegen, A. (1985). Toward a consensual structure of mood. Psychological Bulletin, 98(2), 219-235.

Weinberg, P., \& Gottwald, W. (1982). Impulsive Consumer Buying as a Result of Emotions. Journal of Business Research, 10(1), 43-57. 
Weinstein, M. (2012). TAMS: Text Analysis Markup System: An open source qualitative analysis system, from http://tamsys.sourceforge.net/

Wener, R. E., Evans, G. W., Phillips, D., \& Nadler, N. (2003). Running for the 7:45 The effects of public transit improvements on commuter stress. Transportation, 30, 203-220.

Westbrook, R. A. (1980). Intrapersonal affective influences on consumer satisfaction with products. Journal of Consumer Research, 7, 49-55.

Westbrook, R. A. (1987). Product/consumption-based affective responses and postpurchase processes. Journal of Marketing Research, 24, 258-271.

Wheaton, B. (1990). Where work and family meet: Stress across social roles. In J. Eckenrode \& S. Gore (Eds.), Stress Between Work and Family (pp. 153-174). New York: Pleanum.

Wheaton, B., Muthen, B., Alwin, D. F., \& Summers, G. (1977). Assessing Reliability and Stability in Panel Models. Sociological Methodology, 8(1), 84-136.

Whiting, A. (2009). Push, scream, or leave: how do consumers cope with crowded retail stores? Journal of Services Marketing, 23(7), 487-495.

Wicker, A. W. (1979). An introduction to ecological psychology. New York: Cambridge University Press.

Williams, L. M., Mathersul, D., Palmer, D. M., Gur, R. C., Gur, R. E., \& Gordon, E. (2009). Explicit identification and implicit recognition of facial emotions: I. Age effects in males and females across 10 decades. Journal of Clinical Experimential Neuropsychology, 31(3), 257-277.

Wilson, S. (2003). The effect of music on perceived atmosphere and purchase intentions in a restaurant. Psychology of Music, 31, 93-112.

Woodworth, R. S. (1928). Dynamic psychology. In C. Murchison (Ed.), Psychologies of 1925 (pp. 111-126). Worcester, MA: Clark University Press.

Wright, P., \& Weitz, B. A. (1977). Time Horizon Effects on Product Evaluation Strategies. Journal of Marketing Research, 14, 429-443.

Yalch, R. F., \& Spangenberg, E. R. (1988). An environmental psychological study of foreground and background music as retail atmospheric factors. In A. W. Walle (Ed.), AMA Educators' Conference Proceedings (pp. 106-110). Chicago: American Marketing Association.

Yalch, R. F., \& Spangenberg, E. R. (1990). Effects of store music on shopping behavior. Journal of Consumer Marketing, 7, 55-63.

Yalch, R. F., \& Spangenberg, E. R. (2000). The effects of music in a retail setting on real and perceived shopping times. Journal of Business Research, 49, 139-147.

Yeung, W.-C. H. (1995). Qualitative personal interviews in international business research: Some lessons from a study of Hong Kong transnational corporations. International Business Review, 4, 313-339.

Yow, V. R. (1994). Recording Oral History: A Practical Guide for Social Scientists. Walnut Creek, Calif.: Alta Mira Press. 


\section{VIII . APPENDICES}

\section{Appendix 1}

Interview guidelines (semi-structured personal interviews - qualitative study)

\section{Question groupl:}

1. Why do people shop at the airport?

2. In what emotional state do you think they spend most time in the shops/ are most motivated to shop/ spend the most?

\section{Questions Group 2}

1. What factors influence people's shopping behaviour at the airport?

2. - Physical Environment? (for example space, light, signage etc.)

3. - Other factors? (time pressure, reason for travelling etc.)

4. Which of these have the most significant effect on people?

5. What kind of effect do they have on their shopping behaviour? (Emotions? Approach/ Avoidance?)

\section{Questions Group 3}

1. List elements of Arousal from literature - ask: How about these?

2. How does this change during the process?

3. How do customers feel when they arrive in the check-in area?

4. ...when the enter passenger security/ passport control?

5. ...when they leave security/ passport control and enter the airside retail area?

6. ...when the approach the boarding gate areas?

7. ...when they wait near the gate?

8. What happens in case of flight delays? What happens if they arrive late to the airport? What happens when they experience more queuing then anticipated?

\section{Questions Group 4}

1. To what extent do you take these into account in your day to day activities (selling, development, construction...)? Why?

2. (IF APPLICABLE) at your airport, when you plan airports, how to you design the environment with these in mind?

3. What do you do to influence passenger behaviour at your airport?

4. What steps did you/do you take at your airport to manage these effects?

5. What are the steps that could be taken to manage these effects? 


\section{Appendix 2}

Table 27: List of respondents in semi structured management interviews

\begin{tabular}{|c|c|c|c|c|c|}
\hline Position & Company & Country & $\begin{array}{l}\text { Passengers } \\
2012\end{array}$ & Cat: & type \\
\hline \multirow{2}{*}{$\begin{array}{l}\text { Head of Retail } \\
\text { Operations } \\
\text { Commercial Director }\end{array}$} & Berlin Airports & Germany & $25,389,950$ & $10-20 \mathrm{~m}$ & personal \\
\hline & Birmingham Airport & U.K. & $8,923,777$ & $5-10 \mathrm{~m}$ & personal \\
\hline \multirow{5}{*}{$\begin{array}{l}\text { Senior Manager - } \\
\text { Retail Projects } \\
\text { Director Consumer } \\
\text { Business Unit } \\
\text { Retail Operations } \\
\text { Director } \\
\text { Business Development } \\
\text { Manager - Retail } \\
\text { VP Centre } \\
\text { Management }\end{array}$} & Brussels Airport & Belgium & $18,943,688$ & $10-20 \mathrm{~m}$ & personal \\
\hline & Budapest Airport & Hungary & $8,504,020$ & $5-10 m$ & personal \\
\hline & Dublin Airport & Ireland & $19,096,572$ & $10-20 \mathrm{~m}$ & phone \\
\hline & Gatwick Airport & U.K. & $34,222,405$ & $20-50 \mathrm{~m}$ & personal \\
\hline & Hamburg Airport & Germany & $13,697,401$ & $10-20 \mathrm{~m}$ & personal \\
\hline \multirow{4}{*}{$\begin{array}{l}\text { Director Commercial } \\
\text { VP Centre } \\
\text { Management } \\
\text { SVP Centre } \\
\text { Management } \\
\text { Senior Manager - } \\
\text { Retail }\end{array}$} & $\begin{array}{l}\text { AviAlliance } \\
\text { Airports }\end{array}$ & Germany & $57,627,281$ & $>50 \mathrm{~m}$ & phone \\
\hline & Munich Airport & Germany & $38,360,604$ & $20-50 \mathrm{~m}$ & personal \\
\hline & Vienna Airport & Austria & $22,165,650$ & $20-50 \mathrm{~m}$ & personal \\
\hline & Zürich Airport & Switzerland & $24,751,649$ & $20-50 \mathrm{~m}$ & phone \\
\hline
\end{tabular}

\section{Appendix 3:}

Scales used in quantitative study

\section{Environmental Variables}

\section{Servicescape (5-point Likert scale)}

- Shop assistants were friendly and helpful.

- I didn't have to wait a lot at check-out.

- There was an adequate number of staff in the shop.

- Well-groomed and well-dressed assistants work in the shop.

- The helpfulness of assistants is almost extreme, disturbing.

- I felt shop assistants gladly help customers when needed.

- It is easy to walk around the store and find what you are looking for.

- The shop's architecture gives it an attractive character

- The lighting is appropriate.

- The use of colors adds excitement to the store environment

- The temperature in the shop was comfortable.

- The aisles between the shelves are wide enough to pass through easily, even with luggage.

- I felt uncomfortable because of the many people around me. 
- I felt a disturbingly strong scent in the shop.

- Standing in line at the check-out was uncomfortable, there was too little space around me, and others were standing too close to me.

- The signs and labels used in the shop helped me to find my way, and do my shopping.

\section{Output Measures}

Approach-avoidance - English (Mehrabian and Russel, 1974, from 1-not at all to 7extremely)

- Did you enjoy shopping in this shop?

- Would you avoid ever having to return to this store?

- Is this a place in which you feel friendly and talkative to a stranger who happens to be near you

- Did you avoid looking around or exploring this environment?

- Did you like this store environment?

- Is this a place where you might try to avoid other people and avoid having to talk to them?

- Did you end up spending more money than you originally set out to spend?

- If you had enough time, how long would you want to stay in such a shop?

- Now think of what feelings, mood the security screening triggered in you on the whole, what experience did you have after you left the security screening? Was it a positive experience, are you leaving with pleasant feelings?

\section{Other measures - English}

- time spent browsing in store (self-reported, in mins.)

- time spent in store altogether (self-reported, in mins.)

- time spent in store altogether (actual, in mins.)

\section{Consumer spending - English}

- purchased something (self-reported, yes/no)

- consumer spending in store (self-reported, in EUR)

- consumer spending in store (actual, in EUR)

\section{Emotions Measures}

Basic emotions picture scale - the Umeå University Database of Facial Expressions (Carlbring et al., 2012, scale from 1 - 100)

Interviewer says: "Please look carefully at the following faces showing different feelings, states of mind. Please indicate with the help of the slider RIGHT NOW how characteristic of you the mood, feeling the picture shows is. 1 means the feeling is not 
characteristic of you at all, while 100 means the given feeling, mood is very characteristic of you."

First picture to be displayed, respondent moves a horizontal slider to a score, then next picture.
chose if respondent
male and 18-39 years
$\begin{aligned} & \text { chose if respondent } \\ & \text { female and 18-39 years }\end{aligned}$
chose if respondent
male and over 40 years
chose if respondent
female and over 40 years

Affect grid - English (Russell, 1989)

Responses are recorded as two scores, on scales from 1-pleasant to 9-unpleasant and 1arousal to 9-sleepy, calm.

Interviewer says: "We will now use the "affect grid" to describe feelings, it's a kind of map of how people feel. Please indicate how you are feeling right now: how pleasant or unpleasant your mood is, how stressed, excited or bored, relaxed you are feeling. The center of the square represents a neutral, average, everyday feeling. The vertical axis stands for the degree of arousal, how wide awake, alert or activated you feel.

It is important to emphasise that being aroused may be both positive and negative, and similarly, sleepiness may express that you are bored and indifferent to the outside world, or that you are relaxed and balanced. You may indicate this in the table below. First determine on the horizontal axis how pleasant or unpleasant you are feeling, then on the vertical axis how alert, active, excited you are feeling. Put an $\mathrm{x}$ where the two intersect. Please do not think long about the answer." 


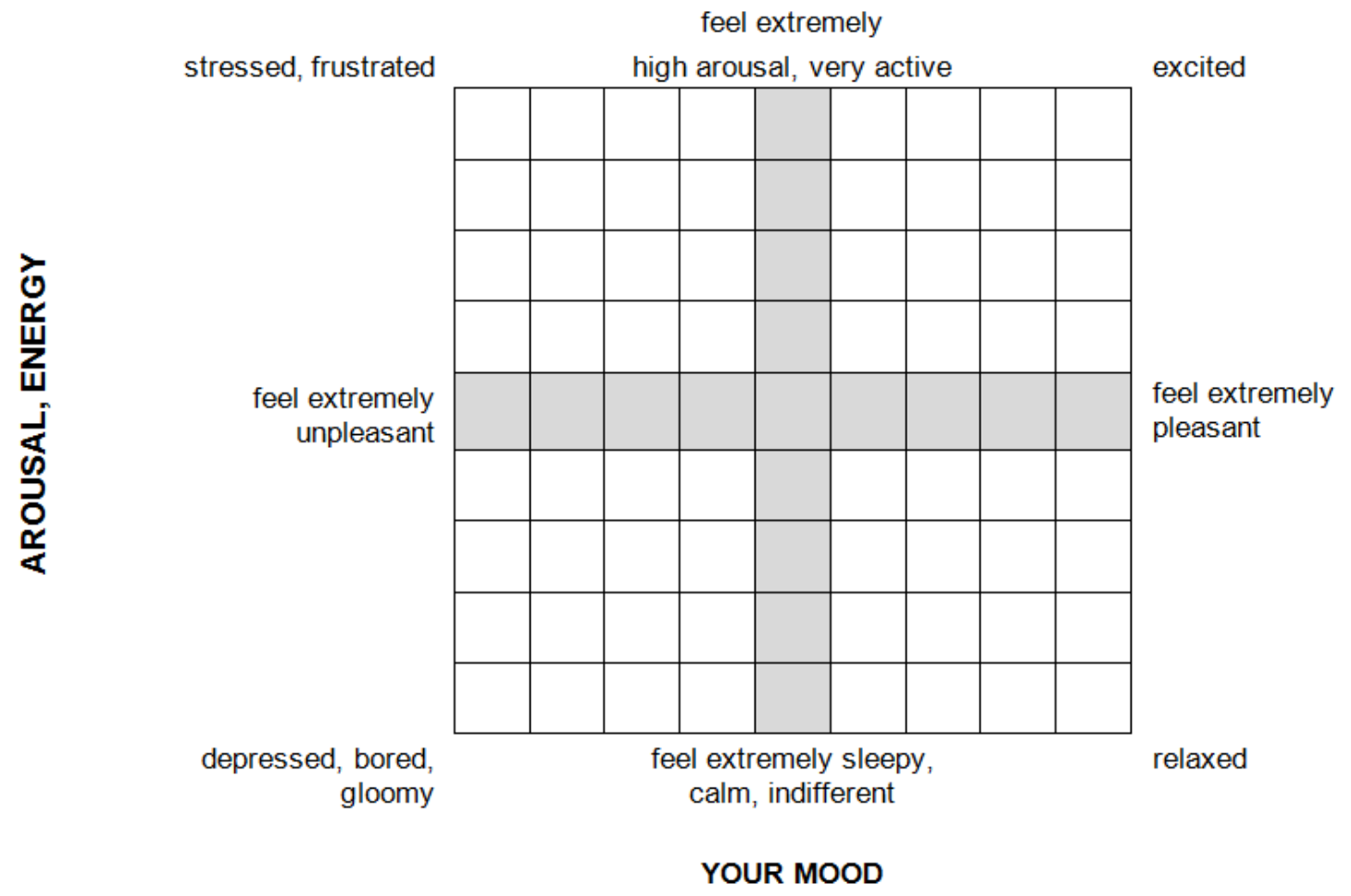

Single-item State Stress Measure - English

- On a scale of 0 to 100 , how tense, stressed are you feeling RIGHT NOW? (from 0not stressed at all to 100-going through massive stress)

Perceived Time Pressure - English (Nowlis, 1995, single-item scale)

- How much time pressure are you feeling right now (that is, you think you have to be in a hurry to do all the necessary activities and the ones you planned, e.g. check-in, security screening, passport control, shopping)? (1=I don't feel time pressure, not worried about having little time $-5=\mathrm{I}$ feel great time pressure, worried about having little time)

\section{Demographic Variables}

age, gender, nationality, country of residence, social status, education

\section{Control Variables}

type of airline, frequency of travel, experience with air travel, familiarity with the store, queue length at security, arrival time until flight departure (total time spend at the airport) 


\section{Appendix 4}

Table 28: Members of the panel of content experts

\begin{tabular}{|l|l|l|l|}
\hline Position & Company & Expertise & Experience \\
\hline $\begin{array}{l}\text { Retail marketing } \\
\text { manager }\end{array}$ & Budapest Airport Zrt. & $\begin{array}{l}\text { airport retail consumer } \\
\text { behaviour, marketing }\end{array}$ & 21 years \\
\hline $\begin{array}{l}\text { Retail marketing } \\
\text { executive }\end{array}$ & Budapest Airport Zrt. & $\begin{array}{l}\text { retail consumer marketing, in- } \\
\text { store consumer research }\end{array}$ & 11 years \\
\hline $\begin{array}{l}\text { Market research } \\
\text { coordinator }\end{array}$ & Budapest Airport Zrt. & $\begin{array}{l}\text { airport passenger survey } \\
\text { questionnaire design }\end{array}$ & 9 years \\
\hline $\begin{array}{l}\text { Business development } \\
\text { manager }\end{array}$ & Budapest Airport Zrt. & $\begin{array}{l}\text { design of airport retail } \\
\text { environments }\end{array}$ & 15 years \\
\hline Client service manager & GfK Hungária Kft. & $\begin{array}{l}\text { airport customer research } \\
\text { questionnaire design }\end{array}$ & 17 years \\
\hline Senior lecturer & $\begin{array}{l}\text { Corvinus University of } \\
\text { Budapest }\end{array}$ & $\begin{array}{l}\text { consumer behaviour research, } \\
\text { applied statistics }\end{array}$ & 16 years \\
\hline
\end{tabular}

\section{Appendix 5}

Results of the testing of the conceptual model

Table 29: Parameter Summary (Group number 1)

\begin{tabular}{|r|rrrrrr|}
\hline & \multirow{2}{*}{ Weights } & $\begin{array}{r}\text { Covaria } \\
\text { nces }\end{array}$ & $\begin{array}{r}\text { Varianc } \\
\text { es }\end{array}$ & Means & Intercept & Total \\
\hline Fixed & 27 & 0 & 0 & 0 & 0 & 27 \\
Labeled & 0 & 0 & 0 & 0 & 0 & 0 \\
Unlabeled & 21 & 3 & 24 & 0 & 0 & 48 \\
Total & 48 & 3 & 24 & 0 & 0 & 75 \\
\hline
\end{tabular}

\section{Computation of degrees of freedom (Default model)}

Number of distinct sample moments:

\section{Result (Default model)}

Minimum was achieved

Chi-square $=235,150$

Degrees of freedom $=123$

Probability level $=, 000$

Estimates (Group number 1 - Default model) 
Regression Weights: (Group number 1 - Default model)

\begin{tabular}{|c|c|c|c|c|c|c|}
\hline & & & $\begin{array}{r}\text { Estimat } \\
\mathrm{e} \\
\end{array}$ & S.E. & C.R. & $\mathrm{P}$ \\
\hline Stress & $<-$ & Physical_factors & -5.526 & 2.57 & -2.151 & 0.032 \\
\hline Pleasure & $<-$ & Physical_factors & 4.42 & 2.158 & 2.048 & 0.041 \\
\hline Pleasure & $<-$ & Time_pressure & 0.772 & 0.731 & 1.055 & 0.291 \\
\hline Stress & $<-$ & Time_pressure & 2.749 & 0.992 & 2.77 & 0.006 \\
\hline Stress & $<-$ & Social_factors & -1.24 & 4.188 & -0.296 & 0.767 \\
\hline Pleasure & $<-$ & Social_factors & 11.008 & 4.324 & 2.546 & 0.011 \\
\hline Approach_Avd. & $<-$ & Pleasure & 0.057 & 0.02 & 2.796 & 0.005 \\
\hline Evaluation & $<-$ & Pleasure & 0.12 & 0.035 & 3.464 & $* * *$ \\
\hline Approach_Avd. & $<-$ & Stress & 0.007 & 0.01 & 0.642 & 0.521 \\
\hline Evaluation & $<-$ & Stress & 0.002 & 0.01 & 0.201 & 0.84 \\
\hline $\begin{array}{l}\text { Staff_appearanc } \\
\text { e }\end{array}$ & $<-$ & Social_factors & 1.239 & 0.189 & 6.544 & $* * *$ \\
\hline Staff_behaviour & $<-$ & Social_factors & 1 & & & \\
\hline Temperature & $<-$ & Physical_factors & 0.918 & 0.115 & 7.976 & $* * *$ \\
\hline Architecture & $<-$ & Physical_factors & 0.883 & 0.113 & 7.789 & $* * *$ \\
\hline Lighting & $<-$ & Physical_factors & 0.92 & 0.103 & 8.966 & $* * *$ \\
\hline Easy_finding & $<-$ & Physical_factors & 1 & & & \\
\hline afraid_reverse & $<-$ & Pleasure & 0.448 & 0.173 & 2.586 & 0.01 \\
\hline Enjoy_shopping & $<-$ & Evaluation & 1 & & & \\
\hline Like_store & $<-$ & Evaluation & 0.744 & 0.096 & 7.773 & $* * *$ \\
\hline Experience & $<-$ & Evaluation & 0.492 & 0.06 & 8.246 & $* * *$ \\
\hline Returning_rev & $<-$ & Approach_Avd. & 1 & & & \\
\hline Exploring_rev & $<-$ & Approach_Avd. & 1.313 & 0.226 & 5.802 & $* * *$ \\
\hline Affiliation_rev & $<-$ & Approach_Avd. & 1.138 & 0.195 & 5.823 & $* * *$ \\
\hline Staff_helpful & $<-$ & Social_factors & 0.682 & 0.193 & 3.53 & $* * *$ \\
\hline happy & $<-$ & Pleasure & 1 & & & \\
\hline angry & $<-$ & Stress & 1 & & & \\
\hline surprised & $<--$ & Stress & 0.568 & 0.276 & 2.056 & 0.04 \\
\hline
\end{tabular}

Standardized Regression Weights: (Group number 1 - Default model)

\begin{tabular}{|lll|r|}
\hline & & & $\begin{array}{r}\text { Estimat } \\
\text { e }\end{array}$ \\
\hline Stress & $<--$ & Physical_factors & -0.308 \\
Pleasure & $<--$ & Physical_factors & 0.345 \\
Pleasure & $<--$ & Time_pressure & 0.085 \\
Stress & $<--$ & Time_pressure & 0.216 \\
Stress & $<--$ & Social_factors & -0.045 \\
Pleasure & $<--$ & Social_factors & 0.56 \\
Approach_Avd. & $<--$ & Pleasure & 0.428 \\
Evaluation & $<--$ & Pleasure & 0.838 \\
Approach_Avd. & $<--$ & Stress & 0.07 \\
Evaluation & $<--$ & Stress & 0.019 \\
Staff_appearanc & $<--$ & Social_factors & 0.648 \\
e & $<--$ & Social_factors & 0.596
\end{tabular}




\begin{tabular}{|lll|r|} 
Temperature & $<--$ & Physical_factors & 0.603 \\
Architecture & $<--$ & Physical_factors & 0.584 \\
Lighting & $<--$ & Physical_factors & 0.728 \\
Easy_findings & $<--$ & Physical_factors & 0.644 \\
afraid_reverse & $<--$ & Pleasure & 0.24 \\
Enjoy_shopping & $<--$ & Evaluation & 0.763 \\
Like_store & $<--$ & Evaluation & 0.574 \\
Experience & $<--$ & Evaluation & 0.627 \\
Returning_rev & $<--$ & Approach_Avd. & 0.545 \\
Exploring_rev & $<--$ & Approach_Avd. & 0.649 \\
Affiliation_rev & $<--$ & Approach_Avd. & 0.625 \\
Staff_helpful & $<--$ & Social_factors & 0.266 \\
Happy & $<--$ & Pleasure & 0.27 \\
angry & $<--$ & Stress & 0.749 \\
surprised & $<--$ & Stress & 0.283 \\
\hline
\end{tabular}

Covariances: (Group number 1 - Default model)

\begin{tabular}{|lll|rrrr}
\hline & & Estimate & S.E. & C.R. & P \\
\hline Social_factors & $<-->$ & Time_pressure & -0.057 & 0.02 & -2.877 & 0.004 \\
Physical_factors & $<-->$ & Time_pressure & -0.099 & 0.027 & -3.629 & $* * *$ \\
Social_factors & $<->$ & Physical_factors & 0.112 & 0.021 & 5.248 & $* * *$ \\
\hline
\end{tabular}

Correlations: (Group number 1 - Default model)

\begin{tabular}{|lll|r|}
\hline & & & Estimate \\
\hline Social_factors & $<-->$ & Time_pressure & -0.235 \\
Physical_factors & $<->$ & Time_pressure & -0.264 \\
Social_factors & $<->$ & Physical_factors & 0.643 \\
\hline
\end{tabular}

Variances: (Group number 1 - Default model)

\begin{tabular}{|l|rrrr|}
\hline & Estimate & S.E. & C.R. & P \\
\hline Social_factors & 0.113 & 0.026 & 4.356 & $* * *$ \\
Physical_factors & 0.266 & 0.049 & 5.376 & $* * *$ \\
Time_pressure & 0.527 & 0.044 & 12 & $* * *$ \\
e28 & 15.204 & 9.76 & 1.558 & 0.119 \\
e29 & 68.231 & 40.792 & 1.673 & 0.094 \\
e30 & 0.635 & 0.172 & 3.702 & $* * *$ \\
e31 & 0.271 & 0.13 & 2.081 & 0.037 \\
e2 & 0.24 & 0.032 & 7.593 & $* * *$ \\
e1 & 0.206 & 0.024 & 8.719 & $* * *$ \\
e9 & 0.393 & 0.039 & 10.04 & $* * *$ \\
e8 & 0.4 & 0.039 & 10.228 & $* * *$
\end{tabular}




\begin{tabular}{|l|rrrr} 
e7 & 0.199 & 0.025 & 8.094 & $* * *$ \\
e4 & 0.376 & 0.039 & 9.56 & $* * *$ \\
e16 17 & 553.023 & 47.832 & 11.562 & $* * *$ \\
e20 & 143.469 & 12.302 & 11.662 & $* * *$ \\
e19 & 67.044 & 40.844 & 1.641 & 0.101 \\
e25 & 316.306 & 29.438 & 10.745 & $* * *$ \\
e26 & 0.636 & 0.1 & 6.348 & $* * *$ \\
e27 & 0.998 & 0.1 & 10.002 & $* * *$ \\
e21 & 0.331 & 0.036 & 9.307 & $* * *$ \\
e22 & 1.81 & 0.198 & 9.162 & $* * *$ \\
e23 & 1.818 & 0.259 & 7.017 & $* * *$ \\
e3 & 1.551 & 0.205 & 7.568 & $* * *$ \\
\end{tabular}

Squared Multiple Correlations: (Group number 1 - Default model)

\begin{tabular}{|lr|}
\hline & Estimate \\
\hline Pleasure & 0.652 \\
Stress & 0.201 \\
Evaluation & 0.694 \\
Approach_Avd. & 0.172 \\
Staff_helpful & 0.071 \\
Affiliation_rev & 0.39 \\
Exploring_rev & 0.421 \\
Returning_rev & 0.298 \\
Experience & 0.393 \\
Like_store & 0.33 \\
Enjoy_shopping & 0.583 \\
Surprised & 0.08 \\
Angry & 0.56 \\
afraid_reverse & 0.058 \\
Happy & 0.073 \\
Easy_finding & 0.414 \\
Lighting & 0.53 \\
Architecture & 0.341 \\
Temperature & 0.364 \\
Staff_behaviour & 0.355 \\
Staff_appearance & 0.419 \\
\hline
\end{tabular}


Model Fit Summary

CMIN

\begin{tabular}{|l|rrrrr|}
\hline Model & NPAR & CMIN & DF & P & CMIN/ \\
\hline Default model & 48 & 235.15 & 123 & 0 & 1.912 \\
Saturated model & 171 & 0 & 0 & & \\
Independence model & 18 & 1016.65 & 153 & 0 & 6.645 \\
\hline
\end{tabular}

\section{RMR, GFI}

\begin{tabular}{|l|rrrr|}
\hline Model & RMR & GFI & AGFI & PGFI \\
\hline Default model & 8.617 & 0.914 & 0.88 & 0.657 \\
Saturated model & 0 & 1 & & \\
Independence model & 11.385 & 0.604 & 0.558 & 0.541 \\
\hline
\end{tabular}

\section{Baseline Comparisons}

\begin{tabular}{|l|rrrrr|}
\hline Model & $\begin{array}{r}\text { NFI } \\
\text { Delta1 }\end{array}$ & $\begin{array}{r}\text { RFI } \\
\text { rho1 }\end{array}$ & $\begin{array}{r}\text { IFI } \\
\text { Delta2 }\end{array}$ & $\begin{array}{r}\text { TLI } \\
\text { rho2 }\end{array}$ & CFI \\
\hline Default model & 0.769 & 0.712 & 0.875 & 0.838 & 0.87 \\
Saturated model & 1 & & 1 & & 1 \\
Independence model & 0 & 0 & 0 & 0 & 0 \\
\hline
\end{tabular}

\section{Parsimony-Adjusted Measures}

\begin{tabular}{|c|c|c|c|}
\hline Model & $\begin{array}{r}\text { PRATI } \\
\text { O }\end{array}$ & PNFI & PCFI \\
\hline Default model & 0.804 & 0.618 & 0.7 \\
\hline Saturated model & 0 & 0 & 0 \\
\hline Independence model & 1 & 0 & 0 \\
\hline
\end{tabular}

\section{NCP}

\begin{tabular}{|l|rrr|}
\hline Model & NCP & LO 90 & HI 90 \\
\hline Default model & 112.15 & 72.653 & 159.455 \\
Saturated model & 0 & 0 & 0 \\
Independence model & 863.65 & 766.482 & 968.293 \\
\hline
\end{tabular}

\section{FMIN}

\begin{tabular}{|l|rrrr|}
\hline Model & FMIN & F0 & LO 90 & HI 90 \\
\hline Default model & 0.816 & 0.389 & 0.252 & 0.554 \\
Saturated model & 0 & 0 & 0 & 0 \\
Independence model & 3.53 & 2.999 & 2.661 & 3.362 \\
\hline
\end{tabular}


RMSEA

\begin{tabular}{|l|rrrr|}
\hline Model & RMSEA & LO 90 & HI 90 & PCLOS \\
\hline Default model & 0.056 & 0.045 & 0.067 & 0.167 \\
Independence model & 0.14 & 0.132 & 0.148 & 0 \\
\hline
\end{tabular}

AIC

\begin{tabular}{|l|rrrr|}
\hline Model & AIC & BCC & BIC & CAIC \\
\hline Default model & 331.15 & 337.931 & 507.139 & 555.139 \\
Saturated model & 342 & 366.156 & 968.959 & 1139.95 \\
& & 1055.19 & 1118.64 & 1136.64 \\
Independence model & 1052.65 & 3 & 6 & 6 \\
\hline
\end{tabular}

ECVI

\begin{tabular}{|l|rrrr|}
\hline Model & ECVI & LO 90 & HI 90 & MECVI \\
\hline Default model & 1.15 & 1.013 & 1.314 & 1.173 \\
Saturated model & 1.188 & 1.188 & 1.188 & 1.271 \\
Independence model & 3.655 & 3.318 & 4.018 & 3.664 \\
\hline
\end{tabular}

HOELTER

\begin{tabular}{|l|rr|}
\hline & HOELT & HOELT \\
Model & ER & ER \\
& .05 & .01 \\
\hline Default model & 184 & 199 \\
Independence model & 52 & 56 \\
\hline
\end{tabular}


Table 30: Pearson correlation matrix for assessment of physical factors, social factors, moderator variables

\begin{tabular}{|c|c|c|c|c|c|c|c|c|c|c|c|c|c|c|}
\hline & & & 1. & 2. & 3. & 4. & 5. & 6. & 7. & 8. & 9. & 10. & 11. & 12. \\
\hline \multirow[b]{3}{*}{ I. } & \multirow[b]{3}{*}{ Physical Factors } & Corr. & $T$ & $324^{\prime \prime}$ & .105 & $.118^{2}$ & .056 & .041 & .064 & -.056 & .049 & -.191 & -.035 & -.056 \\
\hline & & Sig. & & .000 & .073 & .045 & .335 & .484 & .275 & .337 & .600 & .067 & 555 & 335 \\
\hline & & $\mathrm{N}$ & 294 & 294 & 291 & 289 & 294 & 294 & 294 & 294 & 116 & 92 & 294 & 294 \\
\hline \multirow[b]{3}{*}{2.} & \multirow[b]{3}{*}{ Social Factors } & Corr. & $324^{\prime \prime}$ & 1 & .045 & .050 & -.057 & .037 & .041 & .002 & .054 & -.187 & .004 & -.065 \\
\hline & & Sig. & .000 & & .442 & .397 & .330 & .528 & .485 & .967 & .565 & .075 & .940 & 264 \\
\hline & & $\mathrm{N}$ & 294 & 294 & 291 & 289 & 294 & 294 & 294 & 294 & 116 & 92 & 294 & 294 \\
\hline \multirow[b]{3}{*}{3.} & \multirow{3}{*}{$\begin{array}{l}\text { Satisfaction with } \\
\text { life (factor) }\end{array}$} & Corr. & .105 & .045 & 1 & $.301^{\prime \prime}$ & -.083 & .057 & .037 & -.025 & .092 & -.045 & .010 & .022 \\
\hline & & Sig. & .073 & .442 & & .000 & .156 & .332 & .530 & .675 & .326 & .671 & 872 & .711 \\
\hline & & $\mathrm{N}$ & 291 & 291 & 291 & 286 & 291 & 291 & 291 & 291 & 116 & 92 & 291 & 291 \\
\hline & \multirow{3}{*}{$\begin{array}{l}\text { Resilience to } \\
\text { stress (factor) }\end{array}$} & Corr. & $.118^{\circ}$ & .050 & $.301^{11}$ & 1 & -.031 & .037 & .029 & -092 & .078 & -.056 & $.119^{\circ}$ & .091 \\
\hline & & Sig. & .045 & .397 & .000 & & .599 & .533 & .619 & .119 & 411 & .605 & .043 & .121 \\
\hline 4. & & $\mathrm{~N}$ & 289 & 289 & 286 & 289 & 289 & 289 & 289 & 289 & 112 & 89 & 289 & 289 \\
\hline \multirow{3}{*}{\multicolumn{2}{|c|}{$\begin{array}{l}\text { How long before } \\
\text { departure at } \\
\text { airport? }\end{array}$}} & Corr. & .056 & -.057 & -.083 & -.031 & 1 & $.125^{\circ}$ & .099 & $184^{\prime \prime}$ & .167 & .012 & .010 & -.010 \\
\hline & & Sig. & .335 & .330 & .156 & .599 & & .032 & .090 & .002 & .073 & 910 & 859 & .862 \\
\hline & & $\mathrm{N}$ & 294 & 294 & 291 & 289 & 294 & 294 & 294 & 294 & 116 & 92 & 294 & 294 \\
\hline & \multirow{3}{*}{$\begin{array}{l}\text { Time in the shop } \\
\text { (self-reported) }\end{array}$} & Corr. & .041 & .037 & .057 & .037 & $.125^{\circ}$ & 1 & $922^{\prime \prime}$ & $396^{\prime \prime}$ & .084 & .023 & -.071 & $=.133^{\circ}$ \\
\hline & & Sig. & .484 & .528 & .332 & .533 & .032 & & .000 & .000 & 369 & 825 & 225 & .022 \\
\hline 6. & & $\mathrm{~N}$ & 294 & 294 & 291 & 289 & 294 & 294 & 294 & 294 & 116 & 92 & 294 & 294 \\
\hline \multirow{3}{*}{\multicolumn{2}{|c|}{$\begin{array}{l}\text { Time spent } \\
\text { browsing (self- } \\
\text { 7eported) }\end{array}$}} & Corr. & .064 & .041 & .037 & .029 & .099 & $.922^{\prime \prime}$ & 1 & $365^{\prime \prime}$ & .078 & .059 & -.111 & $-.155^{\prime \prime}$ \\
\hline & & Sig. & .275 & .485 & .530 & .619 & .090 & .000 & & .000 & 408 & 577 & .057 & .008 \\
\hline & & $\mathrm{N}$ & 294 & 294 & 291 & 289 & 294 & 294 & 294 & 294 & 116 & 92 & 294 & 294 \\
\hline \multirow{3}{*}{\multicolumn{2}{|c|}{$\begin{array}{l}\text { Time spent in } \\
\text { store (obs.) }\end{array}$}} & Corr. & -056 & .002 & -025 & .092 & $.184^{\prime \prime}$ & $396^{\prime \prime}$ & $365^{\prime \prime}$ & 1 & .181 & -.114 & $-147^{\circ}$ & $=149^{\circ}$ \\
\hline & & Sig. & .337 & .967 & .675 & .119 & .002 & .000 & .000 & & .052 & 281 & .012 & .010 \\
\hline 8. & & $\mathrm{~N}$ & 294 & 294 & 291 & 289 & 294 & 294 & 294 & 294 & 116 & 92 & 294 & 294 \\
\hline \multirow[b]{3}{*}{9.} & \multirow{3}{*}{$\begin{array}{l}\text { Spending (self- } \\
\text { reported) }\end{array}$} & Corr. & .049 & .054 & .092 & .078 & .167 & .084 & .078 & .181 & 1 & $.781^{\circ+}$ & .104 & .132 \\
\hline & & Sig. & .600 & .565 & .326 & .411 & .073 & 369 & 408 & .052 & & .000 & 268 & .156 \\
\hline & & $\mathrm{N}$ & 116 & 116 & 116 & 112 & 116 & 116 & 116 & 116 & 116 & 68 & 116 & 116 \\
\hline 5 & \multirow[b]{3}{*}{ Spending (obs.) } & Corr. & $=, 191$ & -187 & $=045$ & $=, 056$ & .012 & .023 & .059 & -114 & $.781^{27}$ & 1 & .083 & -.099 \\
\hline & & Sig. & .067 & .075 & .671 & .605 & .910 & .825 & .577 & .281 & .000 & & .429 & 350 \\
\hline 10. & & $\mathrm{~N}$ & 92 & 92 & 92 & 89 & 92 & 92 & 92 & 92 & 68 & 92 & 92 & 92 \\
\hline \multirow{3}{*}{\multicolumn{2}{|c|}{$\begin{array}{l}\text { No, of flights } \\
\text { from here last } \\
\text { year? }\end{array}$}} & Corr. & -.035 & .004 & .010 & $.119^{\circ}$ & .010 & $=.071$ & -111 & $-.147^{\circ}$ & .104 & -.083 & 1 & $.742^{24}$ \\
\hline & & Sig. & .555 & .940 & .872 & .043 & .859 & .225 & .057 & .012 & 268 & .429 & & .000 \\
\hline & & $\mathrm{N}$ & 294 & 294 & 291 & 289 & 294 & 294 & 294 & 294 & 116 & 92 & 294 & 294 \\
\hline \multirow{3}{*}{\multicolumn{2}{|c|}{$\begin{array}{l}\text { No. of flights last } \\
\text { year }\end{array}$}} & Cort. & -.056 &,- 065 & .022 & .091 & -.010 & $-133^{2}$ & $-.155^{21}$ & $-.149^{\circ}$ & .132 & -.099 & $.742^{2+}$ & 1 \\
\hline & & Sig. & .335 & .264 & .711 & .121 & .862 & .022 & .008 & .010 & .156 & 350 & .000 & \\
\hline & & $\mathrm{N}$ & 294 & 294 & 291 & 289 & 294 & 294 & 294 & 294 & 116 & 92 & 294 & 294 \\
\hline
\end{tabular}

Source: own data, $* p<.05, * * p<.01$ 
Table 31: Pearson correlation matrix for assessment of emotions, time pressure, Affect

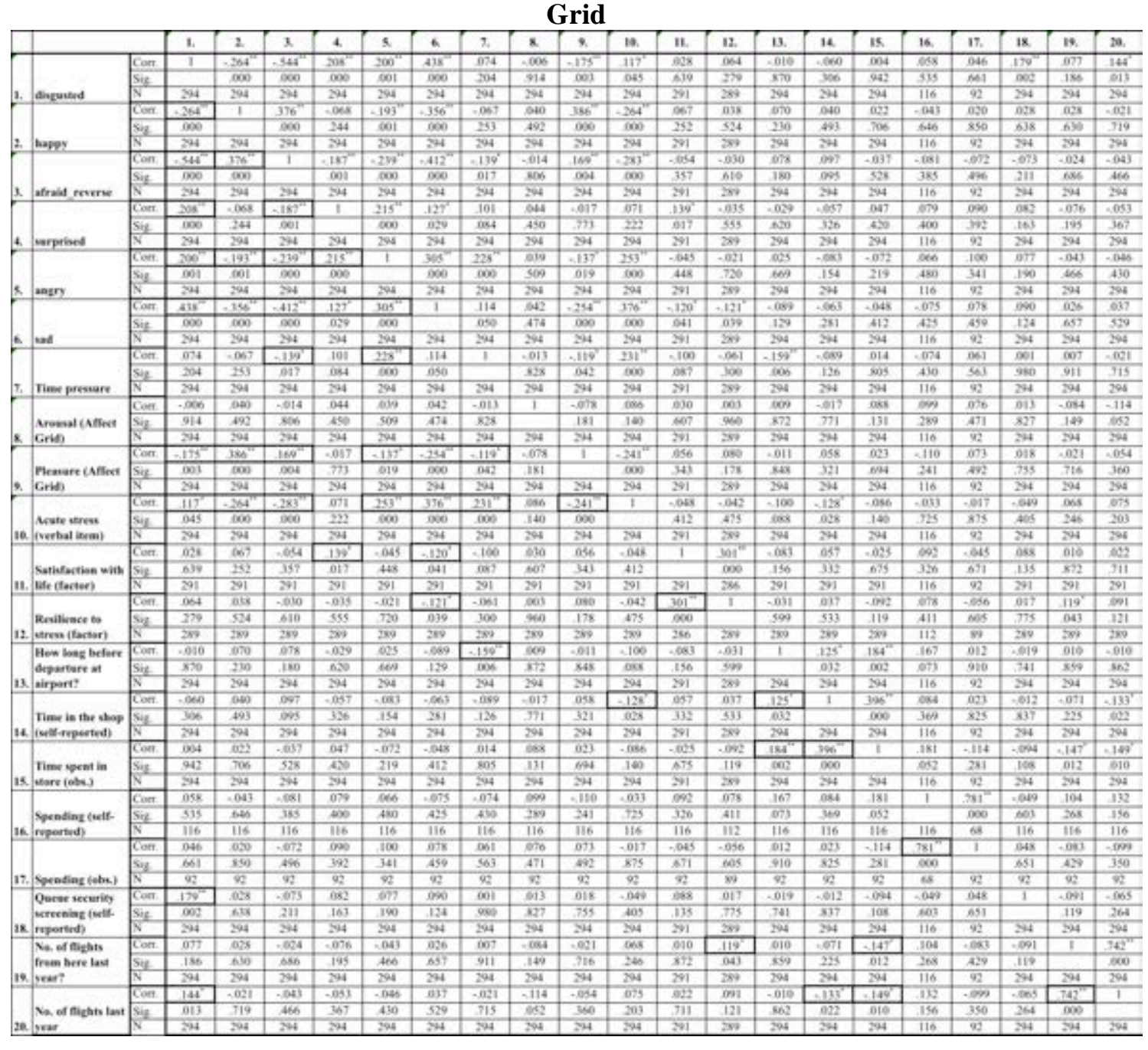

Source: own data, $* p<.05, * * p<.01$ 
Table 32: Pearson correlation matrix for assessment of behavioural and evaluation variables

\begin{tabular}{|c|c|c|c|c|c|c|c|c|c|c|c|c|}
\hline & & & 1. & 2. & 3. & 4. & 5. & 6. & 7. & 8. & 9. & 10. \\
\hline \multirow[b]{3}{*}{1.} & \multirow{3}{*}{\begin{tabular}{|l} 
Approach/ \\
Avoidance
\end{tabular}} & Corr. & 1 & $185^{\circ}$ & .053 & $-126^{\circ}$ & -.055 &,- 052 & .017 & .039 & -003 & .037 \\
\hline & & Sig. & & .007 & .389 & .039 & .371 & .595 & .876 & .529 & .957 & .545 \\
\hline & & $\mathrm{N}$ & 267 & 210 & 267 & 267 & 267 & 108 & 86 & 267 & 267 & 267 \\
\hline \multirow[b]{3}{*}{2.} & \multirow[b]{3}{*}{ Evaluation } & Corr. & $.185^{\prime \prime}$ & 1.000 & -008 & $.233^{\prime \prime}$ & .057 & -.136 & -.150 & .002 & -.099 & -.057 \\
\hline & & Sig. & .007 & & .906 & .001 & .400 & .150 & .170 & .974 & .145 & .405 \\
\hline & & $\mathrm{N}$ & 210 & 218 & 218 & 218 & 218 & 114 & 85 & 218 & 218 & 218 \\
\hline \multirow{3}{*}{\multicolumn{2}{|c|}{$\begin{array}{l}\text { How long before } \\
\text { departure at } \\
\text { airport? }\end{array}$}} & \begin{tabular}{|l|} 
Corr. \\
\end{tabular} & .053 & -.008 & 1.000 & $.125^{\circ}$ & $184^{\prime \prime}$ & .167 & .012 & .010 & -.010 & -.036 \\
\hline & & Sig. & .389 & .906 & & .032 & .002 & .073 & .910 & .859 & .862 & .542 \\
\hline & & $\mathrm{N}$ & 267 & 218 & 294 & 294 & 294 & 116 & 92 & 294 & 294 & 294 \\
\hline \multirow[b]{3}{*}{4.} & \multirow{3}{*}{$\begin{array}{l}\text { Time in the shop } \\
\text { (self-reported) }\end{array}$} & Corr. & $-126^{\circ}$ & $.233^{\prime \prime}$ & $.125^{\circ}$ & 1.000 & $.396^{\prime \prime}$ & .084 & .023 & -.071 & $-.133^{\circ}$ & -.002 \\
\hline & & Sig. & .039 & .001 & .032 & & .000 & .369 & .825 & .225 & .022 & .969 \\
\hline & & $\mathrm{N}$ & 267 & 218 & 294 & 294 & 294 & 116 & 92 & 294 & 294 & 294 \\
\hline \multirow[b]{3}{*}{5.} & \multirow{3}{*}{$\begin{array}{l}\text { Time spent in } \\
\text { store (obs.) }\end{array}$} & \begin{tabular}{|l|} 
Corr. \\
\end{tabular} & .055 & .057 & $184^{\prime \prime}$ & $.396^{\prime \prime}$ & 1.000 & .181 & -.114 & $-.147^{\circ}$ & $-149^{\circ}$ & -.012 \\
\hline & & Sig. & .371 & .400 & .002 & .000 & & .052 & .281 & .012 & .010 & .836 \\
\hline & & $\mathrm{N}$ & 267 & 218 & 294 & 294 & 294 & 116 & 92 & 294 & 294 & 294 \\
\hline \multirow[b]{3}{*}{6.} & \multirow{3}{*}{$\begin{array}{l}\text { Spending (self- } \\
\text { reported) }\end{array}$} & Corr. & -.052 & -.136 & .167 & .084 & .181 & 1.000 & $.781^{\circ}$ & .104 & .132 & -.022 \\
\hline & & Sig. & .595 & .150 & .073 & .369 & .052 & & .000 & .268 & .156 & .817 \\
\hline & & $\mathrm{N}$ & 108 & 114 & 116 & 116 & 116 & 116 & 68 & 116 & 116 & 116 \\
\hline \multirow[b]{3}{*}{7.} & \multirow[b]{3}{*}{ Spending (obs.) } & \begin{tabular}{|l|} 
Corr. \\
\end{tabular} & .017 & -.150 & .012 & .023 & -.114 & $.781^{\prime \prime}$ & 1.000 & -.083 & -.099 & -.132 \\
\hline & & Sig. & .876 & .170 & .910 & .825 & .281 & .000 & & .429 & .350 & .211 \\
\hline & & $\mathrm{N}$ & 86 & 85 & 92 & 92 & 92 & 68 & 92 & 92 & 92 & 92 \\
\hline \multirow[b]{3}{*}{8.} & No. of flights & Corr. & .039 & .002 & .010 & -.071 & $-.147^{\circ}$ & .104 & -.083 & 1.000 & $.742^{*}$ & -.035 \\
\hline & from here last & Sig. & .529 & .974 & .859 & .225 & .012 & .268 & .429 & & .000 & .553 \\
\hline & year? & $\mathrm{N}$ & 267 & 218 & 294 & 294 & 294 & 116 & 92 & 294 & 294 & 294 \\
\hline \multirow[b]{3}{*}{9.} & \multirow{3}{*}{$\begin{array}{l}\text { No. of flights last } \\
\text { year }\end{array}$} & Corr. & -.003 & -099 & .010 & $-133^{\circ}$ & $-149^{\circ}$ & .132 & -099 & $.742^{\circ 1}$ & 1.000 & -.020 \\
\hline & & Sig. & .957 & .145 & .862 & .022 & .010 & .156 & .350 & .000 & & .738 \\
\hline & & $\mathrm{N}$ & 267 & 218 & 294 & 294 & 294 & 116 & 92 & 294 & 294 & 294 \\
\hline \multirow[b]{3}{*}{10.} & \multirow{3}{*}{$\begin{array}{l}\text { Standard of } \\
\text { living }\end{array}$} & Corr. & .037 & -057 & -.036 & -.002 & -.012 & -.022 & -.132 & -035 & -.020 & 1.000 \\
\hline & & Sig. & .545 & .405 & .542 & .969 & .836 & .817 & .211 & .553 & .738 & \\
\hline & & $\mathrm{N}$ & 267 & 218 & 294 & 294 & 294 & 116 & 92 & 294 & 294 & 294 \\
\hline
\end{tabular}

Source: own data, $* p<.05, * * p<.01$

\begin{tabular}{|l|r|r|r|r|r|r|}
\hline & N & Min & Max & Mean & Std. Dev. & Variance \\
\hline STRESS_(angry) & 289 & 0 & 88 & 3.73 & 12.369 & 153.002 \\
STRESS_(surprised) & 289 & 0 & 92 & 7.25 & 18.576 & 345.070 \\
PLEASURE_(happy) & 289 & 0 & 100 & 79.58 & 24.469 & 598.724 \\
PLEASURE_(afraid_rev.) & 289 & 1 & 100 & 97.26 & 12.360 & 152.771 \\
Time pressure_(C07) & 289 & 1 & 5 & 1.31 & .727 & .529 \\
SOCIAL FACTOR_(friendliness of staff_C15x6_1) & 289 & 2 & 5 & 4.62 & .566 & .320 \\
SOCIAL FACTOR_(appearance of staff_C15x9_1) & 289 & 1 & 5 & 4.59 & .644 & .415 \\
SOCIAL FACTOR_(helpfulness of staff_C15X11_1) & 289 & 1 & 5 & 4.59 & .864 & .747 \\
PHYSICAL FACTOR_(easy to find products_C16x1_1) & 289 & 1 & 5 & 4.47 & .803 & .644 \\
PHYSICAL FACTOR_(attractive decor_C16x2_1) & 289 & 1 & 5 & 4.46 & .725 & .526 \\
PHYSICAL FACTOR_(attractive architecture_C16x3_1) & 289 & 1 & 5 & 4.38 & .781 & .609 \\
PHYSICAL FACTOR_(appropriate lighting_C16x4_1) & 289 & 2 & 5 & 4.57 & .653 & .426 \\
PHYSICAL FACTOR_(attractive use of colors_C16x5_1) & 289 & 1 & 5 & 4.30 & .903 & .816 \\
PHYSICAL FACTOR_(comfortable temperature_C16x6_1) & 289 & 1 & 5 & 4.51 & .787 & .619 \\
PHYSICAL FACTOR_(cleanliness_C16x7_1) & 289 & 2 & 5 & 4.61 & .608 & .370 \\
CROWDING_(human crowding_rev.) & 289 & 1 & 5 & 4.06 & 1.287 & 1.656 \\
CROWDING_(disturbing smells_rev.) & 289 & 1 & 5 & 4.06 & 1.298 & 1.684 \\
EVALUATION_(Enjoy shopping in this shop_C20a-1) & 289 & 1 & 7 & 5.35 & 1.236 & 1.528 \\
EVALUATION_(Like this store environment_C20a-5) & 289 & 1 & 7 & 5.69 & 1.222 & 1.494 \\
EVALUATION_(Experience after left the Heinemann & 289 & 2 & 5 & 4.03 & .740 & .548 \\
shop_C17) & & & & & & \\
APPROACH_AVOIDANCE_(Avoid having to return to this & 289 & 1 & 7 & 5.69 & 1.608 & 2.585 \\
store_C20a-2) & & & & &
\end{tabular}


APPROACH_AVOIDANCE_(Avoid looking around or exploring this environment_C20a-4)

APPROACH_AVOIDANCE_(This is a place where try to

avoid other people and avoid having to talk to them_C20a-6)

APPROACH_AVOIDANCE_(Time length staying in such a

shop_C20b-8)

disturbingly helpfulness of staff

wide aisles

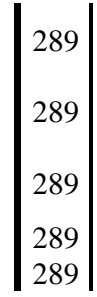

Table 33: Stand. regression weights and reliability coefficients

\begin{tabular}{|c|c|c|c|c|c|c|c|c|}
\hline Construct & Item & $\begin{array}{l}\text { Std. regr. } \\
\text { weight }\end{array}$ & $\mathbf{N}=$ & Alpha & SB* $^{*}$ & CR & AVE & $\begin{array}{l}----- \\
-\cdots--- \\
\end{array}$ \\
\hline \multirow{4}{*}{$\begin{array}{l}\text { Physical } \\
\text { factors }\end{array}$} & Comfortable temperature & $0.588 * * *$ & 289 & \multirow[t]{4}{*}{.731} & \multirow[t]{4}{*}{-} & \multirow[t]{4}{*}{.827} & \multirow[t]{4}{*}{.546} & \\
\hline & Attractive architecture & $0.568 * * *$ & 289 & & & & & \\
\hline & Appropriate lighting & $0.751 * * *$ & 289 & & & & & \\
\hline & Easy to find things & $0.647 * * *$ & 289 & & & & & \\
\hline \multirow{3}{*}{$\begin{array}{l}\text { Social } \\
\text { factors }\end{array}$} & Staff appearance & $0.639 * * *$ & 289 & \multirow[t]{3}{*}{.465} & \multirow[t]{3}{*}{-} & \multirow[t]{3}{*}{.667} & \multirow[t]{3}{*}{.427} & \\
\hline & Staff behaviour & $0.608 * * *$ & 289 & & & & & \\
\hline & Staff helpfulness & $0.266 * * *$ & 289 & & & & & \\
\hline \multirow{4}{*}{ pleasure } & happy & & 294 & \multirow[t]{2}{*}{-} & \multirow[t]{2}{*}{.546} & \multirow[t]{2}{*}{ - } & \multirow[t]{2}{*}{-} & \\
\hline & afraid & & 294 & & & & & \\
\hline & surprised & & 294 & \multirow[t]{2}{*}{-} & \multirow[t]{2}{*}{.354} & \multirow[t]{2}{*}{-} & \multirow[t]{2}{*}{-} & \\
\hline & angry & & 294 & & & & & \\
\hline \multirow{3}{*}{$\begin{array}{l}\text { Approach/ } \\
\text { Avoidance }\end{array}$} & Returning to the store* & $0.592 * * *$ & 289 & \multirow[t]{3}{*}{.632} & \multirow[t]{3}{*}{ - } & \multirow[t]{3}{*}{.404} & \multirow[t]{3}{*}{.345} & \\
\hline & $\begin{array}{l}\text { Exploring the } \\
\text { environment* }\end{array}$ & $0.682 * * *$ & 289 & & & & & \\
\hline & $\begin{array}{l}\text { Affiliating with other } \\
\text { people* }\end{array}$ & $0.582 * * *$ & 289 & & & & & \\
\hline \multirow[t]{3}{*}{ Evaluation } & Enjoyed shopping & $0.739 * * *$ & 289 & \multirow[t]{3}{*}{.655} & \multirow[t]{3}{*}{-} & \multirow[t]{3}{*}{.605} & \multirow[t]{3}{*}{.403} & \\
\hline & Liked store environment & $0.469 * * *$ & 289 & & & & & \\
\hline & $\begin{array}{l}\text { Positive experience of the } \\
\text { store }\end{array}$ & $0.667 * * *$ & 289 & & & & & \\
\hline
\end{tabular}

$\mathrm{SB}=$ Spearman-Brown Coefficient for split half reliability, only calculated for two-item scales. AVE $=$ Average Variance Explained, i.e. $A V E=(\Sigma \lambda i 2) /[(\Sigma \lambda i 2)+\Sigma(1-\lambda i 2)]$ 